\title{
Temperature-Dependent Material Modeling for Structural Steels: Formulation and Application
}

\author{
Mina Seif \\ Joseph Main \\ Jonathan Weigand \\ Fahim Sadek \\ Lisa Choe \\ Chao Zhang \\ John Gross \\ William Luecke \\ David McColskey
}

This publication is available free of charge from: http://dx.doi.org/10.6028/NIST.TN.1907
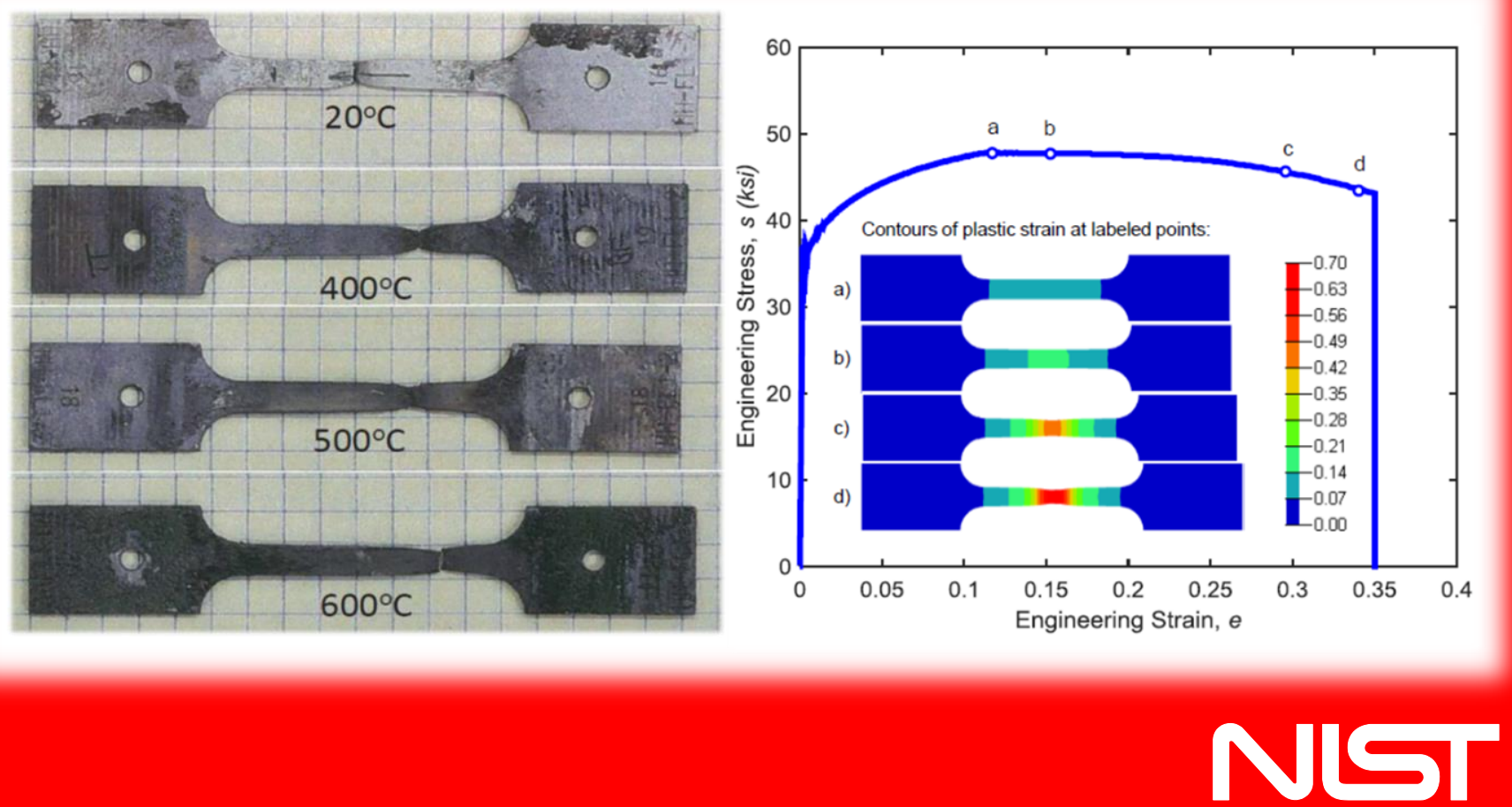

National Institute of Standards and Technology U.S. Department of Commerce 



\section{Temperature-Dependent Material Modeling for Structural Steels: Formulation and Application}

Mina Seif, Joseph Main, Jonathan Weigand, Fahim Sadek

Materials and Structural Systems Division

Engineering Laboratory

Lisa Choe, Chao Zhang, John Gross

Fire Research Division

Engineering Laboratory

William Luecke, David McColskey Materials Science and Engineering Division Material Measurement Laboratory

This publication is available free of charge from:

http://dx.doi.org/10.6028/NIST.TN.1907

April 2016

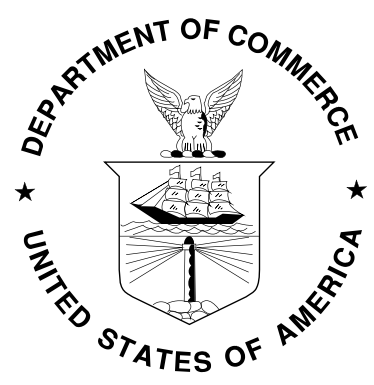

U.S. Department of Commerce

Penny Pritzker, Secretary 
The policy of the National Institute of Standards and Technology is to use metric units in all its published materials. Because this report is intended for the U.S. building construction industry, which uses inch-pound units, it is more practical and less confusing to use inch-pound units, in some cases, rather than metric units. However, in most cases, units are presented in both metric and the inch-pound system.

Certain commercial entities, equipment, products, or materials are identified in this document in order to describe a procedure or concept adequately. Such identification is not intended to imply recommendation or endorsement by the National Institute of

Standards and Technology, nor is it intended to imply that the entities, products, materials, or equipment are necessarily the best available for the purpose.

Another policy of the National Institute of Standards and Technology is to include statements of uncertainty with all NIST measurements. In this document, however, some measurements of authors outside of NIST are presented,

for which uncertainties were not reported and are unknown.

National Institute of Standards and Technology Technical Note 1907

Natl. Inst. Stand. Technol. Tech. Note 1907, 125 pages (April 2016)

CODEN: NTNOEF

This publication is available free of charge from: http://dx.doi.org/10.6028/NIST.TN.1907 


\section{ABSTRACT}

This report presents the formulation and application of a newly developed temperature-dependent material model for structural steels. First it presents a model for computing the stress-strain behavior of structural steels for conditions appropriate to fire. The model is based on the behavior of the retained high-temperature yield strength of 42 individual structural steels, augmented by the post-yield behavior derived from eight of those steels. The model accounts for the change in yield strength with temperature, the change in the amount of post-yield strain hardening with both temperature and ambient-temperature yield strength, and the change in strength with increasing strain rate. The coefficient of variation of the normalized retained yield strength increases linearly with temperature. The quality of the predictions of the stress-strain model are similar to those of the Eurocode 3 stress-strain model. The model is extensible to other steels, such as new fireresistive structural steels, quenched-and-tempered plate steels or bolt steels, with improved or degraded high-temperature properties, either by substituting a new description for the retained yield strength, or by fitting new parameters for the entire stress-strain behavior.

This National Institute of Standards and Technology (NIST) stress-strain model is then used for predicting flexural buckling of steel columns subjected to elevated temperatures. These predictions are intended to evaluate the applicability of the NIST model for predicting the behavior of steel gravity columns at elevated temperatures using the finite-element method. Accurately predicting the fire-performance of columns is critical to evaluating the stability of buildings subjected to fire. In a fire, steel gravity columns can be susceptible to inelastic buckling failure because they have high utilization ratios with the governing loading combination, "1.2[ dead load] + 1.6[live load]". The failure of interior columns can significantly influence the stability of a building because loads supported by these columns need to be redistributed through an alternative load path to prevent progressive collapse. This report presents the results from analytical studies to evaluate the effect of material models on predicting the strength and behavior of steel columns at elevated temperatures.

Besides the stress-strain behavior, another key issue in evaluating the response of structural systems to fire (high-temperature) effects is the modeling of fracture, which is required to capture failure modes such as tear-out in connection plates and bolt-shear. Fracture can be simulated in explicit finite element analysis using element erosion, in which elements are removed from the analysis when specified failure criteria are satisfied. However, the basis for determining and implementing material failure criteria at elevated temperatures is not well-established in the literature. A finite element material modeling methodology is presented for structural steels and structural bolts at elevated temperatures that incorporates erosion-based modeling of fracture. The new NIST stress-strain relationships were combined with a plastic strain-based failure criterion for element erosion to enable modeling of fracture in analysis of structural connections and assemblies. The failure criterion was calibrated against high-temperature experimental data on 
elongation of tensile coupons at fracture, and its dependence on temperature and mesh size was investigated.

Finally, these temperature-dependent material models for structural steel and bolts that incorporate erosion-based modeling of fracture were implemented in high-fidelity finite element models to study the performance of steel moment frame assemblies at elevated temperatures.

The performance of steel moment frames under fire-induced heating was investigated using detailed finite-element modeling. Assemblies consisting of two columns and a single beam span were modeled, with highly refined modeling of the connection regions. Structural analyses were performed under gravity loads in combination with a thermal loading scenario consisting of a heating phase followed by a cooling phase. The influence of axial restraint on the performance of the moment frames was investigated by considering different support conditions for the end columns.

Keywords: Stress-strain relationship; fire loading; structural steel; structural bolt; retained yield; uniform strain; elevated temperatures; steel column; finite element; inelastic buckling; thermal strain; fracture; erosion; steel connection 


\section{Preface}

The division of responsibility for the work presented in this report has been as follows. William Luecke, John Gross, and J. David McColskey were primarily responsible for Chapter 2. William Luecke conducted the high-temperature tensile tests of the fire-resistive steels, developed the stress-strain model, and wrote the chapter. John Gross articulated the requirements of the model for application to structural steel modeling and performance-based design. J. David McColskey conducted most of the high-temperature tensile tests that form the basis of the stress-strain model. Mina Seif, Joseph Main, and Jonathan Weigand developed the methodology for modeling the onset of necking at the ultimate tensile strength and contributed to Sections 2.2. Lisa Choe, Chao Zhang, William Luecke, and John Gross were responsible for Chapter 3. Chao Zhang performed the modeling work presented in Section 3.2 on the critical buckling temperature of steel columns, and Lisa Choe performed the modeling work presented in Section 3.3 on the high-temperature responses of steel columns. Mina Seif, Joseph Main, Jonathan Weigand, William Luecke, and Fahim Sadek were responsible for Chapters 4 and 5. Mina Seif was primarily responsible for the finite-element analyses presented in Chapters 4 and 5, while Joseph Main, Fahim Sadek, and Jonathan Weigand also contributed to the development of the finite element models and the erosion-based approach for modeling of fracture. Mina Seif served as the primary editor for this document, developing the overall outline and coordinating the contributions from the various coauthors. 
This page intentionally left blank. 


\section{TABLE OF CONTENTS}

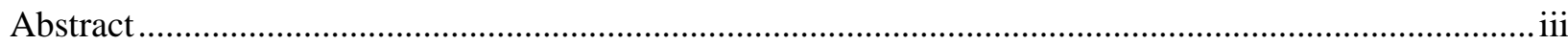

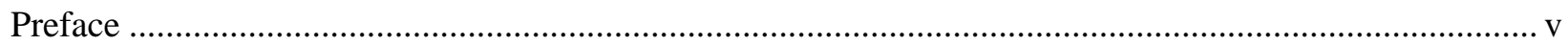

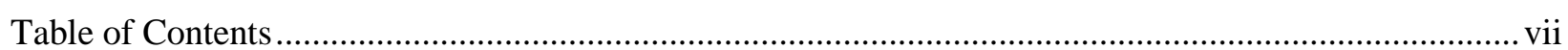

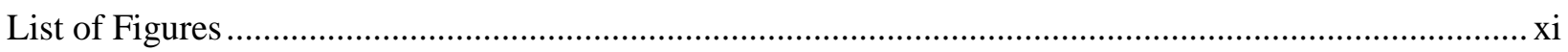

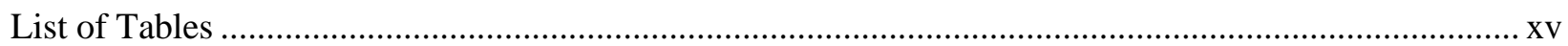

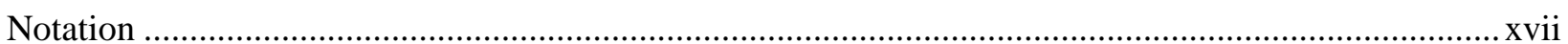

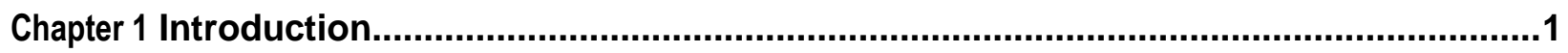

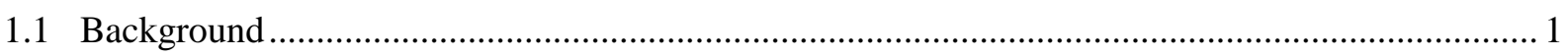

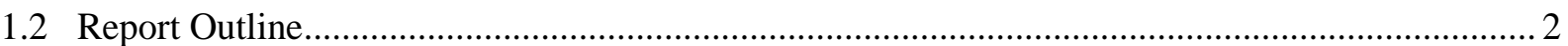

Chapter 2 Formulation of Temperature-Dependent Material Models .....................................3

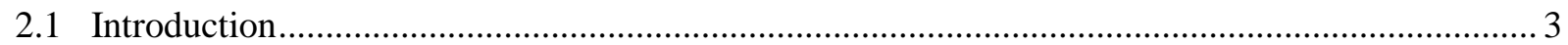

2.1.1 Relation to Previously Published Work …........................................................................... 3

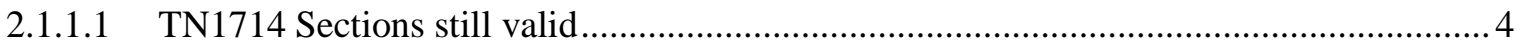

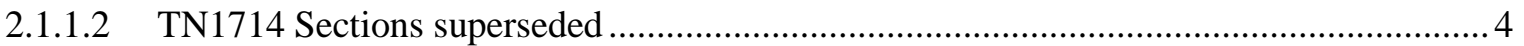

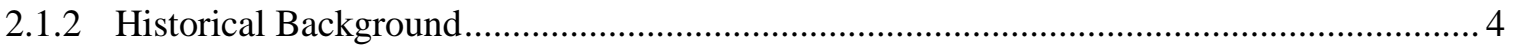

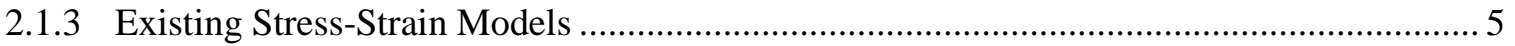

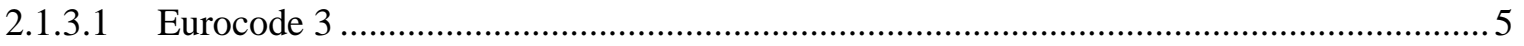

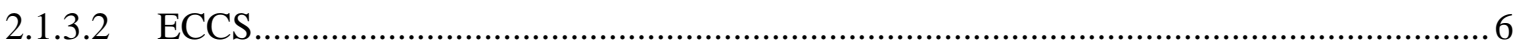

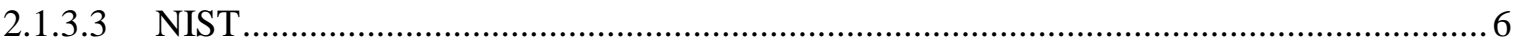

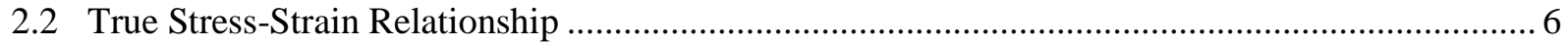

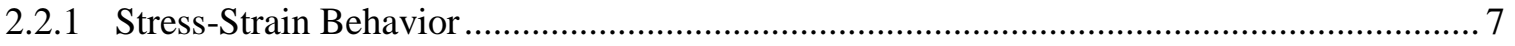

2.2.1.1 Features of real stress-strain behavior for structural steels ........................................... 7

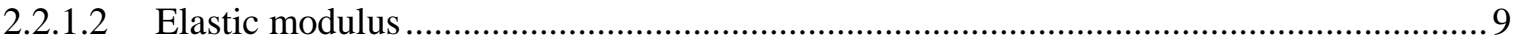

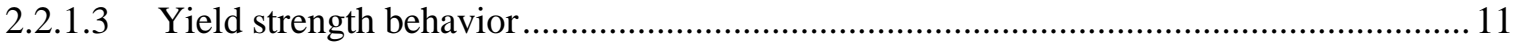

2.2.1.4 Yield strength dependence of the strain hardening ..................................................... 14

2.2.1.5 Temperature dependence of the strain hardening …................................................... 15

2.2.1.6 Temperature dependence of the strain-rate sensitivity ................................................ 15

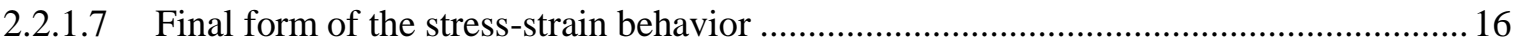

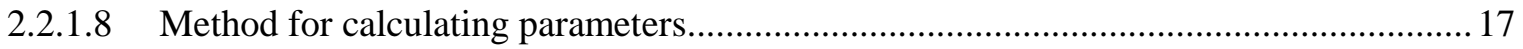

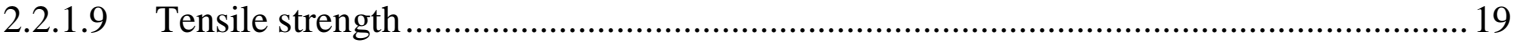




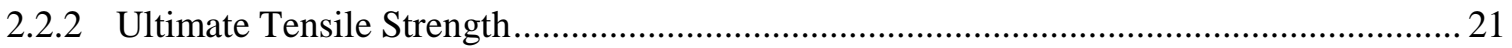

2.2.3 Application and Comparison to Eurocode 3 Behavior ................................................... 24

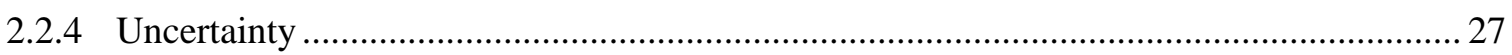

2.2.5 Modifying the Model for Steels with Different High-Temperature Performance.............. 32

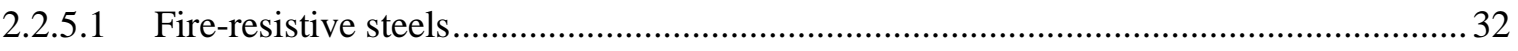

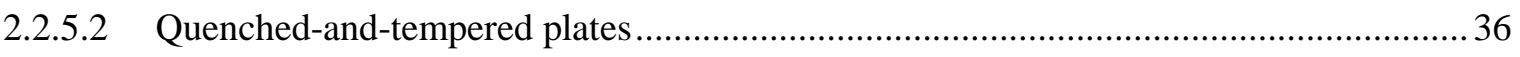

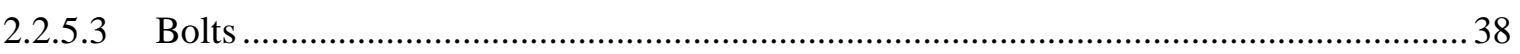

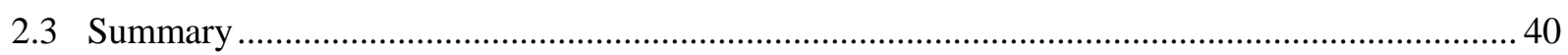

Chapter 3 Use of NIST Material Model to Evaluate Stability of Wide Flange Steel

Columns at Elevated Temperatures .....................................................................................41

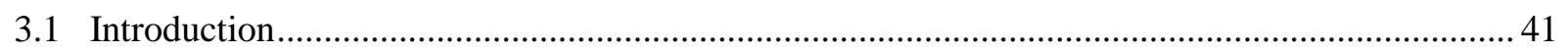

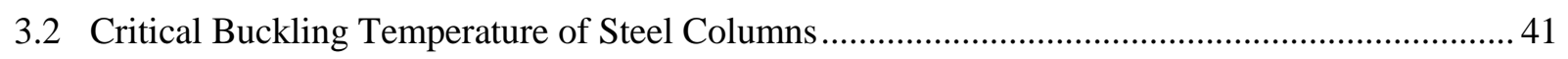

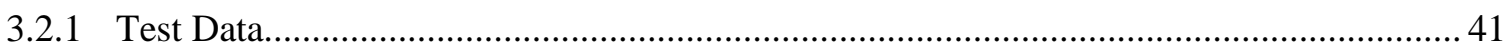

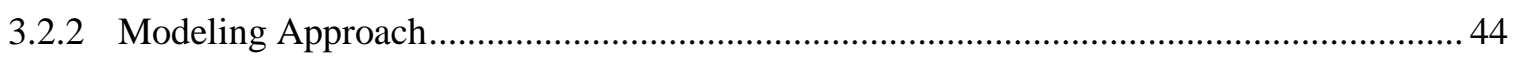

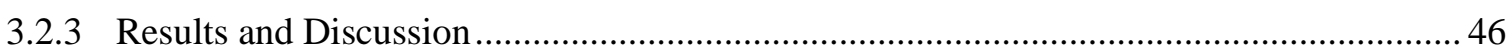

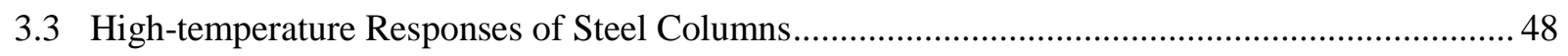

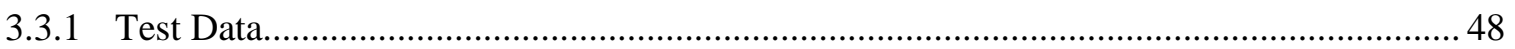

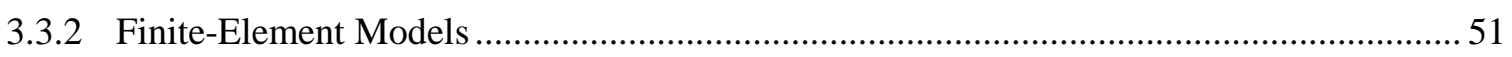

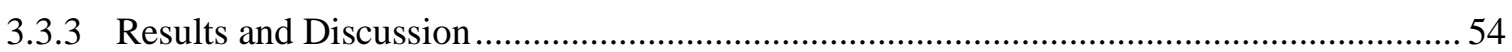

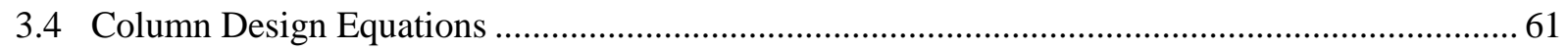

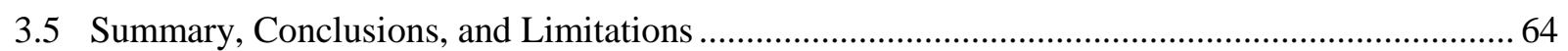

Chapter 4 Modeling of Failure for Finite element Analysis of Structural Steels at Elevated Temperatures...........................................................................................................67

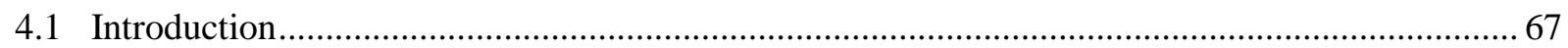

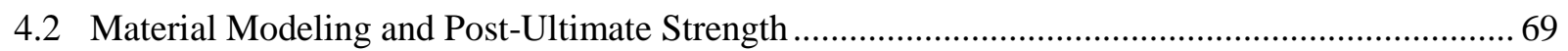

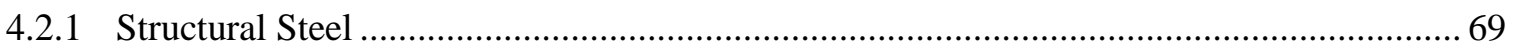

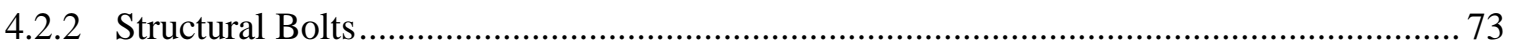

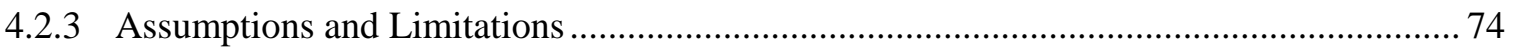

4.3 Analysis of Structural Steel Tensile Coupons.................................................................................. 75

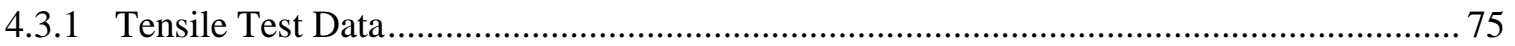

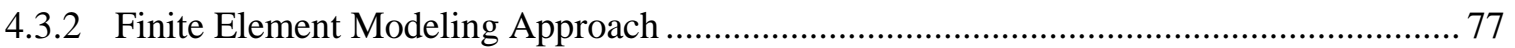

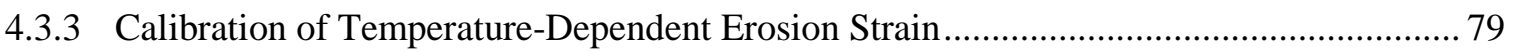

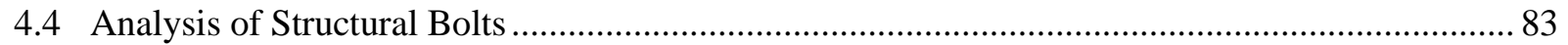

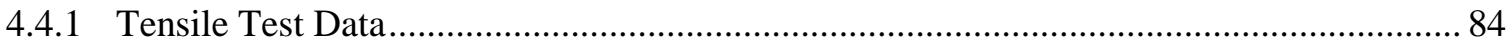




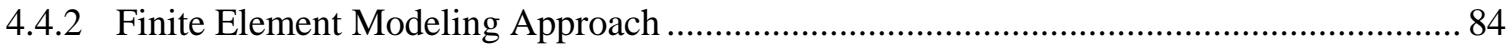

4.4.3 Calibration of Temperature-Dependent Erosion Strain ................................................... 86

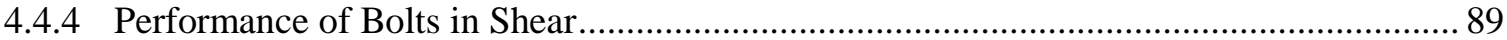

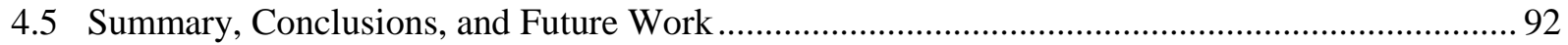

Chapter 5 Application of Material and Failure Models to the Analysis of Steel Moment Connections under Fire Loading ....................................................................................95

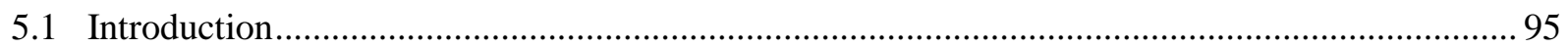

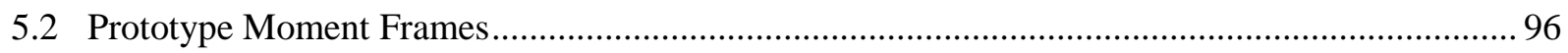

5.3 Modeling and Analysis of Moment-Frame Assemblies .......................................................... 99

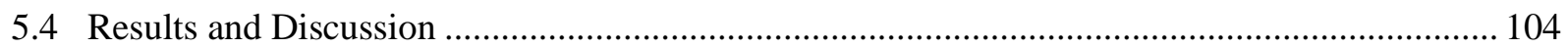

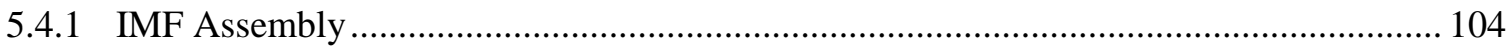

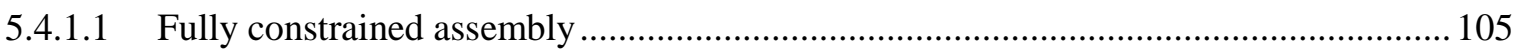

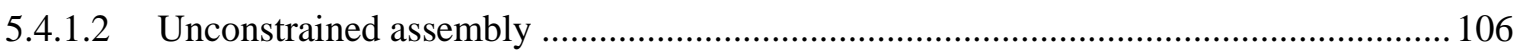

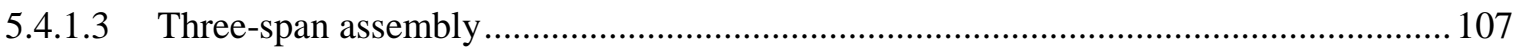

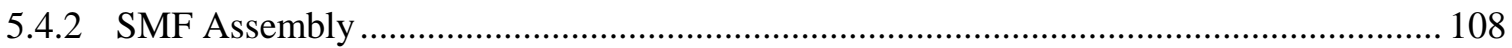

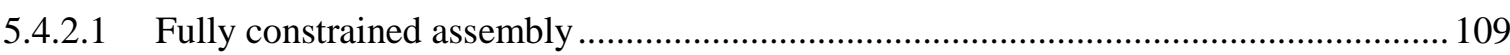

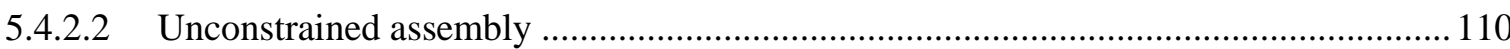

5.4.2.3 Unconstrained assembly, with gradient temperature ................................................. 111

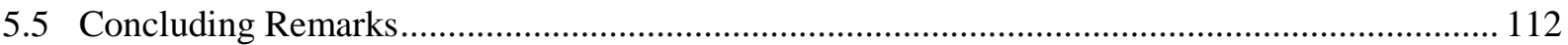

Chapter 6 Summary, Conclusions, and Future Work ........................................................113

6.1 Formulation of Temperature-Dependent Material Model............................................................ 113

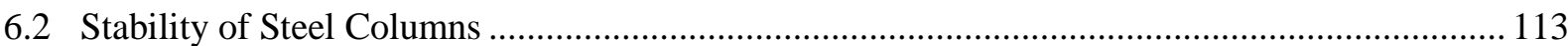

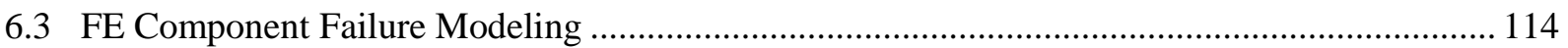

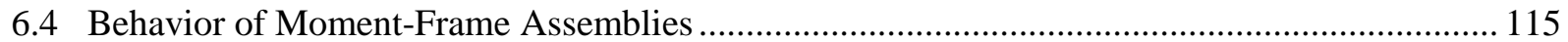

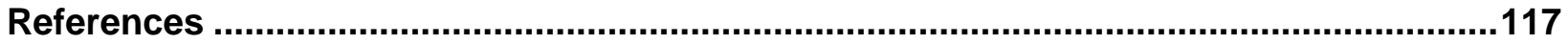


This page intentionally left blank. 


\section{LIST OF FIGURES}

Figure 2-1: Schematic description of the behavior of the stress-strain curve with increasing temperature, room-temperature yield strength, and strain rate. 8

Figure 2-2: Behavior of the reported elastic modulus from tensile tests. See Table 2-1 for key. .. 9

Figure 2-3: Recommended value of the elastic modulus from various organizations, see Table 2-1 for key ..... 10

Figure 2-4: Behavior of the retained yield strength for structural steels. See Table 2-1 for key.. 12

Figure 2-5: Strain-rate sensitivities, m, for literature steels. The solid line is the fit of Eq. (2.9). 16

Figure 2-6: Behavior of the retained tensile strength for structural steels. See Table 2-1 for key.

Figure 2-7 (a) Temperature-dependent normalized uniform strain (Eq. (2.6)) compared with available experimental data and (b) fit to ambient temperature uniform strain based on ambient temperature yield stress with $95 \%$ confidence bounds, compared with available experimental data.

Figure 2-8: Tensile strength resulting from fit to uniform strain for structural steel with Fy $=345$

$\mathrm{MPa}(50 \mathrm{ksi})$, compared with experimental data $(6.895 \mathrm{MPa}=1 \mathrm{ksi})$. 24

Figure 2-9: Comparison of the predictions of the stress-strain model, Eq. (2.10), the

Eurocode 3 (ECS, 2005) model, and the measured stress-strain behavior of A992 steel from

$\mathrm{Hu}$ et al. (2009)

Figure 2-10: Comparison of the predictions of the stress-strain model, Eq. (2.10), the Eurocode 3 (ECS, 2005) model, and the measured stress-strain behavior of AS A186:250 steel from Skinner (1973).

Figure 2-11: Comparison of the predictions of the stress-strain model, Eq. (2.10), the Eurocode 3 (ECS, 2005) model, and the measured stress-strain behavior of A36 steel from Harmathy and Stanzak (1970).

Figure 2-12: Coefficient of variation $V_{R}$ for elastic modulus $E$, as a function of temperature.

Numbers along the $V_{R}=\mathrm{O}$ axis denote the number of different steels used in each determination.

Figure 2-13: Coefficient of variation $V_{R}$ for yield strength $F_{y}$, as a function of temperature.

Numbers along the $V_{R}=\mathrm{O}$ axis denote the number of different steels used in each determination. 30

Figure 2-14: Coefficient of variation $V_{R}$ for tensile strength $F_{u}$, as a function of temperature. .. 31

Figure 2-15: Comparison of the normalized retained yield strength for ordinary (Ord.) and fireresistive (FRS) steels. 
Figure 2-16: Stress-strain data (solid lines) and models (dotted lines) for two fire-resistive steels. Models were computed by fitting R(T), Eq. (2.4), first and then the parameters of the stressstrain model, Eq. (2.10). 35

Figure 2-17: Comparison of the normalized retained yield strength for quenched-and-tempered $100 \mathrm{ksi}$ steel plate and the retained strength model, Eq. (2.4). 36

Figure 2-18: Stress-strain data (solid lines) and model (dotted lines) for $F_{y}=100 \mathrm{ksi}$ plate. Model was computed by fitting R(T) using Eq. (2.4), and then the stress-strain data using Eq. (2.10). 37

Figure 2-19: Comparison of the normalized retained yield strength for high-strength bolt steels and the retained strength model, Eq. (2.4). See Table 2-1 for key to data sets.

Figure 2-20 Degradation of normalized yield strength versus the increase in temperature for rolled structural steel and bolts. 40

Figure 3-1 Structural models for column tests 43

Figure 3-2 Schematic of the column model used in the analysis. 44

Figure 3-3 Predicted vs. reported failure temperature for the (a) NIST and (b) Eurocode 3 models. 46

Figure 3-4 Normalized difference in failure temperature as a function of slenderness ratio $(\lambda) . .47$

Figure 3-5 Column test setup and instrumentation layout. ................................................ 48

Figure 3-6 Axial load-temperature-time histories used in the Purdue column tests. 50

Figure 3-7 (a) Thermal expansion model of steel, (b) Eurocode 3 stress-strain model, (c) NIST stress-strain model. 53

Figure 3-8 Axial load-axial displacement response of the specimen W8×35-AMB................ 54

Figure 3-9 Predicted buckling shape with nodal temperature (NT11) distribution................... 55

Figure 3-10 Axial load-end rotation responses of column specimens................................... 56

Figure 3-11 Axial load-lateral displacement responses of column specimens......................... 57

Figure 3-12 Axial displacements $\left(\delta_{a}\right)$ of the column specimens. .............................................5

Figure 3-13 Normalized difference in critical buckling loads of the FEM models................... 60

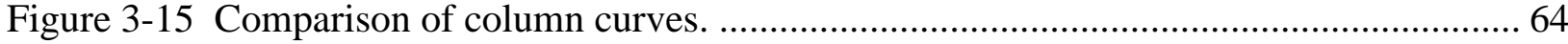

Figure 4-1 Detailed model of a shear tab connection, (b) tear-out failure in beam web, and (c) shear fracture of a bolt. 68

Figure 4-2 Degradation of normalized yield strength and elastic modulus with temperature for structural steel.

Figure 4-3 (a) True stress-strain and (b) engineering stress-strain curves comparing the onset of necking resulting from Eq. (3) with that imposed based on experimental data for $e_{\mathrm{u}}\left(400{ }^{\circ} \mathrm{C}\right.$; $\left.\mathrm{F}_{\mathrm{y} 0}=50 \mathrm{ksi}(345 \mathrm{MPa})\right)$. 
Figure 4-4 True stress-strain curves for A572 steel, generated using Eq. (3) until the onset of necking (red circular marker) with linearly projected stiffness thereafter $(1 \mathrm{ksi}=$

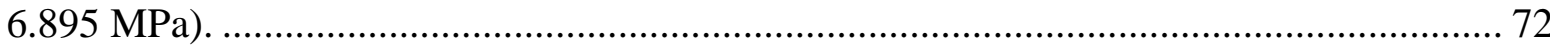

Figure 4-5 True stress-strain curves for A490 bolts $(1 \mathrm{ksi}=6.895 \mathrm{MPa})$............................. 74

Figure 4-6 Experimental coupons; (a) picture of the four specimens after the tensile test was conducted at $20^{\circ} \mathrm{C}, 400{ }^{\circ} \mathrm{C}, 500{ }^{\circ} \mathrm{C}$, and $600^{\circ} \mathrm{C}$, and (b) corresponding stress-strain curves. $*$ 76

Figure 4-7 Experimental values of engineering strain at fracture for structural steel. *.......... 77

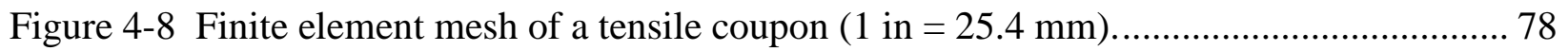

Figure 4-9 FE analysis results for a tensile coupon model at $500{ }^{\circ} \mathrm{C}(1 \mathrm{ksi}=6.895 \mathrm{MPa}) \ldots \ldots . .79$

Figure 4-10 Influence of the erosion strain $\varepsilon_{e r}$ on the computed engineering strain at fracture at

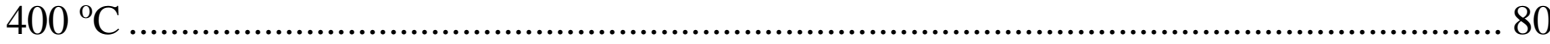

Figure 4-11 Calibrated values of erosion strain versus temperature for structural steel. ........... 80

Figure 4-12 FEA engineering stress-strain curves for selected temperatures with calibrated erosion strain values for structural steel $(1 \mathrm{ksi}=6.895 \mathrm{MPa})$.

Figure 4-13 Engineering stress-strain curves computed from finite-element models of a tensile coupon with different levels of mesh refinement $(1 \mathrm{ksi}=6.895 \mathrm{MPa})$.

Figure 4-14 Experimental values of engineering strain at fracture from Kodur et al. (2012) for

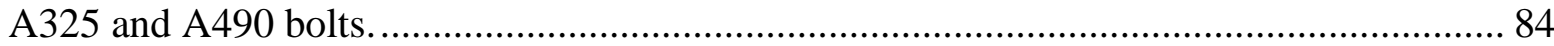

Figure 4-15 Finite element mesh of a bolt tensile coupon................................................ 85

Figure 4-16 FE analysis results for an A490 bolt tensile coupon at $500{ }^{\circ} \mathrm{C}(1 \mathrm{ksi}=6.895 \mathrm{MPa})$.

Figure 4-17 Calibrated values of erosion strain versus temperature for A325 and A490 bolts... 87

Figure 4-18 Computed stress-strain curves from an FE model of an A325 bolt coupon at elevated temperatures $(1 \mathrm{ksi}=6.895 \mathrm{MPa})$.

Figure 4-19 Computed stress-strain curves from and FE model of an A490 bolt coupon at elevated temperatures $(1 \mathrm{ksi}=6.895 \mathrm{MPa})$.

Figure 4-20 Detailed model of a double-shear bolt test: (a) section view, (b) bolt after fracture.

Figure 4-21 FE model and experimental results (Wallaert and Fisher 1965) for shear displacement of an A325 bolt at ambient temperature $(1 \mathrm{ksi}=6.895 \mathrm{MPa})$.

Figure 4-22 FE results for shear displacement of an A325 bolt at selected temperatures (1 ksi= $6.895 \mathrm{MPa})$.

Figure 4-23 FE results for shear displacement of an A490 bolt at selected temperatures ( $1 \mathrm{ksi}=$ $6.895 \mathrm{MPa}$ ). 91

Figure 4-24 Normalized shear strength versus temperature for A325 bolts........................... 92

Figure 5-1 Sketch of a typical assembly. 97 


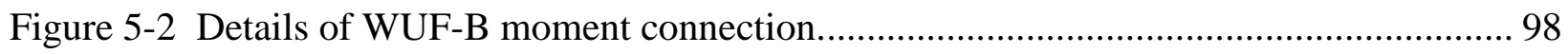

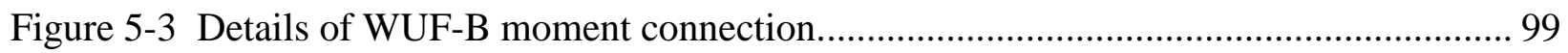

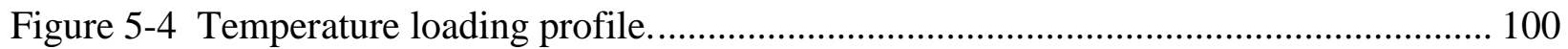

Figure 5-5 Finite-element mesh of the WUF-B assembly: (a) connection region, (b) beam with bolted shear tab, (c) beam, (d) bolt, and (e) shear tab. ............................................... 101

Figure 5-6 Detailed model of the RBS connection............................................................... 102

Figure 5-7 Finite element mesh of the 2 in gauge tensile coupon (a) solid elements, (b) shell

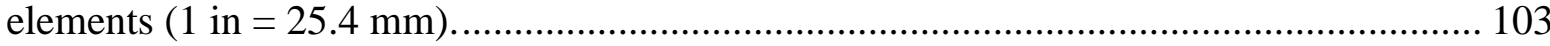

Figure 5-8 Calibrated values of erosion strain versus temperature for structural steel using shell elements for the RBS connection.

Figure 5-9 Column restraint cases considered for the IMF assembly: (a) fully constrained, (b) unconstrained, and (c) three-span.

Figure 5-10 Axial forces in the beam versus temperature for the different WUF-B assembly cases.

Figure 5-11 Local buckling mode of the connection at the end of the heating phase of the analysis of the fully constrained WUF-B assembly.

Figure 5-12 Failure mode of the connection at the end of the heating phase of the analysis of the unconstrained WUF-B assembly.

Figure 5-13 Axial force in the beam versus the temperature for the different RBS assembly cases

Figure 5-14 RBS connection failure modes for the fully constrained SMF assembly: (a) local buckling of connection during heating phase; (b) partial fracture during cooling phase. (1 in $=25.4 \mathrm{~mm}$ )

Figure 5-15 Cross-sectional longitudinal forces in the beam versus the temperature for the unconstrained RBS assembly, heated with a gradient temperature profile through the crosssection of the beam 


\section{LIST OF TABLES}

Table 2-1: Concordance for identifying steels in Fig. 2-2, Fig. 2-3, Fig. 2-4, Fig. 2-5, and Fig. $2-15$,

Table 2-2: Values of the parameters in the stress-strain model, Eq. (2.10), for ordinary (Ord.), fire-resistive (FR), quenched-and-tempered plate (plate), and bolt steels.......................... 19

Table 2-3: Parameters for describing the temperature dependence of the tensile strength of

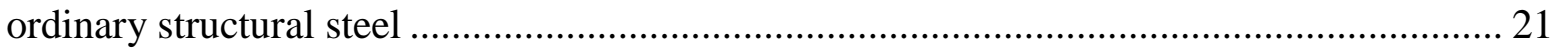

Table 2-4: Summary of coefficient of variation calculations for $E, F_{y}$, and $F_{u} \ldots \ldots \ldots \ldots \ldots \ldots \ldots . \ldots \ldots \ldots$

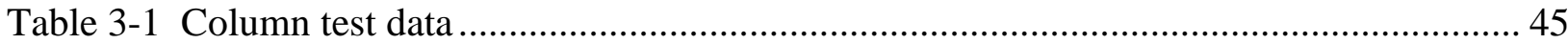

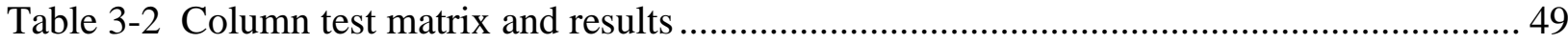

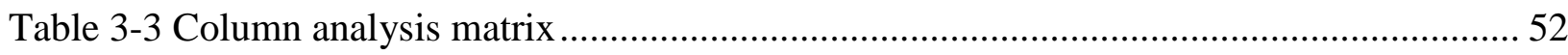

Table 3-5 Summary statistics for the normalized column buckling load ................................ 60

Table 4-1 Engineering and erosion strain values at fracture for structural steel. ..................... 82

Table 4-2 Engineering and erosion strain values at fracture for A325 and A490 bolts.............. 87

Table 5-1 Analysis cases considered for the SMF assembly............................................ 108 
This page intentionally left blank. 


\section{NOTATION}

$V_{R} \quad$ coefficient of variation of a parameter, defined as the standard deviation normalized by the mean

E elastic modulus

$e_{i} \quad$ parameters in the Young's modulus equation, Eq. (2.2)

$K$ prefactor that defines the strength of the steel in the stress-strain curve, defined in $\sigma=K \varepsilon^{n}$ and often called the strength coefficient

$K_{S} \quad$ portion of the strength coefficient, $K$, that depends on the ambient-temperature yield strength, Eq. (2.6)

$K_{T} \quad$ portion of the strength coefficient, $K$, that depends on temperature, Eq. (2.7)

$k_{i} \quad$ parameters in the stress-strain equation, Eq. (2.10)

$n \quad$ strain-hardening exponent defined in $\sigma=K \varepsilon^{n}$

$m \quad$ strain rate sensitivity defined in Eq. (2.8) and Eq. (2.9)

$R \quad$ retained strength, usually yield strength, $S_{y}$, normalized to its ambient-temperature value, $S_{y}^{0}$. Eq. (2.4)

$r_{i} \quad$ parameters in the retained yield and tensile strength equations, Eq. (2.4) and Eq. (2.14)

$S_{u} \quad$ measured tensile strength

$S_{u}^{0} \quad$ measured tensile strength at ambient temperature

$F_{y 0} \quad$ measured yield strength as defined in ASTM E6 (2009b). Sometimes denoted YS in other sources. Can be qualified with the type of yield strength. For example $F_{y 0}(0.2 \%$ offset) is the traditional offset yield strength in mill test reports

$S_{y}^{0} \quad$ measured yield strength at ambient temperature

$T$ temperature, ${ }^{\circ} \mathrm{C}$

$T^{*} \quad$ temperature above ambient temperature: $T^{*}=T-20{ }^{\circ} \mathrm{C}$

$e \quad$ engineering strain: $e=\left(l-l_{0}\right) / l_{0}$, where $l=$ current length and $l_{0}=$ original length

$\varepsilon \quad$ true strain: $e=\ln \left(l / l_{0}\right)$, where $l=$ current length and $l_{0}=$ original length

$\varepsilon_{p} \quad$ true plastic strain, the strain in excess of the elastic strain at yield, Eq. (2.5)

$\dot{\varepsilon} \quad$ true strain rate

$\dot{\varepsilon}_{0} \quad$ true strain rate from an individual test, or $0.005 / \mathrm{mm} / \mathrm{mm} / \mathrm{min}$, Eq. (2.8) 
$\sigma$ true stress: $\sigma=P / A$, where $P=$ force and $A=$ current area

$\sigma_{p} \quad$ plastic portion of the total stress, i.e. the stress in excess of yield stress, Eq. (2.5)

$\sigma_{0} \quad$ reference stress in computing strain rate sensitivity, Eq. (2.8). $\sigma_{0}=1 \mathrm{MPa}$ 


\section{Chapter 1 \\ INTRODUCTION}

\subsection{BACKGROUND}

Structural fire safety has historically been accomplished through hourly fire endurance ratings specified by the applicable building codes, and evaluated via qualification testing on individual members or small assemblies. More recently, the National Institute of Standards and Technology (NIST) and others have recognized the need for performance-based approaches to structural fire safety, rather than the traditional prescriptive approach. Progressing toward performance-based fire specifications is essential to modernizing code-based consideration of fire hazards, and would place fire hazards on an equal-risk basis relative to the other hazards the structure is designed to resist. Similar performance-based methodologies have already proven effective in seismic design, both as a means to design structures to achieve target performance criteria given potential hazard levels and as an effective tool to facilitate communication between engineers and building owners regarding the cost-efficiency of designing more reliable structures.

While the recently constructed National Fire Research Laboratory is intended to enable development of performance-based design approaches by enabling full-scale testing, the imminent availability of full-scale validation testing makes this a critical time for development of predictive modeling and analysis approaches. Finite-element or other analytical models require accurate constitutive models for the behavior of the steels in the beams, columns, and connections, rather than just the typical summary data such as yield and tensile strengths. These models should be based on validated data, and that data should be available for long-term review.

For structural steels in fire conditions, the majority of effort to develop constitutive laws began in the 1980s in Europe (Anderberg, 1983, 1988; Cooke, 1988; ECCS, 1983) and culminated in the stress-strain model of the ECS Eurocode 3 (2005) standard for structural fire design. Despite this development, complete high-temperature stress-strain data sets for structural steels used in buildings are much less common than summary data sets. The NIST report on the collapse of the World Trade Center towers, (Luecke et al., 2005) contains a data set from twelve structural steels recovered from the World Trade Center collapse site. The technical report (Luecke et al., 2011) reanalyzed a subset that included 41 stress-strain curves from eight steels and combined it with critically evaluated literature data to create a generic constitutive model for structural steel that captures the temperature dependence of the yield strength and strain hardening, the yield-strength dependence of the strain hardening, and the overall dependence of the stress-strain behavior on the strain rate. 


\subsection{REPORT OUTLINE}

This report presents the formulation and application of a newly developed temperature-dependent material model for structural steels. It summarizes the model for computing the stress-strain behavior of structural steels at elevated temperatures in Luecke et al. (2011), and shows how this model can be implemented, using both analytical and numerical modeling approaches, to predict the fire-performance of structures. The outline of the report is as follows:

- Chapter 2 describes the formulation of the temperature-dependent constitutive model for structural steels (i.e., NIST Temperature-Dependent (T-D) stress-strain model) used throughout the subsequent chapters.

- Chapter 3 uses the NIST T-D stress-strain model to predict flexural buckling of steel columns at elevated temperature, using the finite-element method, to evaluate the ability of the material model to more accurately predict the stability of buildings subjected to fire. Predictions of the critical buckling temperatures of 47 tested columns are calculated using the finite-element models and compared with those values reported from the experiments. Predictions using the NIST T-D stress-strain model are also compared to predictions calculated using Eurocode 3, ESC (2005), and the NIST T-D stress-strain model is shown to provide better predictions of the buckling response, buckling strength, and failure temperatures of the columns at elevated temperatures.

- Chapter 4 presents a modeling approach developed for capturing fracture, which is required to capture failure modes such as tear-out in connection plates and bolt shear. A finite element material modeling methodology is presented for structural steels and structural bolts at elevated temperatures that incorporates erosion-based modeling of fracture. The new NIST stress-strain relationships were combined with a plastic strain-based failure criterion for element erosion to enable modeling of fracture in analysis of structural connections and assemblies.

- Chapter 5 implements the NIST T-D stress-strain model into detailed continuum finite element models of steel-framed assemblies, including connections, to evaluate the behavior of connections at elevated temperatures. This chapter also shows how connection failure modes, such as tear-out in connection plates and bolt shear, can be captured in explicit thermal-structural finite element analysis using the temperature-dependent plastic strainbased material failure criterion.

- Finally, Chapter 6 provides a summary and main conclusions of the work presented throughout the report. 


\section{Chapter 2 \\ FormuLATION OF TEMPERATURE-DEPENDENT MATERIAL MODELS}

\section{$2.1 \quad$ INTRODUCTION}

This chapter presents a model for computing the stress-strain behavior of structural steels for conditions appropriate to fire. The model is based on the behavior of the retained high-temperature yield strength of 42 individual structural steels, augmented by the post-yield behavior derived from eight of those steels. The model accounts for the change in yield strength with temperature, the change in the amount of post-yield strain hardening with both temperature and ambienttemperature yield strength, and the change in strength with increasing strain rate. The coefficient of variation of the normalized retained yield strength increase linearly with temperature. The quality of the predictions of the stress-strain model are similar to those of the Eurocode 3 stressstrain model. The model is extensible to other steels, such as new fire-resistive structural steels, quenched-and-tempered plate steels or bolt steels, with improved or degraded high-temperature properties, either by substituting a new description for the retained yield strength, or by fitting new parameters for the entire stress-strain behavior.

Structural fire safety has historically been accomplished through the specification of steel members or assemblies, including passive fire protection, that meet by way of qualification testing, building code requirements for a specified fire endurance expressed as an hourly rating. More recently, there has been a trend toward performance-based approaches to structural fire safety, rather than the traditional prescriptive approach. For example, the American Institute of Steel Construction (AISC) Specification for Structural Steel Buildings (2010) beginning in the 2005 edition, addresses structural design for fire by analysis.

Modeling the response of steel structures to fire requires accurate constitutive models for the behavior of the steels in the beams, columns, and connections. Finite-element or other analytical models require the entire stress-strain curve, rather than just the typical summary data such as yield and tensile strengths. This chapter presents a model for computing the stress-strain behavior of structural steels under conditions appropriate for fire modeling. Finite-element or other analytical models require accurate constitutive models for the behavior of the steels in the beams, columns, and connections, rather than just the typical summary data such as yield and tensile strengths. These models should be based on validated data, and that data should be available for long-term review.

\subsubsection{Relation to Previously Published Work}

This chapter represents a correction and augmentation to a previously published NIST Technical Report (Luecke et al., 2011) (TN1714). This chapter supersedes some portions of that document, 
but other sections are still valid. The model development portions of TN1714 are generally obsolete, but the historical summary sections are still valid.

\subsubsection{TN1714 Sections still valid}

- 3.1 Microstructure and Chemistry

- Appendix B Experimental methods

- Appendix C Microstructure and Chemistry

- Appendix D.1 Tensile data

- Appendix D.4 Calculation and analysis of the strain rate sensitivity, $m$

- Appendix E.1 Literature Data

- Appendix E.2 Tabular data for the literature structural steels

- Appendix E.4.3 Notes on literature reports of elastic modulus measurements

- Appendix F.1 and F.2 Eurocode stress-strain model

- Appendix G ECCS stress-strain model

\subsubsection{TN1714 Sections superseded}

- 4.1 Retained Yield strength; superseded by Section 2.2.1.3

- 4.2 Modeling stress-strain curves; superseded by Section 2.2

- 4.3 Comparison with Eurocode Recommended Values

- Appendix E3 Retained Strength; superseded by Section 2.2.2

- Appendix E4.1 Elastic Modulus recommended value; superseded by Section 2.2.1.2

In addition, this chapter corrects errors introduced in transcribing the data from Chen et al. (2006). These corrections did not change the values of the individual retained yield strength model parameters $r_{i}$ from previous unpublished versions of this chapter.

\subsubsection{Historical Background}

For structural steels in fire conditions, the majority of effort to develop full constitutive laws began in the 1980s in Europe (Anderberg, 1983, 1988; Cooke, 1988; ECCS, 1983) and culminated in the stress-strain model of the ECS Eurocode 3 (2005) standard for structural fire design. Despite this interest, complete high-temperature stress-strain data sets for structural steels used in buildings are much less common than summary data sets. The NIST report on the collapse of the World Trade Center (WTC) towers (Luecke et al., 2005) contains a data set comprising twelve structural steels recovered from the WTC collapse site. These steels were important to the modeling effort. The technical report (Luecke et al., 2011) reanalyzed a subset of that data set that included 41 stressstrain curves from eight steels and combined it with critically evaluated literature data to create a 
generic constitutive model for structural steels that captures the temperature dependence of the yield strength and strain hardening, the yield-strength dependence of the strain hardening, and the overall dependence of the stress-strain behavior on the strain rate. The technical report (Luecke et al., 2011) includes tables of the complete data set used to develop the model so that the model origins are transparent. This chapter summarizes the important aspects of that model and compares it to the predictions of two other stress-strain models for structural steel in fire. On-going research into modeling column failure necessitated changes to the choice of elastic modulus reported in that model (Luecke et al., 2011). That substitution changed the values of the stress-strain model parameters slightly.

\subsubsection{Existing Stress-Strain Models}

\subsubsection{Eurocode 3}

The ECS Eurocode 3 (2005) stress-strain model is used widely in Europe. Twilt (1991) documents its origin and the rationales for the values chosen for some of its functional forms and parameters as follows:

A. Maximum consistency with existing data;

B. Direct physical background;

C. Simple mathematical model;

D. Clearly defined effective yield stress level;

E. Practical application range;

F. Official recognition, either internationally or nationally.

Based on these criteria, the committee that developed the Eurocode 3 stress-strain model (ECS, 2005) selected the British Steel Corp. data of Kirby and Preston (1983) for steels taken from wide flange shapes originally supplied to BS $4360(1990)$ grades $43 \mathrm{~A}$ and 50B ( $F_{y}=37 \mathrm{ksi}(255 \mathrm{MPa})$ and $F_{y}=51 \mathrm{ksi}(355 \mathrm{MPa})$ ), respectively. Interestingly, these data were not generated from standard high-temperature tensile tests, similar to ambient-temperature mill tests. Instead, they originated from so-called "transient state" tests in which the specimen is held under constant force while the temperature increases linearly. During this test, the specimen strain increases until it runs away at a critical temperature. Kirby created stress-strain curves from these transient heating tests by assembling the collection of strain-temperature points from the transient state tests at fixed stresses up to engineering strains $e<0.02$. Twilt (1991) indicates that the Eurocode 3 model is based on data from tests conducted only at heating rate $d T / d t=10^{\circ} \mathrm{C} / \mathrm{min}$.

Although Kirby and Preston (1983) originally tested seven different steels at up to three heating rates each, the Eurocode stress-strain model is based on only six tests on one steel and eight on the other, at a single heating rate. Because of the shape of strain-temperature curves in the the transientstate tests, each derived stress-strain curve contains only a few (stress, strain) points past the proportional limit. Twilt's summary (1991) does not explain the details of the analysis of the 
derived stress-strain curves that produced the values of the individual parameters. Those derived stress-strain curves are repeated in tabular form in the 1988 paper; they must represent curve fits, rather than data points, because the transient-state-test analysis only produces two or three points per curve. The shapes of these derived stress-strain curves are very similar to the Eurocode 3 formulation, but they are not identical. In particular, the elastic modulus, which is important for column-buckling calculations, is only about $90 \%$ of the Eurocode 3 value. Twilt does not provide any background on the source of the data for the elastic modulus or for the method by which its variation with temperature was calculated.

\subsubsection{ECCS}

The European Convention for Constructional Steelwork (ECCS) (1983) recommended a stressstrain model based on an effective yield strength that decays smoothly with temperature. The model claims to include time-dependent effects in the yield strength, but the published report that describes it does not document the method for including those time-dependent effects into the stress-strain curve. Very few research groups have used the model.

\subsubsection{NIST}

As part of its World Trade Center collapse investigation, NIST developed an elevated-temperature stress-strain model for structural steels, based on a combination of literature data and tests conducted on relevant structural steel recovered from the collapse site (Luecke et al., 2005). After the publication of the investigation final report, a second report (Luecke et al., 2011) refined the model with additional literature data and improved computation schemes.

This chapter corrects and augments that second report, adds computations of the expected variability of the retained high-temperature modulus of elasticity, yield strength, and tensile strength, and demonstrates how the stress-strain model can be used to represent new steels, with examples for modern construction and fire-resistive steels. For compactness, the chapter omits much of the supporting data for the choices of parameters, but Luecke et al., (2005) documents the computation of each parameter. The original report used elastic modulus data derived from slow dynamic measurements on recovered steel. This paper substitutes a formulation for elastic modulus derived from literature data from hot-tensile tests on structural steel. This substitution changed the absolute values of the parameters of the model.

\section{$2.2 \quad$ TRUE STRESS-STRAIN RELATIONSHIP}

The goal of this chapter is to develop a generic stress-strain model for structural steel in conditions appropriate to fire. As much as possible it should capture the behavior of real structural steel and be extensible to new grades of structural steel, such as fire-resistive steels, that offer enhanced mechanical properties at elevated temperatures. Furthermore, its origins should be transparent and well documented. 
A major impediment to this effort is the scarcity of full stress-strain data at high temperatures in literature reports of the tensile behavior of structural steel. Before the NIST WTC investigation, only a few investigators had reported the full stress-strain behavior of structural steels in a format suitable for modeling (Skinner, 1973; Harmathy and Stanzak, 1970; Hu et al., 2009). A much larger body of literature exists that typically only reports the high-temperature yield and tensile strengths. Incorporating that summary data, however, would help ensure that the modeled behavior truly represents the wide variety of structural steel grades. The additional data also allows estimation of the variability in properties. The NIST World Trade Center Collapse investigation characterized the elevated-temperature stress-strain behavior of more than ten recovered steels. The approach of this study was to use the extensive literature data to model the behavior of the high-temperature yield strength, and to augment that behavior with the post-yield stress-strain behavior derived from the WTC collapse investigation data.

\subsubsection{Stress-Strain Behavior}

\subsubsection{Features of real stress-strain behavior for structural steels}

The stress-strain behavior of structural steel exhibits four trends that any model should capture.

1. The yield strength decreases with increasing temperature.

2. The amount of strain hardening decreases with increasing ambient-temperature yield strength.

3. The strain hardening decreases with increasing temperature.

4. The strain-rate sensitivity, and therefore the increase in strength with increasing strain rate, increases with increasing temperature.

Fig. 2-1 illustrates these four behaviors. 

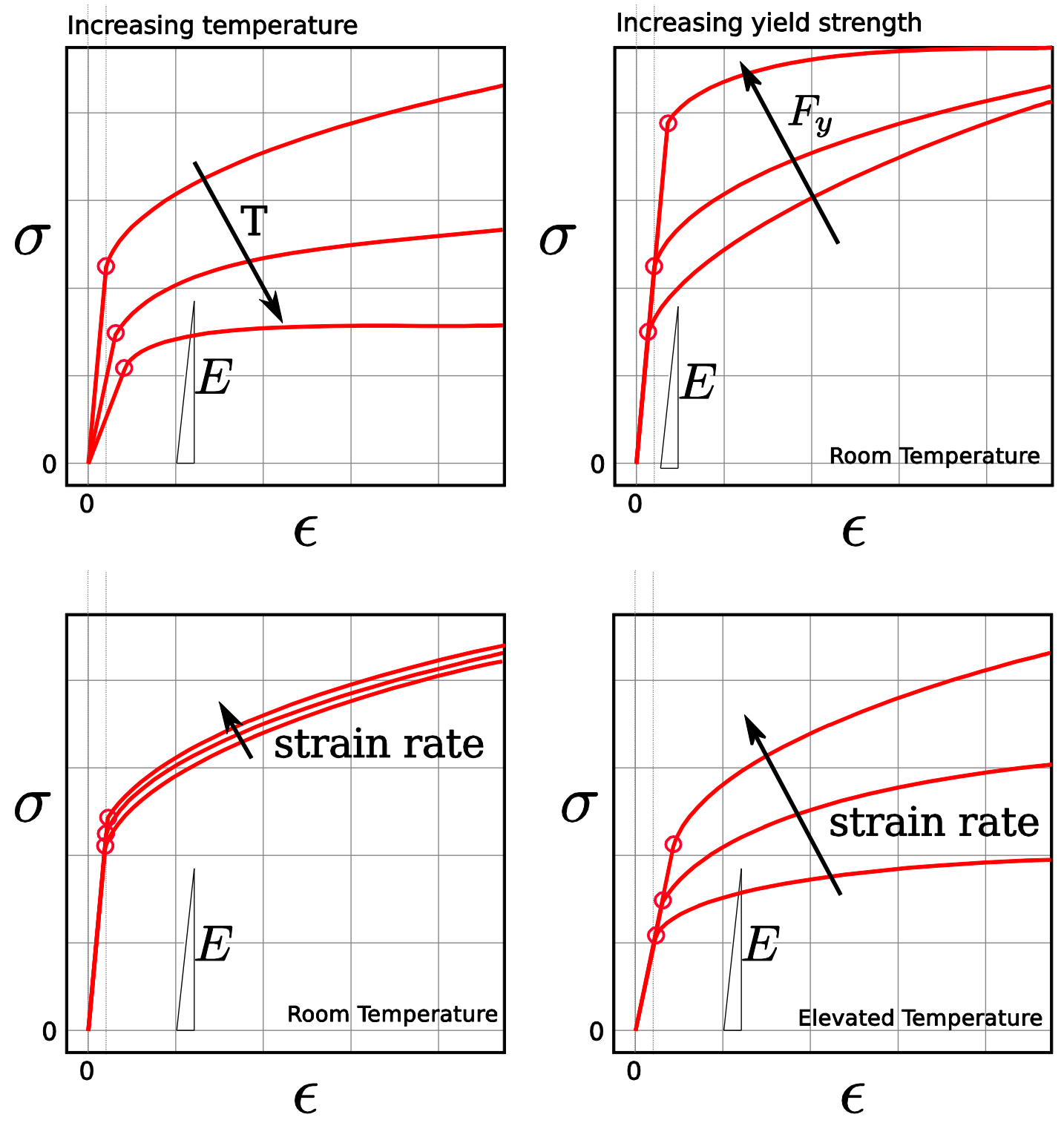

Figure 2-1: Schematic description of the behavior of the stress-strain curve with increasing temperature, ambient-temperature yield strength, and strain rate.

Another goal is to minimize the number of parameters necessary to capture the full behavior. Whenever possible, phenomenological parameters should follow forms that are consistent with the underlying materials science that governs the deformation processes, and they should exhibit conservative behavior outside the limits of the data they are based on.

A general form of a stress-strain, $\sigma-\varepsilon$, equation that can represent these four behaviors is 


$$
\begin{aligned}
& \sigma=E \varepsilon \text { for } \varepsilon<\frac{F_{y 0}}{E} \quad \text { (elastic behavior) } \\
& \sigma=F_{y 0}+K\left(\varepsilon-\frac{F_{y 0}}{E}\right)^{n} \text { for } \varepsilon \geq \frac{F_{y 0}}{E} \text { (plastic behavior) }
\end{aligned}
$$

where $E$ is the modulus of elasticity, $\varepsilon$ is the true strain, and $K$ and $n$ are parameters in the powerlaw equation. The form of Eq. (2.1) joins a temperature-dependent linear-elastic line, $E \varepsilon$, to powerlaw strain-hardening curve for plastic strain. The two branches meet at a temperature-dependent yield strength, $F_{y o}$. The power-law (or Holloman) stress-strain model, $\sigma=K \varepsilon^{n}$, is a common form for representing the plastic behavior of metals.

Each of the following sections details the form of an individual component of Eq. (2.1).

\subsubsection{Elastic modulus}

The technical literature contains a rich set of elastic modulus data measured during tensile tests. Accurate modulus measurement during tensile testing is difficult (Lord et al., 2005), but the slope of the stress-strain curve determines the yield strength, so it may be a useful representation of the very low-strain behavior of the stress-strain curve.

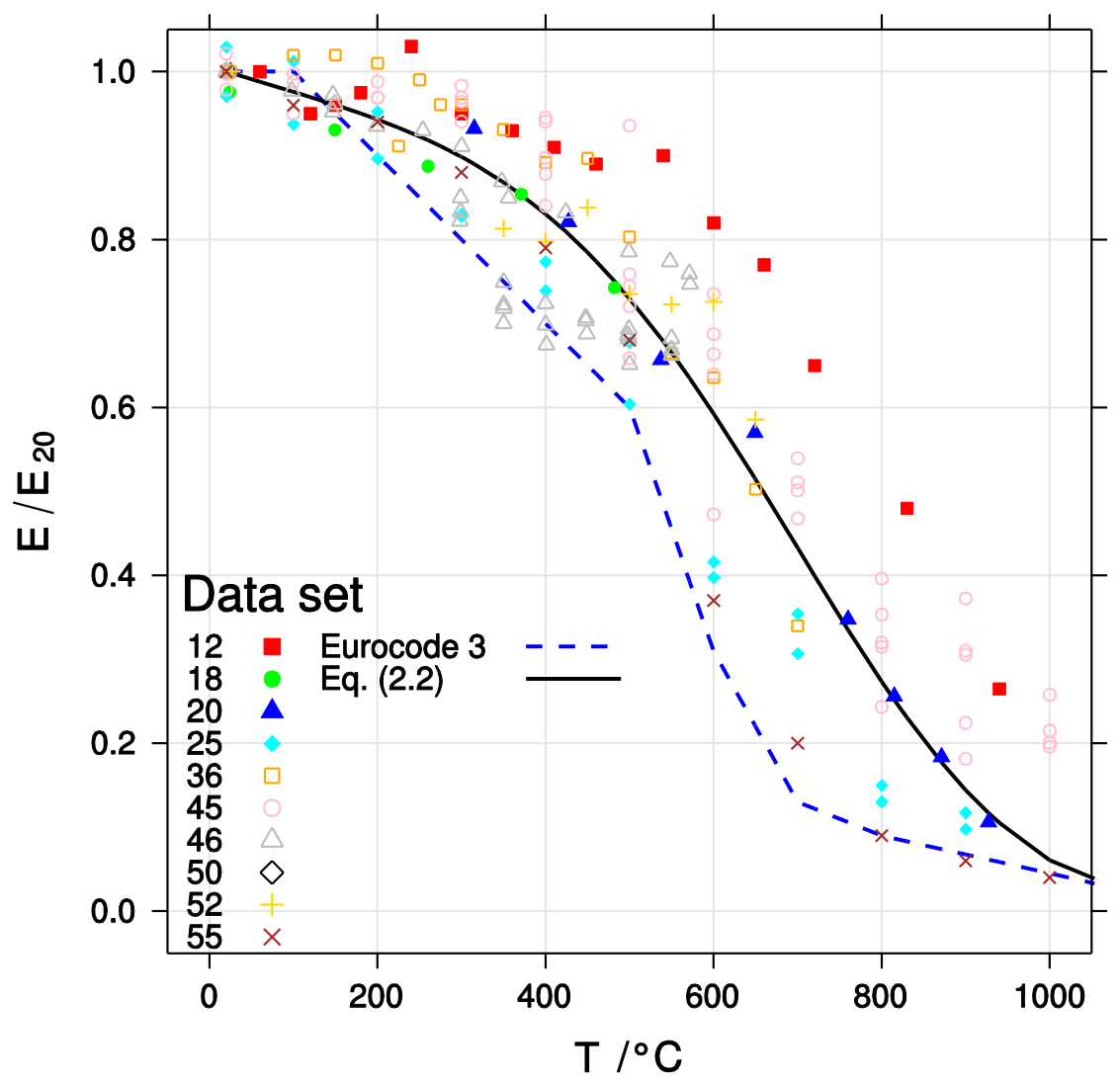

Figure 2-2: Behavior of the reported elastic modulus from tensile tests. See Table 2-1 for key. 
Fig. 2-2 shows that data set, normalized by the reported ambient-temperature value, along with the recommended modulus in the Eurocode 3 stress-strain model. Two characteristics stand out. The spread in retained modulus at every temperature is large, and all but a few of the measurements lie well above the line recommended in the Eurocode 3 formulation. The large spread in the data probably reflect, to a large extent, the difficulty in accurately measuring the modulus using small specimens and extensometers designed to measure large strains. Analysis of the uncertainty in the modulus of elasticity data is provided in Section 2.2.4, where the coefficient of variation in the measured modulus is characterized as a function of temperature. The data of Ritter and McPherson (1970), see Table 2-1, are noteworthy as they measured very different elastic moduli for the same steel heat treated to produce different grain sizes. This result indicates that time-dependent elastic processes are probably significant at elevated temperatures.

Many organizations have produced so-called handbook values for design with structural steel. Fig. 2-3 plots six of them, see Table 2-1. Four of the six are very similar, and all lie well above the Eurocode 3 line. None of six explain the origins of the underlying data or the methods by which the values of the parameters were obtained.

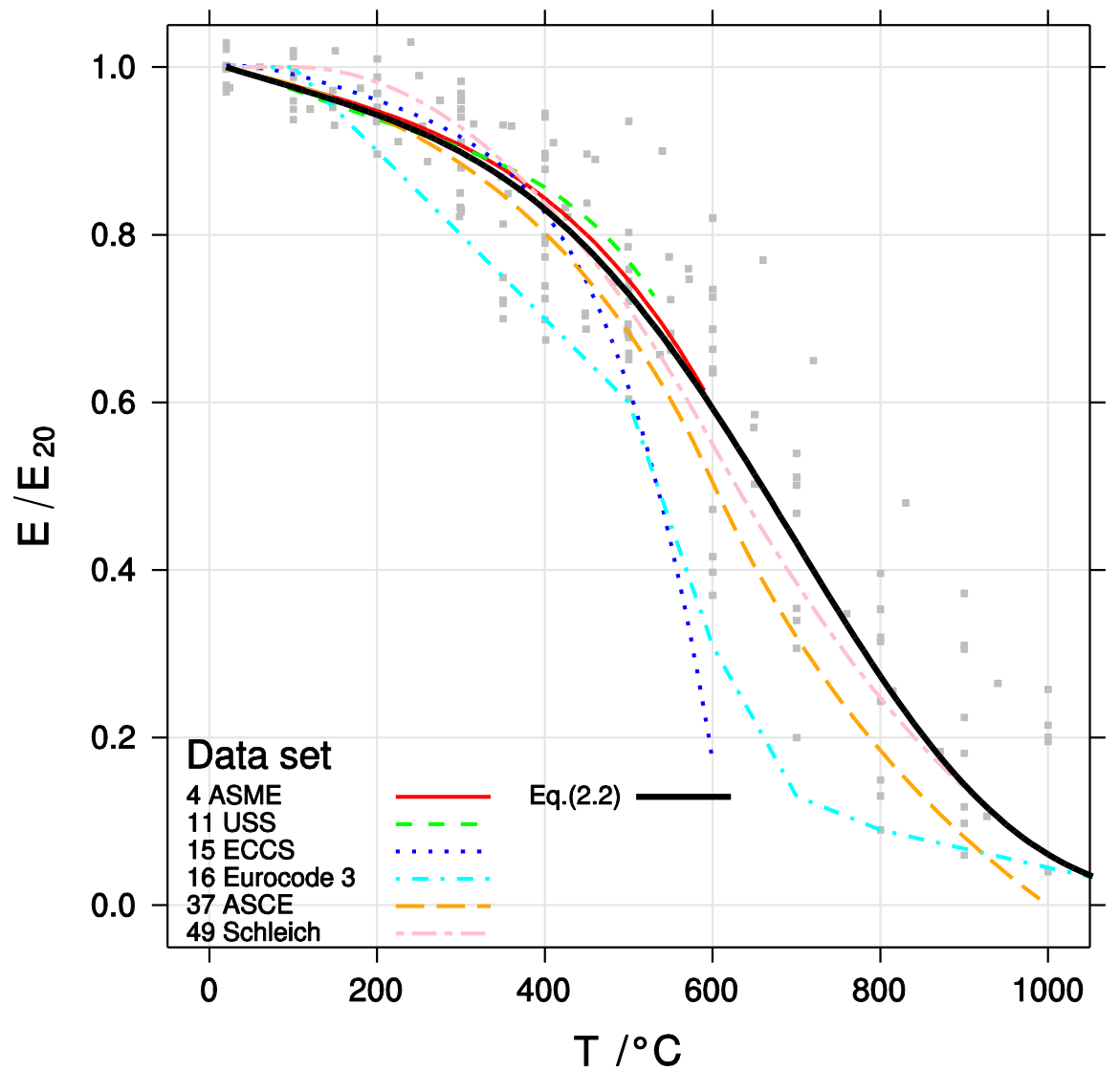

Figure 2-3: Recommended value of the elastic modulus from various organizations, see Table 2-1 for key 
The handbook values use all manner of different smooth or piecewise-continuous functions and discrete data points to represent the behavior of the elastic modulus. In this study, the data were represented by a phenomenological exponential function:

$$
E(T)=E_{0} \exp \left(-\frac{1}{2}\left(\frac{T^{*}}{e_{3}}\right)^{e_{1}}-\frac{1}{2}\left(\frac{T^{*}}{e_{4}}\right)^{e_{2}}\right)
$$

Where $E_{0}$ is the elastic modulus at ambient temperature $\left(T=20^{\circ} \mathrm{C}\right)$. The original technical report (Luecke et al., 2011) used a third-order polynomial fit to a set of data developed from $1 \mathrm{hz}$ dynamic measurements at slow strain. The main advantage of the form of Eq. (2.2) over the polynomial form is that it evaluates to greater than zero at all temperatures. The parameters of Eq. (2.2), Table 2-2, were calculated by non-linear least-squares regression of the data in Fig. 2-2 with $T \leq 725^{\circ} \mathrm{C}$, and $e_{2}$ set to unity and not fit. ${ }^{1}$

The resulting curve is very similar to that of Schleich (1987), and to the ASME 2004 recommendation up to $600{ }^{\circ} \mathrm{C}$.

\subsubsection{Yield strength behavior}

The $0.2 \%$ offset yield strength, $F_{y 0}$, obtained in a high-temperature tensile test, is the most commonly reported parameter. By anchoring the high-temperature stress-strain behavior to the yield strength, the model uses forty years of data on the high-temperature strength of structural steel. To compare steels with different ambient-temperature yield strengths, the yield strength is normalized to its ambient-temperature value, $S_{y}^{0}$ :

$$
R=\frac{F_{y 0}}{F_{y 0(T=20 C)}}=\frac{F_{y 0}}{S_{y}^{0}}
$$

Fig. 2-4 plots the normalized retained yield strength, $R$, as a function of temperature for 42 individual structural steels from 16 different literature sources, identified by number, see Table 2-1. An analysis of the uncertainty in the reported yield strength data is provided in Section 2.2.4.

\footnotetext{
${ }^{1}$ At the end of the production of this report, the authors realized that they had transcribed one data set Chen et al. (2006) incorrectly. Because several research groups had already begun to use the stress-strain model, the authors decided to retain the original set of parameters. The difference between the fits amounts to less than $580 \mathrm{ksi}$ (4 GPa) below $T=600{ }^{\circ} \mathrm{C}$, and less than $1160 \mathrm{ksi}(8 \mathrm{GPa})$ for $T<725^{\circ} \mathrm{C}$.
} 


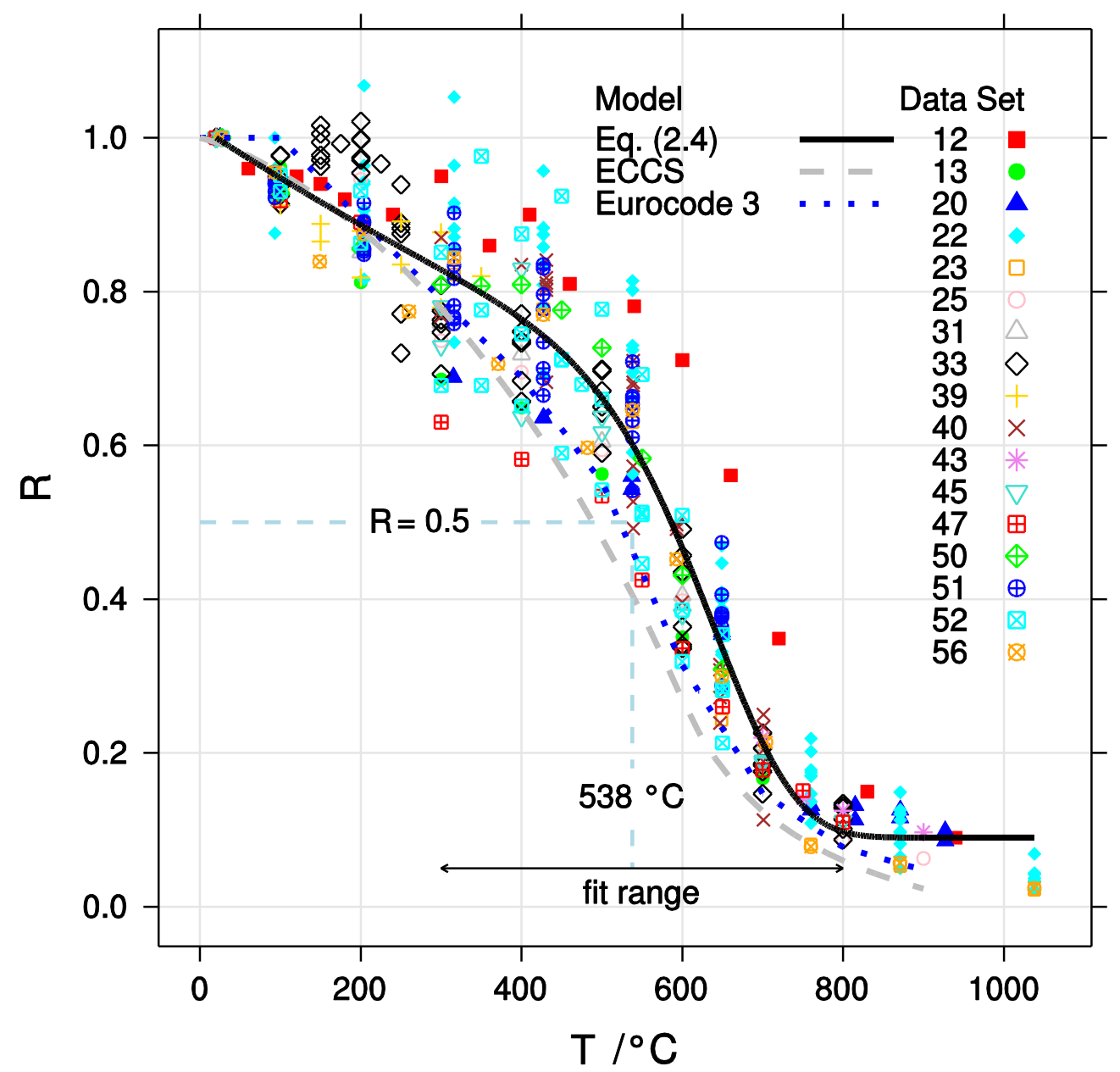

Figure 2-4: Behavior of the retained yield strength for structural steels. See Table 2-1 for key. 
Table 2-1: Concordance for identifying steels in Fig. 2-2, Fig. 2-3, Fig. 2-4, Fig. 2-5, and Fig. 2-19.

\begin{tabular}{|c|c|}
\hline Data Set & Author \\
\hline 4 & ASME (2004) \\
\hline 11 & $\begin{array}{l}\text { Brockenbrough and Johnston } \\
\text { (1968) }\end{array}$ \\
\hline 12 & Chen et al. (2006) \\
\hline 13 & Chijiiwa et al. (1993) \\
\hline 15 & ECCS (1983) \\
\hline 16 & ECS (2005) \\
\hline 18 & Garofalo (1952) \\
\hline 19 & Gonzalez and Lange (2010) \\
\hline 20 & Gowda (1978) \\
\hline 22 & Holt (1964) \\
\hline 23 & Holt (unk) \\
\hline 25 & Hu et al. (2009) \\
\hline 31 & Kirby and Preston (1988) \\
\hline 32 & Kirby (1995) \\
\hline 33 & Kirby and Preston (1991) \\
\hline 35 & Kodur et al. (2012) \\
\hline 36 & Li et al. (2003) \\
\hline 37 & Lie (1992) \\
\hline 39 & Lou and Northwood (1995) \\
\hline 40 & Luecke et al. (2011) \\
\hline 42 & Manjoine (1944) \\
\hline 43 & Outinen et al. (2001) \\
\hline 45 & Poh (1998) \\
\hline 46 & Ritter and McPherson (1970) \\
\hline 47 & Sakumoto (1999) \\
\hline 48 & Sakumoto et al. (1993) \\
\hline 49 & Schleich (1987) \\
\hline 50 & Skinner (1973) \\
\hline 51 & Spaeder Jr. and Brown (1977) \\
\hline 52 & Stevens et al. (1971) \\
\hline 55 & Twilt (1991) \\
\hline 56 & USS (1972) \\
\hline
\end{tabular}

These data were screened from a much larger data set on structural steels, and represent data from reputable testing laboratories with well described test protocols. To remove the effect of strain rate on the strength, those data only include tests conducted in a strain-rate range that includes the range 
of rates allowed in ASTM E21 (2009c), ISO 783 (1999), and JIS G0567 (1998) high-temperature tensile test standards: $3.30 \times 10^{-5} \mathrm{~mm} / \mathrm{mm} / \mathrm{s}<\dot{\varepsilon}<1.35 \times 10^{-4} \mathrm{~mm} / \mathrm{mm} / \mathrm{s}$.

Many functions could represent the behavior of the retained yield strength, $R$. The solid line in Fig. 2-4 is one that faithfully captures the steep drop-off in the range $(400<T<650){ }^{\circ} \mathrm{C}$. Its form is

$$
R=\frac{F_{y 0}}{S_{y}^{0}}=r_{5}+\left(1-r_{5}\right) \exp \left(-\frac{1}{2}\left(\frac{T^{*}}{r_{3}}\right)^{r_{1}}-\frac{1}{2}\left(\frac{T^{*}}{r_{4}}\right)^{r_{2}}\right.
$$

where $T^{*}=T-20$, measured in ${ }^{\circ} \mathrm{C}$. The use of the pre-factor, $r_{5}$, helps capture the relatively constant value of the retained strength at very high temperatures. Only the parameters $r_{1}, r_{3}$, and $r_{4}$ in Eq. (2.4) were fit, and then only in the range $(300 \leq T \leq 800){ }^{\circ} \mathrm{C}$. Limiting the fit to this range enhanced the fidelity of the model to the data in the temperature region where the change in strength is most abrupt. The parameters $r_{1}$ and $r_{5}$ were fixed and not fit; $r_{1}=1$, and $r_{5}$ was estimated from the high-temperature data. The data set is identical to the one in Luecke et al., 2011.

Fig. 2-4 also plots the Eurocode 3 (ECS, 2005) and ECCS (1983) models as well as the general rule that the yield strength falls in half by $538{ }^{\circ} \mathrm{C}\left(1000{ }^{\circ} \mathrm{F}\right)$. The values plotted for the Eurocode 3 represent the $0.2 \%$ offset yield strength computed from the Eurocode 3 stress-strain curve using its modulus as a function of temperature, instead of the proportional limit or stress at $2 \%$ total elongation that the Eurocode 3 model explicitly provides. Almost all the data lie above the Eurocode 3 prediction.

\subsubsection{Yield strength dependence of the strain hardening}

For structural steels, the amount of strain hardening after yield generally decreases with increasing ambient-temperature yield strength. The plastic portion of the stress-strain $\left(\sigma_{p}-\varepsilon_{p}\right)$ curve can be represented by a power-law model:

$$
\sigma_{p}=K_{S}\left(F_{y 0}\right) K_{T}(T) \varepsilon_{p}^{n}
$$

where the temperature and yield-strength dependence of the strength coefficient $K$ are separated. A simple form of the yield-strength dependence of the strength coefficient, $K_{S}$, that can represent the behavior is a linear decrease with increasing ambient-temperature yield strength, $S_{y}^{0}$ :

$$
K_{S}\left(F_{y 0}\right)=k_{3}-k_{4} S_{y}^{0}
$$

with $k_{3}$ and $k_{4}$ constrained so that the strength coefficient, $K_{S}$, cannot be negative for reasonable values of the ambient-temperature yield strength. 


\subsubsection{Temperature dependence of the strain hardening}

One approach to modeling the temperature dependence of the strain hardening would be to make the parameter $n$ in Eq. (2.5) depend on temperature. The results of this approach did not match the observed strain hardening particularly well. An alternate approach fits a single value of the strainhardening coefficient, $n$, for all temperatures and makes only the strength coefficient, $K_{T}$, depend on temperature:

$$
K_{T}(T)=\exp \left(-\left(\frac{T}{k_{2}}\right)^{k_{1}}\right)
$$

This function smoothly degrades from the ambient-temperature value to zero at high temperature and effectively changes the shape of the stress-strain curve after yield.

\subsubsection{Temperature dependence of the strain-rate sensitivity}

As the temperature increases, the sensitivity of the strength of structural steel to deformation rate increases (Gowda, 1978; Hu et al., 2009; Lou and Northwood, 1995; Luecke et al., 2011; Manjoine, 1944; Poh, 1998; Skinner, 1973; Stevens et al., 1971). By $500{ }^{\circ} \mathrm{C}$, increasing the strain rate by ten times can increase the measured strength by $25 \%$. In a constant load test, this behavior manifests itself as creep (Williams-Leir, 1983). Some literature reports recognize the importance of creep effects (Twilt, 1988; ECCS, 1983; Hu et al., 2009). In particular, the ECCS (1983) stressstrain model asserts that time-dependent strength effects are included, but provides no documentation on the method.

Dozens of high-temperature strength models exist that incorporate rate effects, for example Johnson-Cook (1983) and Zerilli-Armstrong (1987). They range from purely phenomenological to sophisticated micromechanical models. One simple and long-used model that captures the observed behavior is a power-law representation in which the stress, $\sigma$, is proportional to the strain rate, $\dot{\varepsilon}$, raised to a power, $m$, called the strain-rate sensitivity.

$$
\frac{\sigma}{\sigma_{0}}=f(\dot{\varepsilon})=\left(\frac{\dot{\varepsilon}}{\dot{\varepsilon}_{0}}\right)^{m}
$$

The terms $\sigma_{0}$ and $\dot{\varepsilon}_{0}$ are normalizing factors. Generally $\sigma_{0}=1 \mathrm{MPa}$ and $\dot{\varepsilon}_{0}=$ $8.33 \times 10^{-5} \mathrm{~mm} / \mathrm{mm} / \mathrm{s}$, the rate used in most high-temperature tensile testing. Fig. $2-5$ plots the strain-rate sensitivity, $m$, as a function of temperature for several structural steels, see Table 2-1 for identification. The strain-rate sensitivity, $m$, is nearly zero at ambient temperature and increases to a maximum at high temperature. Takeuchi and Argon (1976, Section 2.2.4) analyzed powerlaw creep of metals theoretically and demonstrated that the strain-rate sensitivity for engineering alloys should be about $m=0.2$ in the high-temperature creep regime. A simple function that captures this behavior is 


$$
m=m_{0}+m_{3}\left[1-\exp \left(-\left(\frac{T}{m_{2}}\right)^{m_{1}}\right)\right]
$$

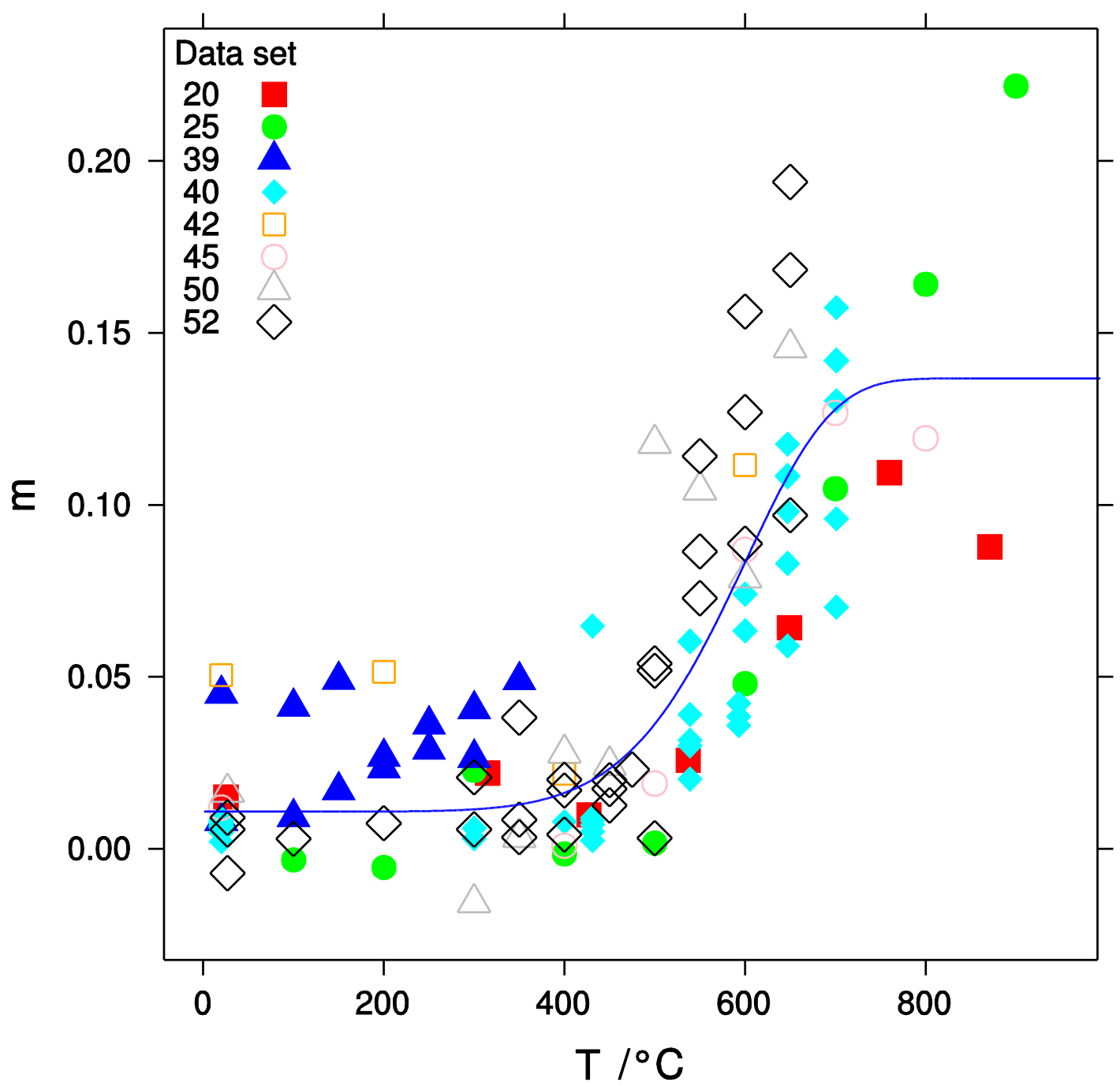

Figure 2-5: Strain-rate sensitivities, $m$, for literature steels. The solid line is the fit of Eq. (2.9).

\subsubsection{Final form of the stress-strain behavior}

The equations for the elastic modulus, $E$, retained strength, $R$, post-yield strain-hardening behavior, and strain-rate sensitivity, $m$, can be combined into the final form of the stress-strain model: for $\varepsilon<\frac{F_{y 0}}{E}$, elastic behavior, $\sigma=E \varepsilon$

for $\varepsilon \geq \frac{F_{y 0}}{E}$, plastic behavior, $\sigma=\left(R S_{y}^{0}+\left(k_{3}-k_{4} S_{y}^{0}\right) \exp \left(-\left(\frac{T}{k_{2}}\right)^{k_{1}}\right)\left(\varepsilon-\frac{R S_{y}^{0}}{E}\right)^{n}\right)\left(\frac{\dot{\varepsilon}}{\dot{\varepsilon}_{0}}\right)^{m}$ 
where the parameters are given by

E Eq. (2.2)

$R$ Eq. (2.4)

$m$ Eq. (2.9)

The entire model was developed for true-stress-true-strain behavior, but it can be recast in terms of engineering stress and strain, $(S-e)$.

$$
\begin{gathered}
\varepsilon=\ln (1+e) \\
\sigma=S \exp (\varepsilon)=S(1+e)
\end{gathered}
$$

Eq. (2.10) becomes

$$
\begin{aligned}
& \text { for } e<\frac{F_{y 0}}{E}, \text { elastic behavior, } \sigma=E \varepsilon \\
& \text { for, } e \geq \frac{F_{y 0}}{E}, \text { plastic behavior, } \\
& \qquad S=\left(\frac{1}{1+e}\right)\left(R S_{y}^{0}+\left(k_{3}-k_{4} S_{y}^{0}\right) \exp \left(-\left(\frac{T}{k_{2}}\right)^{k_{1}}\right)\left(\ln (1+e)-\frac{R S_{y}^{0}}{E}\right)^{n}\right)\left(\frac{\dot{\varepsilon}}{\dot{\varepsilon}_{0}}\right)^{m}
\end{aligned}
$$

where the infinitesimal difference between engineering and true strain is neglected for elastic behavior.

\subsubsection{Method for calculating parameters}

Calculating the values of the parameters in Eq. (2.10) comprised four steps.

1. The values for the elastic modulus, Eq. (2.2), came from a non-linear, least-squares regression of Eq. (2.2) using the data in Fig. 2-2.

2. The temperature dependence of the retained yield strength, $R$, came from a non-linear regression of Eq. (2.4) to the data in Fig. $2-4$ in the range $(300 \leq T \leq 700){ }^{\circ} \mathrm{C}$. That data set includes both literature data and data from the WTC investigation (Luecke et al., 2011).

3. The behavior of the strain hardening came from a non-linear regression of the parameters $k_{1}, k_{2}, k_{3}, k_{4}$ and $n$ in Eq. (2.10) using 41 stress-strain curves from eight different structural steels taken from the NIST WTC investigation, but no other literature data. In this non-linear regression the values of the individual $e_{i}$ in the equation for $E$ (Eq. (2.2)) and $r_{i}$ in the equation for $R$ (Eq. (2.4)) had already been determined in the first and second steps. Since the stress-strain behavior for these eight steels was determined at nominal strain rates $\dot{\varepsilon}=$ $\dot{\varepsilon_{0}}$, the strain-rate sensitivity term evaluates to unity, and drops out of the regression. The 
regression only included data in the strain range $0.005 \leq \varepsilon \leq 0.150$. The specified yield strengths of those eight steels were in the range $\left(36 \geq F_{y 0} \leq 70\right) \mathrm{ksi},\left(250 \geq F_{y 0} \leq 520\right) \mathrm{MPa}$.

4. The strain-rate sensitivity, $m$, Eq. (2.9), came from a non-linear regression of the data in Fig. 2-5.

Table 2-2 summarizes the values of the eighteen parameters for ordinary structural steels (denoted by “'Ord.") in Eq. (2.10). 
Table 2-2: Values of the parameters in the stress-strain model, Eq. (2.10), for ordinary (Ord.), fire-resistive (FR), quenched-and-tempered plate (plate), and bolt steels.

\begin{tabular}{|c|c|c|c|c|c|c|}
\hline Parameter & $\begin{array}{l}\text { Value } \\
\text { (Ord.) }\end{array}$ & $\begin{array}{l}\text { Value } \\
\text { (FR) }\end{array}$ & $\begin{array}{l}\text { Value } \\
\text { (plate) }\end{array}$ & $\begin{array}{l}\text { Value } \\
\text { (bolt) }\end{array}$ & Units & Eq. \\
\hline$r_{1}$ & 7.514 & 9.782 & 10.143 & 4.967 & & $(2.4)$ \\
\hline$r_{2}$ & 1.000 & 1.000 & 1.000 & 1.000 & & (2.4) \\
\hline$r_{3}$ & 588 & 625 & 589 & 456 & ${ }^{\circ} \mathrm{C}$ & $(2.4)$ \\
\hline$r_{4}$ & 676 & 1334 & 837 & 2040 & ${ }^{\circ} \mathrm{C}$ & $(2.4)$ \\
\hline$r_{5}$ & 0.090 & 0 & 0 & 0 & ${ }^{\circ} \mathrm{C}$ & $(2.4)$ \\
\hline$k_{1}$ & 7.820 & 9.814 & 10.616 & & & $\overline{(2.10)}$ \\
\hline$k_{2}$ & 540 & 616 & 811 & & ${ }^{\circ} \mathrm{C}$ & $\overline{(2.10)}$ \\
\hline$k_{3}$ & 1006 & 5835 & 959 & & $\mathrm{MPa}$ & $(2.10)$ \\
\hline$k_{4}$ & 0.759 & 15.846 & 0.766 & & & $(2.10)$ \\
\hline$n$ & 0.503 & 0.456 & 0.349 & & & $(2.10)$ \\
\hline$m_{0}$ & \multicolumn{4}{|c|}{0.0108} & & $(2.9)$ \\
\hline$m_{1}$ & \multicolumn{4}{|c|}{7.308} & & $(2.9)$ \\
\hline$m_{2}$ & \multicolumn{4}{|c|}{613} & ${ }^{\circ} \mathrm{C}$ & $(2.9)$ \\
\hline$m_{3}$ & \multicolumn{4}{|c|}{0.126} & & (2.9) \\
\hline$\dot{\epsilon}_{0}$ & \multicolumn{4}{|c|}{$8.333 \times 10^{-5}$} & $\mathrm{~s}^{-1}$ & $(2.9)$ \\
\hline$E_{0}$ & \multicolumn{4}{|c|}{206.0} & $\mathrm{GPa}$ & $(2.2)$ \\
\hline$e_{1}$ & \multicolumn{4}{|c|}{3.768} & & $(2.2)$ \\
\hline$e_{2}$ & \multicolumn{4}{|c|}{1.000} & & $(2.2)$ \\
\hline$e_{3}$ & \multicolumn{4}{|c|}{639} & ${ }^{\circ} \mathrm{C}$ & $(2.2)$ \\
\hline$e_{4}$ & \multicolumn{4}{|c|}{1650} & ${ }^{\circ} \mathrm{C}$ & $(2.2)$ \\
\hline
\end{tabular}

\subsubsection{Tensile strength}

A typical mill test reports the tensile strength, $S_{u}$, (also sometimes called the ultimate tensile strength) in addition to the yield strength and total elongation. Generally, the tensile strength 
represents the maximum load-carrying capacity of the material. Fig. 2-6 plots the reported tensile strength for the tests also shown in Fig. 2-4.

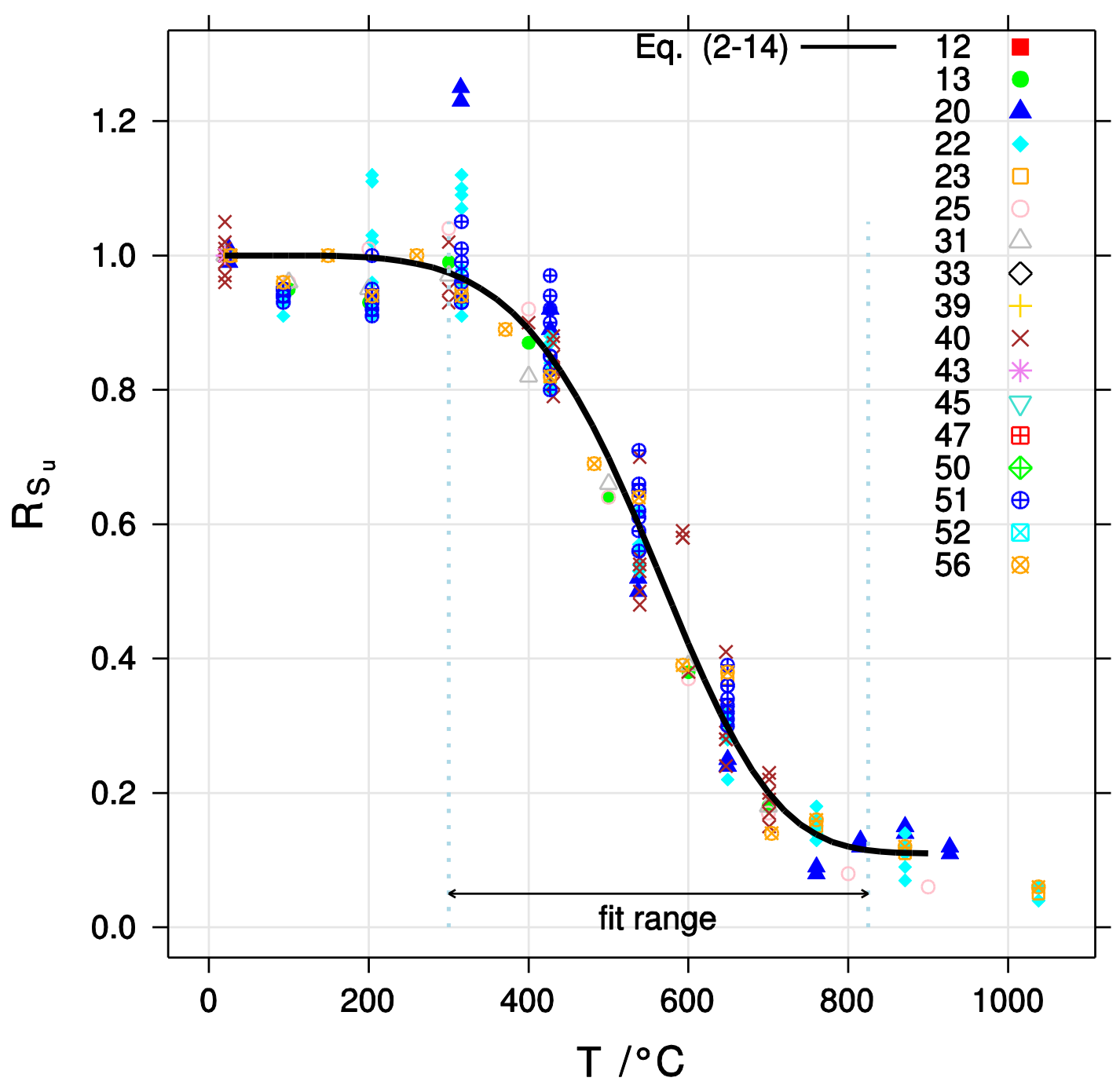

Figure 2-6: Behavior of the retained tensile strength for structural steels. See Table 2-1 for key.

Because structural steel creeps significantly at temperatures above $500{ }^{\circ} \mathrm{C}$, the tensile strength, like the yield strength, begins to depend on time as the temperature increases. Users should therefore exercise care in interpreting the tensile strength for high-temperature design. The hightemperature tensile strength in Fig. 2-6 only represents the maximum engineering stress that a test coupon achieves in a test conducted according to standard conditions. An analysis of the uncertainty in the tensile strength data is provided in Section 2.2.4. 
The behavior of the tensile strength can be represented by the same form as used for the yield strength:

$$
R_{S u}=\frac{S_{u}}{S_{u}^{0}}=r_{10}+\left(1-r_{10}\right) \exp \left(-\frac{1}{2}\left(\frac{T^{*}}{r_{8}}\right)^{r_{6}}-\frac{1}{2}\left(\frac{T^{*}}{r_{9}}\right)^{r_{7}}\right)
$$

where $T^{*}=T-20$, measured in ${ }^{\circ} \mathrm{C}$. The solid line in Fig. 2-6 is a fit to the data in the temperature range $(350 \leq T \leq 825){ }^{\circ} \mathrm{C}$. Table $2-3$ reports the values of the parameters in Eq. (2.14). The value of the minimum retained yield strength, $r_{10}$, was not fit, but instead set to the its mean value for temperatures $T>725^{\circ} \mathrm{C}$.

Table 2-3: Parameters for describing the temperature dependence of the tensile strength of ordinary structural steel

\begin{tabular}{|c|c|c|c|}
\hline Parameter & $\begin{array}{c}\text { Value } \\
(\text { Ord. })\end{array}$ & Units & Eq. \\
\hline$r_{6}$ & 4.906 & & $(2.14)$ \\
\hline$r_{7}$ & 4.906 & & $(2.14)$ \\
\hline$r_{8}$ & 560 & ${ }^{\circ} \mathrm{C}$ & $(2.14)$ \\
\hline$r_{9}$ & 592 & ${ }^{\circ} \mathrm{C}$ & $(2.14)$ \\
\hline$r_{10}$ & 0.110 & & $(2.14)$ \\
\hline
\end{tabular}

\subsubsection{Ultimate Tensile Strength}

The onset of necking in a tensile coupon occurs at the ultimate tensile strength, when the increase in stress due to reduction of the cross-sectional area overcomes the increase in strength due to strain hardening. At this point the strain, which had been uniform within the gauge length, begins to localize. An equation for the engineering strain at the onset of necking (i.e., the uniform strain), was determined based on nonlinear least-squares regression of data available in the literature (Fig. 2-7(a)) as (Seif et al. 2016):

$$
e_{u}(T)=e_{u 0}\left[\exp \left(-\frac{1}{2}\left(\frac{\Delta T}{q_{3}}\right)^{q_{1}}\right)\right]
$$

where $e_{\mathrm{u} 0}$ is the uniform strain at ambient temperature, $q_{1}=3.587$, and $q_{3}=488{ }^{\circ} \mathrm{C}$. The data included in Fig. 2-7 correspond to a subset of the data considered in Section 2.2, for which uniform strain values were reported. The ambient-temperature uniform strain decreases with increasing yield strength (i.e., low-strength steels are typically more ductile than high-strength steels), as 
shown by the experimental data in Fig. 2-7(b), and the following approximate relationship was obtained from linear regression of these data:

$$
e_{u 0}\left(F_{y 0}\right)=p_{1} F_{y 0}+p_{2}
$$

where $p_{1}=-0.00152$ and $p_{2}=0.252$. Together, Eq. (2.15) and Eq. (2.16) provide a complete description of the temperature-dependent uniform strain, based solely on the ambient temperature yield strength, that can be applied to arbitrary strength steels. Although the stress-strain model is limited to steels with nominal yield strengths less than $65 \mathrm{ksi}$ (450 MPa), the relationship in Eq. (2.16) was fit to data over a wider range of nominal yield strengths with a maximum nominal yield strength of $110 \mathrm{ksi}(760 \mathrm{MPa})$. The ultimate tensile strength corresponding to a given value of $e_{u}$ can be calculated using Eq. (2.2), Eq. (2.4), and Eq. (2.10). Fig. 2-8 compares tensile strength values obtained from the proposed uniform strain model (Eq. (2.16)) for $F_{y 0}=50 \mathrm{ksi}$ (345 MPa) with corresponding experimental tensile strength data. 
(a)

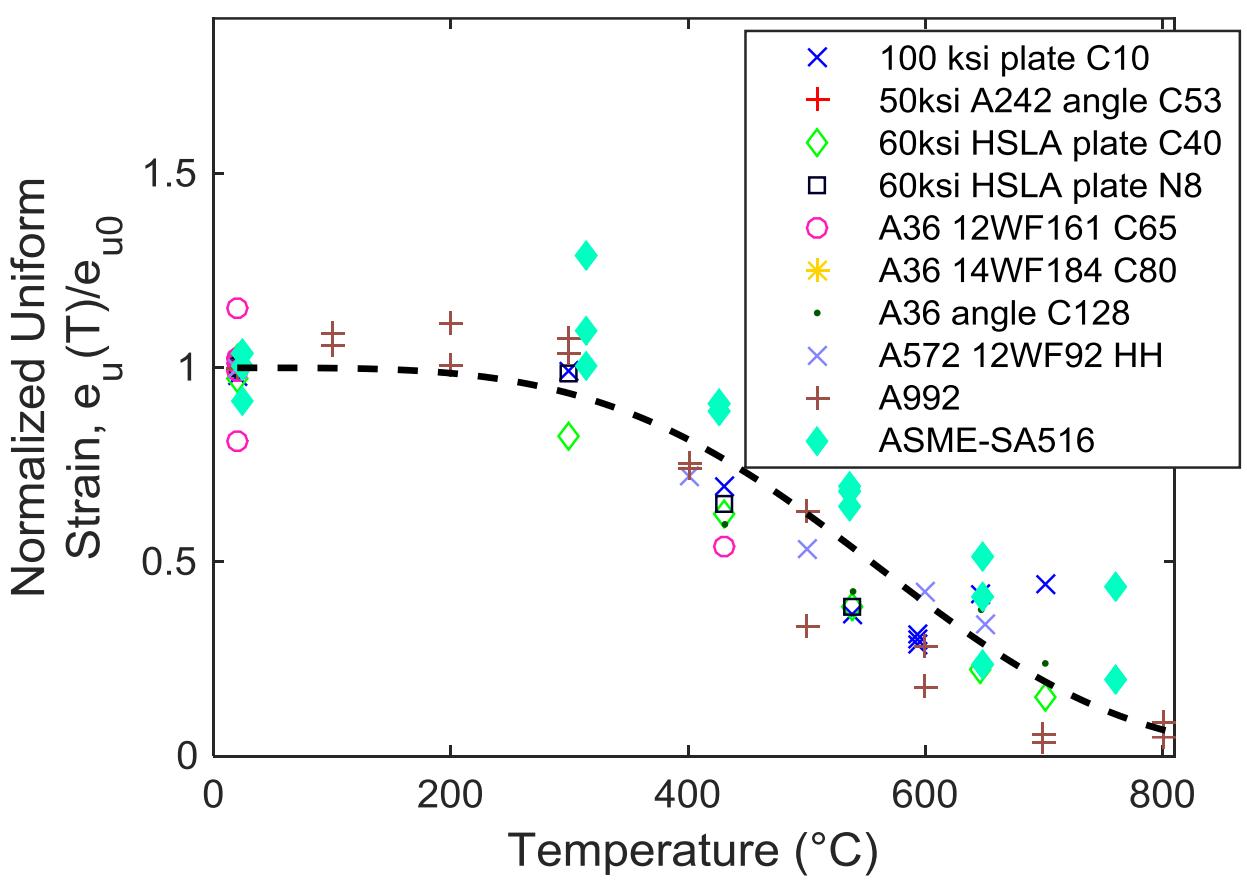

(b)

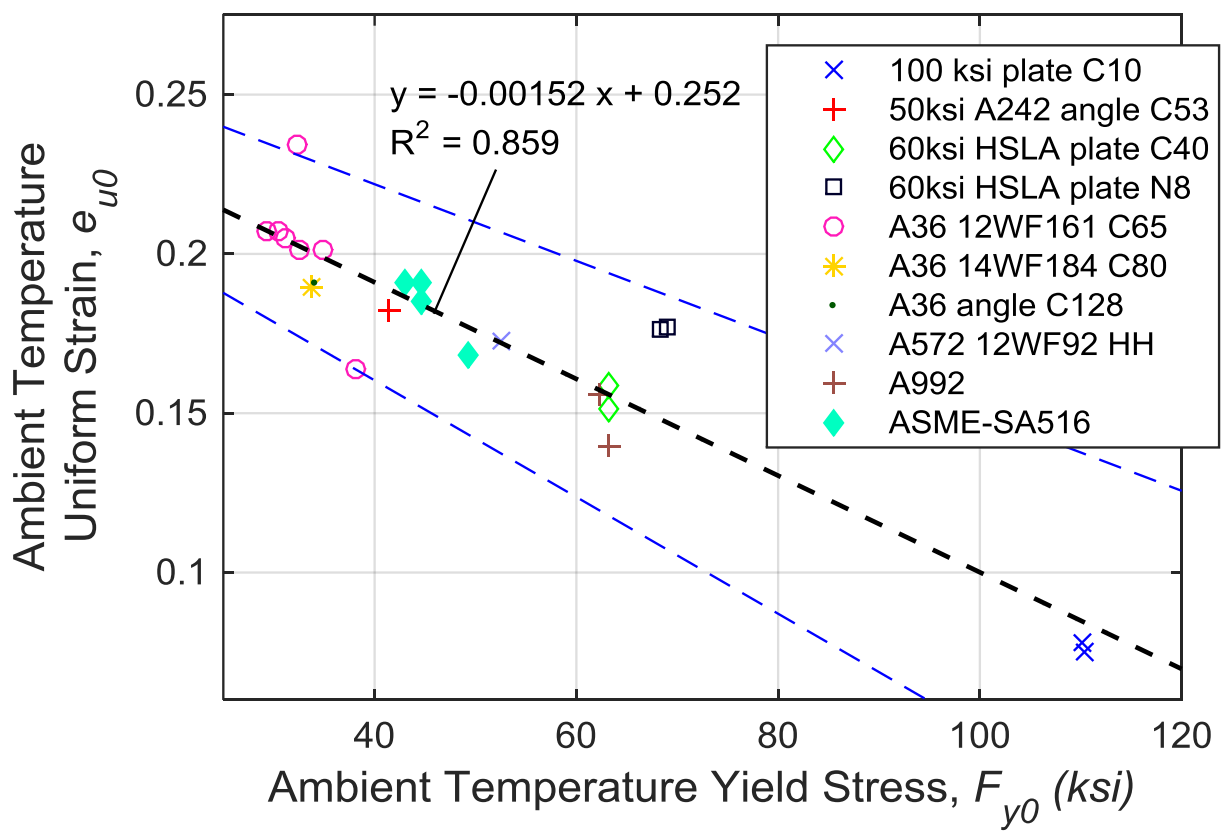

Figure 2-7 (a) Temperature-dependent normalized uniform strain (Eq. (2.6)) compared with available experimental data and (b) fit to ambient temperature uniform strain based on ambient temperature yield stress with $95 \%$ confidence bounds, compared with available experimental data. 


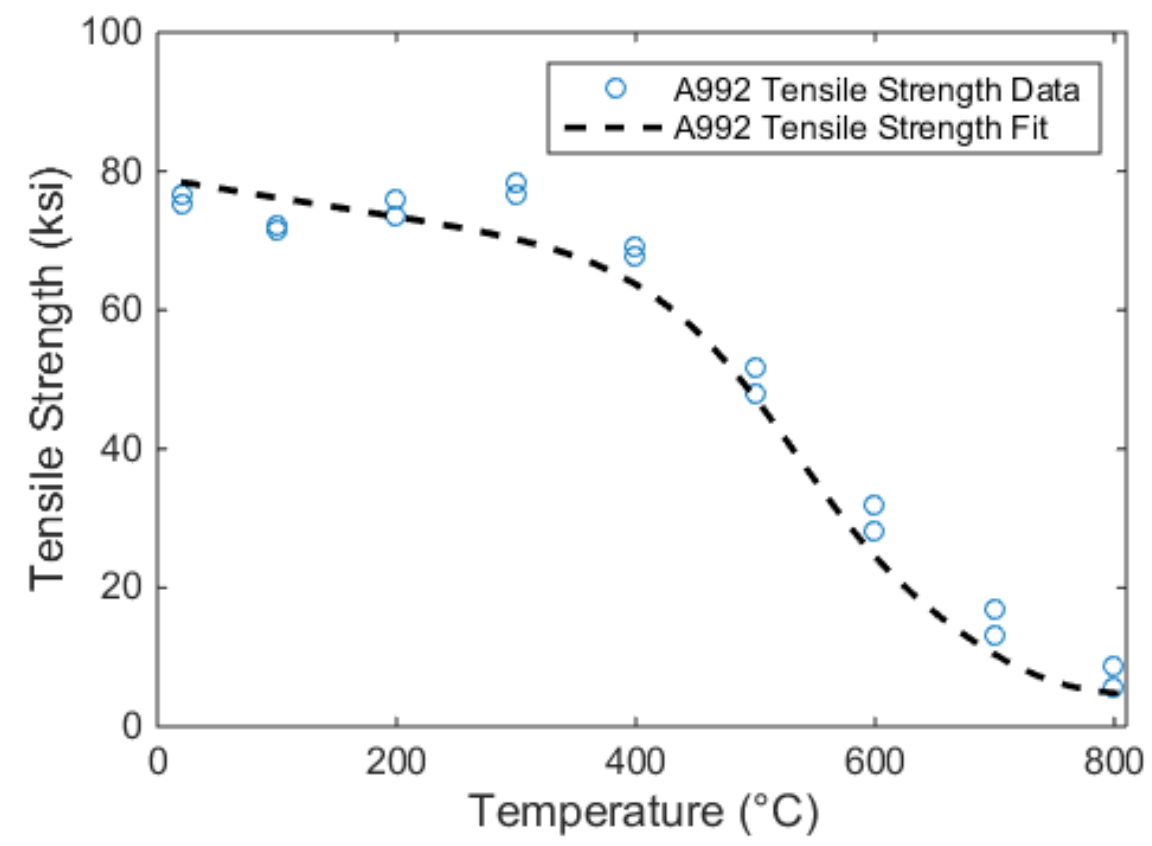

Figure 2-8: Tensile strength resulting from fit to uniform strain for structural steel with $F y=50$ ksi (345 MPa), compared with experimental data.

\subsubsection{Application and Comparison to Eurocode 3 Behavior}

The plastic portion of the stress-strain model, Eq. (2.10), was developed using data on eight structural steels used in the NIST World Trade Center Collapse investigation. Its utility can be assessed by comparing its predictions to stress-strain data from outside the original set. Recently, Hu et al. (2009) published high-temperature stress-strain data for ASTM A992 (2011) structural steel. Neither the retained yield strength nor the stress-strain curves from this data set were used in computing the values of the parameters in Table 2-2. Fig. 2-9 plots that data for some of the reported temperatures. In general the agreement is excellent, given that the only parameter input to the stress-strain model is the ambient-temperature yield strength, $S_{y}^{0}=429 \mathrm{MPa}$, and that the model did not use the data to estimate the parameters. Fig. 2-9 also plots the prediction of the Eurocode 3 (ECS, 2005) model. Both models over-predict the ambient-temperature behavior, but predict the higher temperature behavior similarly. 


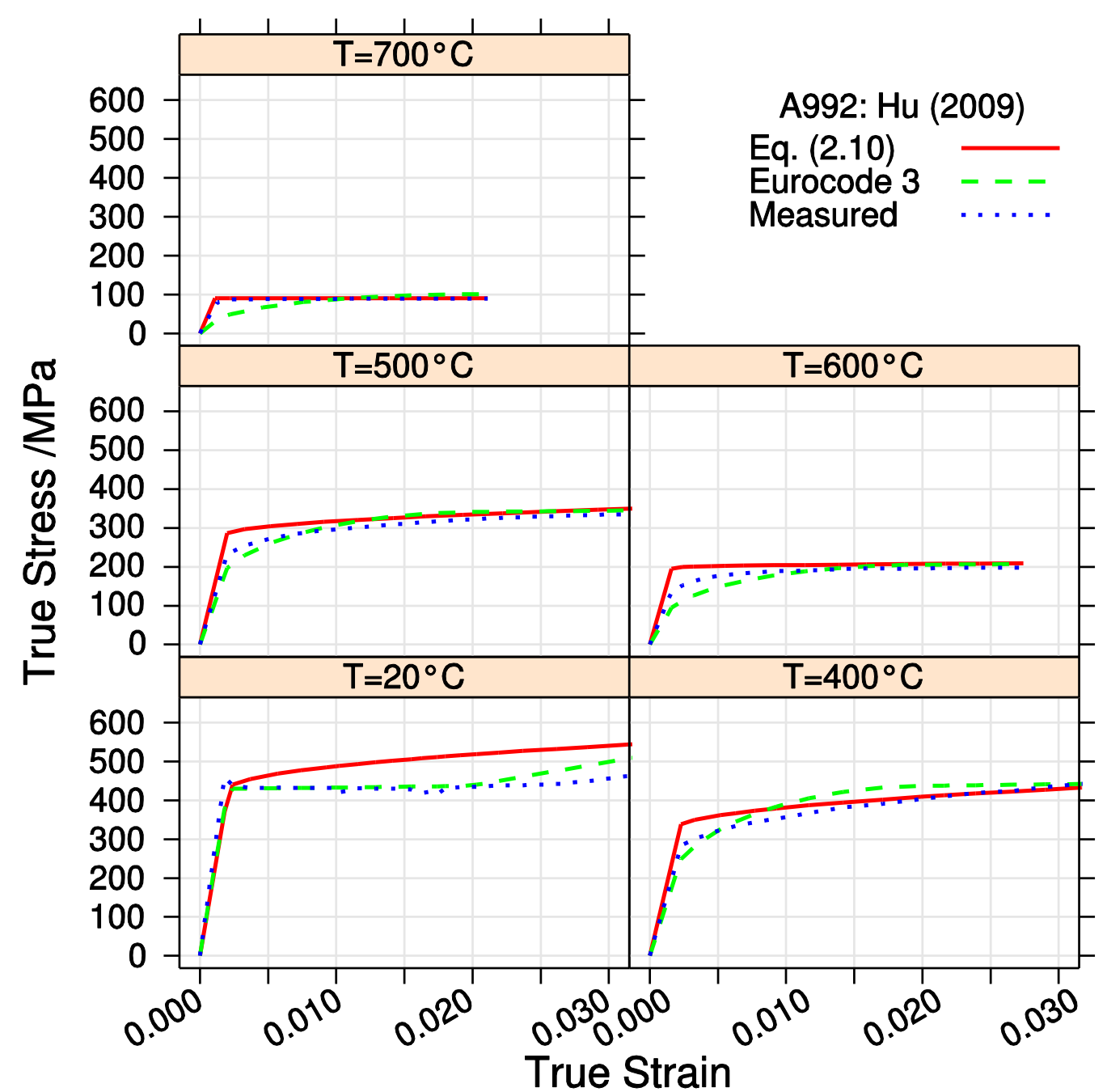

Figure 2-9: Comparison of the predictions of the stress-strain model, Eq. (2.10), the Eurocode 3 (ECS, 2005) model, and the measured stress-strain behavior of A992 steel from Hu et al. (2009)

Fig. 2-10 compares measured stress-strain data for Australian AS A186:250 steel from the extensive data of Skinner (1973) to the model and Eurocode 3 predictions. The yield strength data for this data set was used in the calculation of the retained yield strength, $R$ (Eq. (2.4)), but the post-yield plastic behavior were not used. The predictions of the model of Eq. (2.10) are closer to the measured data than the predictions of the Eurocode 3 model. 


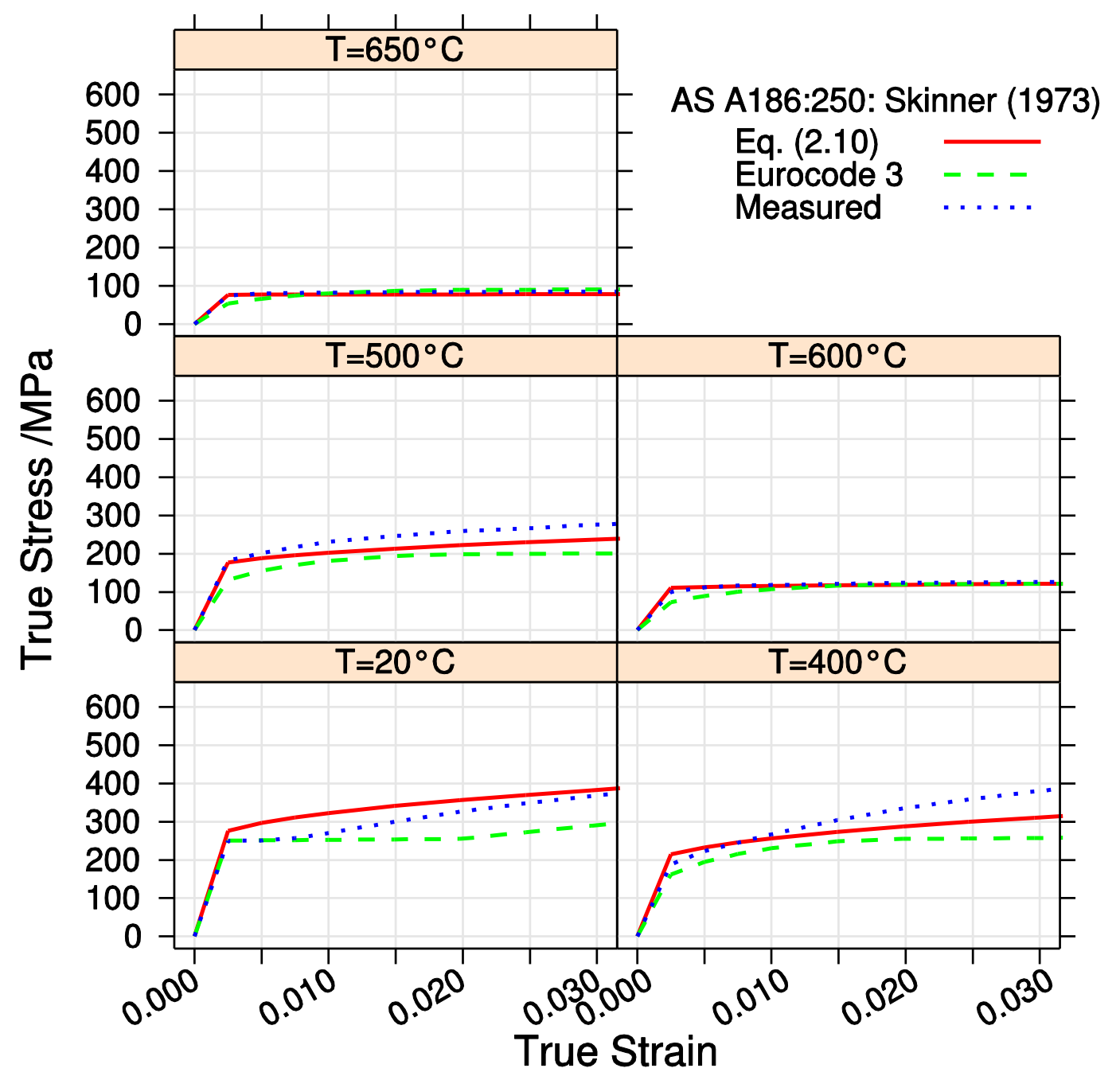

Figure 2-10: Comparison of the predictions of the stress-strain model, Eq. (2.10), the Eurocode 3 (ECS, 2005) model, and the measured stress-strain behavior of AS A186:250 steel from Skinner (1973).

Fig. 2-11 compares measured stress-strain data for A36 steel from Harmathy and Stanzak (1970) to the model and Eurocode 3 predictions. 


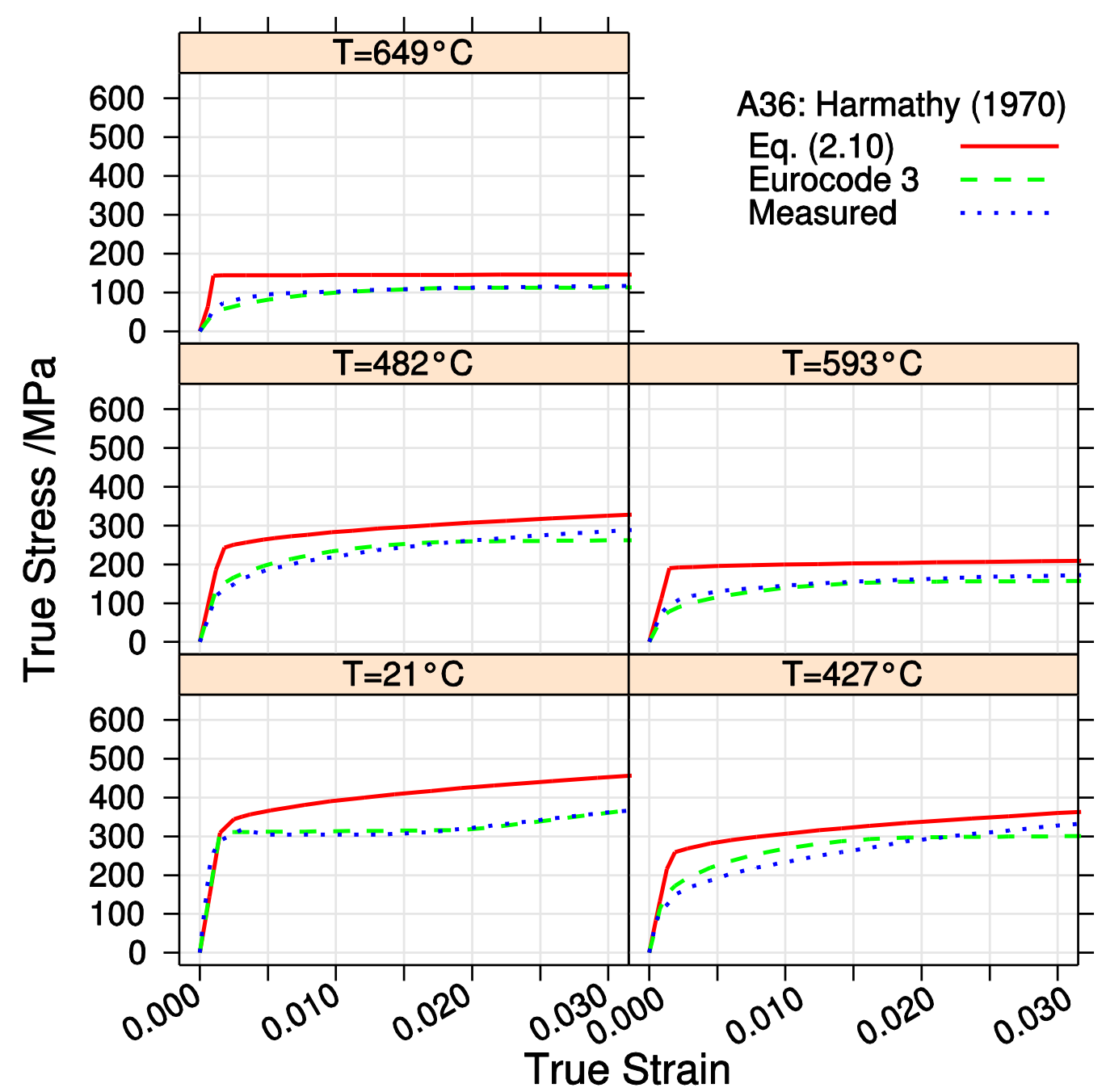

Figure 2-11: Comparison of the predictions of the stress-strain model, Eq. (2.10), the Eurocode 3 (ECS, 2005) model, and the measured stress-strain behavior of A36 steel from Harmathy and Stanzak (1970).

The Harmathy and Stanzak (1970) data were not used in the development of the stress-strain model, because the tests used a higher, non-standard strain rate. The plotted lines in Fig. 2-11 employ the strain rate sensitivity correction, Eq. (2.9), but the agreement between the measured behavior and the model is poorer.

\subsubsection{Uncertainty}

The coefficient of variation, COV or $V_{R}$, of a mechanical property, defined as the ratio of the standard deviation to the mean value, is an essential parameter in calculating the resistance factor, 
$\phi$, in load-and-resistance-factor design (LRFD) (Ellingwood et al., 1980; AISC, 2010). The uncertainty in the functions that describe the change in elastic modulus $E$, yield strength $F_{y}$, and tensile strength $F_{u}$ will be major contributors to the uncertainty in the stress-strain behavior. To estimate the coefficient of variation as a function of temperature, the data were aggregated by temperature. All data that were determined at a temperature within $\delta T=10^{\circ} \mathrm{C}$ were aggregated into a nominal temperature $T_{\text {nom }}$ that was the mean of the individual temperatures. The coefficient of variation is defined as

$$
V_{R}=\frac{1}{R\left(T_{\text {nom }}\right)} \sqrt{\frac{1}{N-1} \sum_{i=1}^{N}\left(R_{i}-R\left(T_{\text {nom }}\right)\right)^{2}}
$$

where $N$ is the number of individual determinations of $R_{i}$ at the nominal temperature.

Fig. 2-12, Fig. 2-13, and Fig. 2-14 show the coefficient of variation for the modulus of elasticity $E$, yield strength $F_{y}$, and tensile strength $F_{u}$, as a function of temperature, respectively. These figures show that the coefficient of variation for each parameter increases with temperature. The dashed line in each figure is a one-parameter linear regression of

$$
V_{R}=v_{1}(T-20)
$$




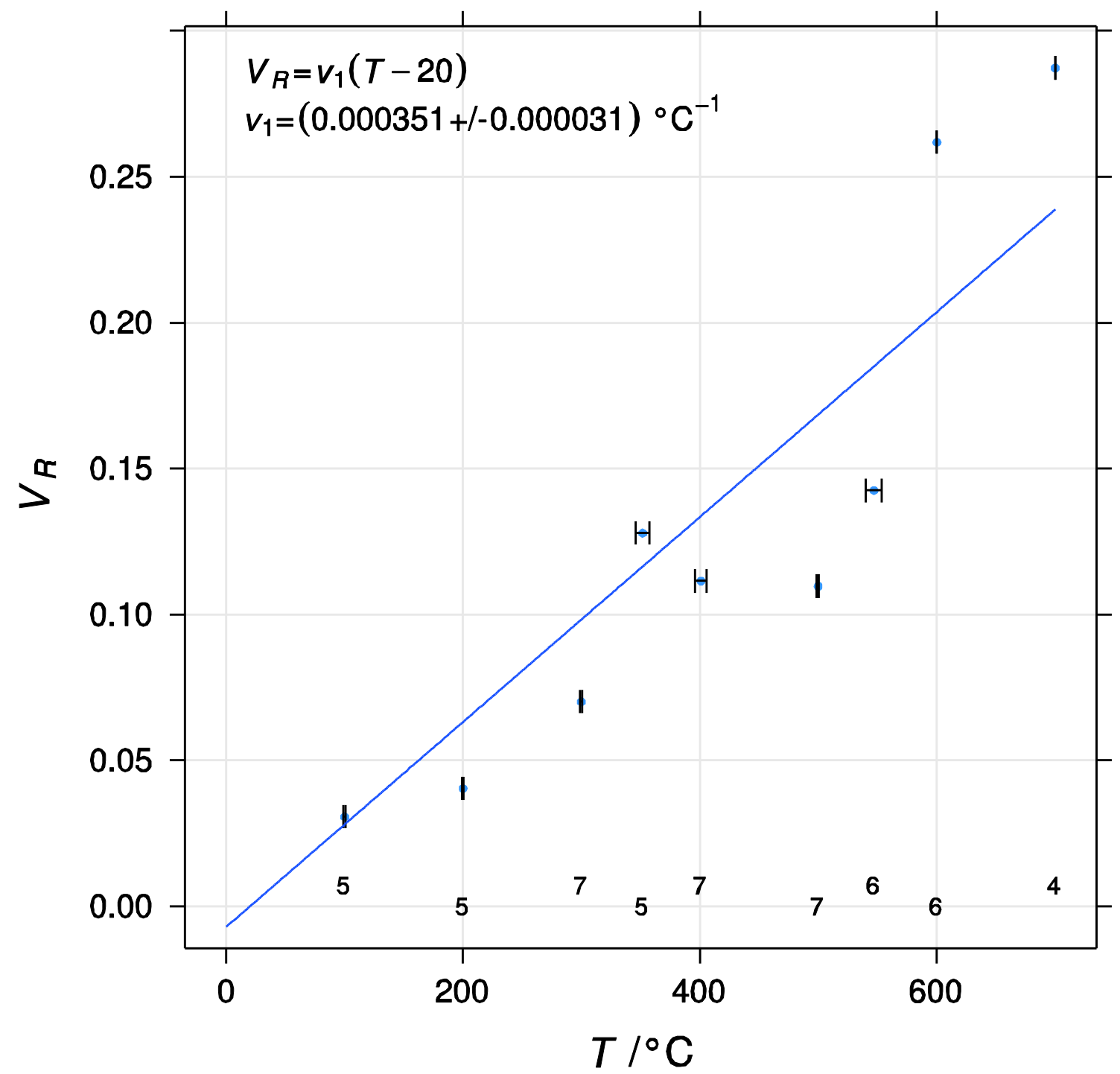

Figure 2-12: Coefficient of variation $V_{R}$ for elastic modulus $E$, as a function of temperature. Numbers along the $V_{R}=0$ axis denote the number of different steels used in each determination.

In the three figures, if a nominal temperature contained fewer than $N_{\min }$ individual determinations, it was omitted from the data set and the regression. In each figure, the horizontal uncertainty bar represents the range of the nominal temperatures. Where present, numbers on the $x$-axis represent the number of different steels in the determination of the coefficient of variation. Table 2-4 summarizes the determinations and regression data, where $R$ is the retained yield strength or modulus function defined in the listed equations, $v_{1}$ is the slope of the regression line, RSD is the residual standard deviation of the regression for $v_{1}$, and DoF is the number of degrees-of-freedom of the regression for $v_{1}$. 


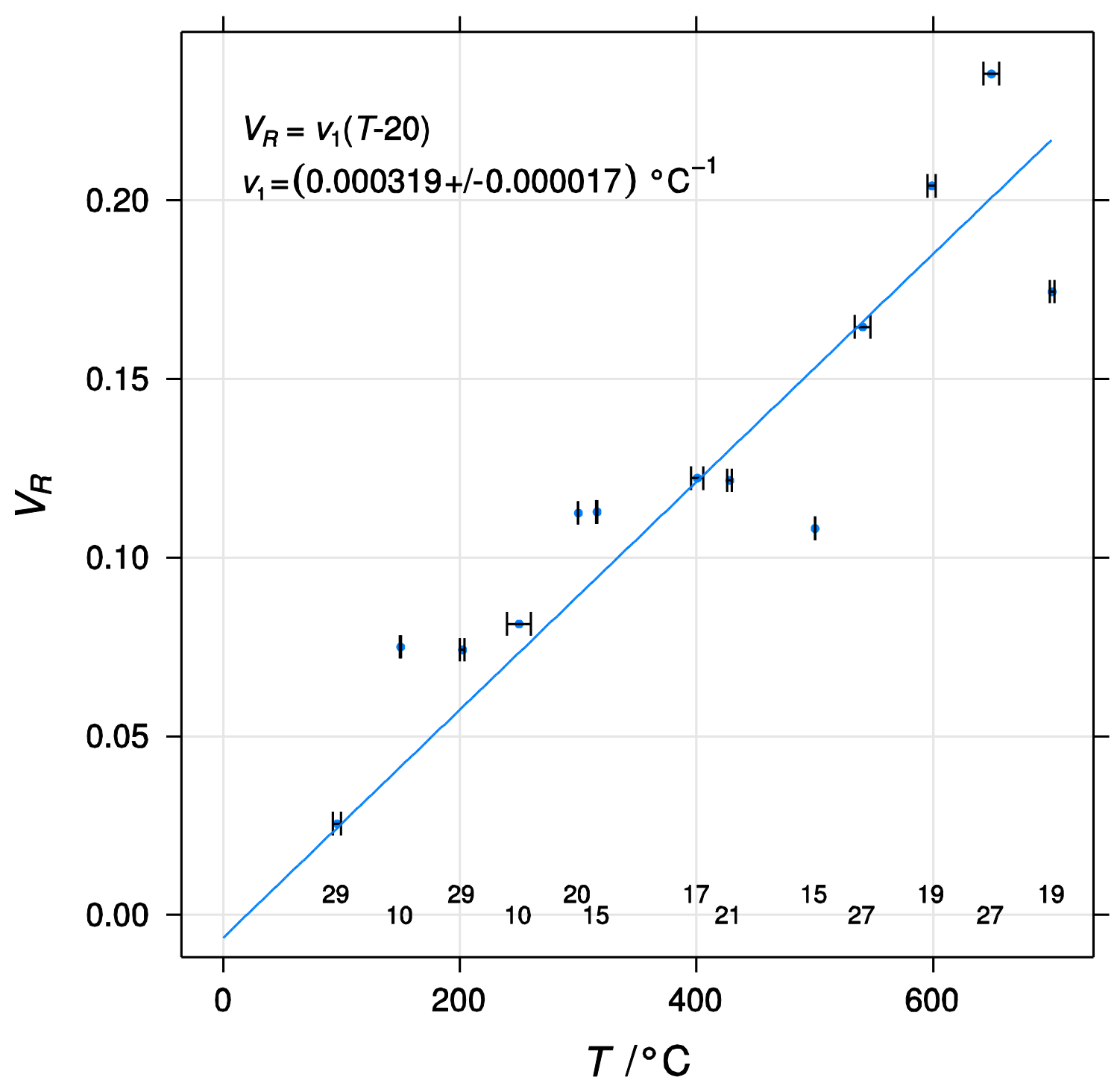

Figure 2-13: Coefficient of variation $V_{R}$ for yield strength $F_{y}$, as a function of temperature. Numbers along the $V_{R}=0$ axis denote the number of different steels used in each determination. 


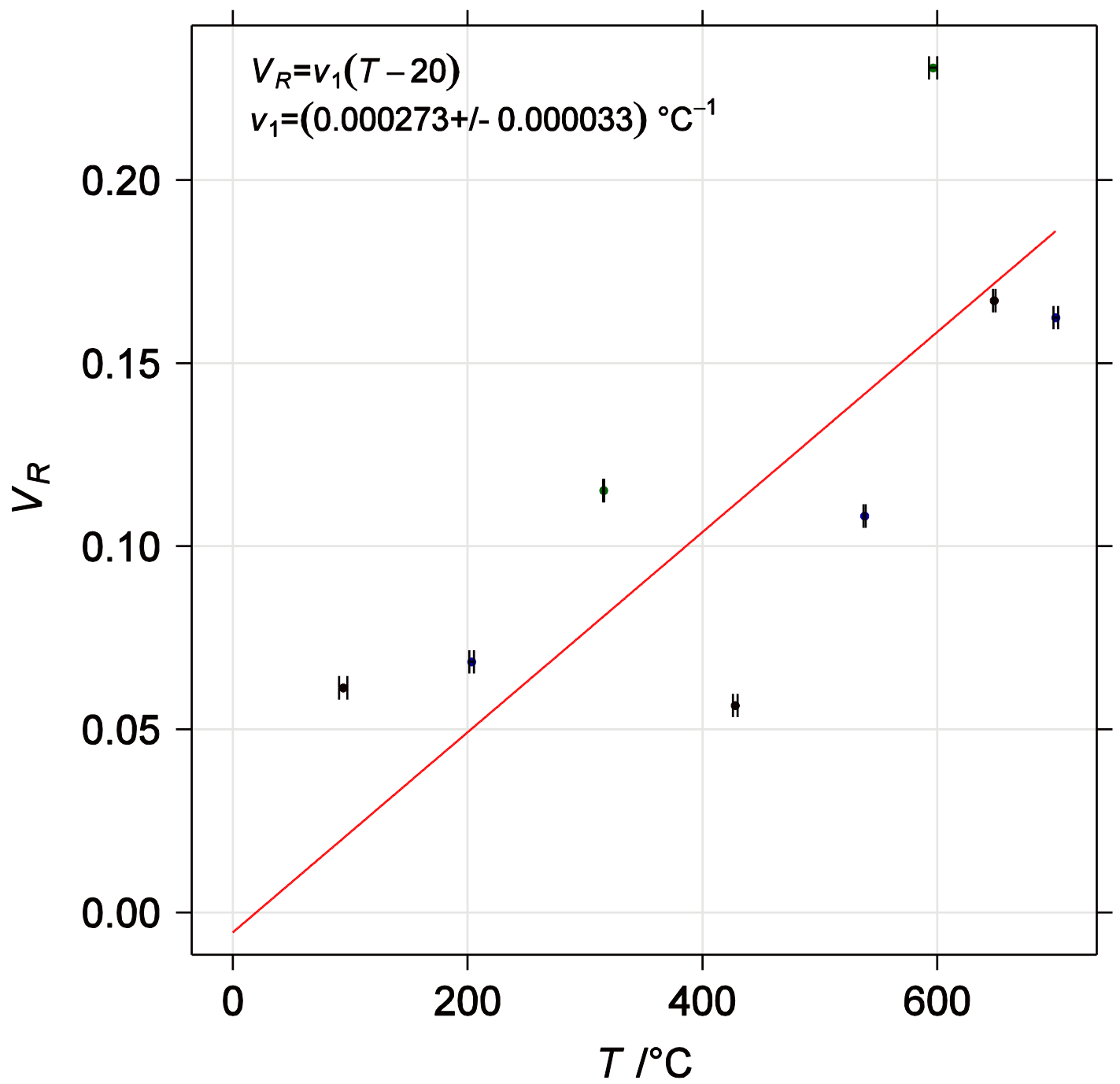

Figure 2-14: Coefficient of variation $V_{R}$ for tensile strength $F_{u}$, as a function of temperature.

Table 2-4: Summary of coefficient of variation calculations for $E, F_{y}$, and $F_{u}$.

\begin{tabular}{|c|c|c|c|c|c|c|c|}
\hline Parameter & Figure & $R$ & $\begin{array}{c}\nu_{1} \\
{ }^{\circ} \mathrm{C}^{-1}\end{array}$ & $\begin{array}{c}\delta T \\
{ }^{\circ} \mathrm{C}\end{array}$ & $\begin{array}{c}N_{\text {min }} \\
\text { RSD }\end{array}$ & DoF \\
\hline$E$ & $2-2$ & Eq. (2.2) & $0.000351 \pm 0.000031$ & 10 & 7 & 0.0402 & 8 \\
\hline$F_{y}$ & $2-4$ & Eq. (2.4) & $0.000310 \pm 0.000017$ & 10 & 10 & 0.0260 & 12 \\
\hline$F_{u}$ & $2-6$ & Eq. (2.14) & $0.000273 \pm 0.000033$ & 10 & 7 & 0.0435 & 7 \\
\hline
\end{tabular}




\subsubsection{Modifying the Model for Steels with Different High-Temperature Performance}

The model for structural steel at elevated temperature was developed with data exclusively from hot-rolled steels. Of course, not all steels used in construction are hot-rolled sections. Other steels, such as the new "fire-resistive" steels, quenched-and-tempered plate steels, and bolt steels are used in construction as well. Because of their different processing, the mechanical properties of these steels will certainly differ from those of hot-rolled shapes. This section shows three examples of how the model can be extended to represent the behavior of these steels.

\subsubsection{Fire-resistive steels}

So-called fire-resistive structural steels have been available for some time in Europe and Japan (Sakumoto, 1999). These steels retain a greater fraction of their ambient-temperature yield strength at higher temperature than do ordinary structural steels, but can be produced to meet accepted standards for construction and weldability. Typically, fire-resistive steels are specified to retain $2 / 3$ of their specified yield strength at $600{ }^{\circ} \mathrm{C}$ in contrast to the commonly accepted $1 / 2$ of the specified yield strength at $538{ }^{\circ} \mathrm{C}$, for ordinary structural steels. Recently these steels have been standardized in the United States under the designation ASTM A1077 (2012). Fig. 2-15 compares the retained yield strength of two fire-resistive steels tested at a nominal strain rate of $8.33 \times$ $10^{-5} \mathrm{~mm} / \mathrm{mm} / \mathrm{s}$, to the ordinary structural steel data from Fig. 2-4. Although these steels could meet the new A1077 standard, they were supplied to proprietary manufacturers' standards. 


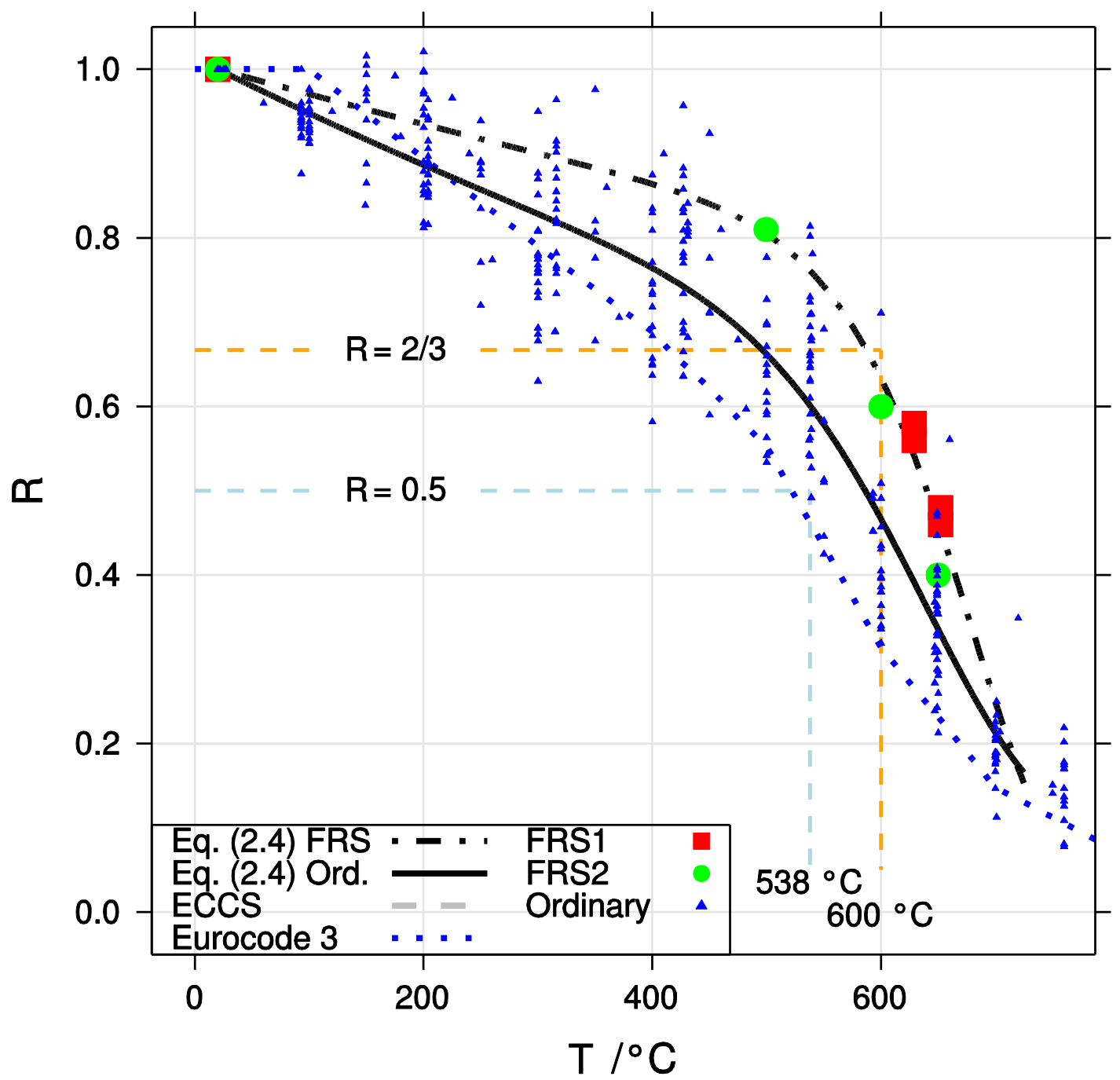

Figure 2-15: Comparison of the normalized retained yield strength for ordinary (Ord.) and fire-resistive (FRS) steels.

Both steels were designed to meet the $R=2 / 3$ at $600{ }^{\circ} \mathrm{C}$ requirement, though in the figure, the steels are normalized to their measured rather than specified ambient-temperature yield strength, which causes the data to dip slightly below the $R=2 / 3$ line. Fig. $2-15$ shows that the retained yield strength of the two fire-resistive steels is greater than all but a few of the ordinary structural steels.

Modeling the performance of these steels, for example for performance-based design (Phan et al., 2010), requires that the model parameters reflect the enhanced performance. The Eurocode 3 (ECS, 2005) model provides no guidance on how steels with improved (or different) hightemperature performance might be modeled, though in principle new parameters for the retained strength, proportional limit, and modulus could be chosen. The model in this report can use high- 
temperature tensile test data from these fire-resistive steels to generate new parameters for either the retained yield strength, $R$, Eq. (2.4), data or the entire set of parameters, Eq. (2.10).

Developing new parameters for the retained yield strength equation is the simpler approach. The dash/dot line in Fig. 2-15 is the non-linear regression of Eq. (2.4) to the yield strength data for the two fire-resistive steels. In the regression, the value of one parameter was fixed at the value for ordinary structural steel and not fit: $r_{2}=1.0$. Fitting four parameters produced unacceptably large uncertainties for the $r_{i}$. Table 2-2 summarizes the values of the parameters.

With complete stress-strain data, it is also straightforward to estimate all the parameters of the stress-strain model. Because the yield strength of fire-resistive steels degrades more slowly than ordinary structural steels, it is reasonable to assume that the strain hardening behavior will also differ from that of ordinary structural steels. Table 2-2 shows the values for the individual $k_{i}$ and $n$ for the fire-resistive steel, obtained by non-linear regression of Eq. (2.10) in the strain range $(0.01<\varepsilon<0.1)$.

Fig. 2-16 compares the stress-strain data for the two fire-resistive steels and two estimates of the stress-strain behavior. The solid lines are the measured stress-strain curves, and the dotted lines are the predictions of the model, Eq. (2.10), with the parameters listed in Table 2-2. In Fig. 2-14(a) and Fig. 2-14(b), only the retained yield strength $R(T)$, was fit, using the yield strength data in Fig. 2-15. That model under-predicts the strain hardening of both steels. In Fig. 2-14(a) and Fig. 2-14(b), in addition to the retained yield strength behavior from Fig. 2-15, the values of the parameters $k_{i}$ and $n$ in Eq. (2.10) were fit. 


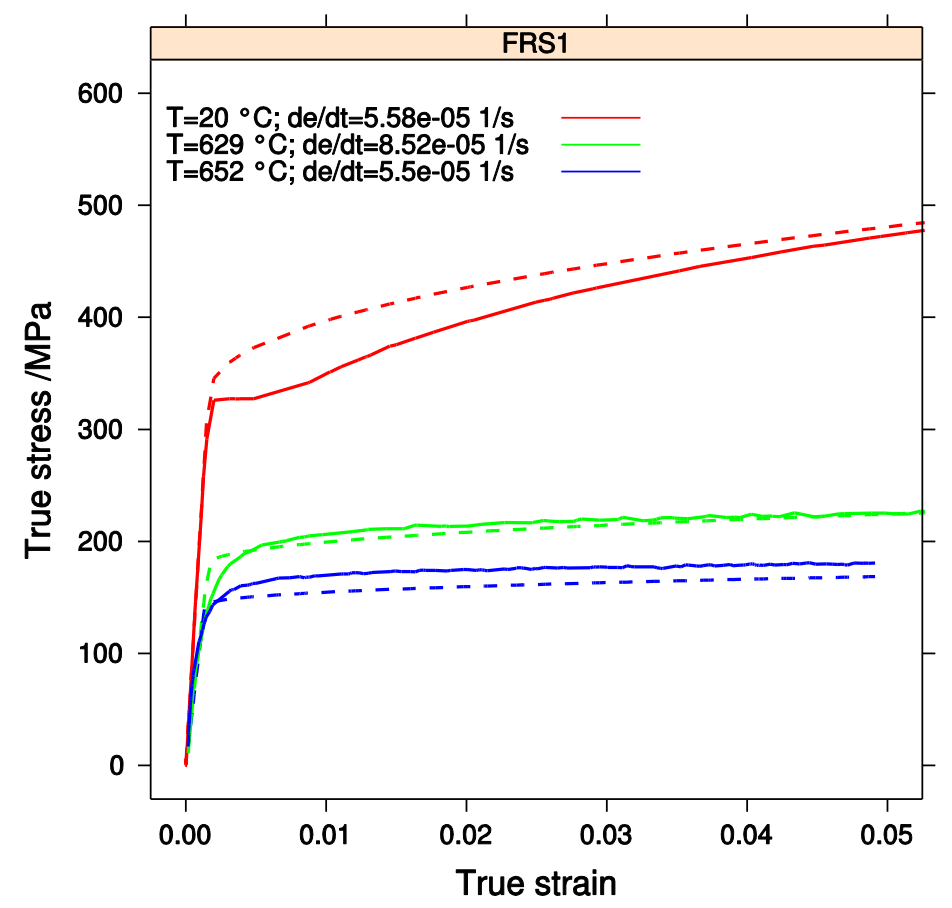

(a) FRS1, fit $r_{i}, k_{i}$, and $n$

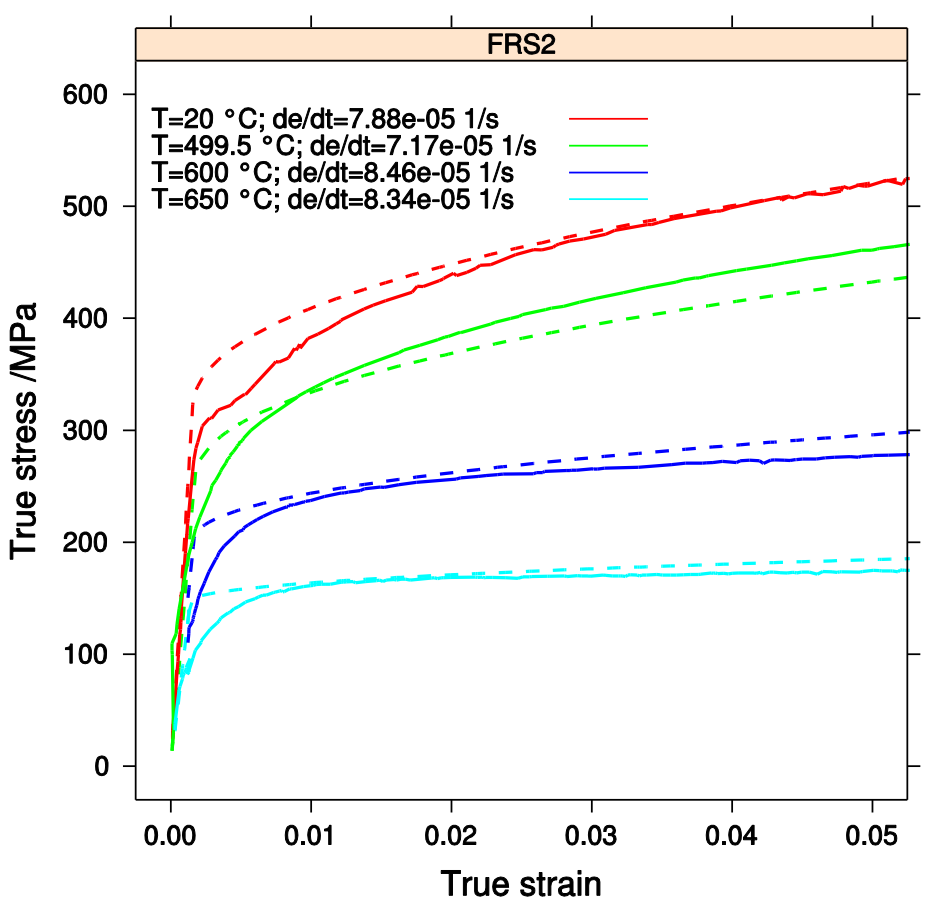

(b) FRS2, fit $r_{i}, k_{i}$, and $n$

Figure 2-16: Stress-strain data (solid lines) and models (dotted lines) for two fire-resistive steels. Models were computed by fitting $R(T)$, Eq. (2.4), first and then the parameters of the stress-strain model, Eq. (2.10). 


\subsubsection{Quenched-and-tempered plates}

Quenched-and-tempered steel plate is uncommon in buildings, but it is used in bridges (Hopwood et al., 2009, for example), which are also subject to fire (Kodur et al., 2010, for example). As part of the WTC investigation (Luecke et al., 2005), NIST characterized the high-temperature stressstrain behavior of specimens taken from $F_{y}=100 \mathrm{ksi}(689 \mathrm{MPa})$ plate with $\mathrm{t}=0.25$ in $(6.3 \mathrm{~mm})$, denoted as specimen C10_C1M_FL. This steel was used extensively in the perimeter columns in the highest floors of two towers. This steel was similar to ASTM A514 (2009a), but was supplied to a proprietary Japanese specification. Fig. $2-17$ shows that above $\mathrm{T}=600{ }^{\circ} \mathrm{C}$ the retained yield strength decreases faster than for hot-rolled steel.

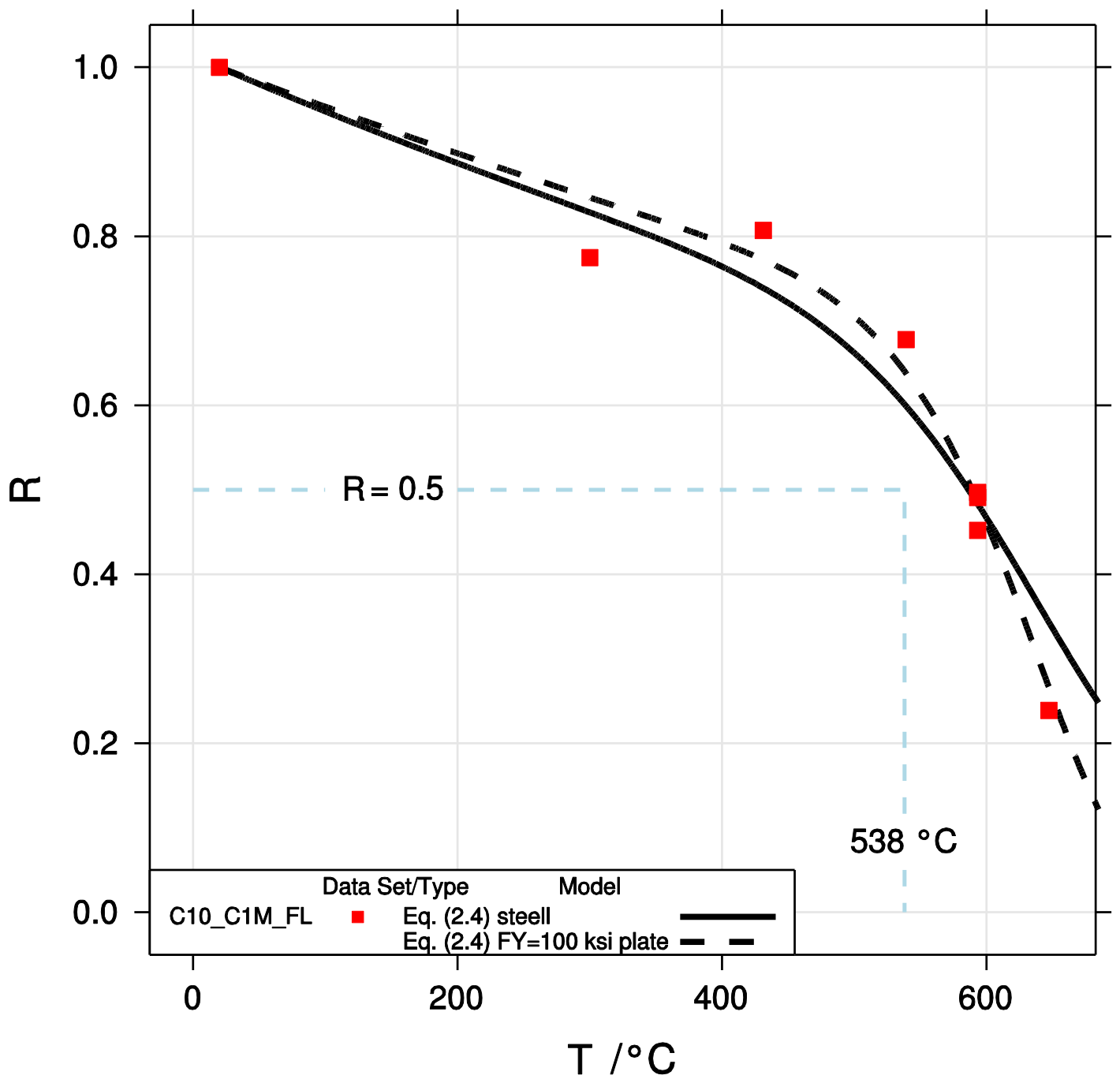

Figure 2-17: Comparison of the normalized retained yield strength for quenched-and-tempered $100 \mathrm{ksi}$ (689 MPa) steel plate and the retained strength model, Eq. (2.4). 
Table 2-2 shows the values of the parameters used in the retained yield strength model, Eq. (2.4), for quenched-and-tempered plate. As with the other models, the value of $r_{2}$ was not fit.

Fig. 2-18 compares the stress-strain data for the quenched-and-tempered plate and the estimate of the stress-strain behavior from the model, Eq. (2.10). The solid lines are the measured stress-strain curves, and the dashed lines are the predictions of the model, Eq. (2.10), with the parameters listed in Table 2-2. In addition, because the fit employed data from a single steel, with a unique ambienttemperature yield strength, it is not reasonable to fit the parameters $k_{3}$ and $k_{4}$, which depend only on the ambient-temperature yield strength. Instead those parameters were set to the values for hotrolled steel. The general agreement is acceptable, but the model over-predicts the low-strain strength.

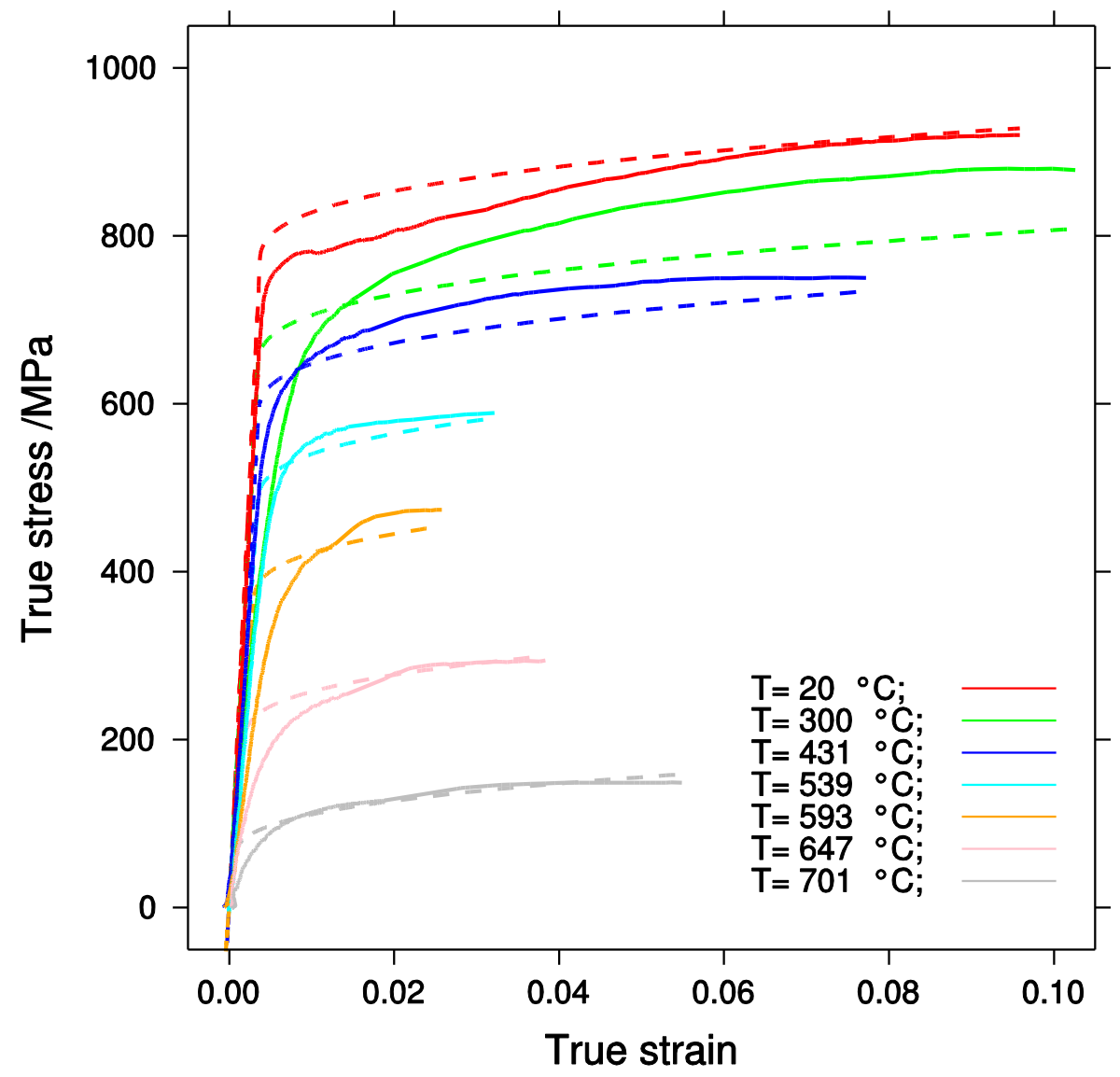

Figure 2-18: Stress-strain data (solid lines) and model (dotted lines) for $F_{y}=100 \mathrm{ksi}$ ( $689 \mathrm{MPa}$ ) plate. Model was computed by fitting $R(T)$ using Eq. (2.4), and then the stress-strain data using Eq. (2.10). 


\subsubsection{Bolts}

The same process can be used to choose appropriate parameters from tensile test data for highstrength steels that are used for heat-treated bolts, whose strength also drops off faster with temperature than structural steel. Fig. 2-19 compares the prediction of the retained yield strength expression, Eq. (2.4), to data for the $0.2 \%$ offset yield strength for steels used for structural steel bolts. In fitting the parameters of Eq. (2.4) to the data, only three parameters were fit, and one was fixed: $r_{2}=1$. The retained strength of the bolt steels drops off much more quickly than ordinary structural steel as the temperature exceeds $400{ }^{\circ} \mathrm{C}$. The figure also shows a fit of Eq. (2.4) to the data for the retained strength of bolt steels. Table 2-2 summarizes the values of the parameters. Although Kodur et al. (2012) plots stress-strain behavior of A325 and A490 bolt steels, the test procedure does not document the strain rate employed.

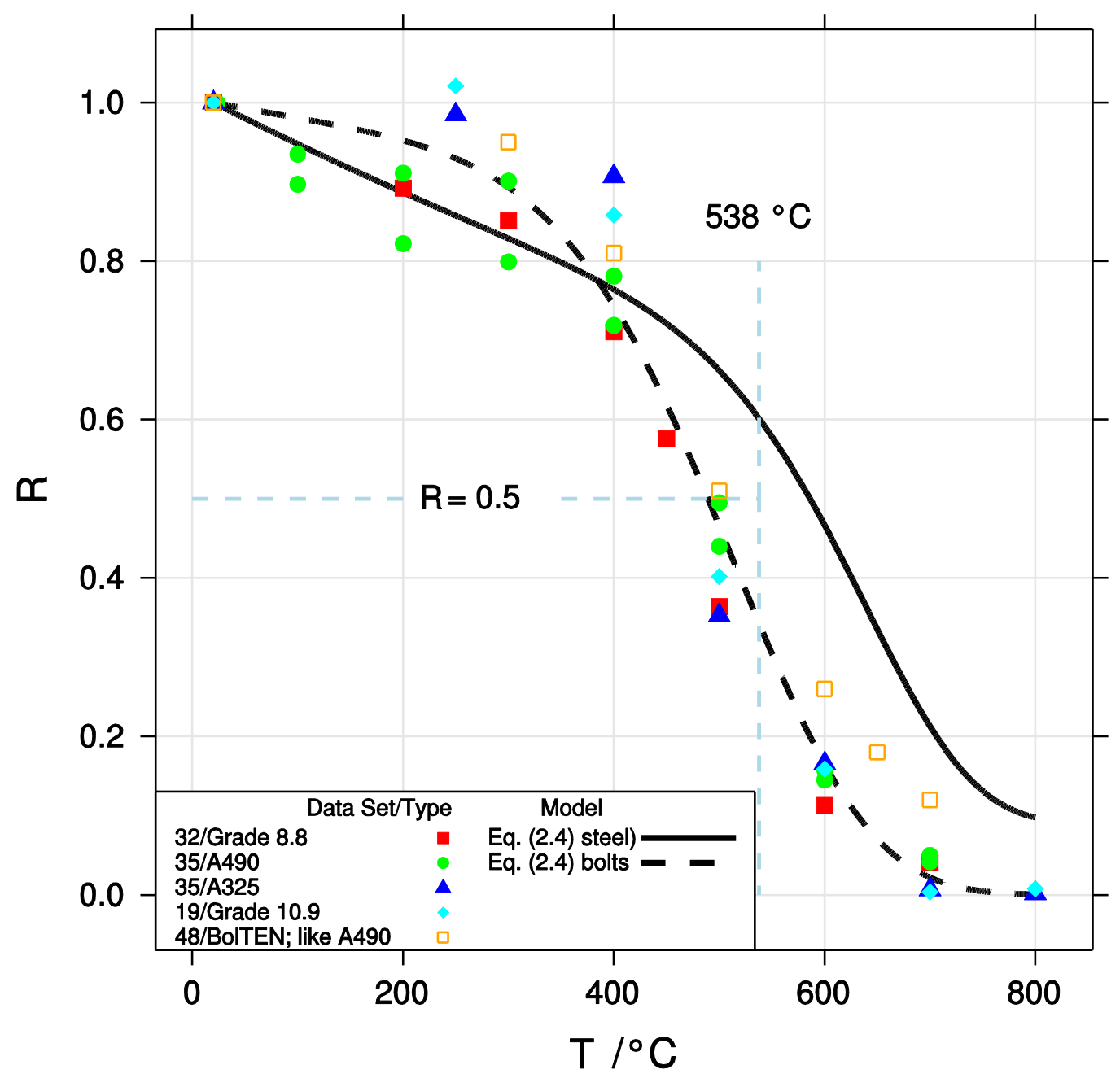

Figure 2-19: Comparison of the normalized retained yield strength for high-strength bolt steels and the retained strength model, Eq. (2.4). See Table 2-1 for key to data sets. 
Insufficient data were available, at present, on structural bolt material properties at elevated temperatures to develop a power-law stress-strain model, as was presented in Eq. (2.10) for structural steel. Rather, a simplified multi-linear representation of the temperature-dependent true stress-strain behavior is proposed in this study, as follows:

$$
\sigma=\left\{\begin{array}{cl}
E(T) \varepsilon, & \varepsilon \leq \varepsilon_{y}(T) \\
F_{y}(T)+\left[F_{u}(T)-F_{y}(T)\right] \frac{\varepsilon-\varepsilon_{y}(T)}{\varepsilon_{u}(T)-\varepsilon_{y}(T)}, & \varepsilon_{y}(T)<\varepsilon
\end{array}\right.
$$

where $\varepsilon_{y}(T)=F_{y}(T) / E(T)$ is the temperature-dependent yield strain. The elastic modulus $E$ is the same for bolts as for structural steel and is calculated from Eq. (2.2).

For A325 and A490 high-strength bolts, the temperature-dependence of the yield strength $F_{y}$ is calculated from Eq. (2.4), with $r_{1}=4.967, r_{2}=1.000, r_{3}=456{ }^{\circ} \mathrm{C}, r_{4}=2040{ }^{\circ} \mathrm{C}$, and $r_{5}=0.000$ (see Section 2.2). Compared to rolled steel, bolts sustain their $F_{y}$ value with the increase of temperature until about $400{ }^{\circ} \mathrm{C}$, after which it reduces dramatically relative to structural steel. Fig. 2-20 shows the degradation of the normalized yield strength with increasing temperature for ASTM A572 rolled steel and ASTM A325 and A490 bolts (ASTM International (2012b), and (2010), respectively). Note that at $400{ }^{\circ} \mathrm{C}$, both rolled steel and bolts sustain about $80 \%$ of their yield capacity. At $600{ }^{\circ} \mathrm{C}$, rolled steel sustains about $50 \%$ of its yield capacity, while bolts sustain about $20 \%$ of their yield capacity. The ultimate tensile strength $F_{u}$ is calculated using Eq. (2.4) with the same values of $r_{1}$ through $r_{5}$ as for the yield strength, but with the ambient-temperature yield strength $F_{y 0}$ replaced by the ambient-temperature ultimate strength $F_{u 0}$. The temperaturedependent uniform strain, $\varepsilon_{u}(T)$, is assumed to have a value of 0.1 at $20{ }^{\circ} \mathrm{C}$ and to decrease linearly with temperature to a value of 0.05 at $600{ }^{\circ} \mathrm{C}$, as summarized in Eq. (2.19).

$$
\varepsilon_{u}(T)=\left\{\begin{array}{cc}
0.1, & T \leq 20^{\circ} \mathrm{C} \\
0.1-0.05\left(\frac{T-20{ }^{\circ} \mathrm{C}}{580{ }^{\circ} \mathrm{C}}\right), & 20{ }^{\circ} \mathrm{C}<T \leq 600^{\circ} \mathrm{C} \\
0.05, & T>600^{\circ} \mathrm{C}
\end{array}\right.
$$

Eq. (2.19) is an approximate linear fit to the elevated-temperature uniform strain data reported by Kodur et al. (2012) for both A325 and A490 structural bolts. 


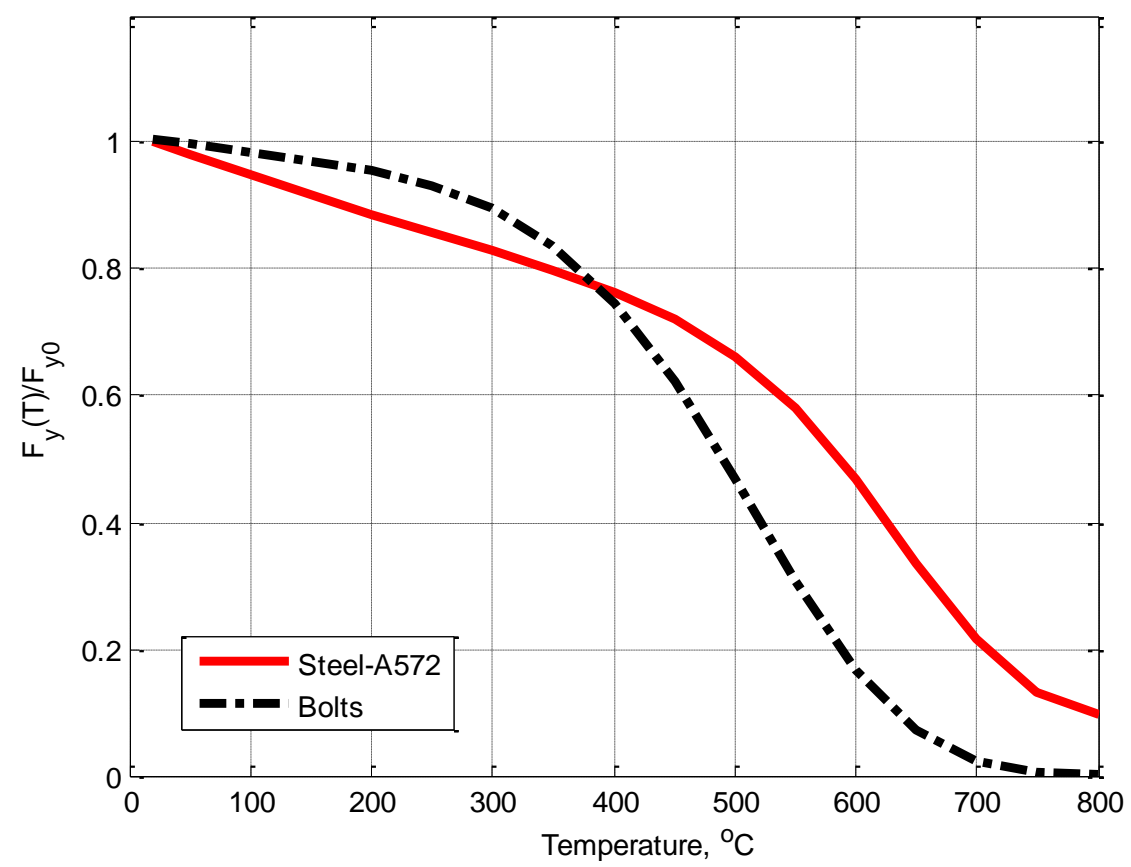

Figure 2-20 Degradation of normalized yield strength versus the increase in temperature for rolled structural steel and bolts.

\section{$2.3 \quad$ SUMMARY}

This chapter presents a stress-strain model for structural steel at elevated temperatures, as an alternative to the stress-strain model used in the Eurocode 3 standard. It is based on a large data set of the yield strength of structural steels, augmented by post-yield behavior derived from eight steels used in the construction of the World Trade Center. It accounts for the temperature dependence of the yield strength, the change in strain hardening with temperature, and the effect of strain rate on strength. The quality of the predictions of the model for stress-strain behavior for new steels, such as ASTM A992, are similar to those of the Eurocode 3 stress-strain model. The coefficient of variation of the retained yield strength, which is the largest component of the variability in the model, increases with increasing temperature. Finally, the model is extensible to steels with improved high-temperature properties by either choosing a new representation of the temperature dependence of the high-temperature yield strength, or by fitting stress-strain data to generate new values of the parameters that describe the temperature dependence of the strain hardening. For structural steel materials, a temperature-dependent power-law model was used to represent the true stress-strain behavior up to the onset of necking at the temperature-dependent uniform strain. The uniform strain was determined based on a least-squares fit to the uniform strain data for elevated temperatures available in the literature. Due to the more limited experimental data on structural bolts at elevated temperatures, a simpler multi-linear material model was proposed to represent the true stress-strain behavior of structural bolts. 


\section{Chapter 3 \\ USE OF NIST MATERIAL MOdEL TO EVALUATE STABILITY OF Wide Flange Steel Columns at Elevated Temperatures}

\subsection{INTRODUCTION}

The main focus of the chapter is to evaluate the applicability of the NIST model for predicting the behavior of steel gravity columns at elevated temperatures using the finite-element method. The NIST stress-strain model is relatively new and has been used for very few analytical studies on fire-structure interaction. In this chapter, the NIST stress-strain model is used to predict flexural buckling of steel columns subjected to elevated temperatures. Accurately predicting the fire performance of columns is critical for evaluating the stability of buildings subjected to fire. In a fire, steel gravity columns can be susceptible to inelastic buckling failure because they have high utilization ratios with the governing loading combination, "1.2[dead load] + 1.6[live load]," (see Agarwal and Varma (2011)). The failure of interior columns can significantly influence the stability of a building system because loads supported by these columns need to be redistributed through an alternative load path to prevent progressive collapse (see Agarwal and Varma (2014)).

This chapter presents results from analytical studies to evaluate the effect of material models on predicting the strength and behavior of steel columns at elevated temperatures: (1) The critical buckling temperatures of 47 tested columns are calculated using the finite-element models and are compared with those reported in the experiments. For computational efficiency and due to the limited amount of test data, the modeling approach used in this study assumes time-independent loading and heating conditions, uniform temperature distribution in columns, and temperatureindependent thermal strains. (2) The high-temperature flexural buckling strength and response of six full-scale steel column specimens are predicted using finite-element models with two different material models. These models use measured steel temperature and axial load data to simulate the column tests as closely as possible. The responses predicted using the NIST stress-strain models (presented in Section 2.2 of this report) are compared with those calculated using Eurocode 3, ESC (2005), stress-strain model as well as test data. (3) The new flexural buckling equations are calibrated using the NIST model and compared with those prescribed in the 2005 and 2010 editions of the ANSI/AISC 360 Appendix 4 (AISC, 2005 and 2010).

\subsection{CRITICAL BUCKLING TEMPERATURE OF STEEL COLUMNS}

\subsubsection{Test Data}

The critical temperature of columns of typical proportions involves inelastic behavior that is a function of both the modulus of elasticity and the yield strength of the steel. At temperatures that 
steel experiences in building-contents fires, both the stiffness and strength are significantly diminished and, therefore, the buckling strength of a steel column exposed to fire can be a small fraction of that at ambient temperature. To evaluate the behavior of steel columns at elevated temperatures, many laboratories have tested axially loaded columns under a variety of boundary conditions and heating regimes. Tests have been conducted either by loading the column specimen and then heating it until failure occurs, or by heating the column to a specific temperature and then applying an axial load to failure. For a given column geometry, fixity, and loading, the experiment yields the temperature at which the column buckles as evidenced by either a decrease in the applied load or runaway displacement. The approach used in this section is to use experimental data from as many laboratories as possible in an attempt to understand representative behavior of columns of various slenderness and fixity conditions.

To evaluate the applicability of the NIST model in predicting the critical temperature, five data sets from various laboratories, chosen from a larger set compiled by Zhang et al. (2012), are employed. Zhang's study analyzed the literature experimental data using the Eurocode 3 column equations for computing the critical temperature for column buckling. In this section, the critical temperatures are recalculated using the finite-element method. The five laboratories represent sources for which the original descriptions of the test protocol were available. The steels originated from Europe and Asia. Four of the five laboratories used pin-end connections. All were conducted by applying the load and then ramping the temperature until failure. Table 3-1 summarizes the data for the steel column tests considered in this study.

Fig. 3-1 illustrates the structural models for five different column tests as described below. The data sets used in this study include 47 individual column tests. All investigators took special care to monitor and accurately record the column temperature at multiple locations.

- Nine tests on bare steel columns with pinned-pinned ends and length $(L)$ of 71 in (1800 $\mathrm{mm}$ ) reported by Ali et al. (1998). The loading frame could apply both axial load and axial restraint to the test column, through half-round graphite-lubricated bearings. The present study considers only cases with no axial restraint. A single-burner furnace heated the column and produced a temperature ramp rate $d T / d t=15^{\circ} \mathrm{C} / \mathrm{min}$ to $400{ }^{\circ} \mathrm{C}$ and $d T / d t$ $=2{ }^{\circ} \mathrm{C} / \mathrm{min}$ above.

- Thirteen tests on bare steel columns of different lengths with pinned-pinned ends and (50 $\leq L \leq 138)$ in $((1270 \leq L \leq 3510) \mathrm{mm})$, reported by Franssen et al. (1996, 1998). The loading frame employed knife edges to achieve the end fixity. Unlike the other tests which used a furnace, ceramic heating mats attached to the column supplied the heat. The heating rate was $5{ }^{\circ} \mathrm{C} / \mathrm{min}$. Some data on these tests was taken from Schleich et al. (1998). Several data sets from Franssen et al. (1996) were omitted because of uncertainty about the test conditions. 
- Three tests on protected steel columns with fixed-fixed ends and $L=150$ in $(3810 \mathrm{~mm})$ reported by Lie and Macauley (1989). The heating condition followed ASTM E119 (2014) (approximately $d T / d t=3.6{ }^{\circ} \mathrm{C} / \mathrm{min}$ ).

- Four tests on bare steel columns with pinned-pinned ends and L = 59 in (1500 mm) reported by Tan et al. (2007). The loading frame could apply axial forces as well as axial restraints, but the present study considered only cases with no axial restraint. Initial imperfections such as column crookedness and load eccentricity were measured by a specially designed facility. An electric furnace heated the columns at $d T / d t=8{ }^{\circ} \mathrm{C} / \mathrm{min}$.

- Eighteen tests on bare steel columns with pinned-rotational restrained ends through pinned, half-roller cylinders and $L=146$ in $(3710 \mathrm{~mm})$, reported by Wang and Davies (2003). The furnace temperature increased at $d T / d t=16.7^{\circ} \mathrm{C} / \mathrm{min}$. The effective lengths of the test columns, obtained by an approximated method (Wang and Davies, 2003), were used in this study.

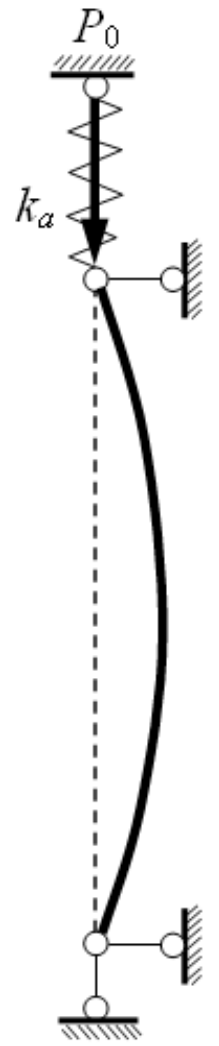

(a) Ali and

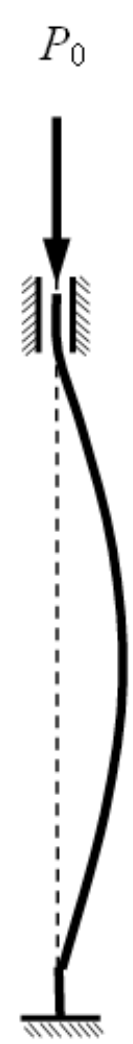

(b) Lie

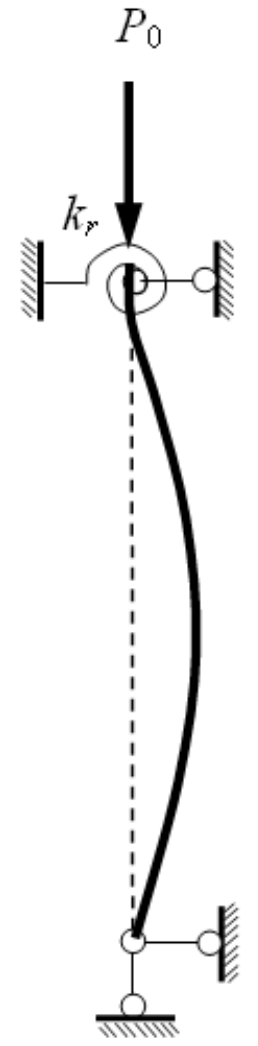

(c) Wang

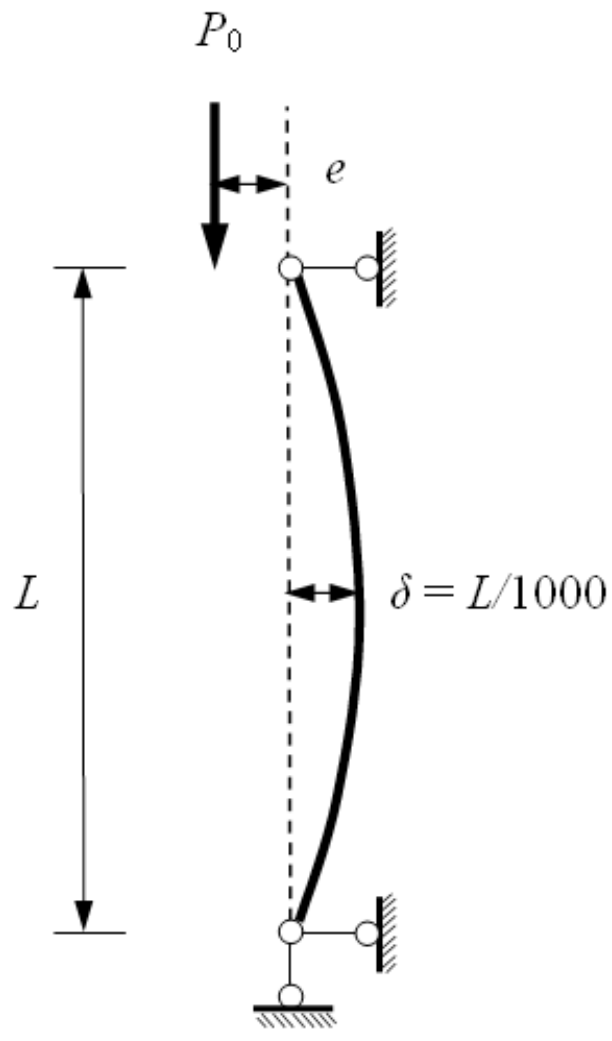

(d) Franssen $(e \neq 0)$

Tan both

with $k_{a}=0$

Figure 3-1 Structural models for column tests 


\subsubsection{Modeling Approach}

Fig. 3-2 shows a schematic model of a steel column with pinned-pinned ends. Each column specimen in Table 3-1 was modeled using ANSYS 14.0.0 (2014) three-dimensional shell element, SHELL181, which is suitable for analyzing thin to moderately thick shell structures. It is a four node element with six degrees of freedom at each node: translations in the $\mathrm{x}, \mathrm{y}$, and $\mathrm{z}$ directions, and rotations about the $\mathrm{x}, \mathrm{y}$, and $\mathrm{z}$ axes. SHELL181 is well suited for linear, large rotation, and large-strain non-linear applications. The shape of initial column crookedness is assumed to be the same as the first buckling mode. The initial deflection amplitude at mid-height, if not specified, was taken as $L / 1000$. The effect of residual stresses was omitted. For restrained column specimens, the model was modified such that the corresponding degrees of freedom were restrained to represent the support conditions as reported in test literature. Regardless of different test protocols used in the tests, all column models were subjected to the axial loads equal to the reported values of axial load capacity in test literature. Then, while the axial load was maintained constant, the steel temperature was increased monotonically until the analysis failed to converge. That temperature is defined as the failure temperature.

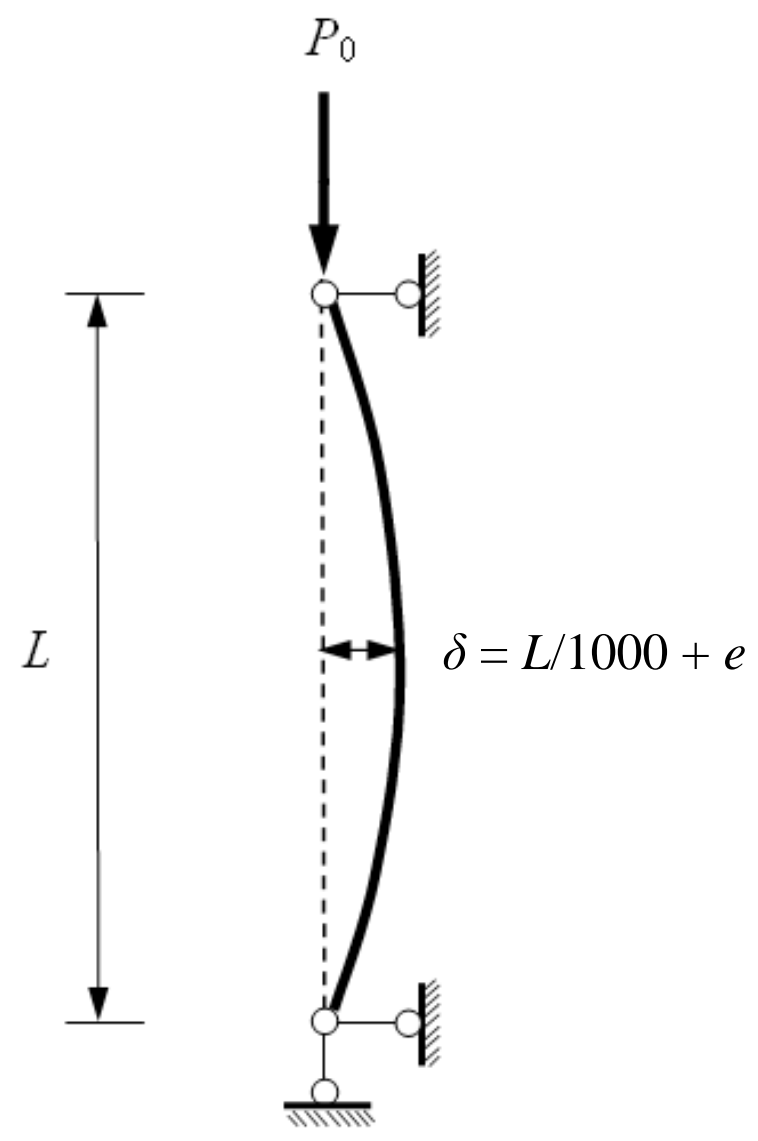

Figure 3-2 Schematic of the column model used in the analysis 
Table 3-1 Column test data

\begin{tabular}{|c|c|c|c|c|c|c|c|c|c|c|c|}
\hline Data & Test & Shape & $\begin{array}{l}F_{y o} \\
(\mathrm{MPa})\end{array}$ & $\begin{array}{l}\boldsymbol{L} \\
(\mathrm{mm})\end{array}$ & $\lambda$ & $\begin{array}{l}\boldsymbol{P}_{\boldsymbol{r}} \\
(\mathrm{kN})\end{array}$ & $\begin{array}{l}\mathbf{e} \\
(\mathrm{mm})\end{array}$ & Ends & $\begin{array}{l}T_{r} \\
\left({ }^{\circ} \mathrm{C}\right)\end{array}$ & $\begin{array}{l}T_{p}\left({ }^{\circ} \mathrm{C}\right) \\
\text { Eurocode }\end{array}$ & NIST \\
\hline Tan & RS45 1 & UC152×152×37 & 326 & 1500 & 38 & 708.5 & 1.74 & P-P & 647 & 507 & 588 \\
\hline Tan & RS55_1 & UB203×133×25 & 357 & 1500 & 47 & 444.3 & 3.19 & P-P & 571 & 520 & 557 \\
\hline Tan & RS81_1 & UB152×89×16 & 312 & 1500 & 70 & 260.6 & 2.38 & P-P & 499 & 401 & 567 \\
\hline Tan & RS97_1 & UB127×76×13 & 320 & 1500 & 83 & 134 & 4.08 & P-P & 606 & 501 & 617 \\
\hline Ali & Ali1 & UC152×152×23 & 320 & 1800 & 47 & 186 & 0 & P-P & 701 & 643 & 758 \\
\hline Ali & Ali2 & UC152×152×23 & 320 & 1800 & 47 & 373 & 0 & P-P & 626 & 550 & 676 \\
\hline Ali & Ali3 & UC152×152×23 & 320 & 1800 & 47 & 559 & 0 & P-P & 557 & 403 & 594 \\
\hline Ali & Ali4 & UB178×102×19 & 320 & 1800 & 75 & 202 & 0 & P-P & 629 & 541 & 662 \\
\hline Ali & Ali5 & UB178×102×19 & 320 & 1801 & 75 & 303 & 0 & P-P & 539 & 395 & 582 \\
\hline Ali & Ali6 & UB178 $\times 102 \times 19$ & 320 & 1802 & 75 & 101 & 0 & P-P & 644 & 643 & 745 \\
\hline Ali & Ali7 & UB127×76×13 & 320 & 1803 & 97 & 50 & 0 & P-P & 717 & 661 & 730 \\
\hline Ali & Ali8 & UB127×76×13 & 320 & 1804 & 97 & 101 & 0 & P-P & 658 & 555 & 647 \\
\hline Ali & Ali9 & UB127×76×13 & 320 & 1805 & 97 & 151 & 0 & P-P & 567 & 438 & 567 \\
\hline Lie & Lie1 & $W 10 \times 60$ & 300 & 3810 & 34 & 1760 & 0 & $\mathrm{~F}-\mathrm{F}$ & 565 & 574 & 591 \\
\hline Lie & Lie2 & W10×49 & 300 & 3810 & 34 & 1424 & 0 & $\mathrm{~F}-\mathrm{F}$ & 586 & 566 & 591 \\
\hline Lie & Lie3 & W10×49 & 300 & 3810 & 34 & 1424 & 0 & F-F & 584 & 566 & 591 \\
\hline Franssen & AL5 & HEA100 & 280 & 2770 & 108 & 127 & 5 & P-P & 457 & 428 & 589 \\
\hline Franssen & BL3 & HEA100 & 287 & 1272 & 50 & 292 & 5 & P-P & 390 & 377 & 528 \\
\hline Franssen & BL5 & HEA100 & 287 & 2772 & 108 & 73 & 5 & P-P & 587 & 573 & 699 \\
\hline Franssen & BL6 & HEA100 & 287 & 3510 & 137 & 105 & 5 & P-P & 446 & 356 & 527 \\
\hline Franssen & CL3 & HEA100 & 293 & 1271 & 50 & 251 & 5 & P-P & 474 & 478 & 581 \\
\hline Franssen & CL5 & HEA100 & 293 & 2771 & 108 & 34 & 5 & P-P & 587 & 677 & 783 \\
\hline Franssen & CL6 & HEA100 & 293 & 3510 & 137 & 90 & 5 & P-P & 493 & 447 & 601 \\
\hline Franssen & DL3 & HEA100 & 283 & 1269 & 49 & 24 & 5 & P-P & 749 & 875 & 818 \\
\hline Franssen & DL6 & HEA100 & 283 & 3510 & 137 & 12 & 5 & P-P & 727 & 802 & 840 \\
\hline Franssen & SL40 & HEA100 & 280 & 2020 & 79 & 170 & 5 & P-P & 525 & 475 & 600 \\
\hline Franssen & SL41 & HEA100 & 280 & 2026 & 79 & 174 & 5 & P-P & 509 & 445 & 584 \\
\hline Franssen & SL42 & HEA100 & 280 & 2020 & 79 & 171 & 5 & P-P & 485 & 458 & 591 \\
\hline Franssen & SL44 & HEA100 & 280 & 2023 & 79 & 173 & 5 & P-P & 495 & 448 & 586 \\
\hline Wang & SCRI1 & UC203×203x46 & 301 & 2968 & 57 & 357.5 & 0 & $\mathrm{R}-\mathrm{R}$ & 646 & 613 & 707 \\
\hline Wang & SCRI2 & UC203×203x46 & 301 & 2875 & 56 & 360.3 & 0 & $\mathrm{R}-\mathrm{R}$ & 681 & 616 & 707 \\
\hline Wang & SCRI3 & UC203x203x46 & 301 & 2875 & 56 & 360 & 0 & $\mathrm{R}-\mathrm{R}$ & 668 & 616 & 707 \\
\hline Wang & SCRI4 & UC203×203x46 & 301 & 3061 & 59 & 600 & 0 & $\mathrm{R}-\mathrm{R}$ & 604 & 527 & 640 \\
\hline Wang & SCRI5 & UC203×203x46 & 301 & 2463 & 48 & 600 & 0 & $\mathrm{R}-\mathrm{R}$ & 597 & 552 & 647 \\
\hline Wang & SCRI6 & UC203x203x46 & 301 & 2745 & 53 & 600 & 0 & $\mathrm{R}-\mathrm{R}$ & 613 & 540 & 644 \\
\hline Wang & SCRI7 & UC203×203x46 & 301 & 3001 & 58 & 840 & 0 & $R-R$ & 556 & 400 & 571 \\
\hline Wang & SCRI8 & UC203×203x46 & 301 & 2894 & 56 & 840 & 0 & $\mathrm{R}-\mathrm{R}$ & 553 & 414 & 574 \\
\hline Wang & SCRI9 & UC203x203x46 & 301 & 3001 & 58 & 840 & 0 & $\mathrm{R}-\mathrm{R}$ & 530 & 400 & 571 \\
\hline Wang & SCRII1 & UC203×203x46 & 301 & 2820 & 55 & 358 & 0 & $\mathrm{R}-\mathrm{R}$ & 680 & 619 & 708 \\
\hline Wang & SCRII2 & UC203x203x46 & 301 & 2849 & 55 & 360 & 0 & $R-R$ & 670 & 617 & 707 \\
\hline Wang & SCRII3 & UC203x203x46 & 301 & 2876 & 56 & 360 & 0 & $\mathrm{R}-\mathrm{R}$ & 675 & 620 & 707 \\
\hline Wang & SCRII4 & UC203×203x46 & 301 & 3079 & 60 & 600 & 0 & $\mathrm{R}-\mathrm{R}$ & 609 & 526 & 639 \\
\hline Wang & SCRII5 & UC203x203x46 & 301 & 2883 & 56 & 600 & 0 & $\mathrm{R}-\mathrm{R}$ & 604 & 534 & 643 \\
\hline Wang & SCRII6 & UC203×203x46 & 301 & 2823 & 55 & 600 & 0 & $\mathrm{R}-\mathrm{R}$ & 629 & 537 & 643 \\
\hline Wang & SCRII7 & UC203×203x46 & 301 & 2916 & 56 & 840 & 0 & $\mathrm{R}-\mathrm{R}$ & 542 & 411 & 573 \\
\hline Wang & SCRII8 & UC203×203x46 & 301 & 2916 & 56 & 840 & 0 & $\mathrm{R}-\mathrm{R}$ & 550 & 411 & 573 \\
\hline Wang & SCRII9 & UC203×203x46 & 301 & 2842 & 55 & 840 & 0 & $\mathrm{R}-\mathrm{R}$ & 549 & 421 & 575 \\
\hline
\end{tabular}




\subsubsection{Results and Discussion}

Fig. 3-3 shows the predicted failure temperature, $T_{p}$, from the ANSYS analysis as a function of reported failure temperature, $T_{r}$, for each test in the five data sets for both the Eurocode 3 stressstrain model and the NIST model. The solid line has unity slope and zero intercept. The Eurocode 3 model predicts the data of Franssen et al. (1996) well since more data points are closer to the unity slope line, but overpredicts the four other data sets. The NIST model underpredicts the data from Franssen et al. (1996), but predicts the four other data sets very well.

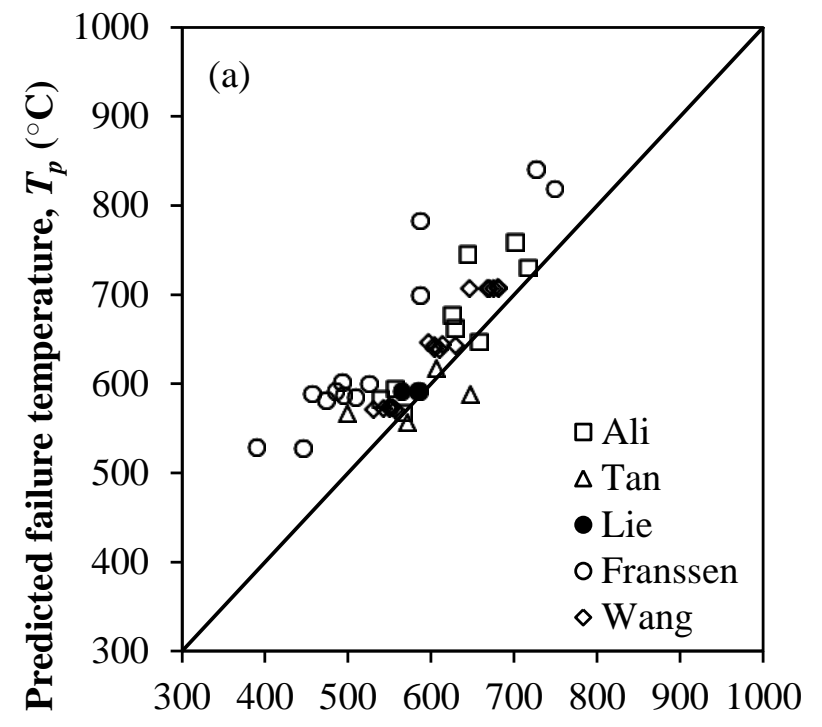

Reported failure temperature, $T_{r}\left({ }^{\circ} \mathrm{C}\right)$

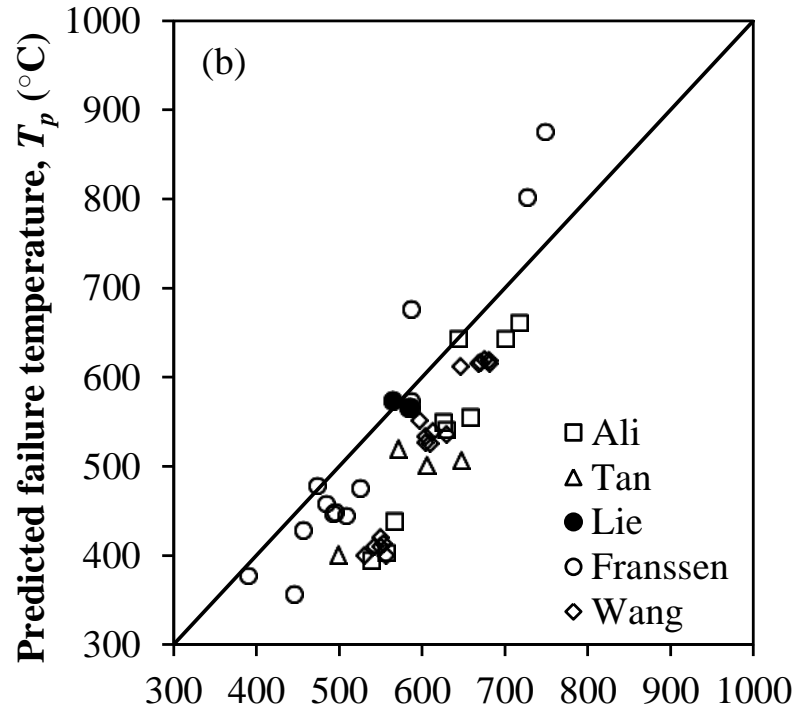

Reported failure temperature, $T_{r}\left({ }_{0} \mathrm{C}\right)$

Figure 3-3 Predicted vs. reported failure temperature for the (a) NIST and (b) Eurocode 3 models.

Fig. 3-4 shows the normalized difference between the predicted and reported failure temperatures for the two stress-strain models as a function of slenderness parameter, $\lambda=L / r$, where $r$ is the governing radius of gyration of the column section. For four of the five data sets, the NIST models more accurately predict the failure temperatures than the Eurocode 3 models in terms of the percentage error, $\left|\left(T_{p}-T_{r}\right) / T_{r}\right| \times 100$. The NIST model tends to significantly overestimate the data of Franssen et al. (1996) by $21 \%$, on average. The Eurocode 3 model underpredicts the failure temperature for most of data sets. The Eurocode 3 model reasonably predicts the data set of Franssen et al. (1996) well (with percentage error of $9 \%$, on average).

Taking the total number of tests as an indicator of the quality of the model is not ideal when the size of the individual data sets differs. Each data set used an individual steel, probably from the same heat, and the same test method, so any deviations from representative behavior will be replicated systematically across the data set. For each data set it shows the number of times each model made a better prediction of the critical temperature. As shown in Fig. 3-4, the NIST model 
makes better predictions for three of the five data sets (Ali, Tan, and Wang), and overestimations for the data set of Franssen. The data set of Lie could be considered a tie, since both models predict the failure temperature to within a few percent.
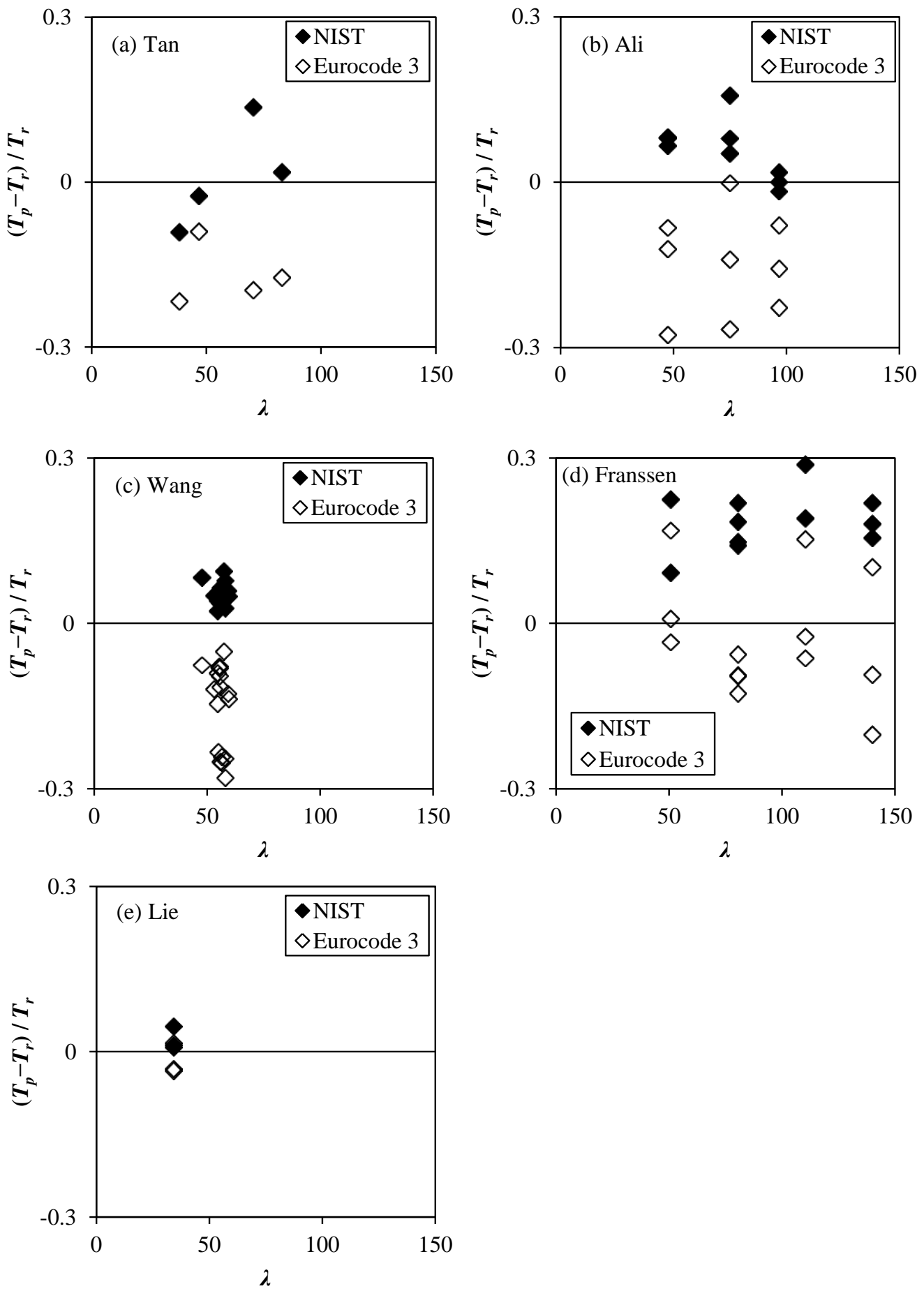

Figure 3-4 Normalized difference in failure temperature as a function of slenderness ratio $(\lambda)$ 


\subsection{HIGH-TEMPERATURE RESPONSES OF STEEL COLUMNS}

\subsubsection{Test Data}

Choe et al. (2011b) tested full-scale steel columns at temperatures of $300{ }^{\circ} \mathrm{C}, 500{ }^{\circ} \mathrm{C}$, or $600{ }^{\circ} \mathrm{C}$. Fig. 3-5 shows the Purdue column test setup and instrumentation layout. The flanges at the mid portion of the column specimen were heated with four radiant heaters. The length of heated region was $6 \mathrm{ft}(1.83 \mathrm{~m})$. Fig. 3-5 also shows the instrumentation layout for measuring steel temperatures, axial loads, deformations, and end rotations. The relevant standard uncertainty in mechanical and thermal measurements was estimated as $\pm 1 \%$ based on calibration of the data acquisition system and instruments (see Choe (2011a)). Although the temperatures over the exposed flange surfaces were uniform (with the maximum absolute difference of $30{ }^{\circ} \mathrm{C}$ ), thermal gradients were developed along the web and the portions outside of heated region toward the column ends. The column supports remained cool $\left(\leq 50{ }^{\circ} \mathrm{C}\right)$ throughout the tests.
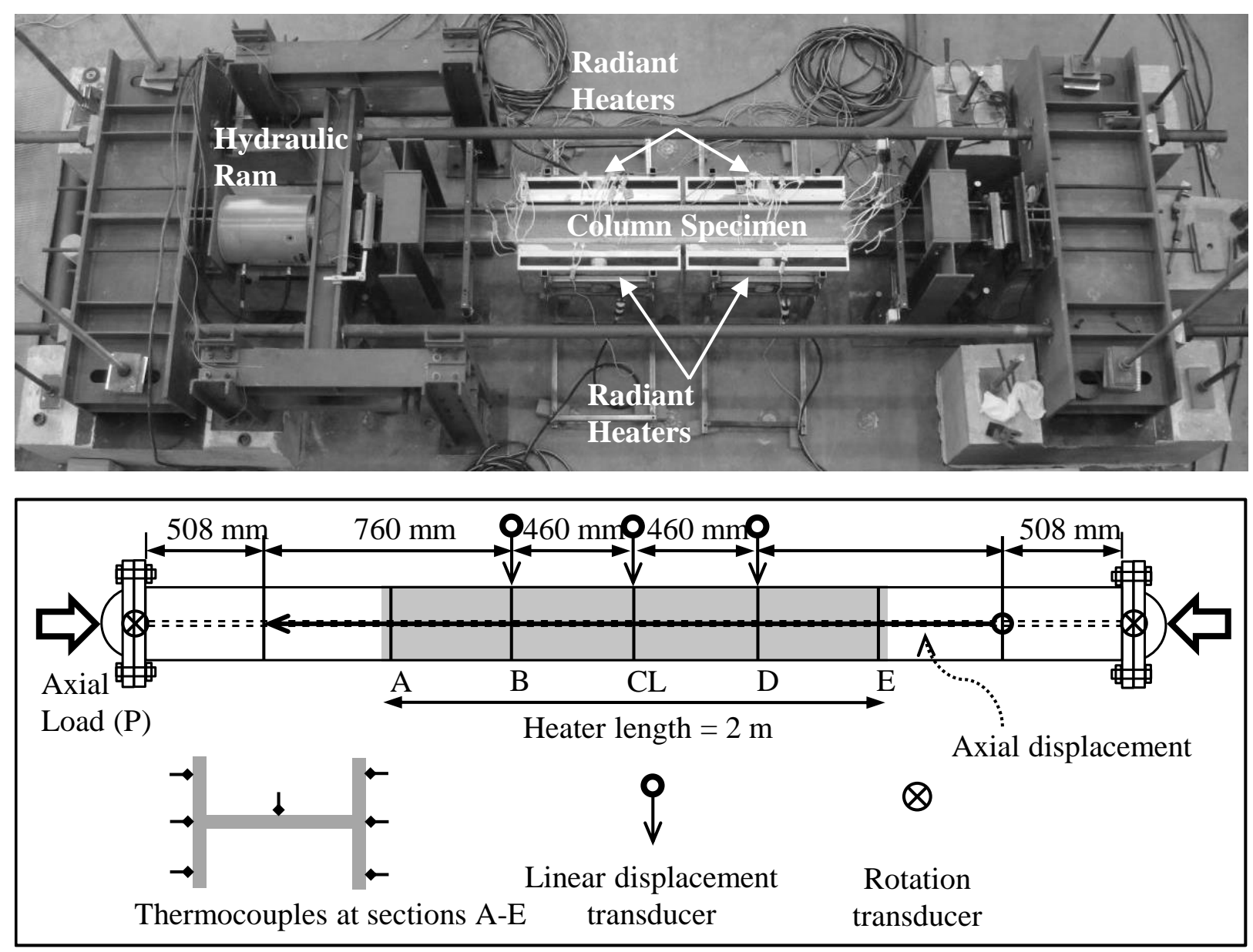

Figure 3-5 Column test setup and instrumentation layout. 
Table 3-2 presents the test matrix for six steel columns of $\mathrm{W} 8 \times 35$ and $\mathrm{W} 14 \times 53$ sections made of ASTM A992 steels. All columns had pinned-pinned support conditions achieved using the halfcylindrical bearings shown in Fig. 3-5. The length $(L)$ of the W8×35 and the W14×53 column specimens was $11.5 \mathrm{ft}(3.5 \mathrm{~m})$ and $11.3 \mathrm{ft}(3.45 \mathrm{~m})$, respectively, which gives slenderness ratios $\left(L / r_{y}\right)$ of 69 and 71 , respectively, where $r_{y}$ is the radius of gyration about the weak axis. The measured average ambient-temperature yield stress $\left(F_{y o}\right)$ of the $\mathrm{W} 8 \times 35$ sections was $60 \mathrm{ksi}$ $(413 \mathrm{MPa})$ and that of the $\mathrm{W} 14 \times 53$ sections was $59 \mathrm{ksi}(406 \mathrm{MPa})$. No fire protection was used for the column specimens tested at elevated temperatures. All column specimens were subjected to concentrically applied axial loads. The test matrix (in Table 3-3) included one control specimen $(\mathrm{W} 8 \times 35-\mathrm{AMB})$, tested at ambient temperature, to commission the structural setup and to compare the behavior of columns at elevated temperature.

Each column specimen was tested under steady heating condition but subjected to increasing axial loads until buckling occurred. Fig. 3-6 shows the axial load-temperature-time histories recorded during the tests. Each plot includes the average temperature-time $(T-t)$ curves measured at the flanges (Flange Temp) and the center of the web (Web Temp) of the cross-sections B, CL, and D shown in Fig. 3-5. Table 3-2 summarizes the column test results, including the average steel temperatures of the flanges $\left(T_{\text {flange }}\right)$ and the center of the web $\left(T_{w e b}\right)$ of the cross-sections B, CL, and $\mathrm{D}$ while the axial loads were increased, the critical buckling load $\left(P_{c r}\right)$, and the axial load rate $(d P / d t)$. All column specimens failed by inelastic flexural buckling about the weak axis, and no flange distortion failures were observed.

Table 3-2 Column test matrix and results

\begin{tabular}{lllllll}
\hline Specimen & $\boldsymbol{F}_{\boldsymbol{y o}}(\mathrm{MPa})$ & $\boldsymbol{L} / \boldsymbol{r}_{\boldsymbol{y}}$ & $\boldsymbol{T}_{\text {flange }}\left({ }^{\circ} \mathbf{C}\right)$ & $\boldsymbol{T}_{\text {web }}\left({ }^{\circ} \mathbf{C}\right)$ & $\boldsymbol{P}_{\boldsymbol{c r}}(\mathbf{k N})$ & $\boldsymbol{d P} / \boldsymbol{d t}$ \\
\hline W8×35-AMB & 413 & 69 & - & - & 2000 & - \\
W8×35-T300 & 413 & 69 & 320 & 190 & 1413 & 1.3 \\
W8×35-T500 & 413 & 69 & 477 & 406 & 1134 & 28 \\
W8×35-T600 & 413 & 71 & 609 & 451 & 800 & 35 \\
W14×53-T500 & 406 & 71 & 504 & 324 & 1435 & 33 \\
W14×53-T600 & 406 & 71 & 608 & 363 & 1070 & 26 \\
\hline
\end{tabular}



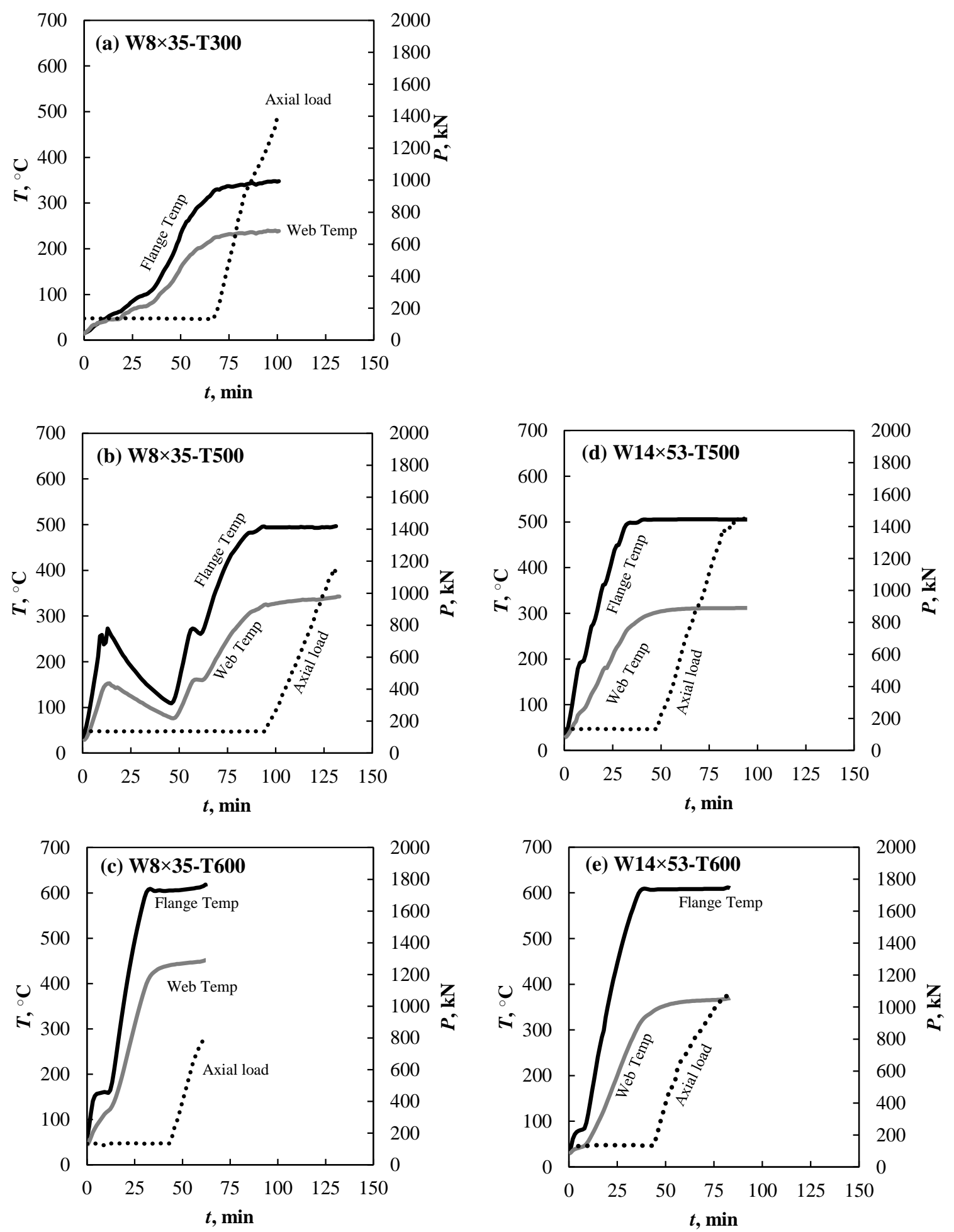

Figure 3-6 Axial load-temperature-time histories used in the Purdue column tests. 


\subsubsection{Finite-Element Models}

Three-dimensional finite-element method (3D FEM) models were developed and analyzed to predict the high-temperature flexural buckling behavior of the column specimens. The models were developed and analyzed using ABAQUS ver. 6.12-2 (2012). As mentioned earlier, detailed finite-element models were developed and analyzed to evaluate the influence of temperaturedependent material models in predicting the behavior and strength of the column specimens. The model geometry, element type, and boundary conditions for all models were identical. These are summarized below first, followed by the development of the column analysis matrix for comparative studies.

Each model used the general-purpose four-node shell elements with reduced integration (S4R) implemented in ABAQUS. The cross-section of the column specimen was discretized into nineteen nodes; the flanges and web were divided into six S4R elements each. These elements had six degrees of freedom per node, five integration points through the thickness of a shell section, and one integration point to form the element stiffness.

For simulating the inelastic buckling failure of steel columns, the 3D FEM model accounted for both material and global geometric imperfections as recommended by Agarwal and Varma (2014). Residual-stress distributions, observed in a typical hot-rolled steel shape, were modeled by creating uneven thermal strains over the cross-section. It was assumed that the flange tips and the center of the web cooled down faster than the flange-to-web junctions. The maximum residual stress was assumed as $30 \%$ of the ambient-temperature yield stress as specified in ANSI/AISC 360-10 (2010). The global geometric imperfection (sweep) was assumed equal to $L / 1500$, which was the mean value of the experimentally measured initial crookedness of hotrolled wide-flange shapes reported in Bjorhovde, 1972. The bending stresses and deformations due to the column self-weight were also included as initial imperfections because the column specimen was aligned horizontally as shown in Fig. 3-5.

The column specimens were modeled with pinned-pinned boundary conditions. Both ends were free to rotate about the weak axis of the cross-section, but rotations about the strong axis of the cross-section and about the longitudinal axis of the specimen were restrained. Similar to the test specimen, one of the column ends was free to move in the direction of axial loading to allow thermal elongation while temperatures increased. The axial force and the boundary conditions were applied to the centroid of the cross-section at both column ends.

Table 3-3 shows the analytical matrix of 3D FEM models for the nonlinear analysis of the column specimens. Each model generated the output including the load-displacement (or load-end rotation) behavior and the critical buckling load $\left(P_{F E M}\right)$ of the specimens. These analytical results were also compared with the Purdue test results. 
Table 3-3 Column analysis matrix

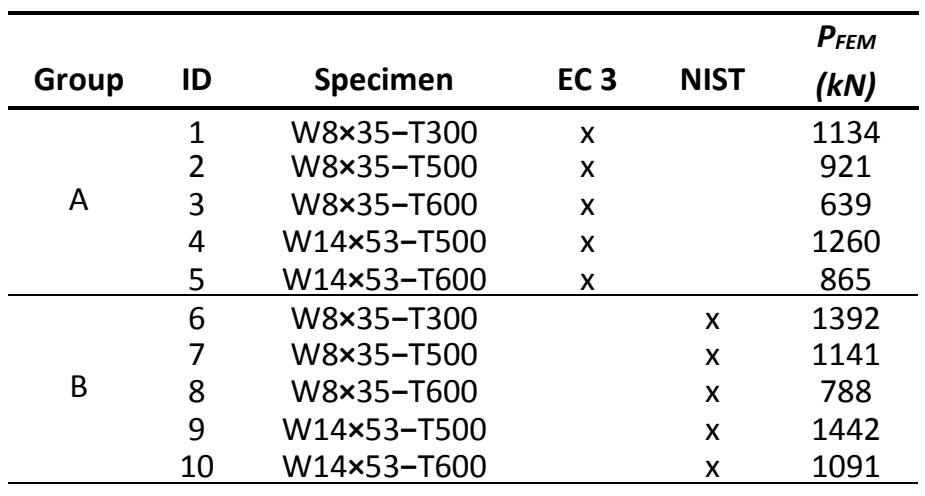

Fig. 3-7 shows the material models used in the analyses. Both the temperature-dependent stressstrain relationship and the coefficient of thermal expansion were required for simulating the behavior of a column specimen simultaneously subjected to axial loading and elevated temperatures. Each 3D FEM model in Table 3-3 used either the Eurocode 3 (EC 3) or the NIST material model for temperature-dependent mechanical material properties of steel. In ABAQUS, the stress-strain behavior was defined using two components: isotropic elastic behavior with Poisson's ratio equal to 0.3 and plastic behavior defined by the Von Mises yield surface, associated flow rule, and kinematic hardening. The temperature-dependent elastic moduli and plastic strains were calculated using the average yield stress $\left(F_{y o}\right.$ in Table 3-2) and elastic modulus $\left(E_{o}\right)$ of $30,500 \mathrm{ksi}(210 \mathrm{GPa})$ measured at ambient temperature. The coefficients of thermal expansion at temperatures varying from $20{ }^{\circ} \mathrm{C}$ to $730{ }^{\circ} \mathrm{C}$ were used to compute thermal strains in the column specimen with increasing temperatures. Thermal creep properties were not explicitly included. 

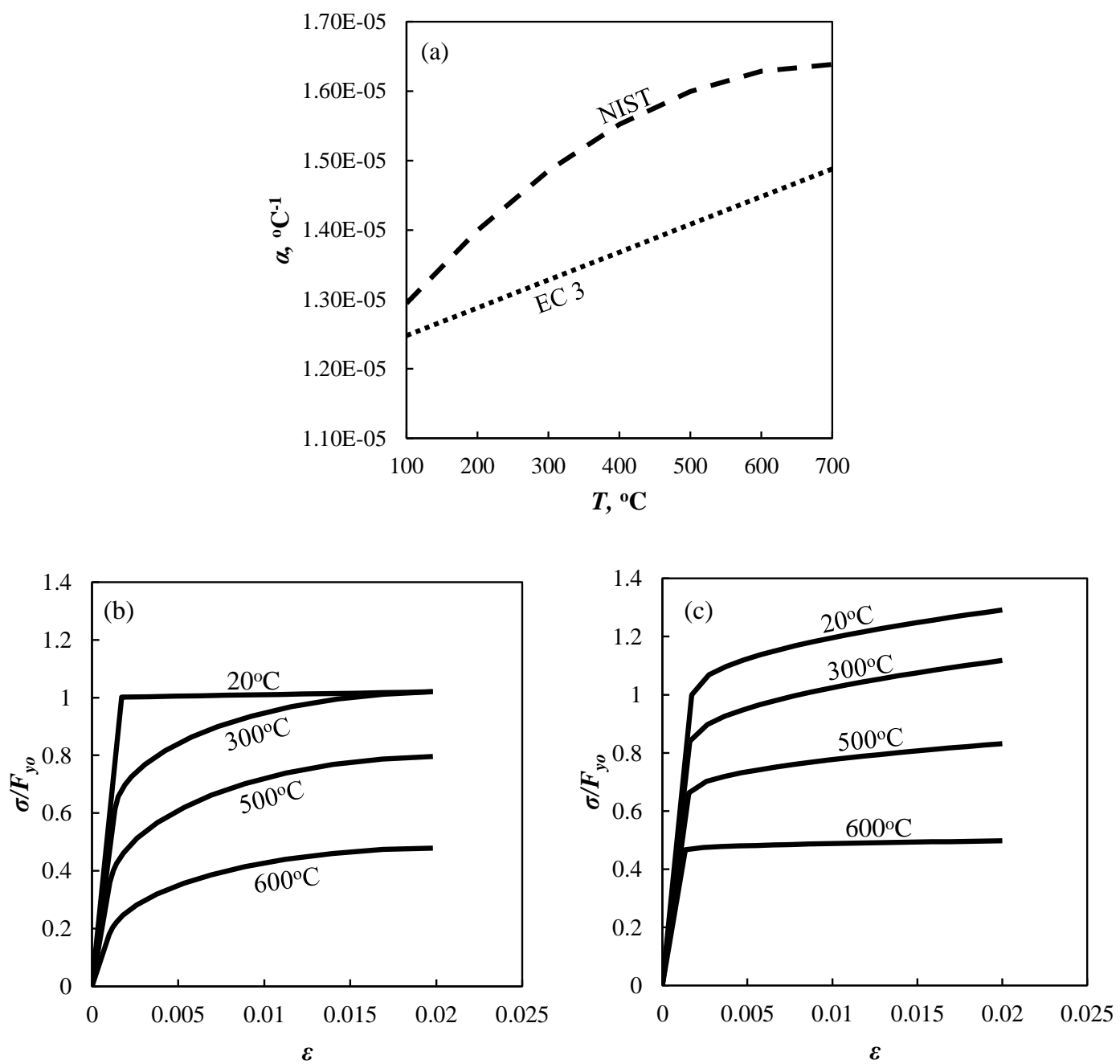

Figure 3-7 (a) Thermal expansion model of steel, (b) Eurocode 3 stress-strain model, (c) NIST stress-strain model.

For simulating the Purdue column tests, a series of nonlinear static analyses were conducted sequentially in accordance with the testing protocol. These analyses consisted of three steps: (1) applying an initial axial load of $30 \mathrm{kip}(133 \mathrm{kN})$ at ambient temperature, (2) increasing steel temperatures while the initial axial load was maintained, and (3) increasing the axial load under relatively steady heating until buckling occurred. The Purdue test conditions were modeled using the actual test data, including thermal gradients developed in column specimens and actual variations in axial loads and temperatures during the tests. The Eurocode 3 and NIST stress-strain models were evaluated by comparing the numerically predicted displacements and rotations with those measured from the experiments.

The modified Newton-Raphson algorithm was used to predict the behavior of the column specimens using the measured axial loads and temperatures. The 3D FEM models were analyzed using the measured axial load-temperature-time $(P-T-t)$ data as input, where temperatures were 
assigned at thermocouple locations as shown in Fig. 3-5. It was assumed that temperatures at elements between thermocouple locations were equal to the average of temperatures measured at two adjacent thermocouples, and temperatures at column ends were assumed to be $20{ }^{\circ} \mathrm{C}$. Heat transfer analysis was performed to obtain the temperature-time curves for all nodes of each column model using the Eurocode 3 thermal properties for steel. Structural responses (strains, displacements, and rotations) were then computed for each load and temperature increment following the $P-T-t$ histories until inelastic buckling occurred. The stability failure of the column specimens was indicated when the analysis terminated due to non-convergence. The last axial load step in which convergence was achieved was defined as the critical buckling load $\left(P_{F E M}\right)$.

\subsubsection{Results and Discussion}

Fig. 3-8 compares the experimentally measured load-displacement responses of the specimen W8x35-AMB, tested at ambient temperatures, with those analytically predicted using the 3D FEM models. Both the Eurocode 3 and the NIST stress-strain models predicted the axial stiffness reasonably with differences less than $3 \%$ with respect to the measured axial stiffness. Both models also reasonably predicted the critical buckling loads $\left(P_{F E M}\right)$ with differences less than $10 \%$ on the conservative side with respect to the measured critical buckling load $\left(P_{c r}\right)$.

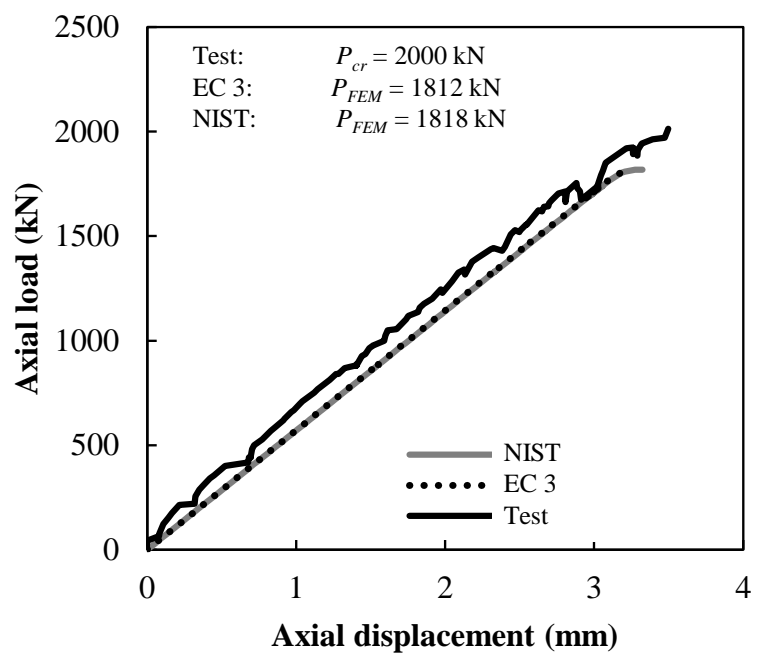

Figure 3-8 Axial load-axial displacement response of the specimen $\mathrm{W} \times \mathbf{3 5}$-AMB.

Fig. 3-9 shows the predicted buckling shape of the column specimen W8 $\times 35-\mathrm{T} 300$ and W14 $\times 53-T 500$ with scale factor of 10 . The results indicated that the predicted failure mode of all the specimens was inelastic flexural buckling regardless of the applied temperature distributions. Although the columns were heated unevenly, temperature distributions in the cross-section and about the vertical axis at mid-span remained close to symmetric; therefore, the governing failure 
mode was flexural buckling. The 3D FEM models also accurately predicted the downward direction of lateral displacements for all column specimens due to inelastic flexural buckling. The initial lateral displacement resulting from the column self-weight combined with axial loading induced second order moments that caused the column to sag downward.

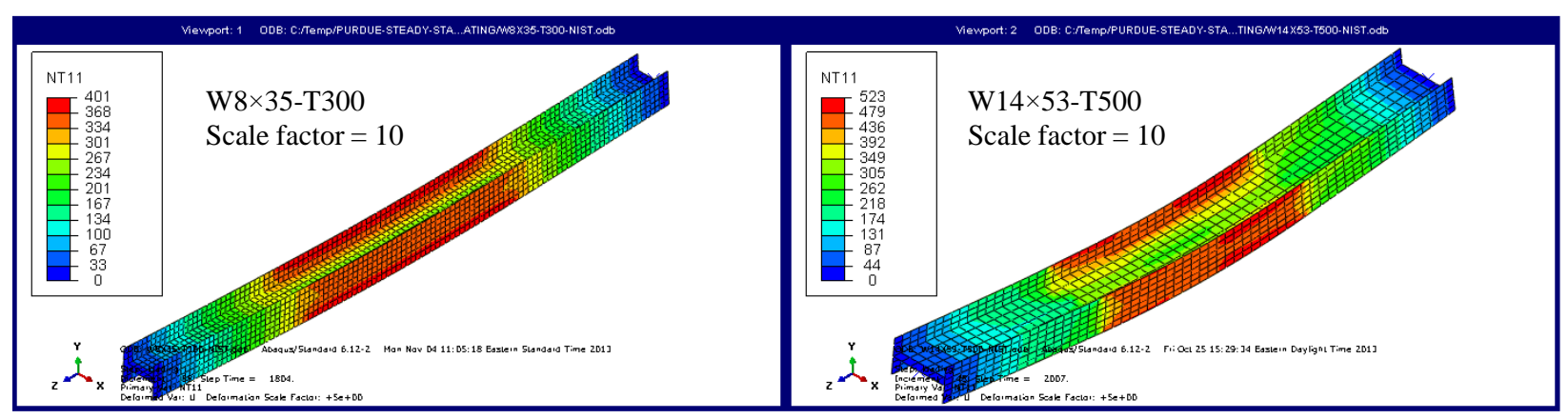

Figure 3-9 Predicted buckling shape with nodal temperature (NT11) distribution.

Fig. 3-10 compares the axial load-end rotation responses predicted using the finite-element models with those measured experimentally. As shown for the specimens subjected to a target temperature of $300{ }^{\circ} \mathrm{C}$ or higher, the NIST material model was better for predicting the end rotations with increasing axial loads. The end rotations of the specimens W8 $\times 35-\mathrm{T} 500$ and $\mathrm{W} 14 \times 53-\mathrm{T} 600$ predicted using the NIST model compare very well with the test results (within $\pm 1 \%$ difference).

Fig. 3-11 compares the axial load-lateral displacement responses predicted using the finite-element models with those measured in the experiments at elevated temperatures. As shown, the NIST model accurately computed the lateral displacements of the specimens W8 $\times 35-\mathrm{T} 600$, W14 $\times 53-$ T500, and W14×53-T600. Note that Fig. 3-11 shows no test results for specimens W8 $\times 35-T 300$ and W8 $\times 35-T 500$ because lateral displacements were not measured for these specimens (see Choe et al. (2011)). 

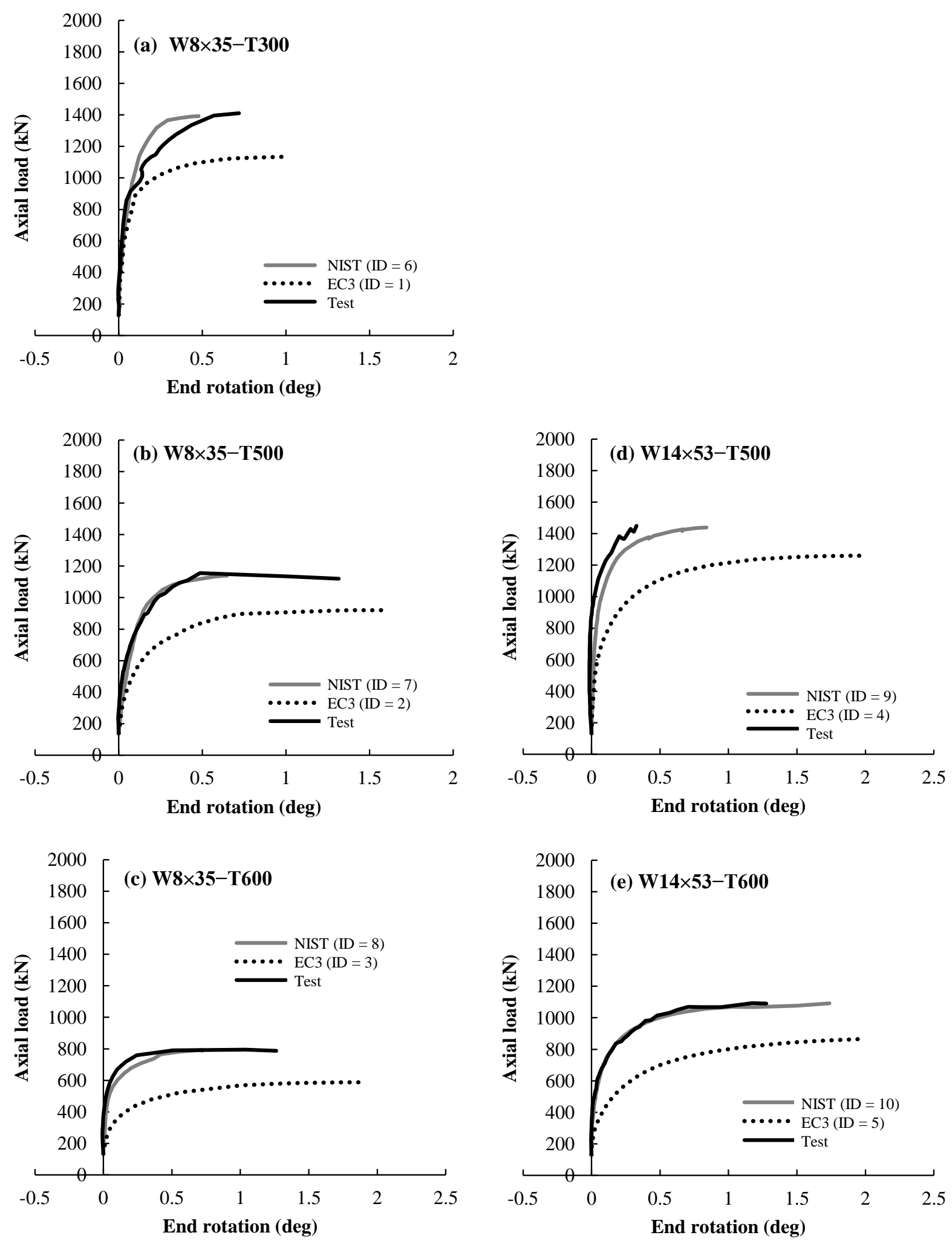

Figure 3-10 Axial load-end rotation responses of column specimens. 

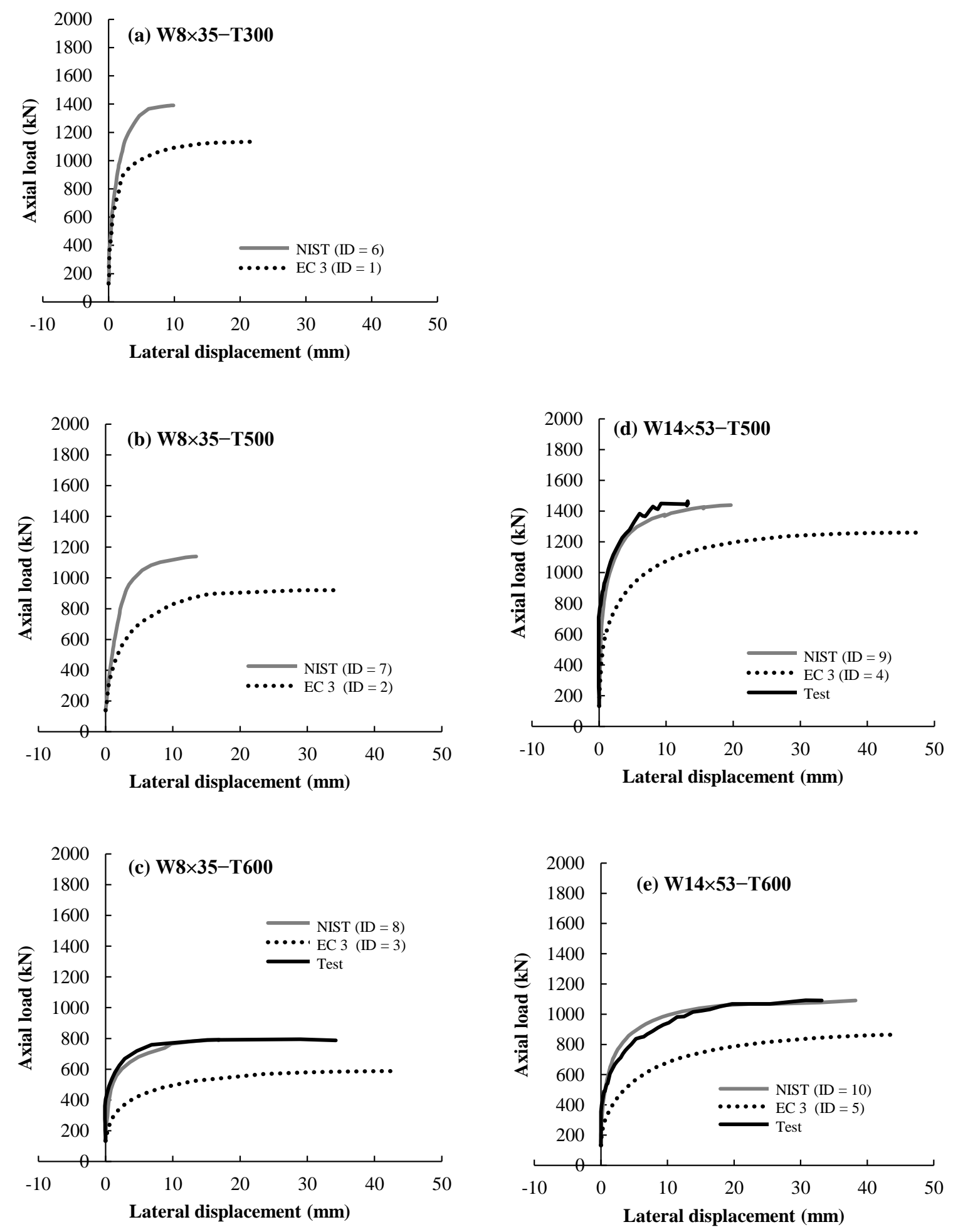

Figure 3-11 Axial load-lateral displacement responses of column specimens. 
It was observed that the 3D FEM results with the Eurocode 3 model indicated that the column stiffness decreased significantly at the earlier stage of axial loading at elevated temperatures, as opposed to those with the NIST model. Given that the initial geometric imperfections were equally applied to all models, the induced second-order moments on the deformed shape remained comparable. As shown in Fig. 3-7, however, the Eurocode 3 model indicates that the tangent modulus decreases significantly beyond the elastic region (after the proportional limit, the maximum stress at which the stress-strain relationship is linear). This nonlinear behavior (tangent modulus degradation) starts at strains less than $0.1 \%$, and the maximum stresses (strength) in this small strain region are much smaller compared to the NIST model. Therefore, the Eurocode 3 model tends to underpredict the tangent modulus in the elastic regime, and eventually underpredict the overall inelastic buckling behavior of a column.

Fig. 3-12 compares the predicted axial displacement-time responses with corresponding test results. Each plot includes the axial displacements at both thermal loading and axial loading phases: the positive slope indicates the thermal elongation of the pin-ended column specimen while steel temperature was increased to a target value. The negative slope indicates the axial shortening in response to increasing axial loads under steady-heating conditions. The axial shortening of the specimen W8×35-T300 in Fig. 3-12(a) was not experimentally measured due to the malfunction of an axial displacement transducer (see Choe et al (2011)). The comparison indicates that both the Eurocode-3 and NIST thermal expansion $(\alpha-T)$ models accurately predicted the thermal elongations of the column specimens (within $\pm 1 \%$ ). The predicted displacement behavior during the axial loading phase also shows similar trends as compared to the test results.

The NIST models were found to be more appropriate for predicting the time of failure (at the onset of buckling) as shown in Fig. 3-12. The failure time is indicated with an asterisk symbol (*) on each plot. The Eurocode 3 models conservatively predicted the time of failure. Given that the period of axial loading was shorter than 1 hour and the average temperatures through crosssections were lower than $600{ }^{\circ} \mathrm{C}$, the effects of thermal creep on the column experiments presented in this paper appeared to be negligible.

Fig. 3-13 shows the normalized difference between the measured critical buckling loads $\left(P_{c r}\right)$ and the predicted critical buckling loads $\left(P_{F E M}\right)$ using the 3D FEM models. Individual values of $P_{c r}$ and $P_{F E M}$ are listed in Table 3-2 and Table 3-3, respectively. Table 3-5 shows the summary statistics including the mean ratio $(\bar{X})$ of $P_{F E M} / P_{c r}$, standard deviation $(S)$, and coefficient of variation $(C V)$ defined as the ratio of $\mathrm{S} / \bar{X}$. Overall, the critical buckling load predicted by the NIST models compared favorably with the test results. The mean difference was less than $1 \%$. In contrast, the Eurocode 3 model tends to underestimate the compressive strength of all the column specimens. The critical buckling load predicted by the Eurocode 3 models (Group A, ID = 1 through 5) was $18 \%$ lower than the test results on average. 

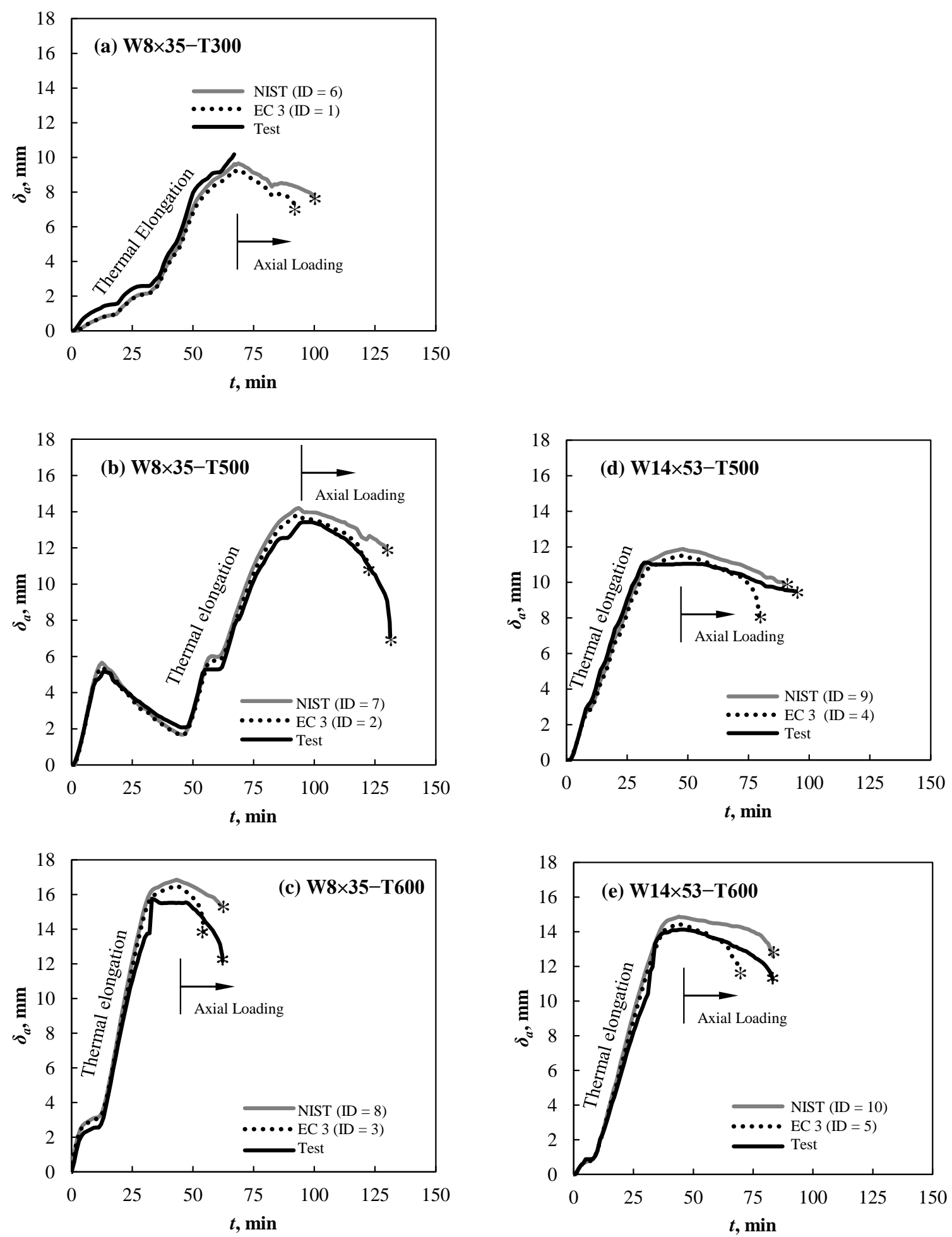

Figure 3-12 Axial displacements $\left(\delta_{a}\right)$ of the column specimens. 
Table 3-4 Summary statistics for the normalized column buckling load

\begin{tabular}{ccc}
\hline Group & A & B \\
\hline $\begin{array}{c}\text { Material } \\
\text { Model }\end{array}$ & EC 3 & NIST \\
$\bar{X}$ & 0.82 & 1.00 \\
$S$ & 0.03 & 0.01 \\
CV & 0.04 & 0.01 \\
\hline
\end{tabular}

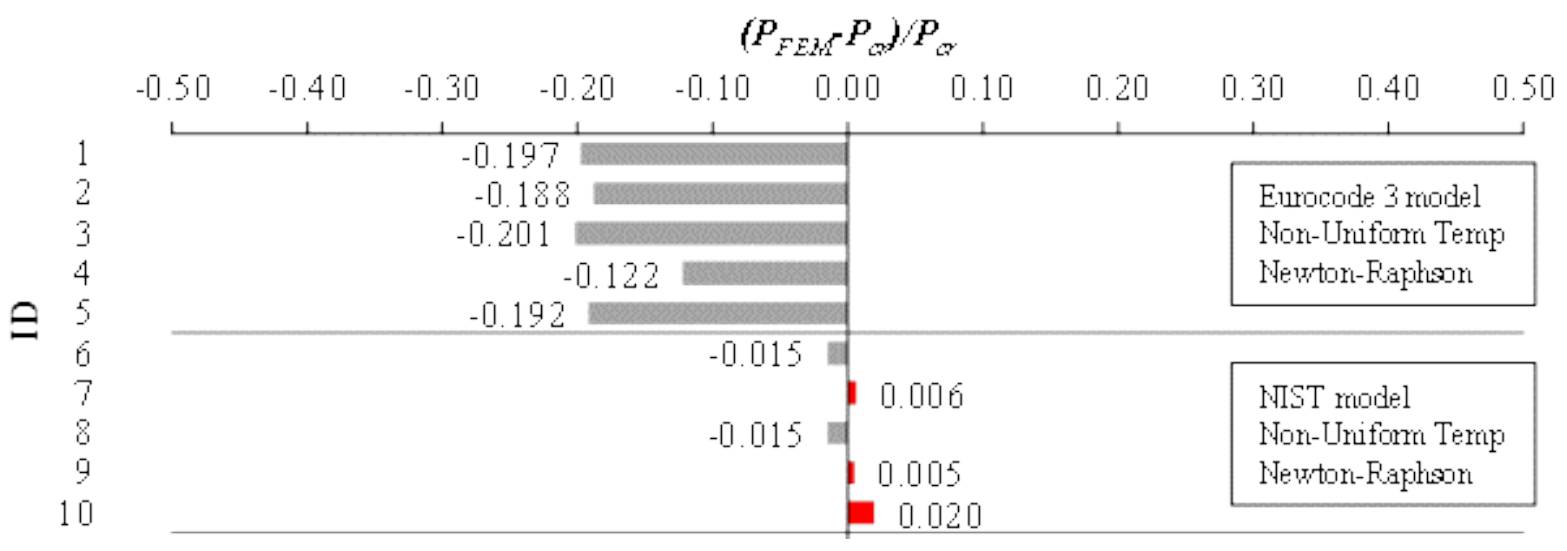

Figure 3-13 Normalized difference in critical buckling loads of the FEM models. 


\subsection{COLUMN DESIGN EQUATIONS}

The 2005 and 2010 editions of the ANSI/AISC-360 Appendix 4 specify to use the Eurocode 3 temperature-dependent mechanical properties of structural steel for design of steel members at elevated temperatures. However, those two editions include different design equations for column strength for flexural buckling under fire conditions. According to the 2005 edition, the design strength for steel column for fire conditions can be computed using the standard design equations (i.e., in Chapter E of the ANSI/AISC-360) with the temperature-dependent values of elastic modulus and yield strength. The same resistance factor, $\phi=0.9$ at ambient temperature can be used. Below are the standard AISC design equations for flexural buckling of columns. $F_{c r}(T)$ is the critical buckling stress, and $F_{e}(T)$ is elastic buckling stress defined in Eq. (3.3). $E(T)$ is the high-temperature modulus of elasticity, $F_{y}(T)$ is the yield strength at elevated temperature, and $K L / r$ is the column slenderness ratio.

$$
\begin{array}{ll}
F_{c r}(T)=\left[0.658^{\frac{F_{y}(T)}{F_{e}(T)}}\right] \cdot F_{y}(T) & \text { for } F_{e}(T) \geq 0.44 F_{y}(T) \\
F_{c r}(T)=0.877 \cdot F_{e}(T) & \text { For } F_{e}(T)<0.44 F_{y}(T) \\
F_{e}(T)=\frac{\pi^{2} E(T)}{\left(\frac{K L}{r}\right)^{2}} &
\end{array}
$$

However, Takagi and Deierlein (2007) showed that the standard design equations overestimate the flexural buckling strength of steel members at elevated temperatures. Their study indicated that the approach in the 2005 edition, namely, simply reducing the values of elastic modulus and yield strength in the standard equations, does not reflect the nonlinear inelastic behavior of the Eurocode 3 stress-strain relationship. To accurately account for the temperature-dependent material degradation of steel, new design equation (Eq. (3.4)) was introduced with the parameters, $a_{0}=0.42$ and $a_{1}=1 / 2$. These parameters were developed based on the results from the finite-element models with the Eurocode 3 stress-strain relationship. These equations have been adopted in the 2010 edition while the resistance factor remains unchanged $(\phi=0.9)$.

$$
F_{c r}(T)=F_{y}(T) \cdot a_{0}^{\left(F_{y}(T) / F_{e}(T)\right)^{a_{1}}}
$$

Takagi and Deierlein's equation (Eq. (3.4)) was essentially a curve fit to finite element solutions using the Eurocode 3 material model. The critical buckling stress does not pass through 1.0 at 
$L / r=0$. So, Eq. (3.4) was limited to temperature above $200{ }^{\circ} \mathrm{C}$. The parameters $\left(a_{0}\right.$ and $\left.a_{1}\right)$ used in Eq. (3.4) need to be recalibrated if other stress-strain models are used (Agarwal and Varma 2011).

This section presents the column strength computed using the AISC design equations with the NIST mechanical properties (temperature-dependent elastic modulus and yield strength of steel), compared with the results from the finite-element models. For the finite-element simulation, the same variables are used as in Takagi and Deierlein (2007), which are listed in Table 3-5.

Table 3-5 Variables considered in the finite-element models

\begin{tabular}{|l|l|}
\hline Structural Shapes & ${ }^{2} \mathrm{~W} 14 \times 90,{ }^{3} \mathrm{~W} 14 \times 22$ \\
\hline Temperatures $\left({ }^{\circ} \mathrm{C}\right)$ & $20,100,200,300,400,500,600,700,800$ \\
\hline Slenderness,$L / r$ & $20,40,60,80,100,120,140,160,180,200$ \\
\hline Minimum yield strength, $F_{y}(\mathrm{MPa})$ & 250,345 \\
\hline Stress-strain model & NIST, EC3 \\
\hline
\end{tabular}

The finite-element models were developed using the ABAQUS software. Each model used the general-purpose four-node shell elements with reduced integration (S4R). The cross-section of the column specimen was divided into 32 elements; the flanges and web were divided into eight S4R elements each. Note that Takagi and Deierlein (2007) divided the column length into 32 elements, which resulted in inconsistent aspect ratio of the elements for all different length of columns. In this study, the aspect ratio $(\approx 1: 1)$ of the elements remained the same for all columns. The analysis was conducted using the modified Newton-Raphson approach to compute the critical buckling load at various steel temperatures.

For comparison, the finite-element models used in this study also followed the same assumptions as those used by Takagi and Deierlein (2007), including (i) uniform temperature distributions in columns, (ii) initial column imperfections with the maximum initial displacement of $L / 1000$ at the midspan, and (iii) a pin-ended boundary condition. Takagi and Deierlein assumed that the residual stress in hot-rolled section decreases at elevated temperatures from a fire and used the temperaturedependent residual stresses, $F_{r}(T)$ equal to $k_{y}(T) \times 69 \mathrm{MPa}$, where $k_{y}(T)$ is the Eurocode- 3 retention factor for yield strength. Instead, this study assumed that, for the high-temperature member strength design, the residual stress, typically observed in hot-rolled shape, is not a function of applied steel temperature from a fire and the maximum value of $0.2 F_{y}(=10 \mathrm{ksi}(69 \mathrm{MPa})$ for $\mathrm{Gr} 50$ steel), which is similar to the assumed value $\left(0.3 F_{y}\right)$ in the AISC standard equation at ambient temperature.

\footnotetext{
${ }^{2}$ Cross-sectional Area, $A=16,832 \mathrm{~mm}^{2}$; Plastic Modulus, $\mathrm{Z}_{\mathrm{x}}=2,525,632 \mathrm{~mm}^{3}$

${ }^{3}$ Cross-sectional Area, $A=4,094 \mathrm{~mm}^{2}$; Plastic Modulus, $\mathrm{Z}_{\mathrm{x}}=526,850 \mathrm{~mm}^{3}$
} 
Fig. 3-15 compares the nominal compressive strength normalized to the elevated temperatureyield strength, which include the results from finite-element analysis (W14×90-Gr50, W14×22Gr50), the AISC 2005 equations (Eq. (3.1), Eq. (3.2)) with NIST proposed $F_{y}(T)$ and $E(T)$, the AISC 2010 equation (Eq. (3.4)) which uses the Eurocode 3 values for $F_{y}(T)$ and $E(T)$. Each plot also includes the re-calibrated column curve (Eq. (3.4)) with new parameters $a_{0}$ and $a_{1}$, using the NIST stress-strain model. For calibration, the results from the finite-element analyses and test data in Table 3-1 were used. The values of $a_{0}$ and $a_{l}$ were re-estimated through non-linear, least-squares regression of the predicted critical buckling stress, $F_{c r}(T)$, on temperature, using the equations for yield strength and modulus of elasticity in Chapter 2. The regression analysis shows that $a_{0}=0.61$ \pm 0.0034 and $a_{1}=0.86 \pm 0.011$ with residual standard error $=8.88$ on 358 degrees of freedom.

The comparison shows that the standard AISC equations with the NIST proposed $F_{y}(T)$ and $E(T)$ compare very well with the results from the finite-element analysis. The difference between the finite-element solutions and the AISC 2010 equations is greatest for columns with slenderness ratios between 50 and 100 at high temperatures. 
(a) $\mathbf{T}=300{ }^{\circ} \mathrm{C}$

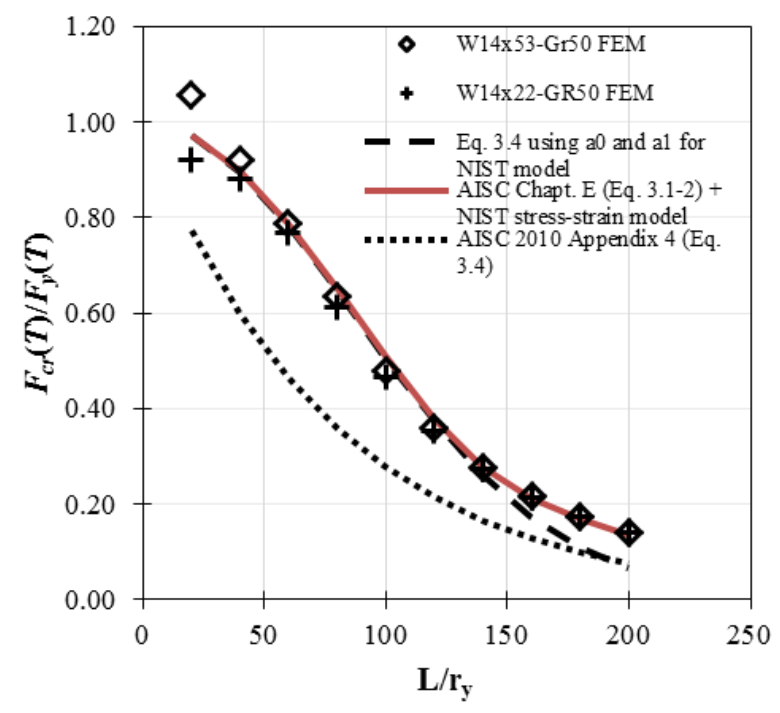

(b) $\mathrm{T}=\mathbf{5 0 0}^{\circ} \mathrm{C}$

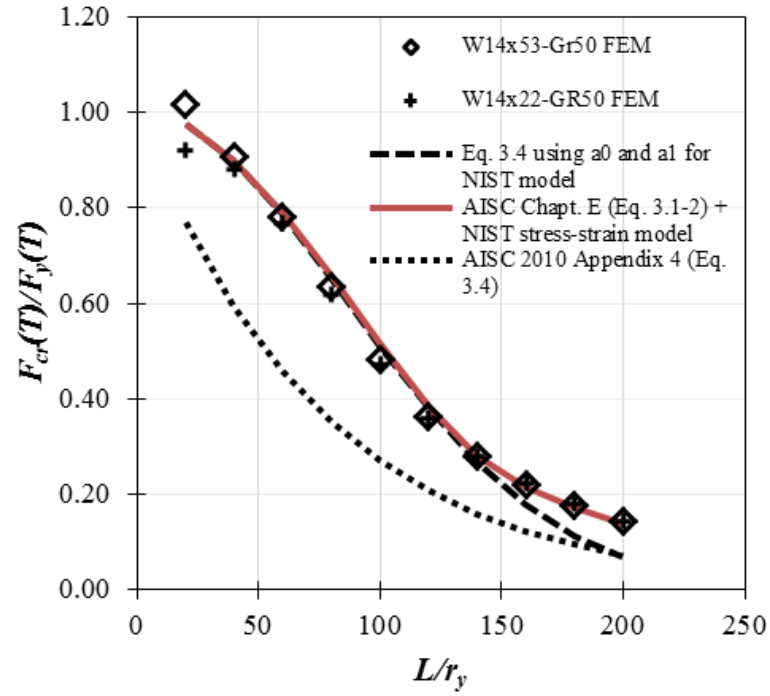

(c) $\mathrm{T}=700{ }^{\circ} \mathrm{C}$

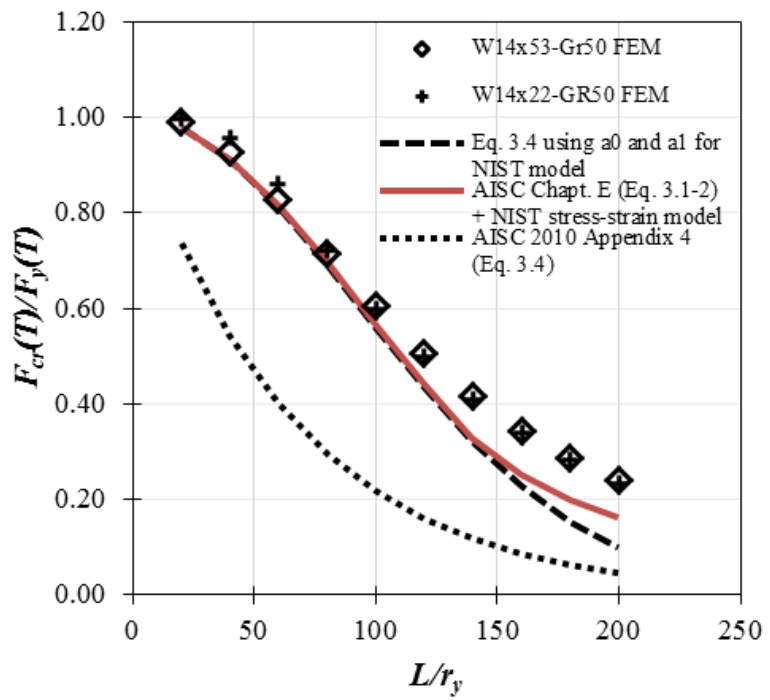

Figure 3-14 Comparison of column curves.

\subsection{SUMMARY, CONCLUSIONS, AND LIMITATIONS}

This chapter compares the high-temperature flexural buckling of steel columns predicted using two different stress-strain models: Eurocode 3 model and the model recently proposed by the National Institute of Standards and Technology. 
First, the simplified FEM models were used to compute the critical buckling temperature of 47 column specimens. The results indicate that the NIST stress-strain model predicts the critical temperature for column buckling failure more accurately than the Eurocode 3 model for four of five data sets considered in Table 3-1.

Then, the FEM models were developed to analyze the behavior and strength of the column specimens tested at Purdue University. The results show that (1) the NIST stress-strain model accurately predict the response, buckling strength, and failure time of columns at elevated temperatures. The Eurocode 3 model tends to conservatively estimate the stiffness and buckling strength of tested specimens. (2) Both NIST-proposed and Eurocode-3 thermal expansion models accurately predicted the thermal elongations of column specimens within $\pm 1 \%$ difference. (3) Overall, the NIST models accurately predicted the critical buckling load compared with the test results with the maximum difference of $2 \%$. The Eurocode 3 models systematically underestimate the compressive strength of all the column specimens by $18 \%$ on average.

Finally, the member strength computed using the AISC design equations with the NIST mechanical properties (temperature-dependent elastic modulus and yield strength of steel), compared with the results from the finite-element models. Also the parameters $\left(a_{0}=0.61\right.$ and $a_{1}$ $=0.86$ ) for Eq. (3.4) were re-calibrated using the NIST stress-strain model. The comparison shows that the standard AISC equations with the NIST proposed $F_{y}(T)$ and $E(T)$ compare very well with the results from the finite-element analysis. The difference between and the AISC 2010 equation, which was developed using the Eurocode 3 stress-strain model, is greatest for columns with the slenderness ratio from 50 to 100 at elevated temperatures.

The findings from the study are limited to the range of parameters included in the experimental investigations and finite-element models. This paper is not intended to draw any conclusions about columns with failure modes other than inelastic flexural buckling or cases where the thermal creep behavior is critical. Further work is recommended for evaluating predictions using the NISTproposed steel material model for other failure mechanisms (yielding or lateral-torsional buckling), various fire loading conditions (e.g., transient heating condition or localized fire), various boundary conditions (e.g., the effects of thermally induced axial and rotational restraints), and cases where the thermal creep behavior is critical. 
This page intentionally left blank. 


\section{Chapter 4 \\ MODELING OF FAILURE FOR FINITE ELEMENT ANALYSIS OF Structural SteElS at EleVATEd Temperatures}

A key issue in evaluating the response of structural systems to fire effects is the representation of material behavior at elevated temperatures. In addition to stress-strain behavior developed in Chapter 2, modeling of fracture is required to capture failure modes such as tear-out in connection plates and bolt shear. Fracture can be simulated in explicit finite element analysis using element erosion, in which elements are removed from the analysis when specified failure criteria are satisfied. However, the basis for determining and implementing material failure criteria at elevated temperatures is not well-established in the literature. A finite element material modeling methodology is presented for structural steels and structural bolts at elevated temperatures that incorporates erosion-based modeling of fracture. Temperature-dependent stress-strain relationships (presented in Chapter 2) for structural steel and structural bolts were combined with a plastic strain-based failure criterion for element erosion to enable modeling of fracture in analysis of structural connections and assemblies. The failure criterion was calibrated against hightemperature experimental data on elongation of tensile coupons at fracture, and its dependence on temperature and mesh size was investigated.

\subsection{INTRODUCTION}

Fire effects on steel structures can produce failures of connections, including fracture of connection plates, shear rupture of bolts, and bolt tear-out failure of beam webs or connection plates. Fig. 4-1 illustrates such failure modes for a typical shear tab connection at elevated temperatures, based on explicit finite element analyses described by Seif et al. (2013). Whether such failures occur depends not only on the loads that can be sustained by the various components of a connection, but also on the deformations that can be accommodated prior to fracture, since fire-induced forces result from the restraint of thermal expansion or contraction. The ductility of steel components thus plays an important role in the performance of connections at elevated temperatures. In addition, ductility can potentially allow redistribution of loads after failure of one or more connection components.

While implicit finite element methods are prone to convergence problems when local failures occur, explicit finite element methods are well suited for simulating successive failures and the subsequent redistribution of loads. Fracture for both tensile and shear failure modes can be simulated in explicit analyses (in an approximate sense) using element erosion, in which elements are automatically removed from the analysis when specified failure criteria are met. The erosion process may continue until a component has lost elements across its entire section, representing complete fracture, as illustrated in Fig. 4-1(c). The basis for determining and implementing 
material failure criteria at elevated temperatures, however, is not well-established in the literature. The objective of this chapter is to demonstrate a practical material modeling approach for structural steel and structural bolts at elevated temperatures that incorporates erosion-based modeling of fracture and that can be implemented in FE analysis using currently available tensile coupon data at elevated temperatures. Such an approach is needed in the context of performance-based design, to enable evaluation of the performance structural components, assemblies, and systems under fire effects.

(a)

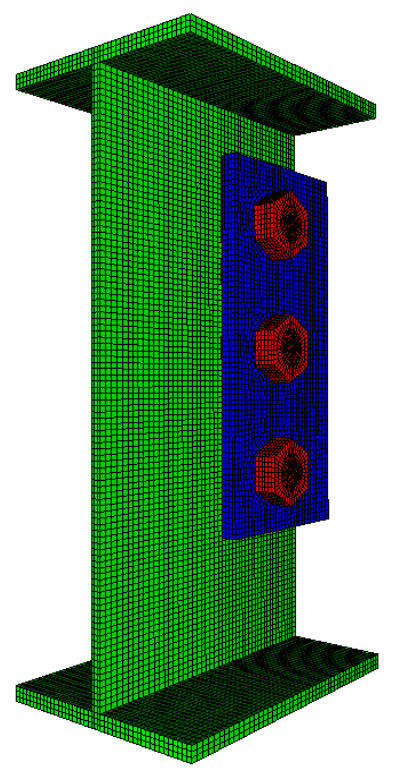

(b)

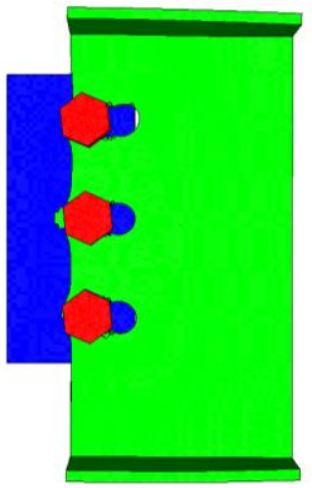

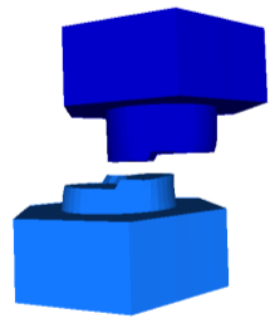

(c)

Figure 4-1 Detailed model of a shear tab connection, (b) tear-out failure in beam web, and (c) shear fracture of a bolt.

Failure modes such as tear-out and bolt shear rupture are ductile fractures with significant plastic deformation before fracture, particularly at elevated temperatures. Key factors influencing the initiation of ductile fracture in steel are the equivalent plastic strain and the stress triaxiality, defined as the ratio of the mean or hydrostatic stress to the effective or von Mises stress. Micromechanics-based models for predicting ductile fracture generally require calibration against experimental fracture data at different levels of triaxiality (e.g., Kanvinde and Deierlein (2006)). However, experimental data on fracture of steel at elevated temperatures are currently insufficient to enable calibration of such micromechanics-based models. Accordingly, researchers tend to model strain hardening and softening, but do not address fracture at elevated temperatures (e.g. Garlock and Selamet (2010), Sarraj et al. (2007), and Pakala et al. (2012)). The material model for structural steel at elevated temperatures in the Eurocode (2001) also does not address material fracture. Instead, the yield strength is reduced to zero with a linear material softening between $15 \%$ and $20 \%$ strain.

The proposed material modeling approach for structural steel uses the recently developed empirical power-law form of stress-strain relationship presented in Chapter 2, which was fit to a 
large set of experimental data at elevated temperatures. The bi-linear stress-strain relationship presented in Chapter 2 is proposed to model the temperature-dependent behavior of structural bolts, for which experimental data at elevated temperatures are more limited. Rather than using a micromechanics-based model, a relatively simple plastic strain-based failure criterion is proposed for modeling fracture of both structural steel and structural bolts in structural system analyses. Similar approaches have been successfully implemented in detailed finite element analyses of moment connections (Sadek et al. 2013) and simple shear connections (Main and Sadek 2013) under column removal scenarios at ambient temperature. In this study, the erosion strain (the local plastic strain at which element erosion is activated) was calibrated against available hightemperature experimental data on elongation of tensile coupons at fracture, and it was found that a temperature-dependent value of the erosion strain was required to capture the experimental data. The dependence of the failure criterion on temperature and mesh size was also investigated, and for structural bolts, analyses of double-shear tests were performed to assess the performance of the material modeling approach under shear loading.

\subsection{MATERIAL MODELING AND POST-ULTIMATE STRENGTH}

\subsubsection{Structural Steel}

The temperature-dependent material model described in Chapter 2 is an empirical model for any structural steel with nominal yield strength less than $65 \mathrm{ksi}(450 \mathrm{MPa})$. The equations required for implementation of the material model in this chapter are extracted from Chapter 2, and repeated here for clarity. The temperature-dependent relationship between true stress and true strain incorporates temperature-dependent expressions for the modulus of elasticity and the yield strength. The temperature-dependent modulus of elasticity $E$ is:

$$
E(T)=E_{0}\left[\exp \left(-\frac{1}{2}\left(\frac{\Delta T}{e_{3}}\right)^{e_{1}}-\frac{1}{2}\left(\frac{\Delta T}{e_{4}}\right)^{e_{2}}\right)\right]
$$

where $E_{0}=29,900 \mathrm{ksi}(206 \mathrm{GPa})$ is the value at ambient temperature, $\Delta T$ (in ${ }^{\circ} \mathrm{C}$ ) is the increase in temperature above the ambient temperature, and $e_{1}$ through $e_{4}$ are coefficients that depend on the type of steel. For rolled structural steel, $e_{1}=3.768, e_{2}=1.000, e_{3}=639{ }^{\circ} \mathrm{C}$, and $e_{4}=1650{ }^{\circ} \mathrm{C}$. Fig. 4-2 shows the degradation of the normalized elastic modulus (i.e., $E(T) / E_{0}$ ) with increasing temperature calculated using Eq. (4.1) with the listed coefficients. The temperature-dependence of the yield strength $F_{y}$ is given by: 


$$
F_{y}(T)=F_{y 0}\left[r_{5}+\left(1-r_{5}\right) \cdot \exp \left(-\frac{1}{2}\left(\frac{\Delta T}{r_{3}}\right)^{r_{1}}-\frac{1}{2}\left(\frac{\Delta T}{r_{4}}\right)^{r_{2}}\right)\right]
$$

where $F_{y 0}$ is the yield strength at ambient temperature and $r_{1}$ through $r_{5}$ are coefficients that depend on the type of steel. For rolled structural steel, $r_{1}=7.514, r_{2}=1.000, r_{3}=588{ }^{\circ} \mathrm{C}, r_{4}=676{ }^{\circ} \mathrm{C}$, and $r_{5}=0.090$. The degradation of the normalized yield strength (i.e., $F_{y}(T) / F_{y 0}$ ) with increasing temperature is also shown in Fig. 4-2, calculated using Eq. (4.2) with the listed coefficients.

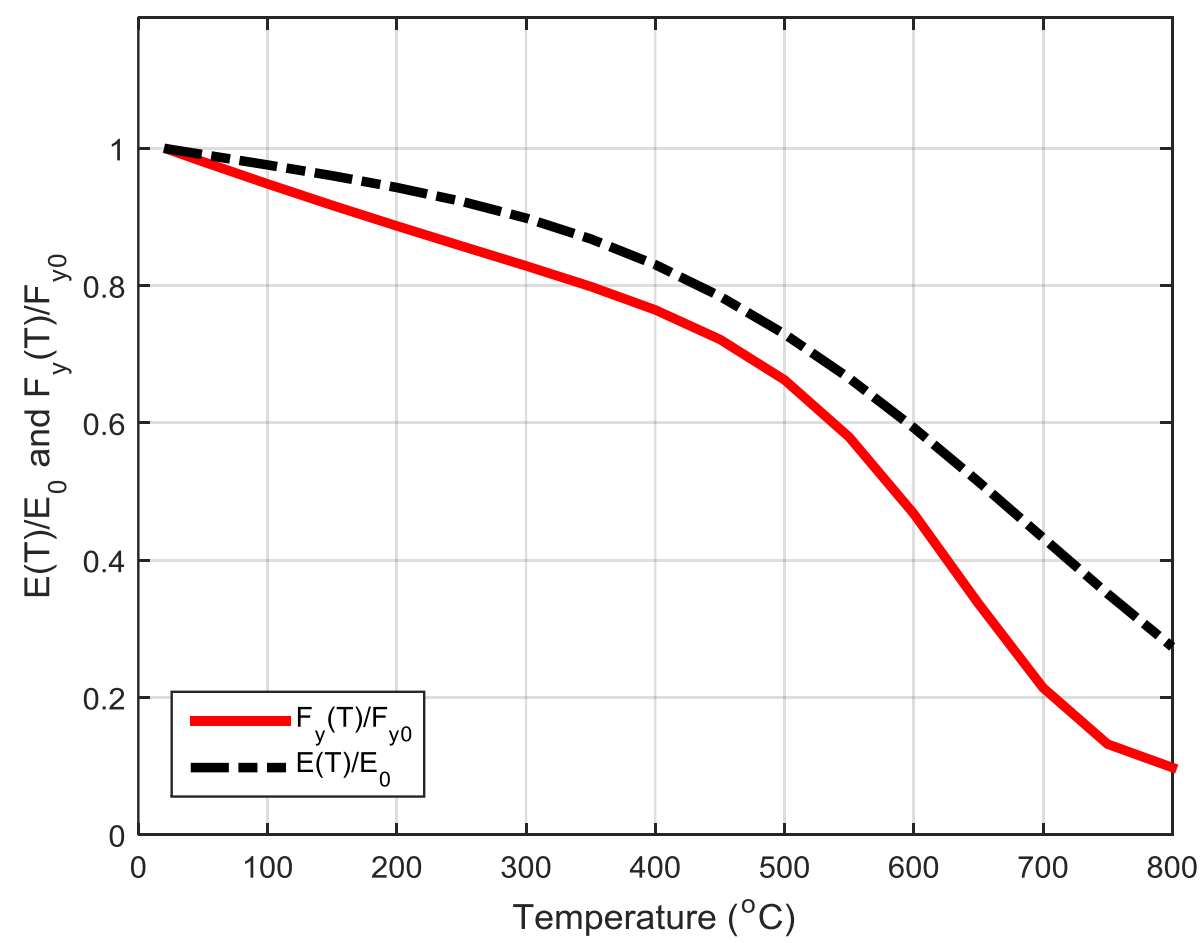

Figure 4-2 Degradation of normalized yield strength and elastic modulus with temperature for structural steel.

Using the temperature-dependent modulus of elasticity and yield strength, the true stress $\sigma$ is expressed as a function of true strain $\varepsilon$ as:

$$
\sigma=\left\{\begin{array}{cc}
E(T) \varepsilon, & \varepsilon<\varepsilon_{y}(T) \\
{\left[F_{y}(T)+\left(k_{3}-k_{4} F_{y 0}\right) \exp \left(-\left(\frac{T}{k_{2}}\right)^{k_{1}}\right)\left(\varepsilon-\varepsilon_{y}(T)\right)^{n}\right],} & \varepsilon \geq \varepsilon_{y}(T)
\end{array}\right.
$$


where $T$ is temperature (in ${ }^{\circ} \mathrm{C}$ ), $\varepsilon_{y}(T)=F_{y}(T) / E(T)$ is the temperature-dependent yield strain, $n=$ 0.503 is the strain hardening exponent, and the coefficients $k_{1}$ through $k_{4}$ have the following values: $k_{1}=7.820, k_{2}=540{ }^{\circ} \mathrm{C}, k_{3}=145.9 \mathrm{ksi}(1006 \mathrm{MPa})$, and $k_{4}=0.759$ (see Section 2.2).

The true stress-strain relationship in Eq. (4.3) was calibrated based on the available tensile coupon data up to the ultimate tensile strength, which corresponds to the uniform strain $e_{u}$ given by Eq. (2.15). In finite element modeling of tensile coupons, direct application of Eq. (4.3) for strains exceeding $e_{u}$ was found to result in delayed onset of necking in comparison with the experimental data. This was illustrated in Fig. 2-7, in which Fig. 2-7(a) shows the true stress-strain curve at $400{ }^{\circ} \mathrm{C}$ from Eq. (4.3) (for $F_{y 0}=50 \mathrm{ksi}$ (345 MPa)) and Fig. 2-7(b) shows the corresponding engineering stress-strain curve generated from finite-element analysis of a tensile coupon, using the approach discussed subsequently. The onset of necking corresponds to the Considère criterion for instability in tension (e.g., Dieter (1976)), in which the true stress is equal to the slope of the true stress-strain curve, $\sigma=\mathrm{d} \sigma / \mathrm{d} \varepsilon$. In Fig. 2-7(a), this point corresponds to the intersection of the solid curve, representing $\sigma(\varepsilon)$ from Eq. (4.3), with the dashed curve, representing $\mathrm{d} \sigma / \mathrm{d} \varepsilon$. This intersection occurs at a true strain of $\varepsilon=0.293$, which corresponds to an engineering strain of $e=$ 0.340 according to Eq. (2.11). From Eq. (2.15) and Eq. (2.16), based on experimental data, the expected uniform strain at $400{ }^{\circ} \mathrm{C}$ for $F_{y 0}=50 \mathrm{ksi}(345 \mathrm{MPa})$ is $e_{\mathrm{u}}=0.150$. Direct application of Eq. (4.3) for strains exceeding $e_{\mathrm{u}}$ thus results in onset of necking at a uniform strain approximately twice as large as the expected experimental value.
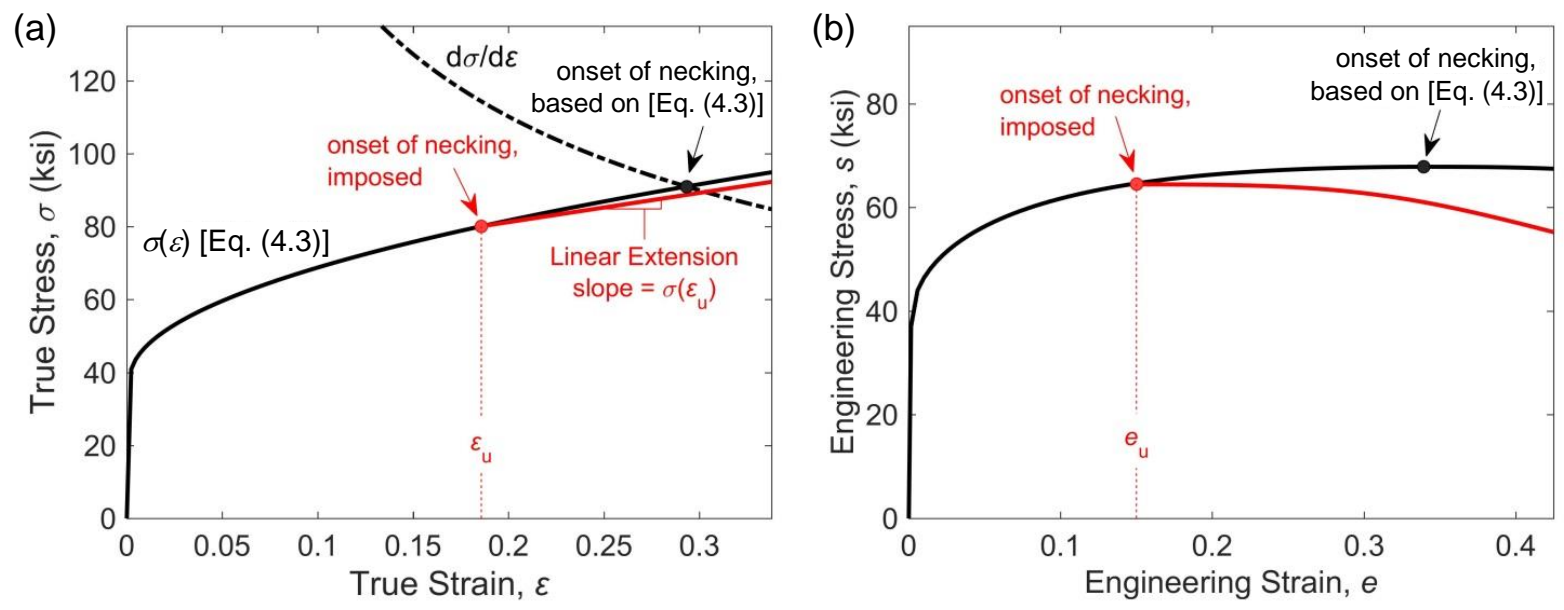

Figure 4-3 (a) True stress-strain and (b) engineering stress-strain curves comparing the onset of necking resulting from Eq. (4.3) with that imposed based on experimental data for $e_{\mathrm{u}}\left(400{ }^{\circ} \mathrm{C} ; \mathrm{Fy}_{\mathrm{y} 0}=50 \mathrm{ksi}\right.$ (345 MPa)).

To overcome this discrepancy, the approach used in this chapter was to specify the true stressstrain relationship using Eq. (4.3) only up to the uniform strain defined by Eq. (2.15). At this point, necking was imposed by reducing the slope of the true stress-strain curve to equal the true stress, thus satisfying the Considère criterion, and projecting the true stress-strain curve linearly thereafter, as follows: 


$$
\left.\frac{d \sigma}{d \varepsilon}\right|_{\varepsilon>\varepsilon_{u}}=\sigma\left(\varepsilon_{u}\right)
$$

where $\varepsilon_{u}=\ln \left(e_{u}+1\right)$ according to Eq. (2.11). Fig. 4-4 shows true stress-strain curves for ASTM A572 Grade 50 steel (ASTM International (2013) at various temperatures, generated using this approach. The point corresponding to the onset of necking for each temperature is indicated by the filled red circles. Fig. 4-4 shows that at $600{ }^{\circ} \mathrm{C}$, necking initiates at a relatively small strain of $\varepsilon_{u}=$ $6.7 \%$, so that the post-ultimate necking phase constitutes a greater portion of the material response.

In the proposed finite element modeling approach, the failure criterion for element erosion is based on the effective plastic strain, a scalar measure of plastic strain that incorporates its various tensor components. Element erosion is activated when the effective plastic strain in any element exceeds a specified critical value, called the erosion strain $\varepsilon_{e r}$. The erosion strain depends on the temperature and on the element discretization in the region of fracture, as is discussed subsequently. As described in the following section, finite element analyses of tensile coupons were performed to calibrate the erosion strain values against available experimental data on elongation of tensile coupons at fracture.

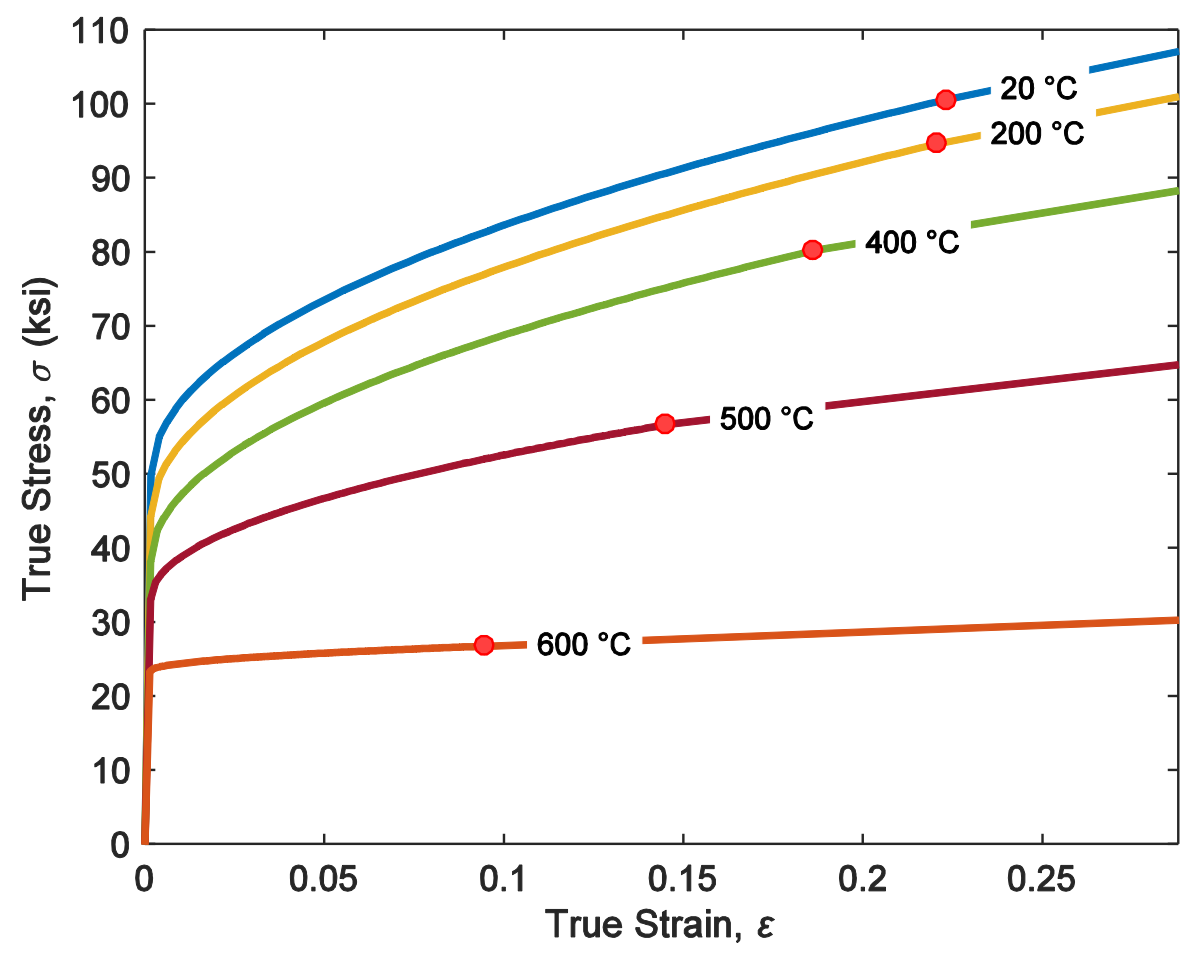

Figure 4-4 True stress-strain curves for A572 steel, generated using Eq. (4-3) until the onset of necking (red circular marker) with linearly projected stiffness thereafter $(1 \mathrm{ksi}=6.895 \mathrm{MPa})$. 


\subsubsection{Structural Bolts}

The bi-linear temperature-dependent true stress-strain representation presented in Chapter 2, Eq. (2.18) is extended to a tri-linear representation in this for implementation in high-fidelity finite element analyses, as follows:

$$
\sigma=\left\{\begin{array}{cc}
E(T) \varepsilon, & \varepsilon \leq \varepsilon_{y}(T) \\
F_{y}(T)+\left[F_{u}(T)-F_{y}(T)\right] \frac{\varepsilon-\varepsilon_{y}(T)}{\varepsilon_{u}(T)-\varepsilon_{y}(T)}, & \varepsilon_{y}(T)<\varepsilon \leq \varepsilon_{u}(T) \\
F_{u}(T)+0.0008 E(T)\left[\varepsilon-\varepsilon_{u}(T)\right], & \varepsilon_{u}(T)<\varepsilon
\end{array}\right.
$$

where $\varepsilon_{y}(T)=F_{y}(T) / E(T)$ is the temperature-dependent yield strain. The elastic modulus $E$ is the same for bolts as for structural steel and is calculated from Eq. (4.1).

For A325 and A490 high-strength bolts, the temperature-dependence of the yield strength $F_{y}$ is calculated from Eq. (4.2), with $r_{1}=4.967, r_{2}=1.000, r_{3}=456{ }^{\circ} \mathrm{C}, r_{4}=2040{ }^{\circ} \mathrm{C}$, and $r_{5}=0.000$.

The ultimate tensile strength $F_{u}$ is calculated using Eq. (4.2) using the same values of $r_{1}$ through $r_{5}$ as for the yield strength, but with the ambient-temperature yield strength $F_{y 0}$ replaced by the ambient-temperature ultimate tensile strength $F_{u 0}$. The temperature-dependent uniform strain, $\varepsilon_{u}(T)$, is assumed to have a value of 0.1 at $20{ }^{\circ} \mathrm{C}$ and to decrease linearly with temperature to a value of 0.05 at $600{ }^{\circ} \mathrm{C}$.

Beyond the uniform strain, the slope of the true stress-strain relationship in Eq. (4.5) was taken as $0.08 \%$ of the elastic modulus $E(T)$, which was found to produce necking and softening behavior that were reasonably consistent with experimental data by Kodur et al. (2012). Fig. 4-5 shows the stress-strain relationship of the A490 bolts at temperatures of $20{ }^{\circ} \mathrm{C}, 400{ }^{\circ} \mathrm{C}, 500{ }^{\circ} \mathrm{C}$, and $600{ }^{\circ} \mathrm{C}$. 


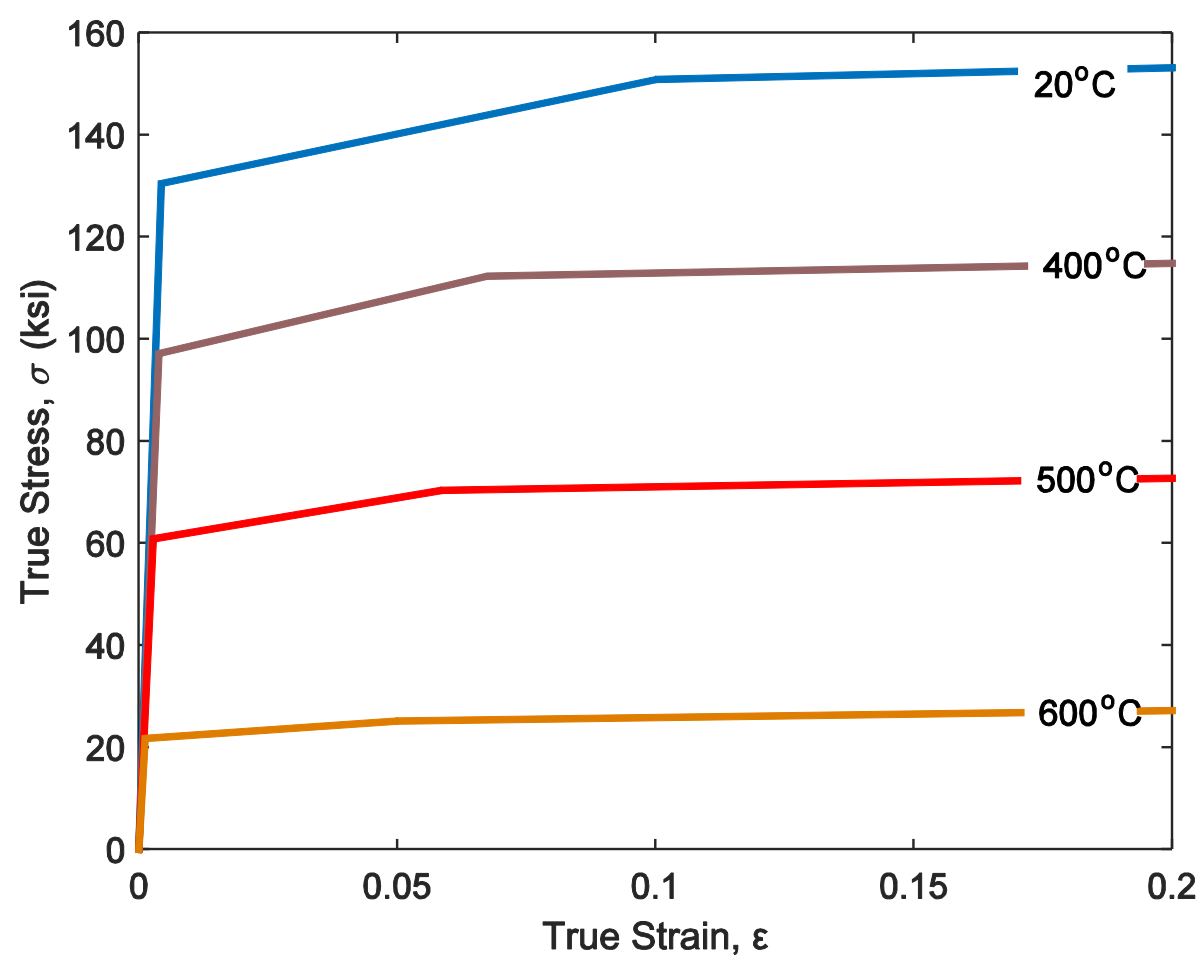

Figure 4-5 True stress-strain curves for A490 bolts (1 ksi = 6.895 MPa).

\subsubsection{Assumptions and Limitations}

For strains exceeding the temperature-dependent uniform strain (Eq. (2.16)), linear projection of the true stress-strain curves, based on the Considère criterion, successfully initiated necking for all mesh sizes considered. However, it is well known that softening behavior in continuum finite element analyses introduces first-order mesh dependence, and thus the values of erosion strain, which were calibrated against the available tensile test data (see Section 4.4), are mesh-sizedependent. In addition, the erosion strains were calibrated to material within the gauge length of tensile coupons (at elevated temperatures) at their instantaneous triaxiality at fracture. For cases in which the material triaxiality at fracture may differ significantly from that of a tension test, the erosion strain may need to be modified accordingly.

Despite these limitations, this chapter provides a rational approach to incorporating modelling of fracture in structural steels at elevated temperatures with currently available FE software and tensile coupon data. There does not currently exist sufficient data to support a more sophisticated approach that includes the effects of triaxiality at elevated temperatures. 


\subsection{ANALYSIS OF STRUCTURAL STEEL TENSILE COUPONS}

Temperature-dependent values of erosion strain for structural steel members were calibrated against fracture strains from elevated-temperature coupon tests reported by Luecke et al. (2005) and $\mathrm{Hu}$ et al. (2009). Using finite-element models of tensile coupons, the erosion strains were calibrated so that the computed engineering strain at fracture for each temperature matched the average experimental value. Since the simulation of post-ultimate necking and fracture can depend on the mesh discretization, the mesh size used in the calibration procedure needs to be consistent with the mesh size to be used in modeling fracture of a structural component. The influence of mesh size on the computed results is further discussed in Section 4.4.3.

\subsubsection{Tensile Test Data}

Luecke et al. (2005) tested a set of A572 Grade 50 steel tensile coupons at elevated temperatures, and four of these coupons are shown in Fig. 4-6(a) to illustrate the effect of elevated temperature on the shape and size of the necked region. The thickness of the coupons was 0.125 in $(3.2 \mathrm{~mm})$, and the reduced section (where necking and fracture occurred) had a length of $A_{o}=1.25$ in $(31.8 \mathrm{~mm})$ and a width of $0.24 \mathrm{in}(6.1 \mathrm{~mm})$. The extensometer used in the tests had a gauge length of 0.5 in $(12.7 \mathrm{~mm})$. The coupons were first heated to the desired temperature, and then subjected to displacement-controlled tensile loading until fracture. Fig. 4-6(b) shows engineering stressstrain curves corresponding to the tensile coupons shown in Fig. 4-6(a). The initial portions of the curves, up to the ultimate tensile strength (plotted using solid lines), correspond to the strain measured by the extensometer. The post-ultimate portions of the curves (plotted with dashed lines) do not represent measured data but are simply straight-line segments connecting the point of necking initiation (at the ultimate tensile strength) to the point of fracture, as explained in the next paragraph. 
(a)

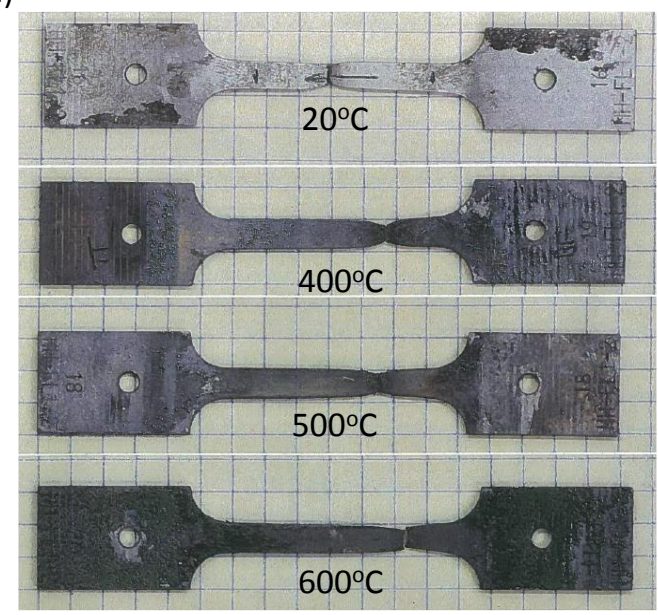

(b)

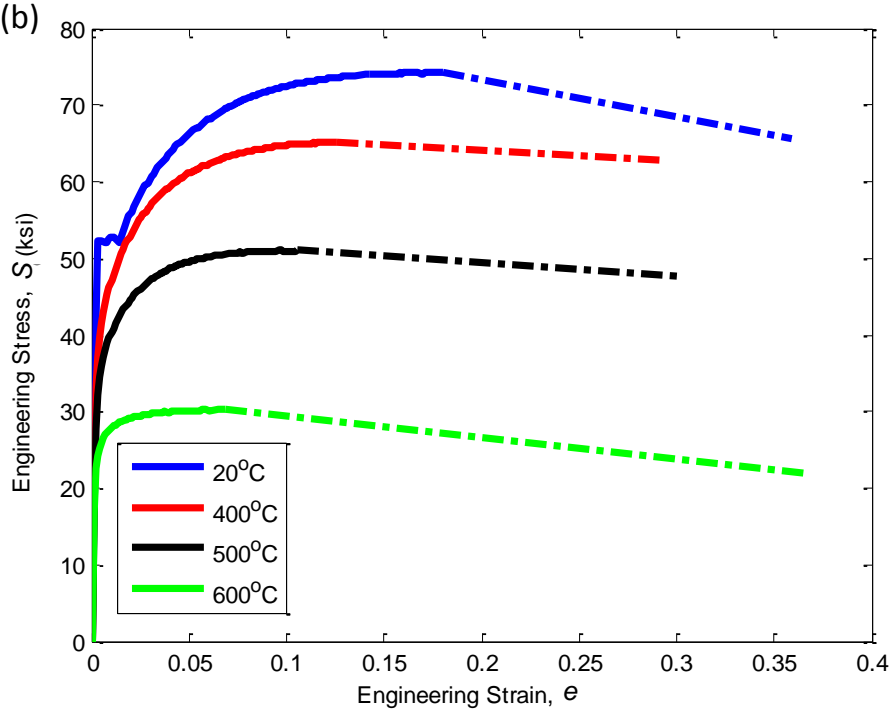

Figure 4-6 Experimental coupons; (a) picture of the four specimens after the tensile test was conducted at $20{ }^{\circ} \mathrm{C}, 400{ }^{\circ} \mathrm{C}, 500{ }^{\circ} \mathrm{C}$, and $600{ }^{\circ} \mathrm{C}$, and (b) corresponding stress-strain curves $(1 \mathrm{ksi}=6.895 \mathrm{MPa}) . *$

* Estimated coefficient of variation in measured data is $4 \%$.

For consistency with the experiments of Hu et al. (2009), discussed subsequently, the engineering strain values at fracture in Fig. 4-6(b) correspond to a gauge length of $G_{o}=1$ in $(25.4 \mathrm{~mm})$. This gauge length included $80 \%$ of the reduced section and was sufficient to capture the necked region for all specimens. Fracture strain measurements for the 1 in $(25.4 \mathrm{~mm})$ gauge length were obtained by using the measured displacement of the actuator in conjunction with the extensometer measurements. The uniform strain at the onset of necking was first obtained from the extensometer measurements. The strain increment from the onset of necking to the time of fracture was then computed by dividing the measured actuator displacement over this time interval by the 1 in (25.4 mm) gauge length. Finally, the computed strain increment was added to the uniform strain at the onset of necking to obtain the total engineering strain at fracture. While elastic rebound of the tensile coupon outside of the necking region was not included in this approach, the associated strains are negligibly small relative to the measured strains at fracture. The resulting values of engineering strain at fracture are plotted at the failure point in Fig. 4-6(b) and are also plotted as a function of temperature in Fig. 4-7, along with data from $\mathrm{Hu}$ et al. (2009). 


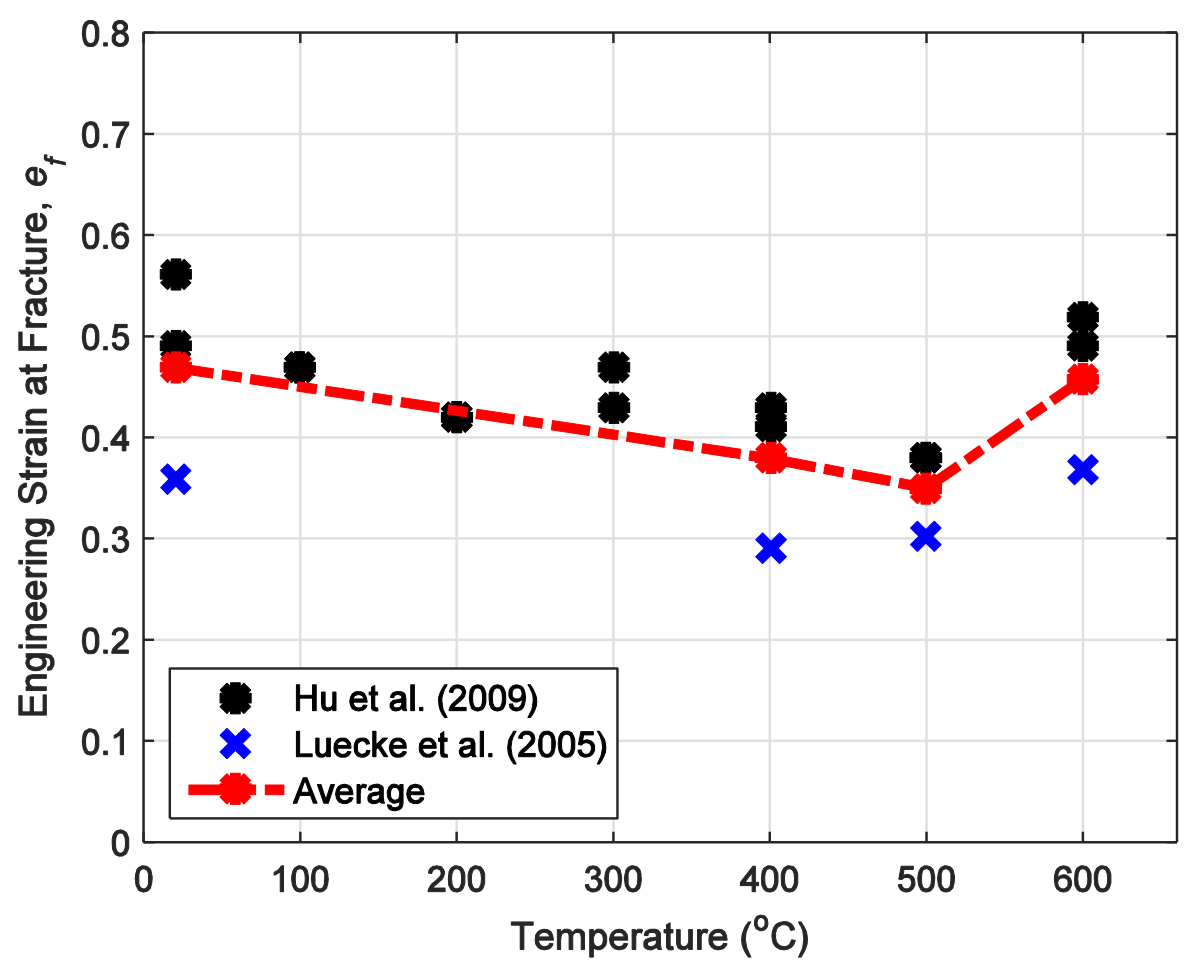

Figure 4-7 Experimental values of engineering strain at fracture for structural steel $($ Gauge length: 1 in = $25.4 \mathrm{~mm}) *$.

* Estimated coefficient of variation in measured data is $4 \%$.

$\mathrm{Hu}$ et al. (2009) presented coupon test data for ASTM A992 steel (ASTM 2012c) at elevated temperatures, reporting values of engineering strain at fracture for two specimens at each temperature with a gauge length of 1 in $(25.4 \mathrm{~mm})$. The data from both Luecke et al. (2005) and Hu et al. (2009) in Fig. 4-7 show a similar trend, with the fracture strain initially decreasing with temperature, reaching a minimum value around $400{ }^{\circ} \mathrm{C}$ or $500{ }^{\circ} \mathrm{C}$, and then increasing with temperature above $500{ }^{\circ} \mathrm{C}$. The fracture strain values for ASTM A992 steel from Hu et al. (2009) are generally somewhat higher than the values for ASTM A572 Grade 50 steel from Luecke et al. (2005). Average values of the experimental data at temperatures of $20{ }^{\circ} \mathrm{C}, 400{ }^{\circ} \mathrm{C}, 500{ }^{\circ} \mathrm{C}$, and $600{ }^{\circ} \mathrm{C}$ are plotted in Fig. 4-7, connected by a dashed line. These average values were selected as representative failure strains for structural steel and were used as target values in calibration of temperature-dependent erosion strains, as described subsequently.

\subsubsection{Finite Element Modeling Approach}

The tensile coupons were modeled using three-dimensional solid elements, as shown in Fig. 4-8. Fully integrated eight-node elements were used with a typical element size of 0.06 in $(1.5 \mathrm{~mm})$. Thus, the reduced section was meshed with four elements across the width and two elements through the thickness. Analyses were performed at uniform temperatures of $20{ }^{\circ} \mathrm{C}, 400{ }^{\circ} \mathrm{C}, 500{ }^{\circ} \mathrm{C}$, and $600{ }^{\circ} \mathrm{C}$. The analyses were performed using explicit time integration in LS-DYNA (Livermore 
Software Technology Corporation 2012), and a smooth functional form of tensile displacement vs. time was used to ensure that dynamic effects were negligible (i.e., to ensure quasi-static loading conditions). The coupons were subjected to tensile loading in the analysis until fracture across the reduced section occurred through element erosion. Element erosion in the necking zone initiated when the effective plastic strain in any element reached the specified erosion strain $\varepsilon_{e r}$, at which that element was removed from the analysis, leading rapidly to erosion of successive elements across the reduced section.

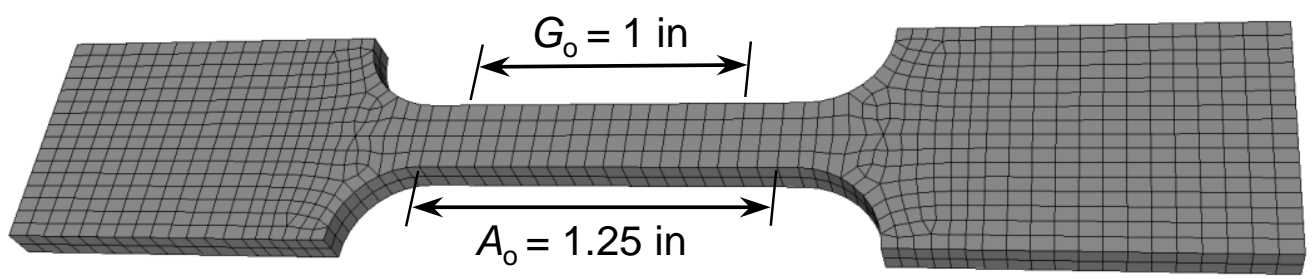

Figure 4-8 Finite element mesh of a tensile coupon $(1$ in $=25.4 \mathrm{~mm})$.

Fig. 4-9 shows analysis results from uniaxial extension of a tensile coupon at $500{ }^{\circ} \mathrm{C}$. Engineering strain values in the stress-strain curve of Fig. 4-9 were calculated based on the relative displacement of two nodes at each end of the gauge section, with an initial length of $G_{o}=1$ in (25.4 mm). Contours of effective plastic strain are also shown in Fig. 4-9 at different points labeled along the computed stress-strain curve. Point $a$ is around the onset of necking (at the ultimate tensile strength) and point $b$ is shortly after. The corresponding plastic strain contours show fairly uniform plastic strains along the gauge length that are comparable to the corresponding engineering strains. For example, point $b$ corresponds to an engineering strain of 0.15 , and comparable plastic strains of about 0.14 are observed. However, points $c$ and $d$ are after the onset of necking, and the contours of plastic strain clearly indicate localization of strain near the center of the gauge length, with plastic strains significantly exceeding the corresponding engineering strains. For example, point $d$ (just prior to fracture) corresponds to an engineering strain of 0.35 , but larger plastic strains of about 0.70 in the necked region. Because of this localization of plastic strain that occurs during necking, erosion strains are generally larger than the engineering strains at which fracture occurs. An erosion strain of $\varepsilon_{e r}=0.80$ was used for the analysis in Fig. 4-9 to achieve fracture at an engineering strain of 0.35 . The following section discusses determination of temperature-dependent erosion strains for structural steel. 


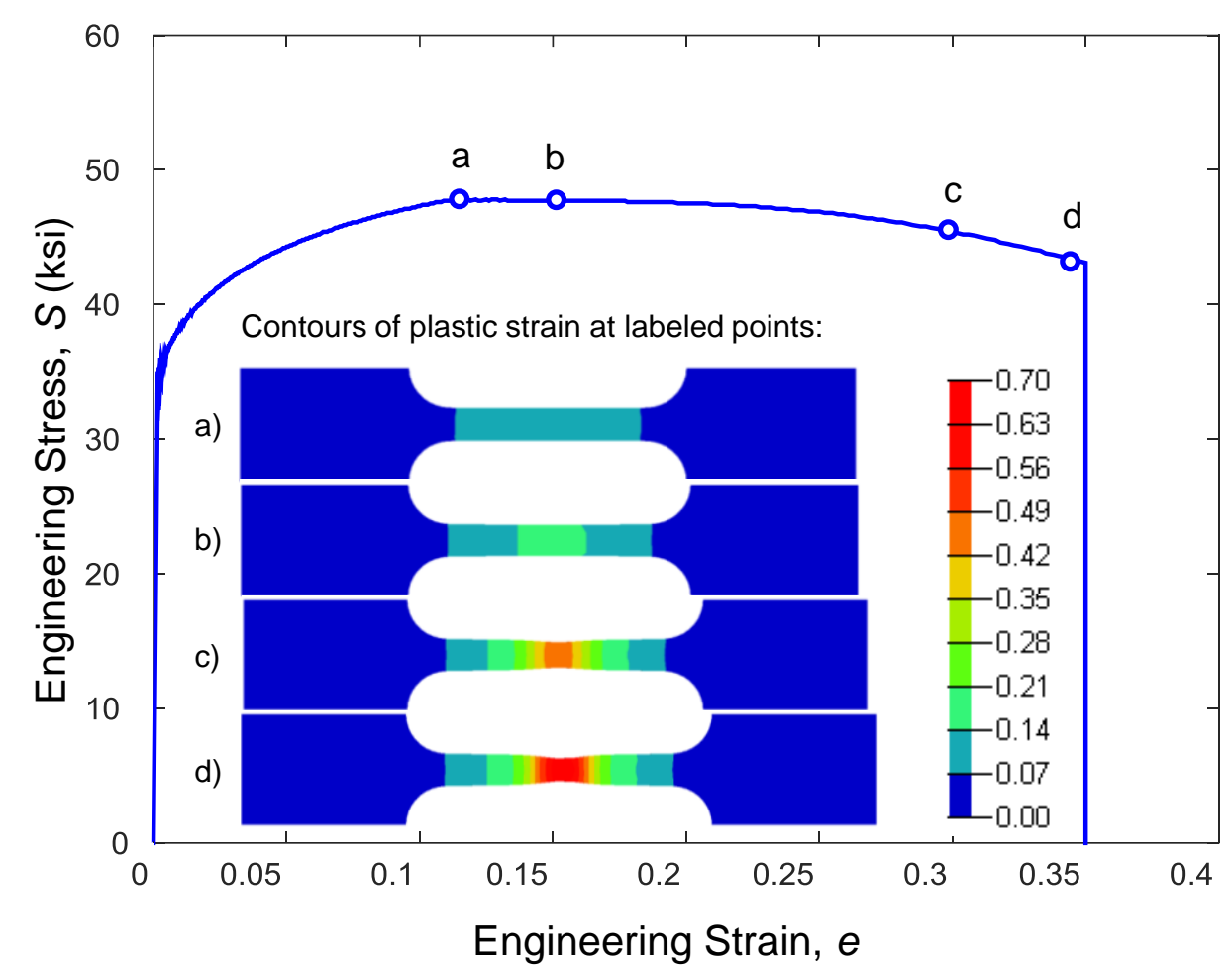

Figure 4-9 FE analysis results for a tensile coupon model at $500{ }^{\circ} \mathrm{C}(1 \mathrm{ksi}=6.895 \mathrm{MPa})$.

\subsubsection{Calibration of Temperature-Dependent Erosion Strain}

Fig. 4-10 shows the influence of the erosion strain $\varepsilon_{e r}$ (the local plastic strain at fracture) on the corresponding engineering strain at fracture obtained from the finite element model of a tensile coupon at $400{ }^{\circ} \mathrm{C}$. As the value of $\varepsilon_{e r}$ increases, the engineering strain at fracture also increases. For instance, when $\varepsilon_{e r}$, increases from 0.55 to 0.80 , the engineering strain at fracture, $e_{f}$, increases by about $19 \%$ from 0.32 to 0.38 . Larger values of the erosion strain produce a longer descending branch of the engineering stress-strain curve, which is associated with more extensive necking. To determine the appropriate value of erosion strain at each temperature, the erosion strain was adjusted until the resulting engineering strain at fracture matched the target value, which is the average of the experimental data shown in Fig. 4-7.

Fig. 4-11 shows the values of erosion strain $\varepsilon_{e r}$ used in the FE analyses to obtain the target values of engineering strain at fracture shown in Fig. 4-7. For each case, the erosion strain is significantly greater than the engineering strain at fracture (e.g., 1.63 vs. 0.46 , respectively, at $600{ }^{\circ} \mathrm{C}$ ), indicating extensive necking and associated localization of plastic strains in the post-ultimate phase prior to fracture. When high values of erosion strain are required in a material model, care must be taken to extend the stress-strain curves to the specified erosion strain. Defining stressstrain curves only up to the engineering strain at fracture would require the software to extrapolate stress-strain curves, possibly yielding unreliable results. 


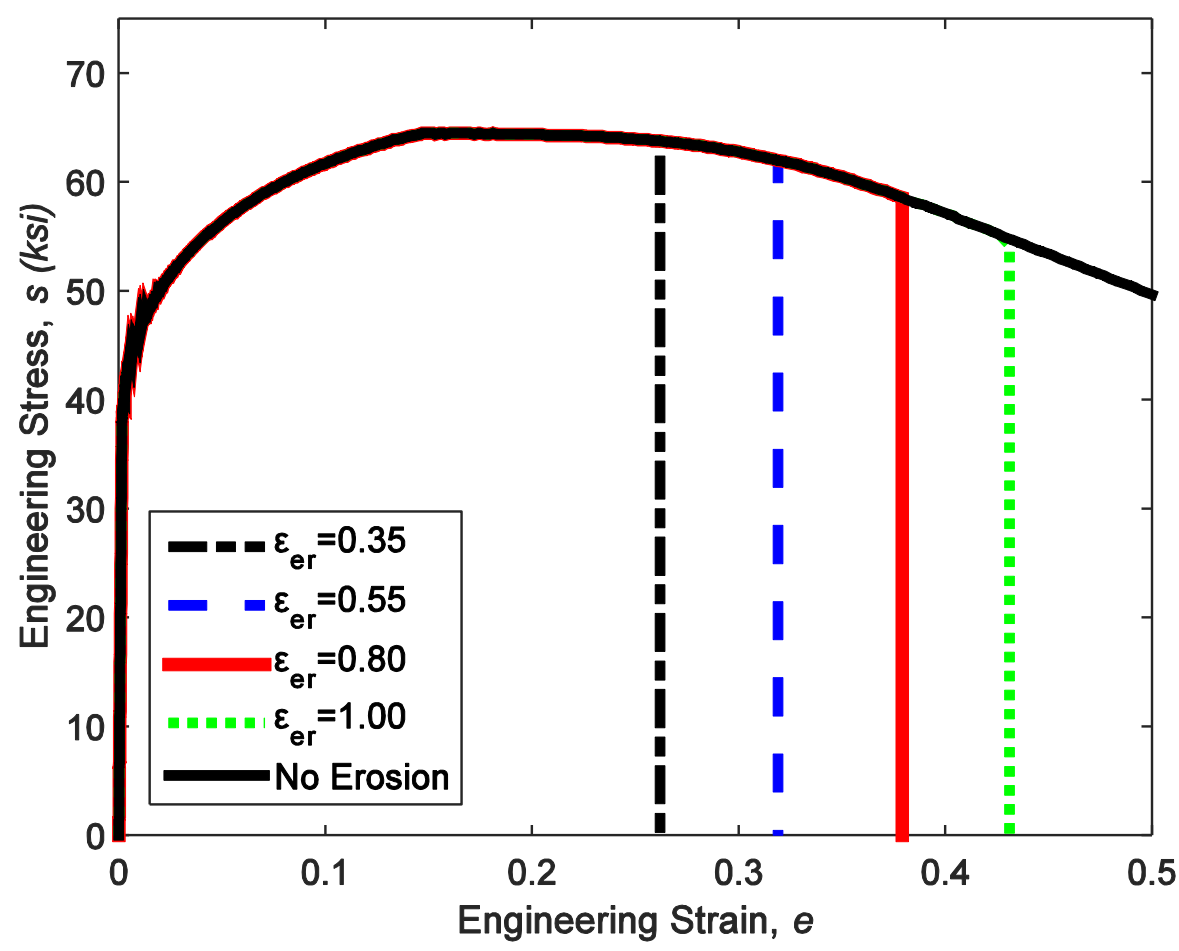

Figure 4-10 Influence of the erosion strain $\varepsilon_{e r}$ on the computed engineering strain at fracture at $400{ }^{\circ} \mathrm{C}$ (1 ksi = 6.895 MPa).

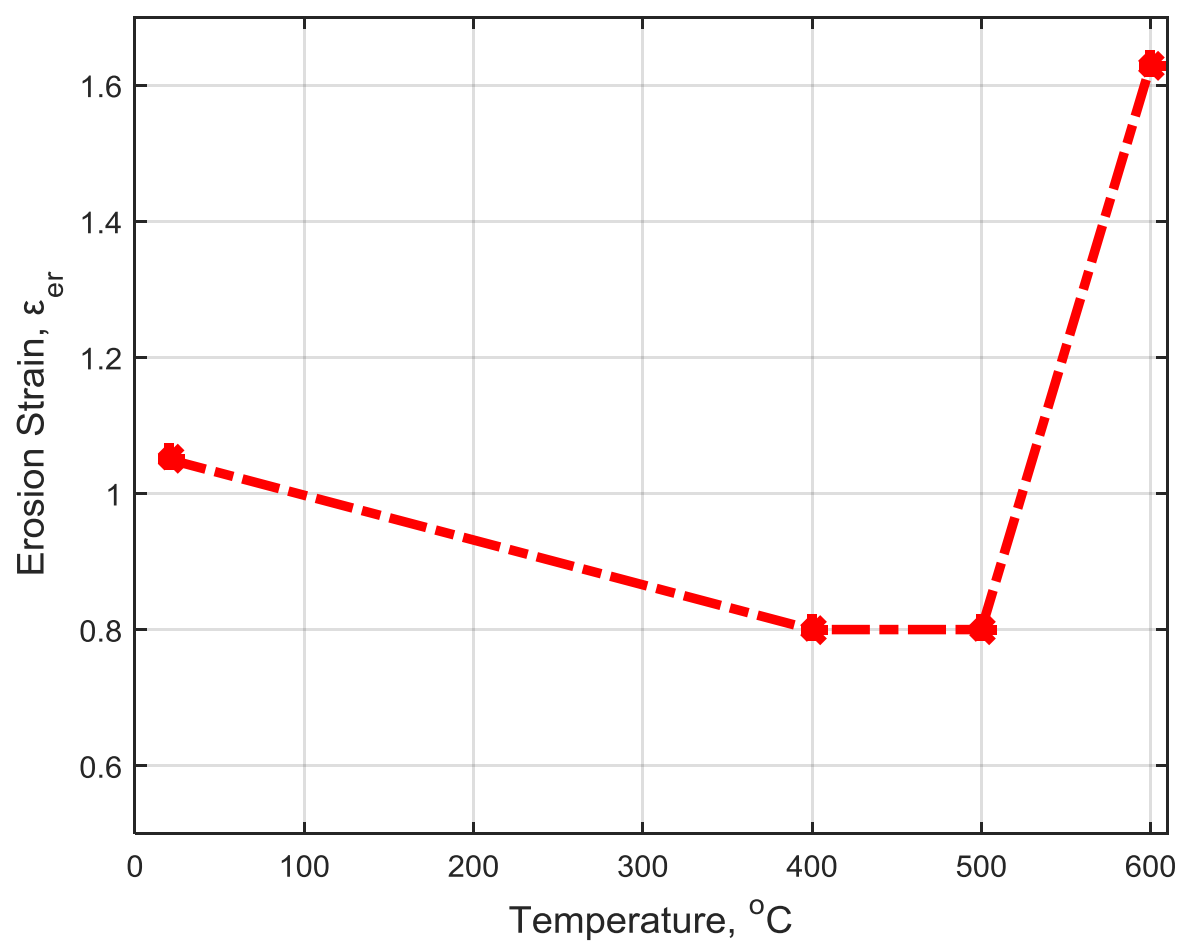

Figure 4-11 Calibrated values of erosion strain versus temperature for structural steel. 
Fig. 4-12 shows engineering stress-strain curves obtained from $\mathrm{FE}$ analysis of tensile coupons with the erosion strain values shown in Fig. $4-11$ at temperatures of $20{ }^{\circ} \mathrm{C}, 400{ }^{\circ} \mathrm{C}, 500{ }^{\circ} \mathrm{C}$, and $600{ }^{\circ} \mathrm{C}$. As a consequence of the calibration procedure described above, the engineering strain values at fracture in Fig. 4-12 match the target values in Fig. 4-7. Note that the stress-strain curves in Fig. 4-12 should not be expected to closely match the experimental stress-strain curves in Fig. 4-6(b) for the following reasons:

- The stress-strain curves in Fig. 4-12 are based on the power-law model in Eq. (4.3), which was fit to a large set of experimental data, whereas the stress-strain curves in Fig. 4-6(b) were obtained from individual coupon tests.

- The fracture strains in Fig. 4-12 were calibrated to match the average experimental values in Fig. 4-7, whereas the fracture strains in Fig. 4-6(b) were obtained from individual coupon tests.

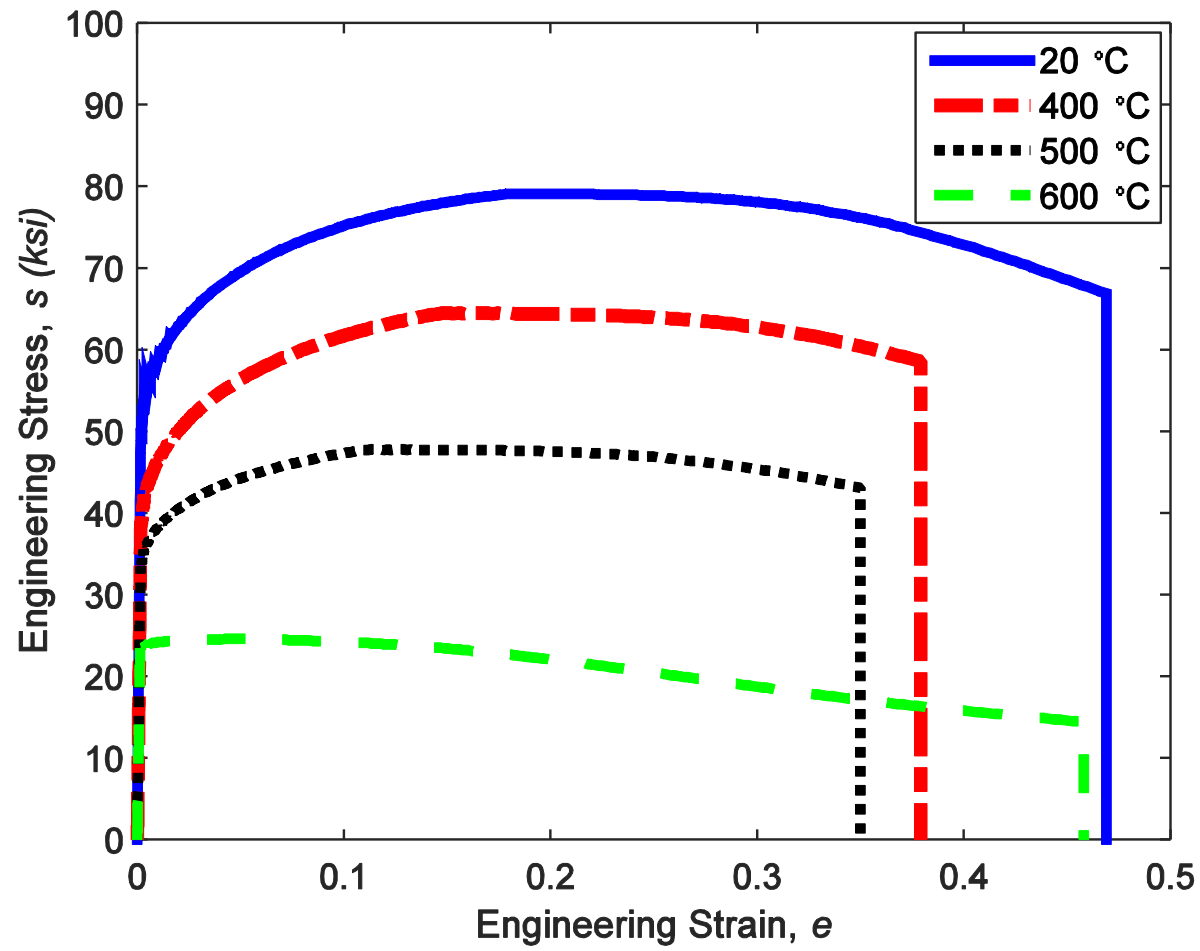

Figure 4-12 FEA engineering stress-strain curves for selected temperatures with calibrated erosion strain values for structural steel $(1 \mathrm{ksi}=6.895 \mathrm{MPa})$.

In spite of these differences, some general similarities can be observed between the computed and experimental curves, including degradation in the ultimate tensile strength with increasing 
temperature, reduced fracture strains at temperatures of $400{ }^{\circ} \mathrm{C}$ and $500{ }^{\circ} \mathrm{C}$, and the early onset of necking and extensive post-ultimate portion of the stress-strain curve at $600{ }^{\circ} \mathrm{C}$. These similarities confirm that the proposed modeling approach captures key aspects of the material behavior at elevated temperatures.

The appropriate values of erosion strain depend on the mesh discretization. The erosion strains in Fig. 4-11 were calibrated for coupon models with a typical element size of 0.06 in $(1.5 \mathrm{~mm})$ (see Fig. 4-8). Using a different level of mesh refinement would require recalibration of the erosion strains to achieve the same engineering strains at failure. Table 4-1 shows calibrated erosion strains for the original mesh and for a refined mesh with a typical element size of 0.03 in $(0.75 \mathrm{~mm})$, along with the target engineering strains at fracture used in the calibration. These results show that reducing the element size by one-half requires using erosion strains that are $41 \%$ to $46 \%$ higher for temperatures up to $500{ }^{\circ} \mathrm{C}$ and $33 \%$ higher for $600{ }^{\circ} \mathrm{C}$. Fig. $4-13$ shows engineering stressstrain curves computed from finite-element models of a tensile coupon for both the original mesh and the refined mesh. These results demonstrate that the proposed calibration procedure allows consistent values of engineering strain at failure to be achieved using multiple levels of mesh refinement. Fig. 4-13 also includes markers to indicate the premature fracture that would occur if erosion strain values were not recalibrated for the refined mesh. Only the post-ultimate behavior depends on the mesh discretization, because of the softening and strain localization that occur during necking. Larger erosion strains are required for the refined mesh because of the greater localization that occurs, which also results in somewhat reduced values of engineering stress at fracture, as evident in Fig. 4-13. The results in Fig. 4-13 and Table 4-1 demonstrate the importance of using the same element size in the calibration procedure as will be used in modeling the parts of the structural components in which fracture is expected. A fracture-energy based approach could potentially be used to account for this dependence on element size, and such an approach is being explored in ongoing research.

Table 4-1 Engineering and erosion strain values at fracture for structural steel.

\begin{tabular}{|c|c|c|c|c|}
\hline \multirow{2}{*}{$\begin{array}{c}\text { Temperature } \\
\left({ }^{\circ} \mathrm{C}\right)\end{array}$} & \multirow{2}{*}{$\begin{array}{c}\text { Engineering } \\
\text { Strain at Fracture }\end{array}$} & $\begin{array}{c}|c| \\
\text { element size: 0.06 in } \\
\text { (solid elements) }\end{array}$ & $\begin{array}{c}\text { element size: 0.03 in } \\
\text { (solid elements) }\end{array}$ & $\begin{array}{c}\text { element size: 0.06 in * } \\
\text { (shell elements) }\end{array}$ \\
\hline 20 & 0.470 & 1.050 & 1.53 & 0.400 \\
\hline 400 & 0.380 & 0.800 & 1.14 & 0.395 \\
\hline 500 & 0.350 & 0.800 & 1.13 & 0.375 \\
\hline 600 & 0.460 & 1.630 & 2.16 & 0.565 \\
\hline
\end{tabular}

* 1 in $=25.4 \mathrm{~mm}$ 


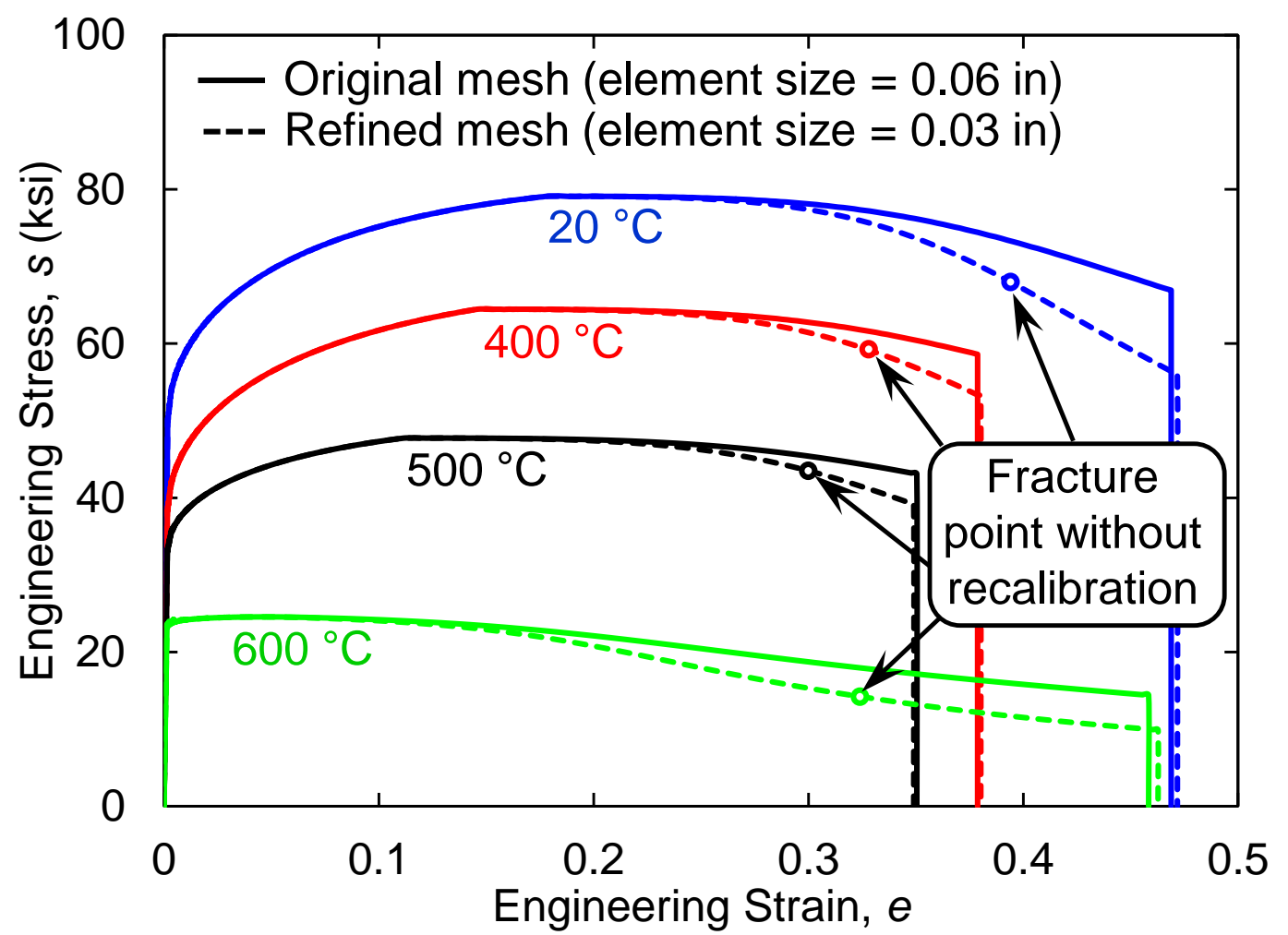

Figure 4-13 Engineering stress-strain curves computed from finite-element models of a tensile coupon with different levels of mesh refinement $(1 \mathrm{ksi}=6.895 \mathrm{MPa})$.

The appropriate values of erosion strain also depend on the element type and formulation. Using 2D shell elements instead of the 3D solid elements will yield lower erosion strain values. 2D shell elements were used to remodel the coupons, and analyses were performed at the same $20{ }^{\circ} \mathrm{C}$, $400{ }^{\circ} \mathrm{C}, 500{ }^{\circ} \mathrm{C}$ temperatures. The fifth column of Table 4-1 shows the erosion strains $\varepsilon_{e r}$ used in the FE analyses to obtain the target engineering strains at fracture shown in Fig. 4-7 and in the second column of Table 4-1.

\subsection{ANALYSIS OF STRUCTURAL BOLTS}

Erosion strains used to model the failure of structural bolts need to be calibrated against experimental data at elevated temperatures. Since the shear behavior of bolts is often of primary concern in connection performance, we considered the possibility of calibrating erosion strain values using bolt shear test data at elevated temperatures from Yu (2006). However, the measured data included deformations of the test plates that imposed shear forces on the bolts, so that the bolt shear deformations could not be isolated from the published results. Therefore, similar to the procedure used for structural steel, erosion strains for structural bolts were calibrated against tensile test data at elevated temperatures, using bolt coupon data from Kodur at al. (2012), presented in Section 4.4.1. After using finite element models of bolt coupons (Section 4.4.2) to 
calibrate the erosion strains against the tensile test data (Section 4.4.3), the behavior of the proposed modeling approach under shear loading is considered in Section 4.4.4.

\subsubsection{Tensile Test Data}

Fig. 4-14 presents values of engineering strain at fracture for both A325 and A490 bolts reported by Kodur et al. (2012) based on tensile tests of bolt coupons at temperatures of $20{ }^{\circ} \mathrm{C}, 400{ }^{\circ} \mathrm{C}$, $500{ }^{\circ} \mathrm{C}$, and $600{ }^{\circ} \mathrm{C}$. The reported engineering strains at fracture correspond to a gauge length of 2.0 in $(50.8 \mathrm{~mm})$. The fracture strains in Fig. 4-14 were used as target values in calibration of the erosion strains, as described subsequently.

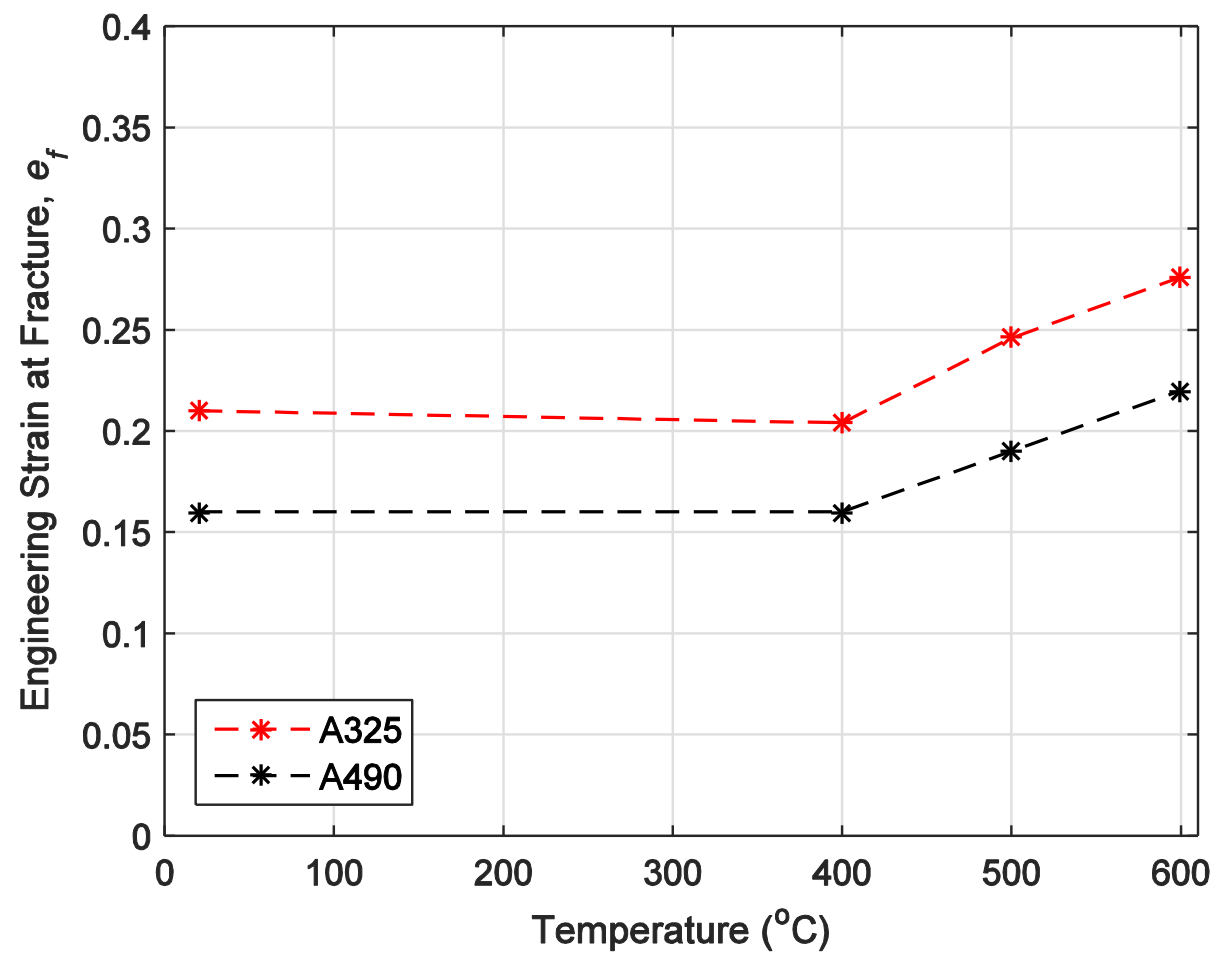

Figure 4-14 Experimental values of engineering strain at fracture from Kodur et al. (2012) for A325 and A490 bolts.

\subsubsection{Finite Element Modeling Approach}

Tensile coupons machined from A325 and A490 bolts were modeled using three-dimensional solid elements, as illustrated in Fig. 4-15. Fully integrated eight-node elements were used with a typical element size of 0.06 in $(1.5 \mathrm{~mm})$. Analyses were performed at uniform temperatures of $20{ }^{\circ} \mathrm{C}$, $400{ }^{\circ} \mathrm{C}, 500{ }^{\circ} \mathrm{C}$, and $600{ }^{\circ} \mathrm{C}$. The bolts were subjected to tensile loading in the analysis until necking and fracture occurred in the reduced section of the bolt coupon. Fracture was modeled using element erosion, which initiated when the effective plastic strain in elements in the necking zone reached the specified erosion strain, $\varepsilon_{e r}$. 
Fig. 4-16 shows analysis results from uniaxial extension of an A490 bolt coupon at $500{ }^{\circ} \mathrm{C}$. Engineering strain values were calculated based on the relative displacement of nodes at each end of the gauge section, with an initial length of $G_{o}=2.0$ in $(50.8 \mathrm{~mm})$, corresponding to the tests by Kodur et al. (2012). Contours of effective plastic strain are also shown in Fig. 4-16 for the points labeled on the computed stress-strain curve. Point $a$ is at the onset of necking, and the corresponding plastic strain contours show uniform plastic strains of about 0.06 along the gauge length that are comparable to the corresponding engineering strain value of 0.06 . However, points $b$ and $c$ are after the onset of necking, and the contours of plastic strain clearly indicate localization of strain where necking occurs near the center of the reduced section. The plastic strains in the necking zone significantly exceed the corresponding engineering strains. For example, point $c$ (just prior to fracture) corresponds to an engineering strain of about 0.16 , but much larger plastic strains of about 0.39 are observed in the necking region. The following section discusses determination of temperature-dependent erosion strains for bolts.

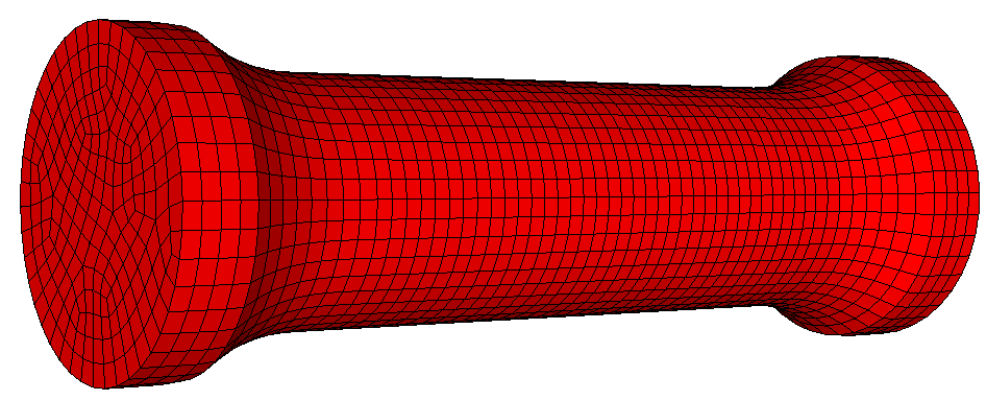

Figure 4-15 Finite element mesh of a bolt tensile coupon. 


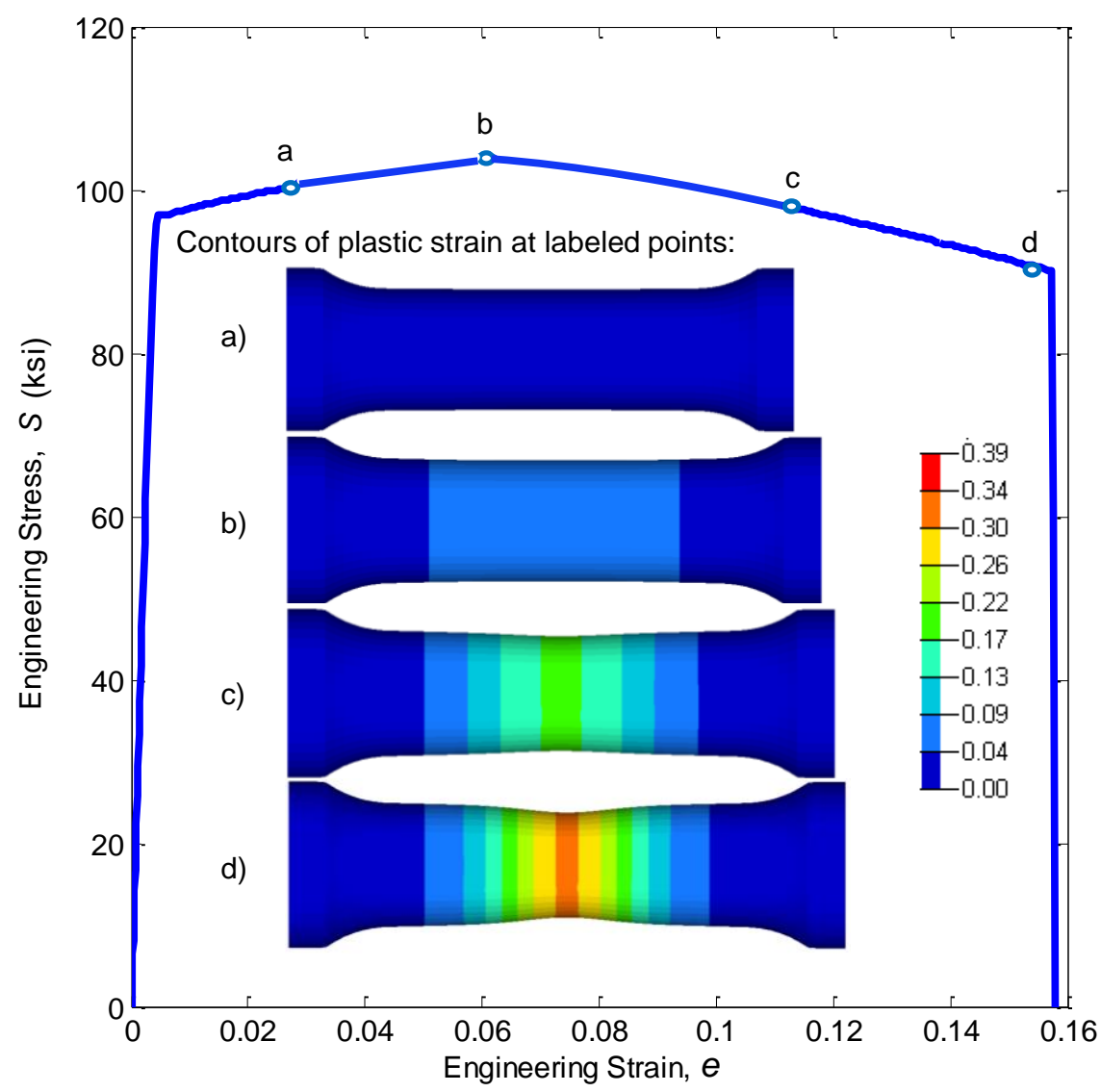

Figure 4-16 $\mathrm{FE}$ analysis results for an $\mathrm{A490}$ bolt tensile coupon at $500{ }^{\circ} \mathrm{C}(1 \mathrm{ksi}=6.895 \mathrm{MPa})$.

\subsubsection{Calibration of Temperature-Dependent Erosion Strain}

To determine the appropriate erosion strain at each temperature, the erosion strain was adjusted until the resulting engineering strain at fracture matched the target value shown in Fig. 4-14, obtained from the experimental data of Kodur at al. (2012). These target engineering strains at fracture are also listed in Table 4-2 (columns 2 and 3), along with the calibrated erosion strains used in the FE models (columns 3 and 4). The calibrated erosion strains are plotted against temperature in Fig. 4-17. Fig. 4-18 and Fig. 4-19 show engineering stress-strain curves obtained from FE analysis of A325 and A490 bolts, respectively, at temperatures of $20{ }^{\circ} \mathrm{C}, 400{ }^{\circ} \mathrm{C}, 500{ }^{\circ} \mathrm{C}$, and $600{ }^{\circ} \mathrm{C}$. At all temperatures, the $\mathrm{A} 490$ bolts are stronger and fracture at lower engineering strains than the A325 bolts. For both types of bolts, the engineering strain at fracture is fairly constant from ambient temperature up to about $400{ }^{\circ} \mathrm{C}$, but increases above $400{ }^{\circ} \mathrm{C}$. Above $400{ }^{\circ} \mathrm{C}$ the strength of bolts decreases more rapidly than the strength of rolled structural steel, as shown in Fig. 4-13. 
Table 4-2 Engineering and erosion strain values at fracture for A325 and A490 bolts.

\begin{tabular}{|c|c|c|c|c|}
\hline \multirow{2}{*}{ Temperature $\left({ }^{\circ} \mathrm{C}\right)$} & \multicolumn{2}{|c|}{ Engineering Strain at Fracture } & \multicolumn{2}{c|}{ Erosion Strain at Fracture ${ }^{*}$} \\
\cline { 2 - 5 } & A325 & A490 & A325 & A490 \\
\hline 20 & 0.21 & 0.16 & 0.50 & 0.35 \\
\hline 400 & 0.20 & 0.16 & 0.55 & 0.40 \\
\hline 500 & 0.25 & 0.19 & 0.75 & 0.55 \\
\hline 600 & 0.28 & 0.22 & 0.75 & 0.60 \\
\hline
\end{tabular}

${ }^{*}$ Typical element size of 0.06 in $(1.50 \mathrm{~mm})$.

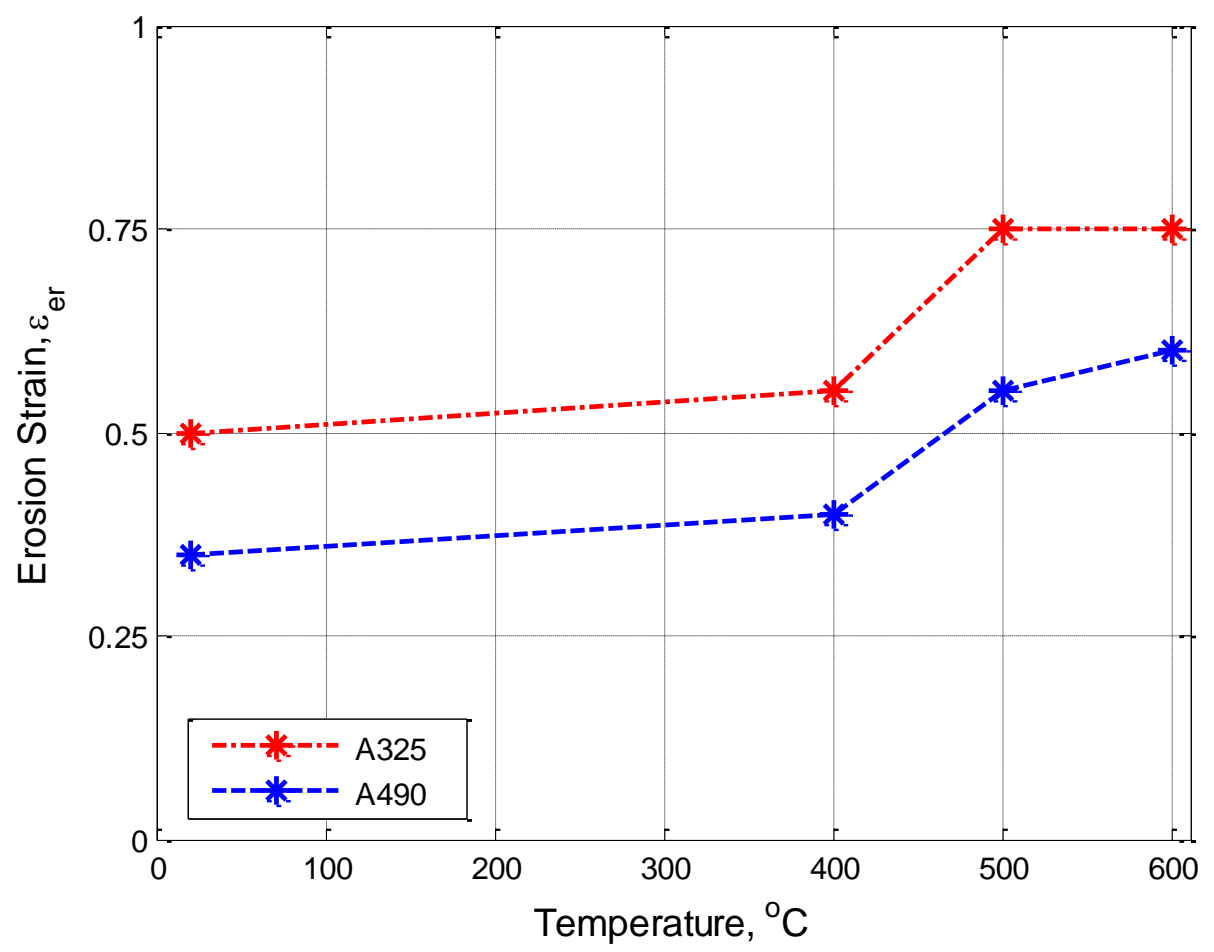

Figure 4-17 Calibrated values of erosion strain versus temperature for A325 and A490 bolts. 


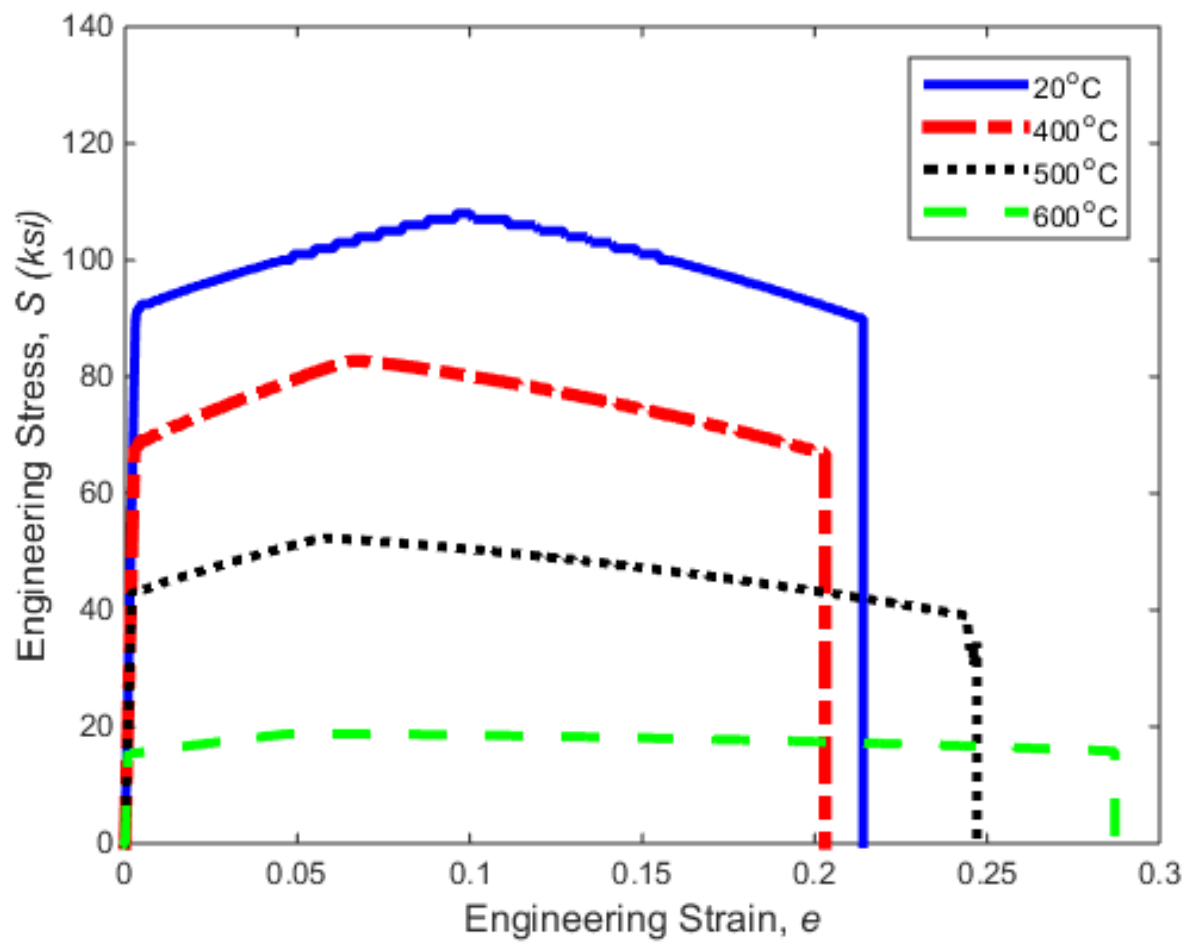

Figure 4-18 Computed stress-strain curves from an FE model of an A325 bolt coupon at elevated temperatures $(1 \mathrm{ksi}=6.895 \mathrm{MPa})$.

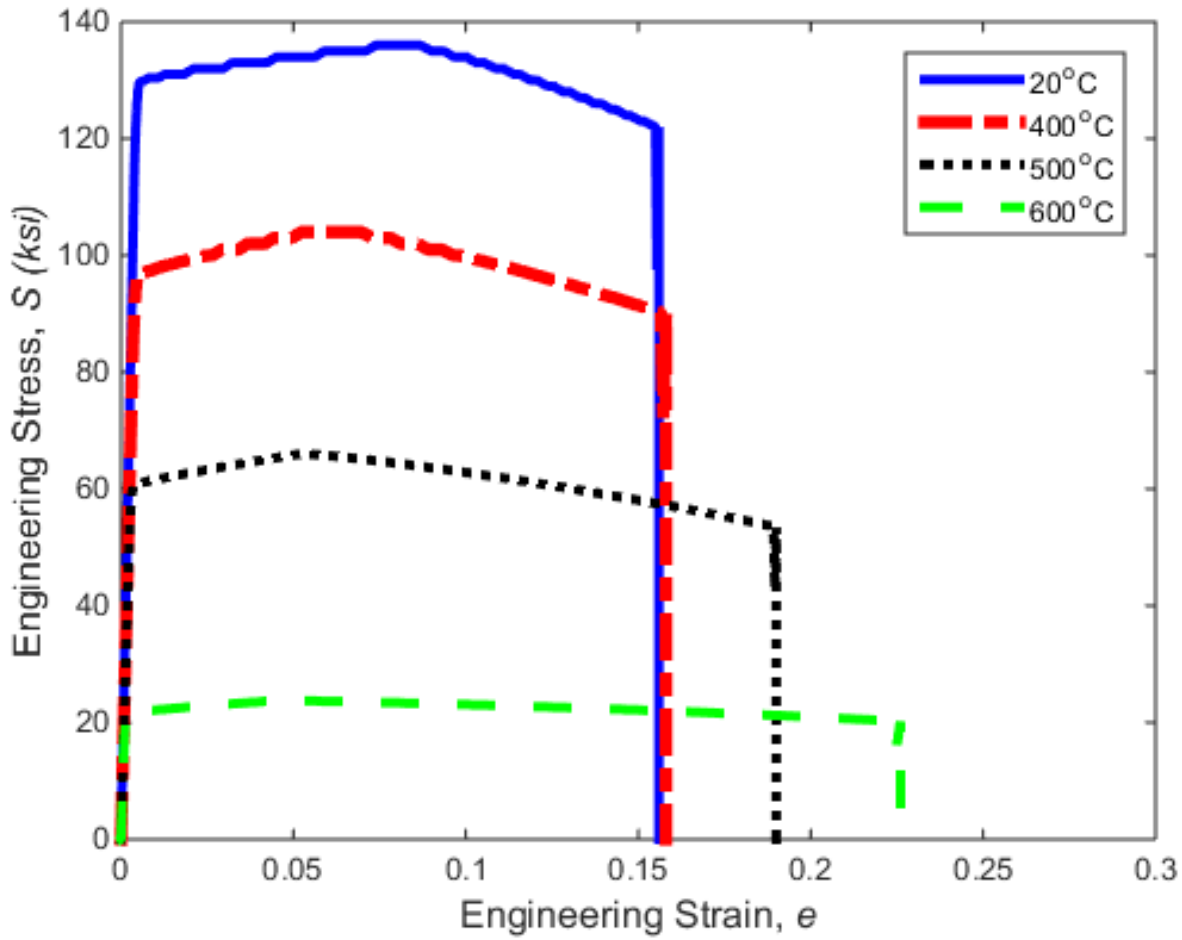

Figure 4-19 Computed stress-strain curves from and FE model of an A490 bolt coupon at elevated temperatures $(1 \mathrm{ksi}=6.895 \mathrm{MPa})$. 


\subsubsection{Performance of Bolts in Shear}

While the material model for structural bolts and the associated erosion strains were developed and calibrated using tensile test data, it is important that the modeling approach is also capable of capturing the behavior and failure of structural bolts in shear. To verify the adequacy of the modeling approach in representing shear behavior, FE analyses of a series of double-shear bolt tests were performed. Solid-element models of bolt double-shear specimens were developed, with dimensions corresponding to tests conducted by Wallaert and Fisher (1965) at ambient temperature. Material properties for ASTM A36 steel (ASTM International 2012a) were used for modeling the bearing plates, which are comparable to the properties of the steel plates used in the tests. Due to symmetry, only half of each specimen was modeled, with boundary conditions reflecting the symmetry as shown in Fig. 4-20(a). The center plate was subjected to tensile loading in the analysis, which subjected the bolts to double shear until fracture across the bolt occurred. Fracture initiated when the effective plastic strain in any element reached the specified erosion strain, $\varepsilon_{e r}$, as discussed in previous sections. Fig. 4-20(b) shows the solid-element mesh of the bolt after shear rupture.

(a)

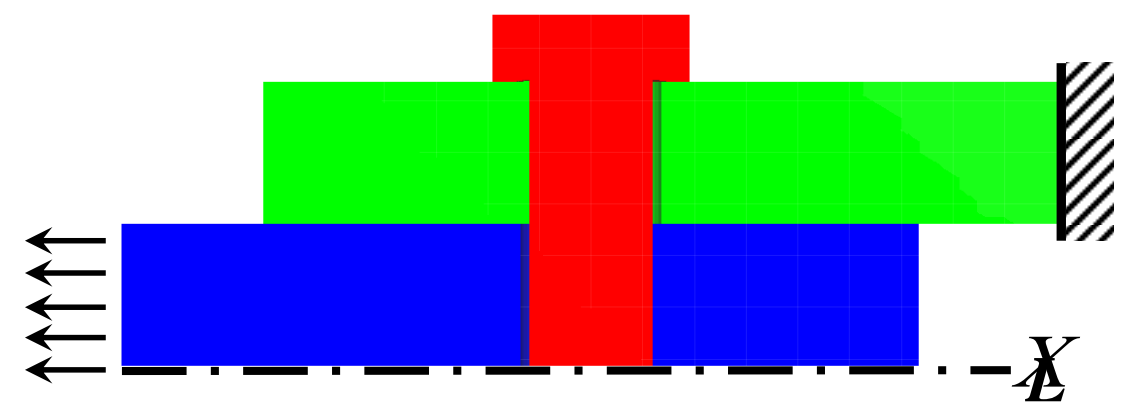

(b)

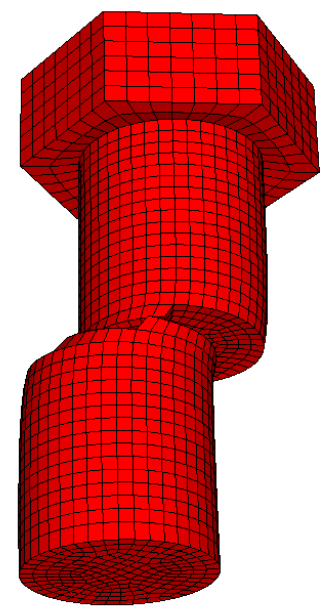

Figure 4-20 Detailed model of a double-shear bolt test: (a) section view, (b) bolt after fracture.

The double-shear analysis results for an A325 bolt at ambient temperature are plotted in Fig. 4-21 with experimental results from Wallaert and Fisher (1965). Note that these experimental curves are best fit to data from several tests; the estimated coefficient of variation in measurements is $4 \%$. At ambient temperatures, the shear capacity of the A325 bolts was $79 \mathrm{ksi}$ (545 MPa), which is within $1 \%$ of the experimental results, and within $5 \%$ of the nominal shear capacity of $75 \mathrm{ksi}$ (517 MPa) specified by the Research Council on Structural Connections (RCSC 2004). The FE results simulated the experimental results reasonably well, particularly for the shear stress at fracture. The test specimen sustained somewhat larger deformations than the FE model before fracture, likely due to the deformations of the plates during the experiment. The shear capacity obtained from the FE model for the A490 bolts at ambient temperature was $96 \mathrm{ksi}$ (660 MPa), 
within $2 \%$ of the nominal shear capacity of $94 \mathrm{ksi}$ (646 MPa) specified by RCSC (2004). Note that the nominal shear capacities reported here were obtained by dividing the nominal shear capacity listed in Table 5.1 of the specification (RCSC 2004) by a factor of 0.80 to eliminate the reduction in strength that accounts for non-uniform shear force distribution, since the shear force is carried by a single bolt.

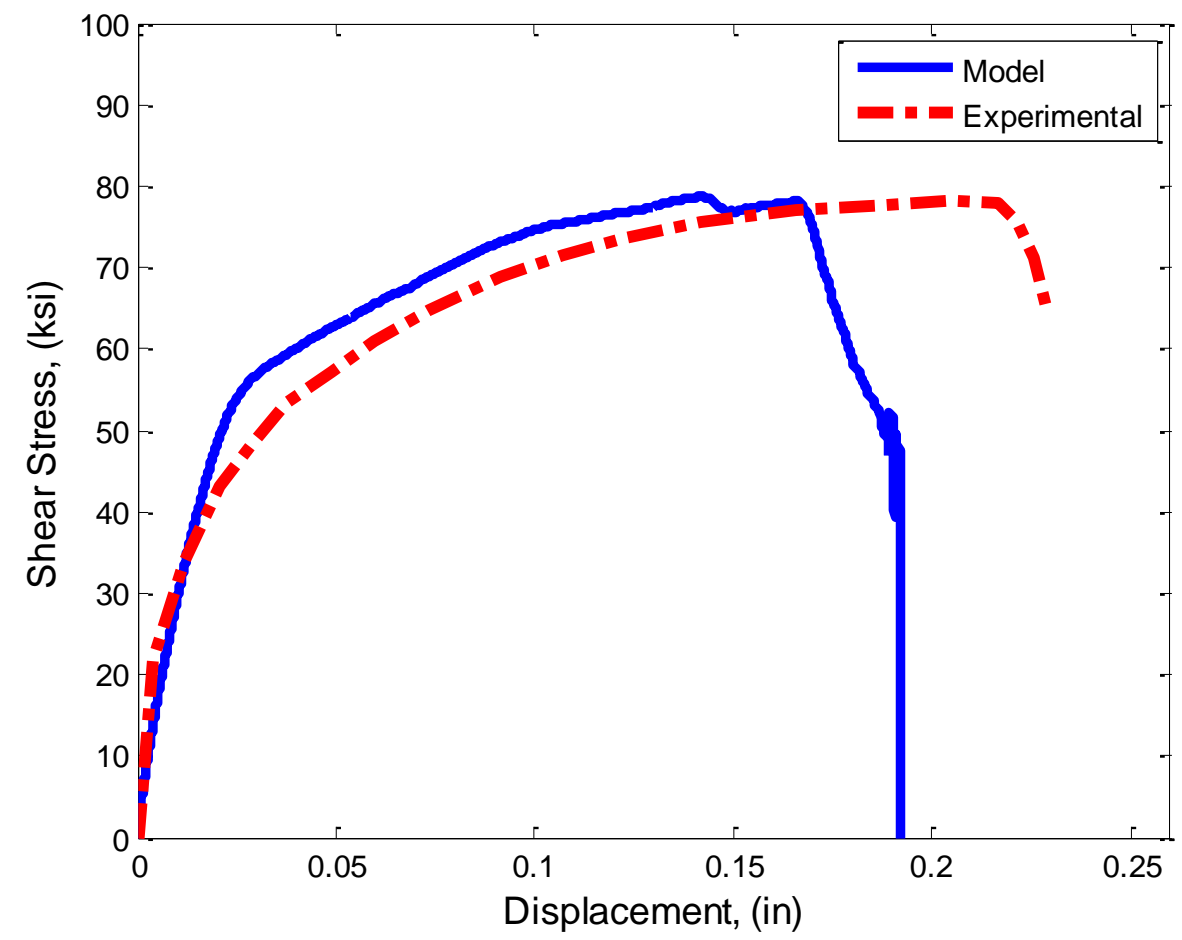

Figure 4-21 FE model and experimental results (Wallaert and Fisher 1965) for shear displacement of an A325 bolt at ambient temperature $(1 \mathrm{ksi}=6.895 \mathrm{MPa})$.

Using the proposed modeling approach for structural bolts, Fig. 4-22 and Fig. 4-23 show shear stress vs. deformation curves for bolt shear failure from the $\mathrm{FE}$ analyses at $20{ }^{\circ} \mathrm{C}, 400{ }^{\circ} \mathrm{C}, 500{ }^{\circ} \mathrm{C}$, and $600{ }^{\circ} \mathrm{C}$, for the A325 and A490 bolts, respectively. Fig. 4-24 shows a comparison of the computed shear strength values for A325 bolts from Fig. 4-22 with experimental measurements reported by $\mathrm{Yu}$ (2006) and by Kodur et al. (2012), with all results normalized by the ambienttemperature shear strength. While there is significant scatter in the experimental data in Fig. 4-24, the computed values are seen to be quite consistent with the measured data, confirming that the proposed modeling approach can capture the degradation in the shear strength of bolts with increasing temperature. 


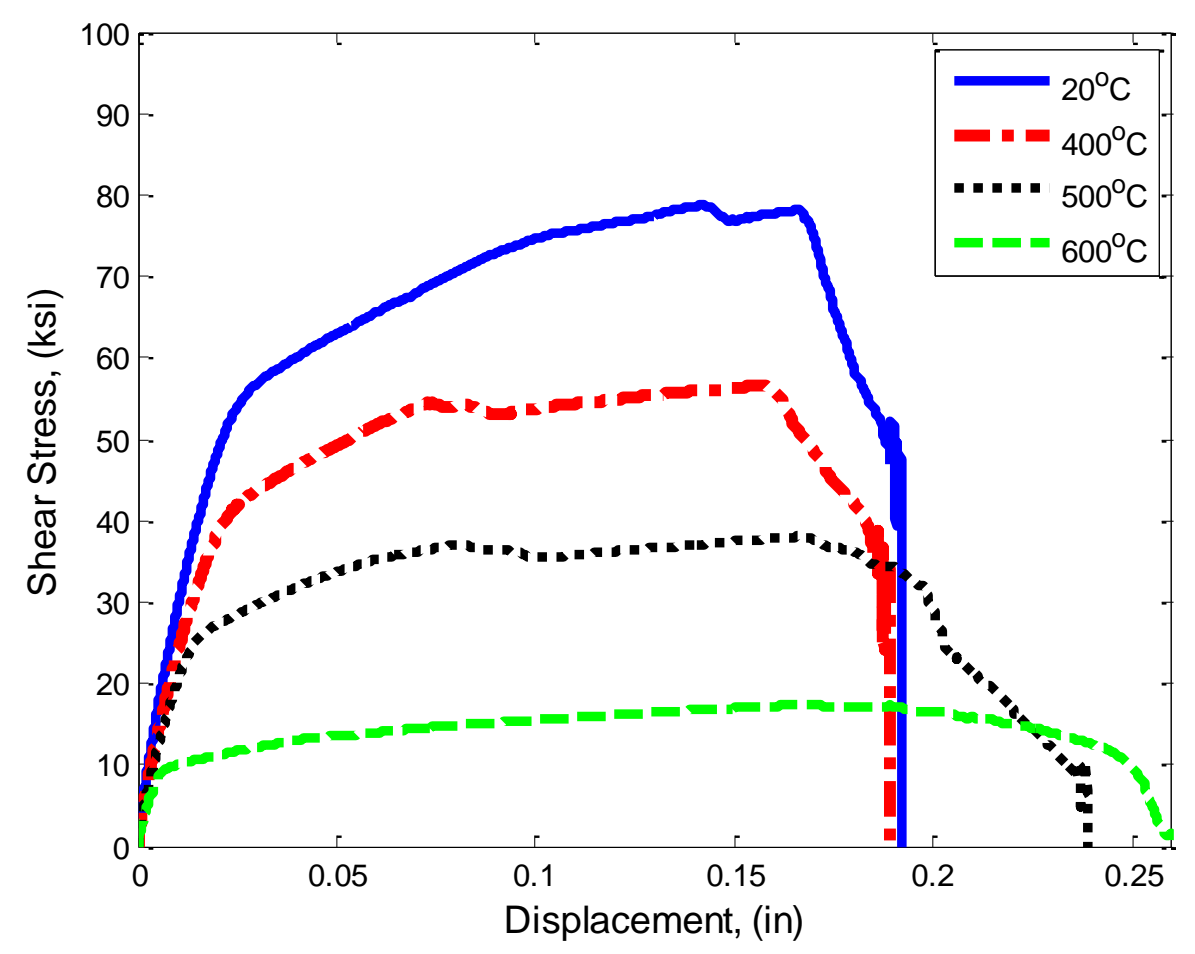

Figure 4-22 FE results for shear displacement of an A325 bolt at selected temperatures $(1 \mathrm{ksi}=6.895 \mathrm{MPa})$.

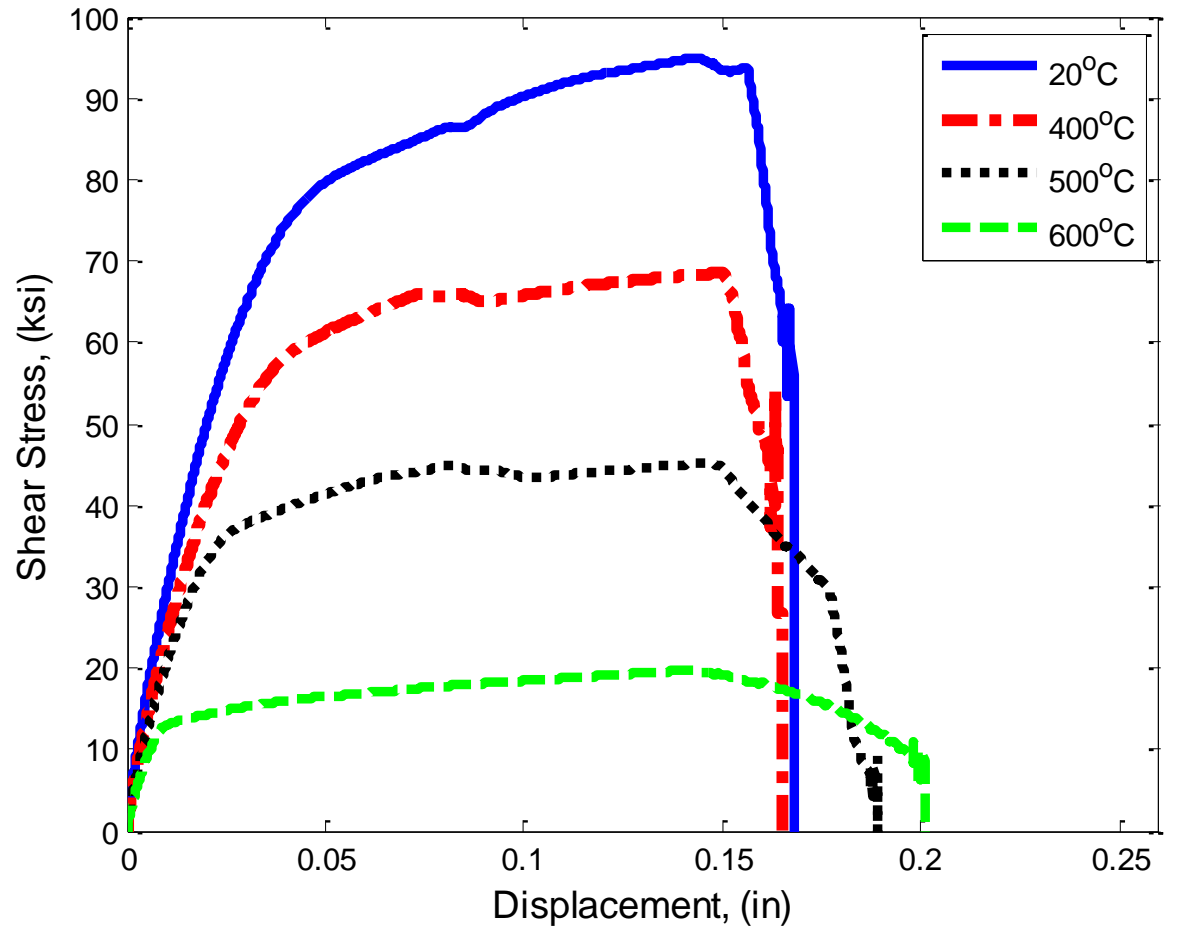

Figure 4-23 FE results for shear displacement of an A490 bolt at selected temperatures $(1 \mathrm{ksi}=6.895 \mathrm{MPa})$. 


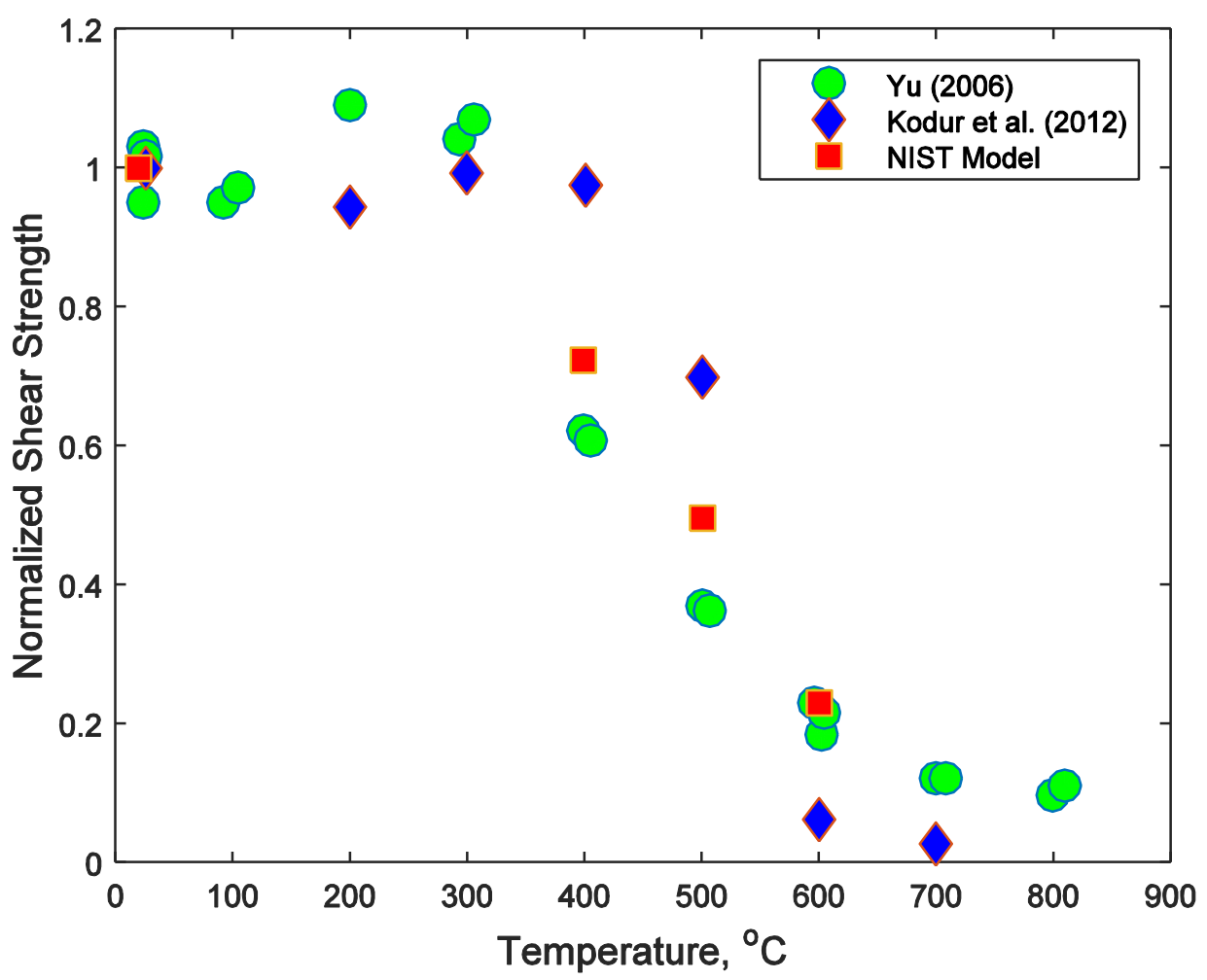

Figure 4-24 Normalized shear strength versus temperature for A325 bolts.

\subsection{SUMMARY, CONCLUSIONS, AND FUTURE WORK}

A practical modeling approach has been developed to represent temperature-dependent nonlinear behavior and failure of structural steel and structural bolts at elevated temperatures, using element erosion to represent material failure. This modeling approach can be used in explicit finite element analyses to represent the successive failures of components in bolted connections under fireinduced heating and the subsequent redistribution of loads. For structural steel materials, a temperature-dependent power-law model was used to represent the true stress-strain behavior up to the onset of necking at the temperature-dependent uniform strain. The uniform strain was determined based on a nonlinear least-squares fit to the uniform strain data for elevated temperatures available in the literature. The post-ultimate behavior was represented using a linear projection of the true stress-strain curve, based on the Considère criterion, to initiate necking at the uniform strain. Due to the more limited experimental data on structural bolts at elevated temperatures, a simpler tri-linear material model was proposed to represent the true stress-strain behavior of structural bolts.

A relatively simple plastic strain-based failure criterion was used to activate element erosion, 
noting that the currently available experimental data on fracture of structural steel and structural bolts at elevated temperatures are insufficient to enable calibration of micromechanics-based models for ductile fracture. Values of erosion strain at elevated temperatures were calibrated against experimental data on the engineering strain at fracture of tensile coupons, using FE models of tensile coupons to determine appropriate erosion strains at each temperature. For structural steels, average failure strains from tensile coupons of ASTM A572 Grade 50 and ASTM A992 steel were used as target values in the calibration of erosion strain. For structural bolts, erosion strains were calibrated separately for ASTM A325 and A490 bolts, using failure strain data from tensile coupons of each type of bolt.

Because the modeling of post-ultimate softening and strain-localization behavior is known to depend on the mesh discretization, FE analyses of tensile coupons were performed with two levels of mesh refinement, to investigate the sensitivity of the results to mesh size. The results were found to be particularly sensitive to mesh size at high temperatures, because of the earlier onset of necking and the more extensive softening behavior prior to fracture. When the element size was reduced by one-half in an $\mathrm{FE}$ analysis of a tensile coupon at $600{ }^{\circ} \mathrm{C}$, with the erosion strain unchanged, the computed engineering strain at fracture was reduced by $44 \%$. The computed results at lower temperatures were less sensitive to the mesh refinement, with their computed engineering strains at fracture reduced by approximately $20 \%$. However, these results confirmed the importance of calibrating erosion strains using the same mesh size that will be used in analyzing the failure of structural components.

Because the material model and erosion strains for structural bolts were developed and calibrated to represent tensile behavior, FE analyses of double-shear test specimens were performed to verify that the model was also capable of representing the behavior of structural bolts under shear loading. The computed shear behavior for an A325 bolt compared well with experimental data at ambient temperature: the ultimate shear capacity was within $1 \%$ of the experimental value, although the experimental displacement at fracture was somewhat higher than that predicted by the FE analysis, likely due to deformation of the plates during the experiment. Comparing to the nominal shear capacities, the shear capacity computed from the FE analyses at ambient temperature was found to be within $5 \%$ for A325 bolts and within $2 \%$ for A490 bolts.

The primary conclusions from this research are:

- Analysis of the available experimental data showed that the uniform strain (i.e., the engineering strain at the onset of necking) decreased with increasing temperature.

- Imposing a reduced stiffness onto the true stress-true strain curve for strains greater than the uniform strain, based on the Considère criterion, was sufficient to initiate necking at the uniform strain at each temperature.

- The fracture strain was dependent on the temperature.

Due to the limitations both in the presented modeling approach and in the currently available experimental data for material behavior and fracture at elevated temperatures, NIST researchers 
are currently planning future work that includes carefully controlled experiments with different levels of triaxiality at different temperatures. These tests will be used to explore ductile fracture characteristics at elevated temperatures. 


\section{Chapter 5 \\ APPLICATION OF MATERIAL AND FAILURE MODELS TO THE ANALYSIS OF STEEL MOMENT CONNECTIONS UNDER FIRE LOADING}

Performance-based methodologies to evaluate the fire-performance of structures are needed to move beyond the prescriptive procedures presently in use. Analytical methods are needed for simulating the performance of structural systems, including connections, subject to realistic fire effects. Framing connections may be subject to large unanticipated deformations and loads during fire events, and connection failure may lead to other failures or local collapse. To achieve this purpose, the materials and failure models, developed in Chapter 2 and Chapter 4, respectively, are used in this chapter to analyze moment-resisting frames to demonstrate how these models can be used for design and evaluation purposes. The performance of steel moment frames under fireinduced heating was investigated using detailed finite-element modeling. Models of two types of seismically designed steel moment frames were developed, including (i) an intermediate moment frame with welded unreinforced flange, bolted web (WUF-B) connections, and (ii) a special moment frame with reduced beam section (RBS) connections. Assemblies consisting of two columns and a single beam span were modeled, with highly refined modeling of the connection regions. Structural analyses were performed under gravity loads in combination with a thermal loading scenario consisting of a heating phase followed by a cooling phase. The temperaturedependent material models for structural steel and bolts (presented in Chapter 2) that incorporate erosion-based modeling of fracture (presented in Chapter 4) were implemented in the study presented in this chapter. The influence of axial restraint on the performance of the moment frames was investigated by considering different support conditions for the end columns.

\section{$5.1 \quad$ INTRODUCTION}

Development of design tools for evaluating fire effects requires adequately accounting for the relevant behaviors and failure modes of members, connections, and systems. Detailed finiteelement (FE) analyses can play an important role in identifying and understanding the relevant behavior and failure modes at elevated temperatures, which can include local buckling and fracture.

During exposure to fire, large axial compressive and/or tensile forces may develop in floor beams and their connections. A number of researchers have studied the effects of fire on connections, though most of the literature addresses shear connections and semi-rigid connections. Sarraj et al. (2007) developed detailed solid element models for shear tab connections with bolts to evaluate bolt shear and bearing behavior. Yu et al. (2009) performed an experimental investigation of the behavior of shear tab connections subjected to vertical shear and tensile forces at elevated temperatures and measured their moment-rotation capacity. Seif et al. (2013) discussed failure 
modes of shear-tab connections at elevated temperatures, while Seif et al. (2014) similarly discussed failure modes of moment connections under similar heating conditions. For moment connections, Yang et al. (2009) conducted experiments on welded moment connections where the connections and members immediately adjacent to the connection were heated up to $650{ }^{\circ} \mathrm{C}$, and then loaded to failure under an applied moment. Yielding, necking, fracture, bolt shear deformation, and local buckling were observed, and a reduction of member stiffness to $25 \%$ of ambient values was reported. Quiel and Garlock (2010) conducted detailed finite element analyses of shear and moment connections for 2D and 3D building frames. Their results indicated that thermal gradients can produce significant changes in the deflection mechanics and the plastic limitstate behavior associated with the interaction of axial forces and bending moments.

This Chapter presents results from a study employing FE analyses with geometric and material nonlinearities, using solid and shell elements to model the failure modes of typical steel moment connections in response to elevated temperatures, using the material model developed in Chapter 2 and the failure model developed in Chapter 4. The purpose of the analyses is to examine the applicability of the material and failure models into the analysis of subsystems, and to gain better insights into the behavior of moment connections, including failure modes, when subjected to fire exposure and various restraining conditions. The results presented illustrate the behavior and failure modes of connections and assemblies under varying load, temperature, and boundary conditions.

\subsection{PROTOTYPE MOMENT FRAMES}

As described in Lew et al. (2013), the National Institute of Standards and Technology (NIST) worked with a panel of practicing structural engineers across the U.S. to develop a number of prototype steel-frame building designs for use in assessing the robustness of structural systems. The buildings were designed according to the American Society of Civil Engineers 7-02 standard (ASCE 2002) and its referenced material design standards, including the American Institute of Steel Construction (AISC) Load and Resistance Factor Design Specification for Structural Steel Buildings (AISC 1999) and the AISC Seismic Provisions for Structural Steel Buildings (AISC 2002). Two types of moment frames from the prototype buildings were selected for analysis in this study. These included an intermediate moment frame (IMF) with welded unreinforced flange, bolted web (WUF-B) connections, and a special moment frame (SMF) with reduced beam section (RBS) connections. The assemblies considered in this study were portions of these moment frames consisting of a beam supported on two columns and joined using two moment connections. Fig. 5-1 shows a sketch of a typical assembly. 


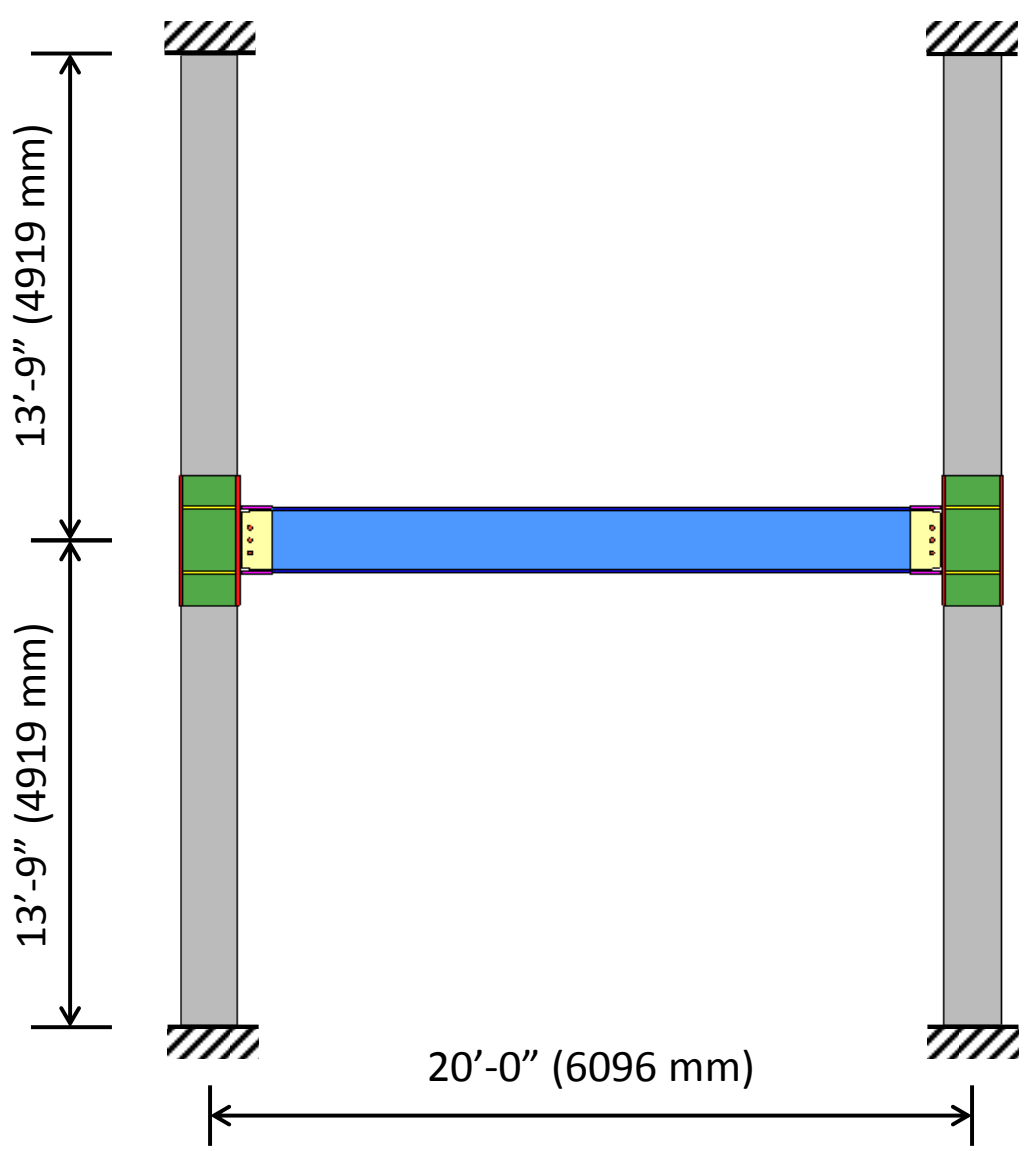

Figure 5-1 Sketch of a typical assembly.

$(1 \mathrm{ft}=0.305 \mathrm{~m}, 1 \mathrm{in}=25.4 \mathrm{~mm})$

The moment-frame assembly with WUF-B connections was taken from the second-floor level of a seismically designed IMF in a 10-story prototype building designed for Seismic Design Category C. Fig. 5-2 shows details of the WUF-B connection used in the IMF assembly considered in this study. The beam flanges are joined to the column flange using complete joint penetration (CJP) groove welds. ASTM A992 structural steel, with an ambient-temperature nominal specified yield strength of $F_{y 0}=50 \mathrm{ksi}\left(345 \mathrm{MPa}\right.$ ) was used in all beams and columns. ASTM A36 steel, with $F_{y 0}$ $=36 \mathrm{ksi}(248 \mathrm{MPa})$ was used for the shear tabs and continuity plates at the beam-column connections. ASTM A490 bolts, with $F_{y 0}=130 \mathrm{ksi}(896 \mathrm{MPa})$, were used to connect the shear tab to the beam web. 


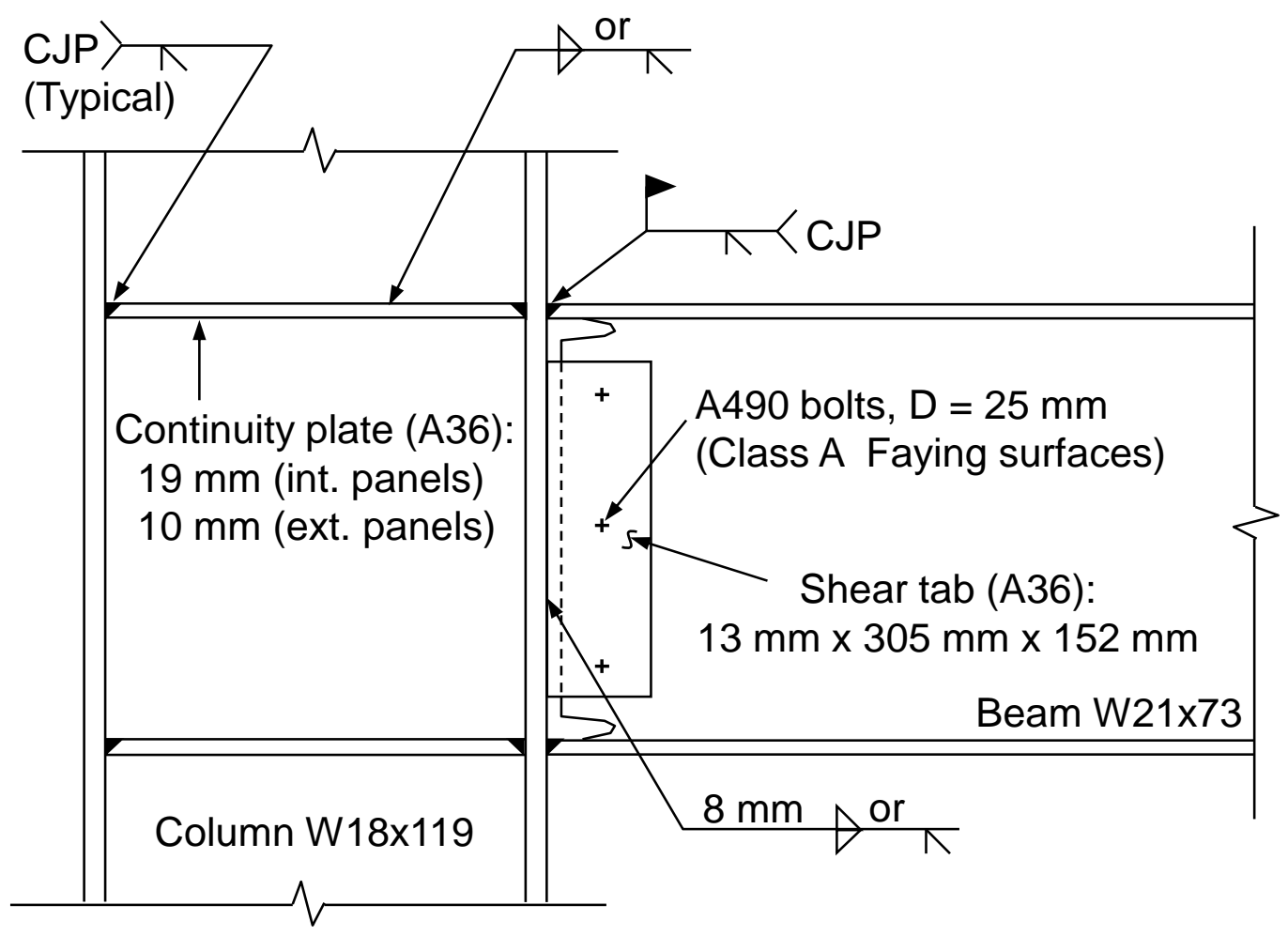

Figure 5-2 Details of WUF-B moment connection.

$(1 \mathrm{in}=25.4 \mathrm{~mm})$

Similarly, the moment-frame assembly with RBS connections was taken from the second-floor level of a seismically designed SMF in a 10-story prototype building designed for Seismic Design Category D. The RBS connection is created by cutting away a portion of the top and bottom flanges of the beam at a distance from the beam-column interface so that yielding is concentrated in this reduced area. Therefore, the reduced section acts as a structural fuse to protect the connection against premature fracture. Fig. 5-3 shows details of the RBS connection used in the SMF assembly considered in this study. ASTM A992 structural steel was used for the beams and columns. 


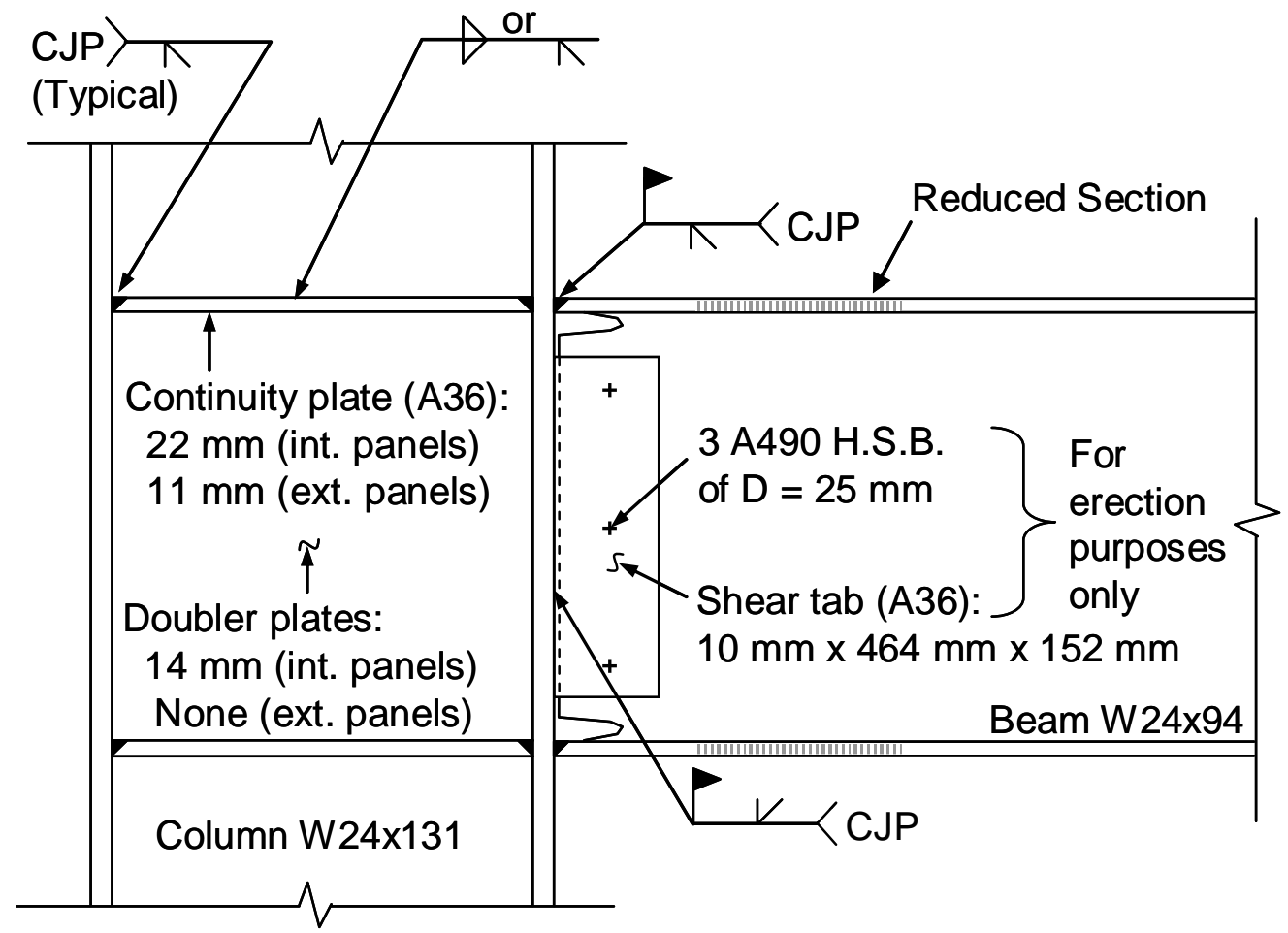

Figure 5-3 Details of WUF-B moment connection.

$(1 \mathrm{in}=25.4 \mathrm{~mm})$

\subsection{MODELING AND ANALYSIS OF MOMENT-FRAME ASSEMBLIES}

Detailed nonlinear FE analyses were conducted to simulate the behavior and failure modes of the moment-frame assemblies under elevated temperatures. All analyses were performed using explicit time integration in LS-DYNA (LSTC 2012). In each analysis, the assembly was subjected to a uniform gravity load along the beam (applied along the centerline of the top flange), as well as a prescribed temperature time history for the beam and connections. The columns were unheated. The gravity load applied to the beam is from a 1.2(Dead Load) +0.5 (Live Load) combination of $113 \mathrm{psf}(5.41 \mathrm{kPa})$ on the adjacent slabs (refer to Main and Sadek (2012) for a discussion of gravity loads on the prototype buildings). The gravity load was gradually applied over $0.5 \mathrm{~s}$ to avoid any dynamic amplification. The temperature time history, which is illustrated in Fig. 5-4, included both a heating phase and a cooling phase. The temperature was gradually ramped up from ambient temperature $\left(20^{\circ} \mathrm{C}\right)$ to a peak temperature, was held constant at the peak temperature, and then was dropped back to ambient temperature. It was assumed that the material properties of structural steel are similar in compression and tension (heating and cooling). Most analyses considered a uniform temperature for the beams and connections, with a peak temperature of $700{ }^{\circ} \mathrm{C}$, while specific analyses considered the influence of a temperature gradient through the beam depth and of heating to a lower peak temperature. Different restraint conditions for the columns at beam level were also considered, and details of the specific analysis cases considered are presented in Section 5.4. 


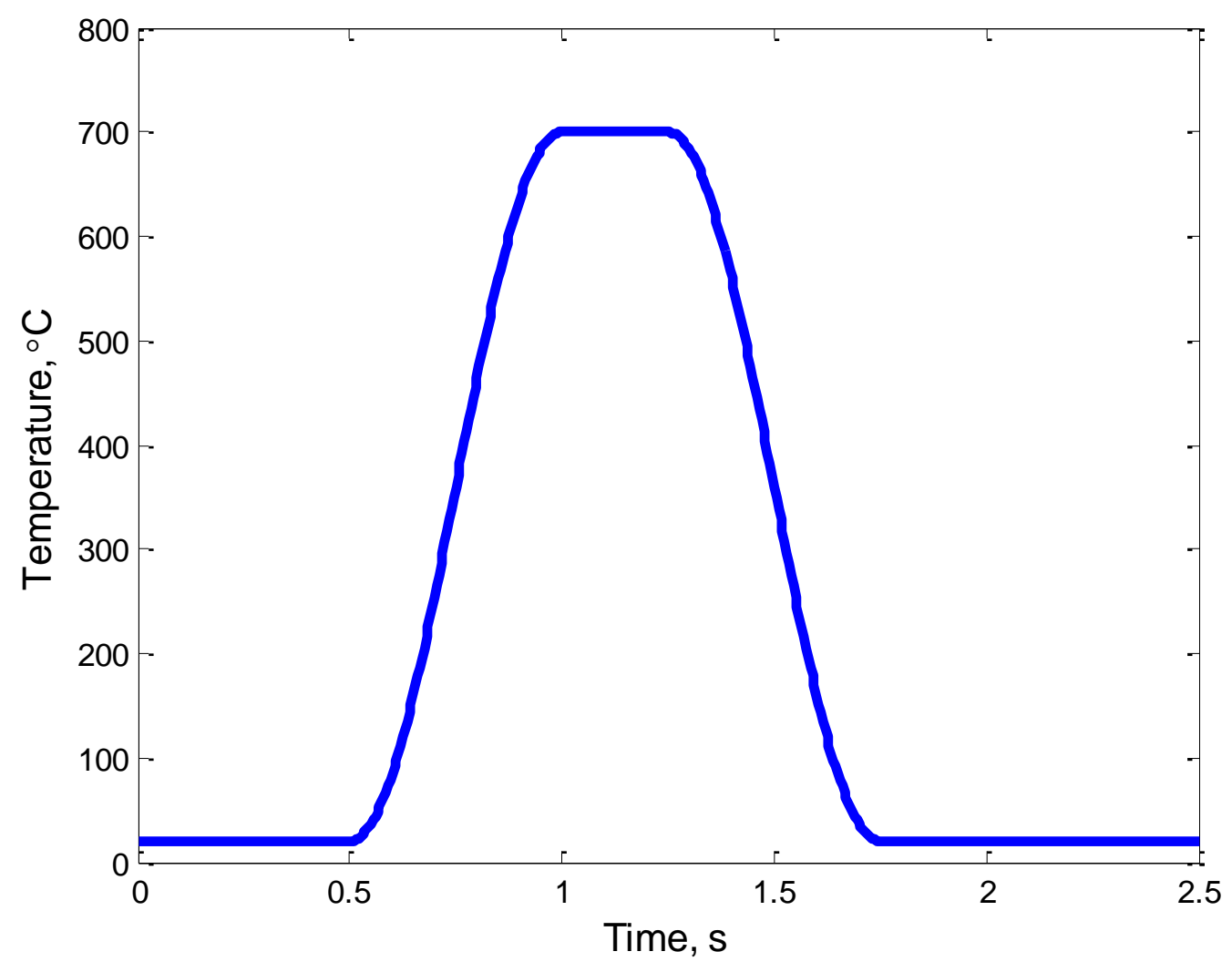

Figure 5-4 Temperature loading profile.

The WUF-B connections in the IMF assembly (Fig. 5-2) were modeled using finely meshed threedimensional solid elements for the beam, bolts, and shear tab, as shown in Fig. 5-5. Fully integrated eight-node solid elements were used. A typical element size of 0.12 in $(3 \mathrm{~mm})$ was used for the beam and the shear tab. A finer mesh with a typical element size of 0.06 in $(1.5 \mathrm{~mm})$ was used for the bolts. Contact was defined between the bolts, shear tab, and beam web to model the transfer of forces through the bolted connection, including friction, with a value of 0.3 assumed for both the static and dynamic coefficients of friction. No pre-tension in the bolts was considered in the analyses, because experimental and computational results have shown that pre-tension slightly affects the initial response of a bolt in shear but does not significantly affect the ultimate behavior or fracture of the bolt (see Kulak et al. (1986)). Fracture was modeled using element erosion, in which elements were removed from the analysis when specified failure criteria were satisfied, as discussed in Chapter 4. Element erosion was activated only for the solid elements. Outside of the connection regions, the beams and columns were modeled using shell elements, and nodal constraints were used to enforce continuity of displacements and rotations at the interfaces between the solid and shell elements. 
(a)

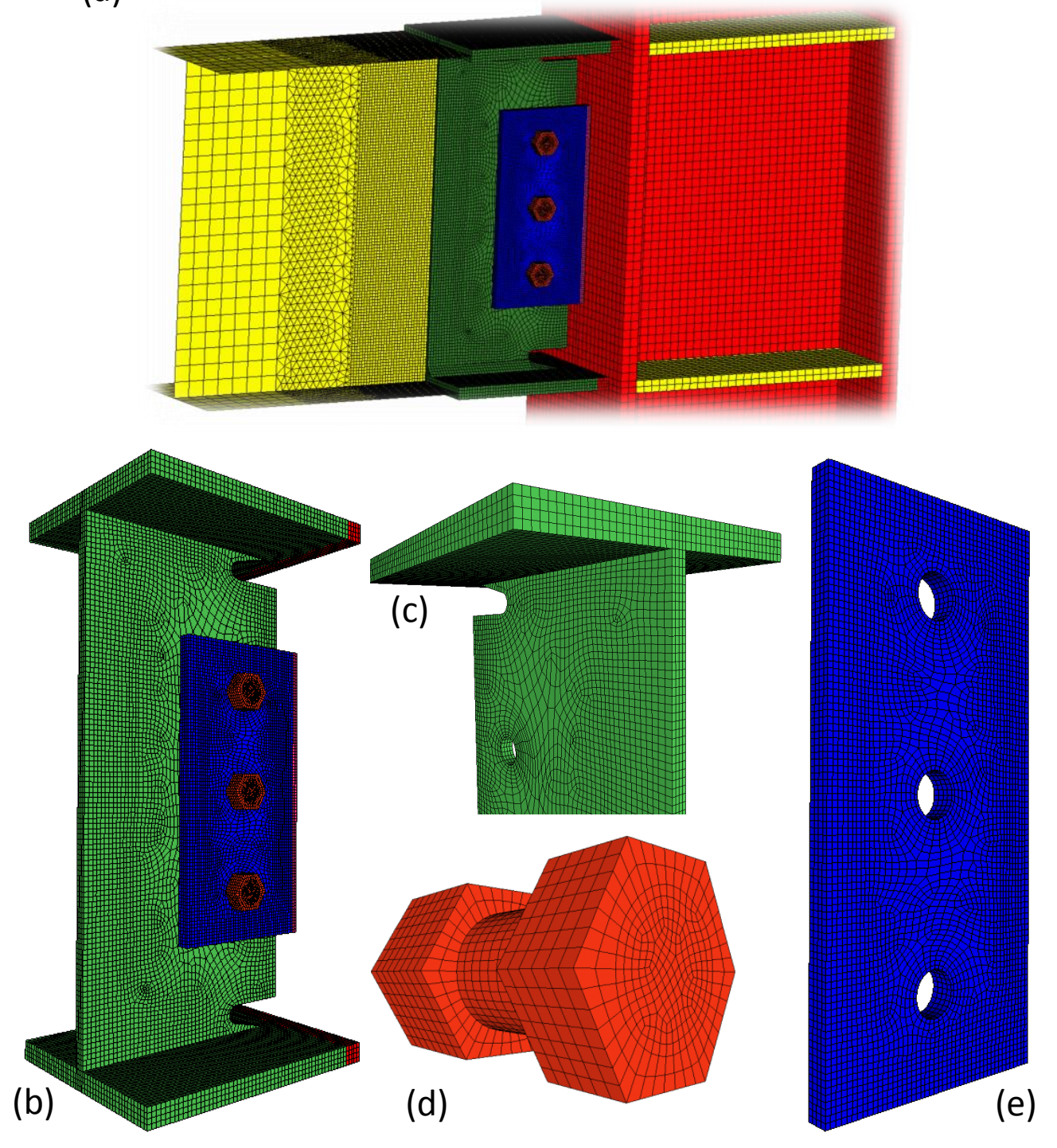

Figure 5-5 Finite-element mesh of the WUF-B assembly: (a) connection region, (b) beam with bolted shear tab, (c) beam, (d) bolt, and (e) shear tab.

The RBS connections in the SMF assembly (Fig. 5-3) were modeled using finely meshed twodimensional shell elements, as shown in Fig. 5-6. The reduced section of the beam was modeled using a fine mesh with an average element size of about 0.50 in $(12.7 \mathrm{~mm})$. Away from the reduced section, a coarser mesh was used, with an element size of about 1 in $(25.4 \mathrm{~mm})$. Fully integrated four-node shell elements were used. Fracture was considered in the analyses using element erosion, and the temperature-dependent erosion strain values were calibrated against experimental data for the specific mesh size used in the model, as discussed below. The following section discusses the temperature-dependent material models used for the various components of the assemblies at elevated temperatures. 


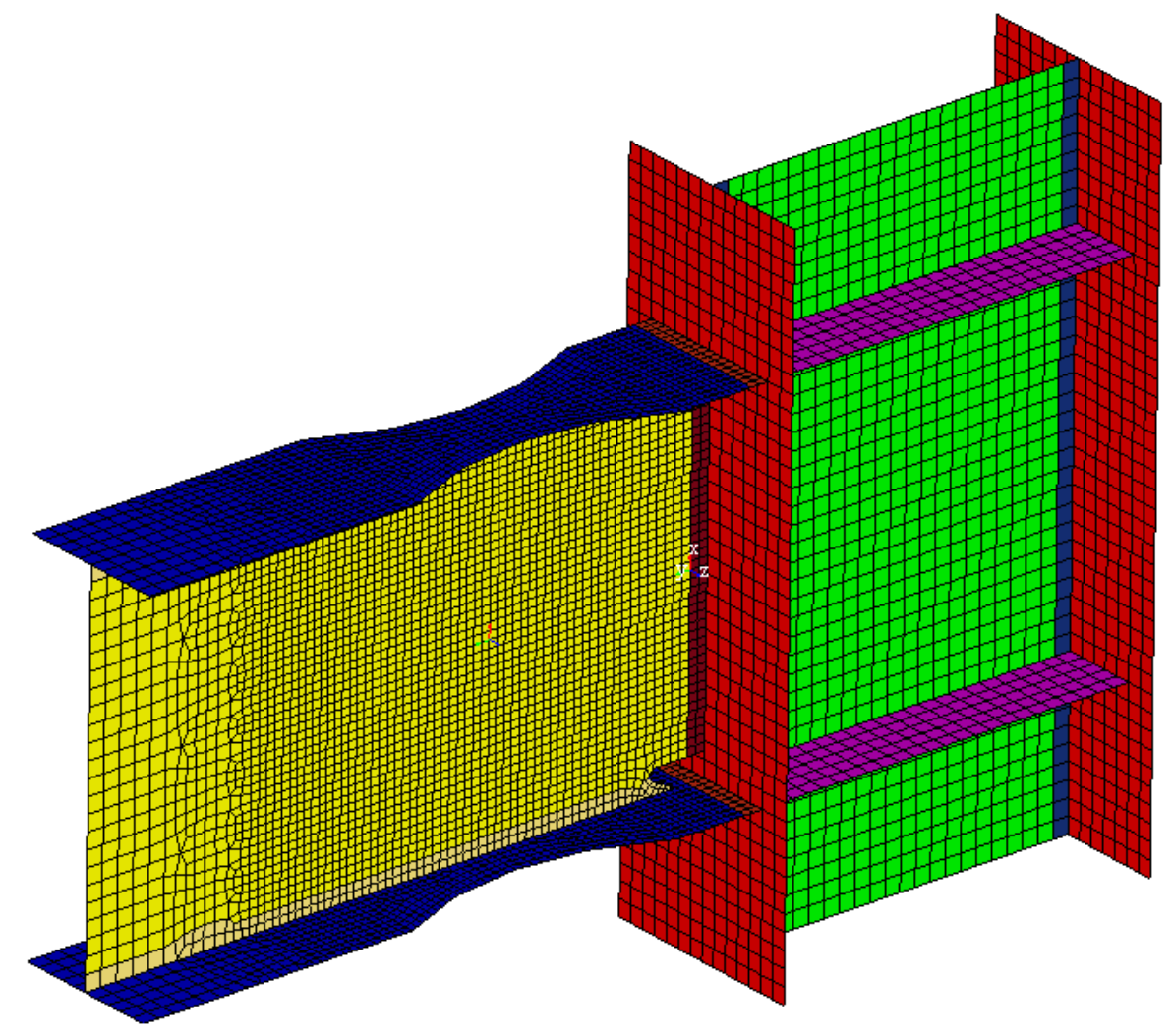

Figure 5-6 Detailed model of the RBS connection.

The stress-strain behavior for structural steel and bolts discussed in Chapter 2, along with the modeling of fracture discussed in Chapter 4 are used herein to capture failure modes such as tearout in connection plates and bolt shear rupture.

As noted in Chapter 4, the erosion strains, $\varepsilon_{e}$, are mesh dependent, and must be calibrated for the specific element size in the area where fracture is expected. For the solid elements used in the critical zones of the WUF-B connections, the mesh density was the same as that used for calibrating the erosion strains, $\varepsilon_{e r}$, in Section 4.3.3, thus those values (values are given in Table 4-1, and presented on Fig. 4-11) were used for the analysis of the IMF assemblies. However, a similar approach was needed to calibrate the required erosion strains for the shell elements used in the SMF assemblies herein. Thus, to calibrate the required strains, solid elements with the same mesh density used for the original calibration, along with their associated erosion strain values were used to model a 2 in gauge coupon. The engineering fracture strains, $\varepsilon f$, at which these coupons fractured were used as the target fracture strains for the shell elements. The 2 in gauge coupons were then modeled using shell elements with a mesh density as that used for the modeling of the RBS connections (shown in Fig. 5-6), and the required erosion strains were calibrated to match the target fracture strains. Fig. 5-7 shows the 2 in-gauge coupon models used for the calibration analysis, and Fig. 5-8 shows the calibrated erosion strains at different temperatures. 

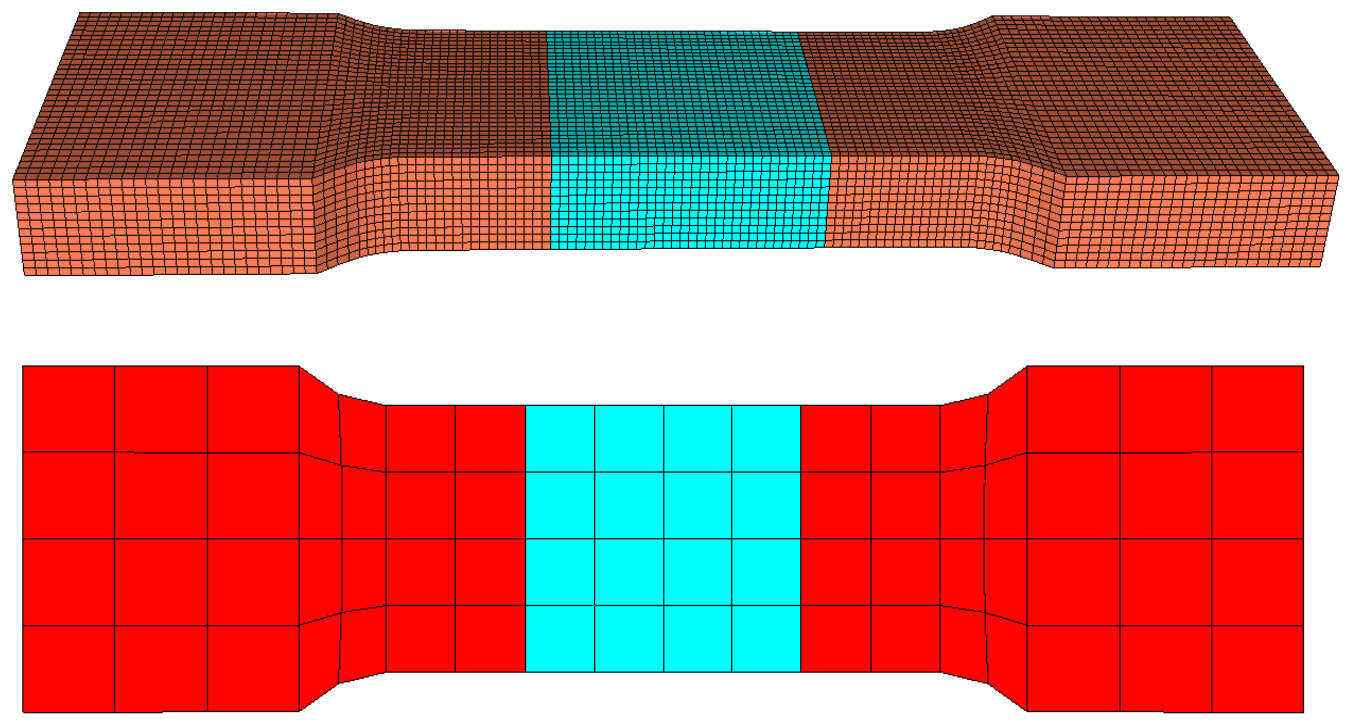

Figure 5-7 Finite element mesh of the 2 in-gauge tensile coupon $(a)$ solid elements, $($ b) shell elements $(1$ in $=$ $25.4 \mathrm{~mm})$.

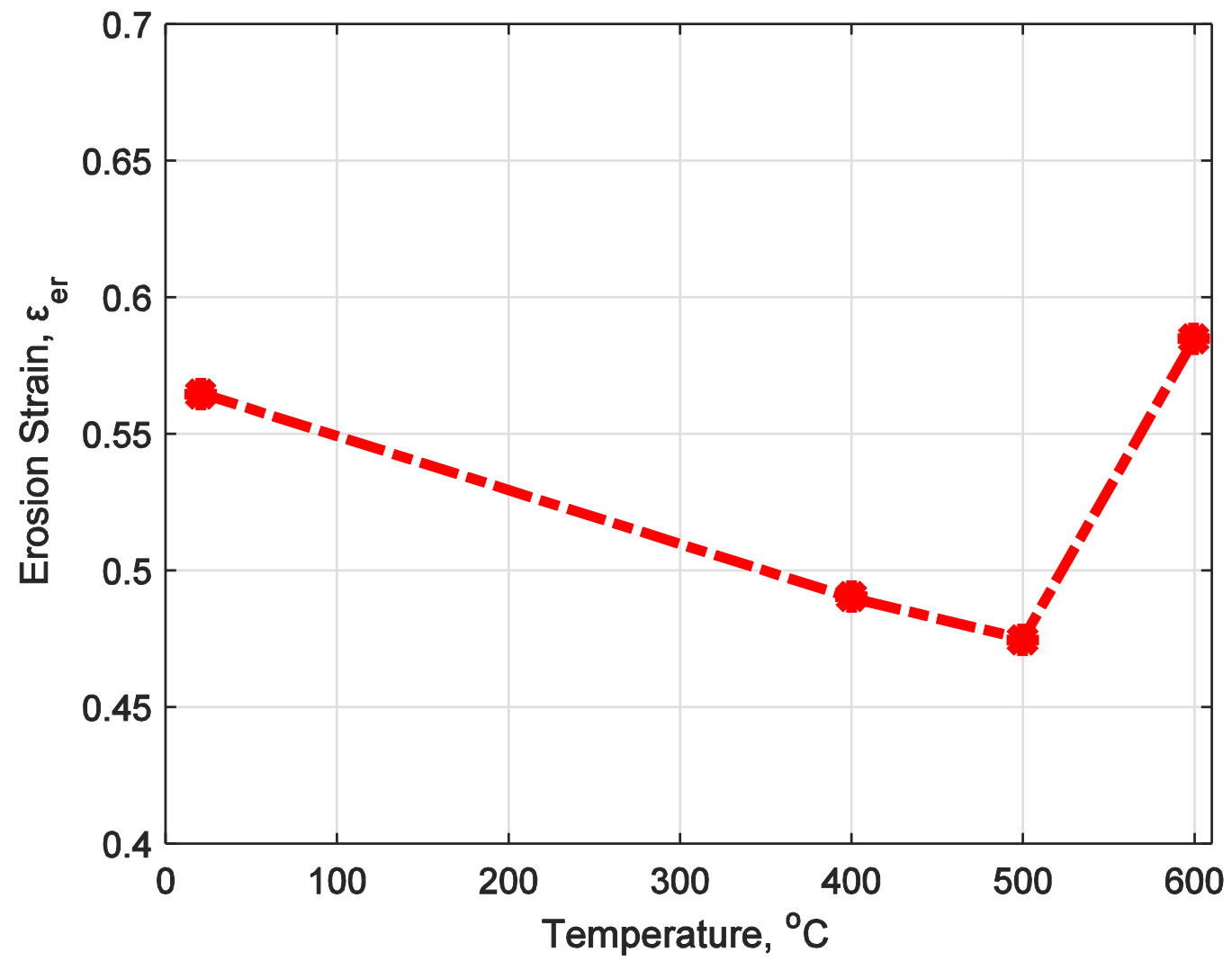

Figure 5-8 Calibrated values of erosion strain versus temperature for structural steel using shell elements for the RBS connection. 


\section{$5.4 \quad$ RESULTS AND DISCUSSION}

The discussion in this section focuses on the behavior and failure modes of the moment-frame assemblies.

\subsubsection{IMF Assembly}

As illustrated in Fig. 5-9, three cases are considered for the IMF assembly with WUF-B connections: (a) an assembly with fully constrained beam ends (assuming perfect rigidity of adjacent spans), (b) an assembly with unconstrained beam ends (assuming no adjacent spans), and (c) a three-span assembly, with the outer bays modeled using beam elements and reduced-order connection models and kept at ambient temperature (see Sadek et al. (2013) for a description of these reduced-order models). Fig. 5-10 shows the axial force in the beam plotted against the prescribed temperature for each of these three analysis cases. The results for each case are discussed in the following sections.

(a)

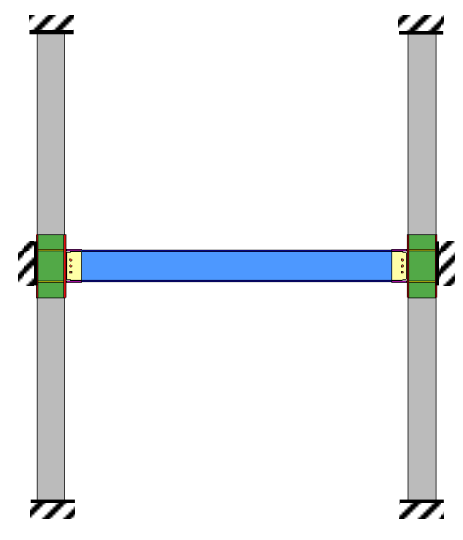

(c)

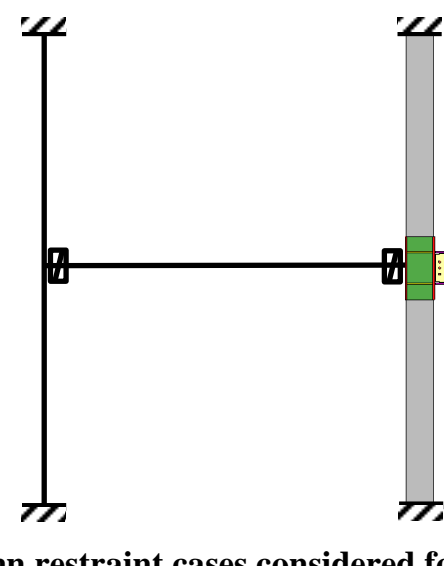

(b)
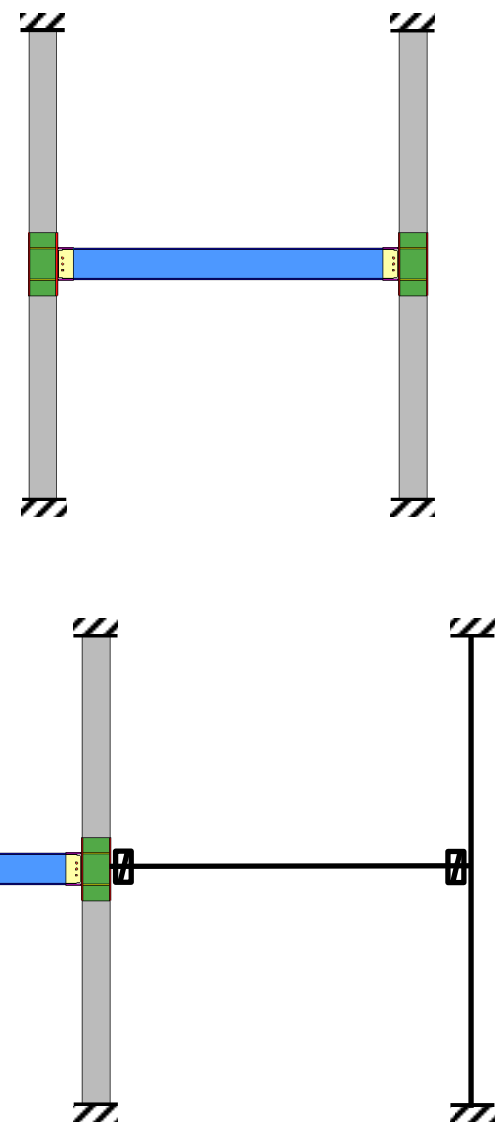

Figure 5-9 Column restraint cases considered for the IMF assembly: (a) fully constrained, (b) unconstrained, and (c) three-span. 


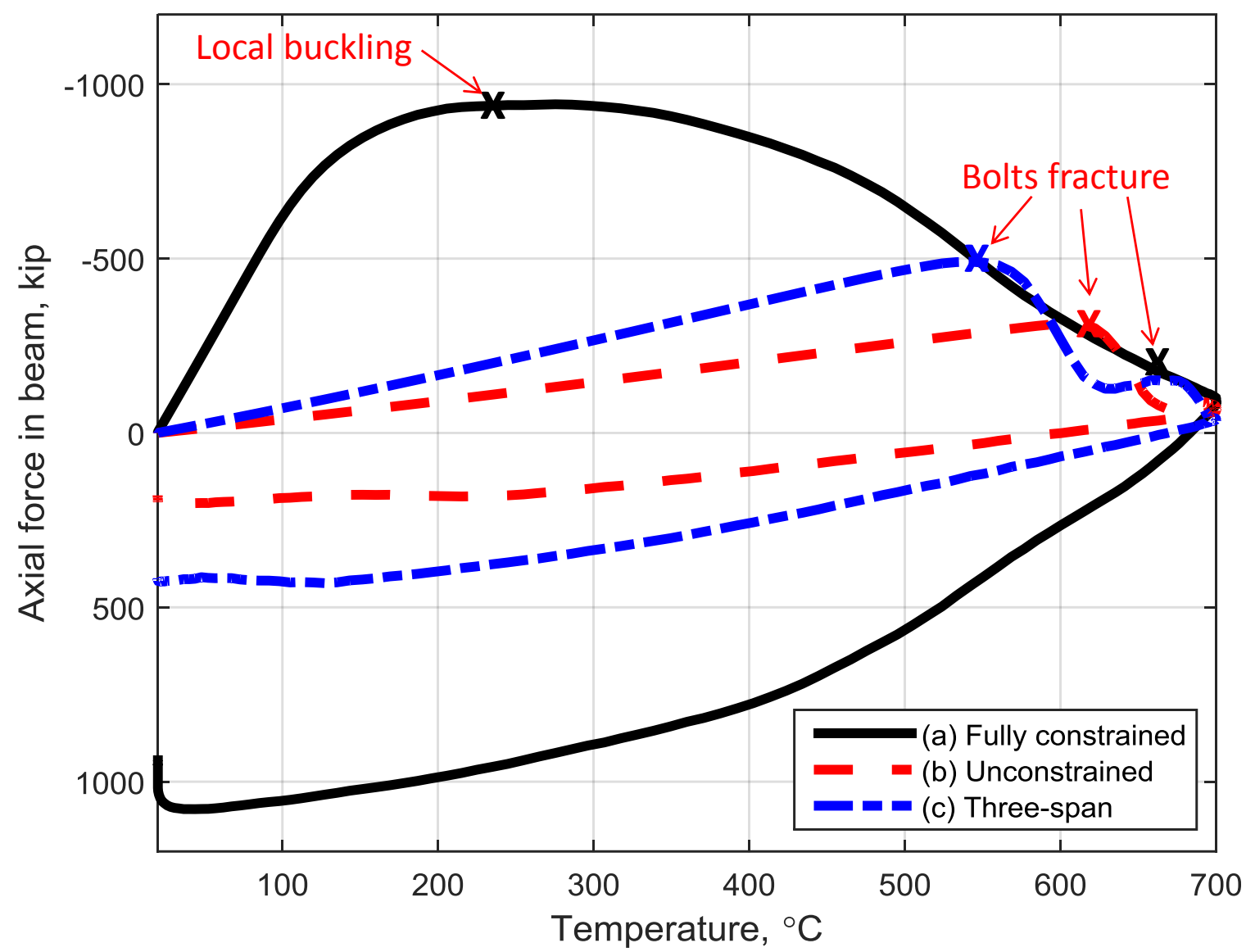

Figure 5-10 Axial forces in the beam versus temperature for the different WUF-B assembly cases (1 kip = $4.448 \mathrm{kN})$.

\subsubsection{Fully constrained assembly}

For the case of the fully constrained assembly, the beam was not allowed to expand beyond its original length. This led to high axial compressive forces in the beam and connections at relatively low temperatures in the heating phase. As shown in Fig. 5-10, the compressive axial force in the beam reached a peak value of about $944 \mathrm{kip}(4200 \mathrm{kN})$, at $225^{\circ} \mathrm{C}$. At this point, the connection failed in a local buckling mode, relieving the axial compression in the beam. As the beam continued to heat, the buckled connection deformations increased and the forces in the beam continued to decrease. When the temperature reached about $610^{\circ} \mathrm{C}$, the bolts fractured in shear, and the load continued to decrease until it reached about $10 \%$ of its peak value at $700{ }^{\circ} \mathrm{C}$. Fig. $5-11$ shows the local buckling mode of the connection at the end of the heating phase of the analysis for the fully constrained WUF-B assembly. 
In the cooling phase, the axial compression in the beam reversed into high tensile forces, partially reversing the buckled connection deformations. The axial tension in the beam reached a peak of about $1080 \mathrm{kip}(4804 \mathrm{kN})$ as the beam cooled to about $45^{\circ} \mathrm{C}$, triggering partial fracture of both the upper and lower beam flanges at the welds to the column face, as the strains exceeded the specified values for the erosion strains, $\varepsilon_{e r}$. However, the extent of fracture was small, and the connection was able to sustain the applied gravity loads throughout the analysis without collapsing.

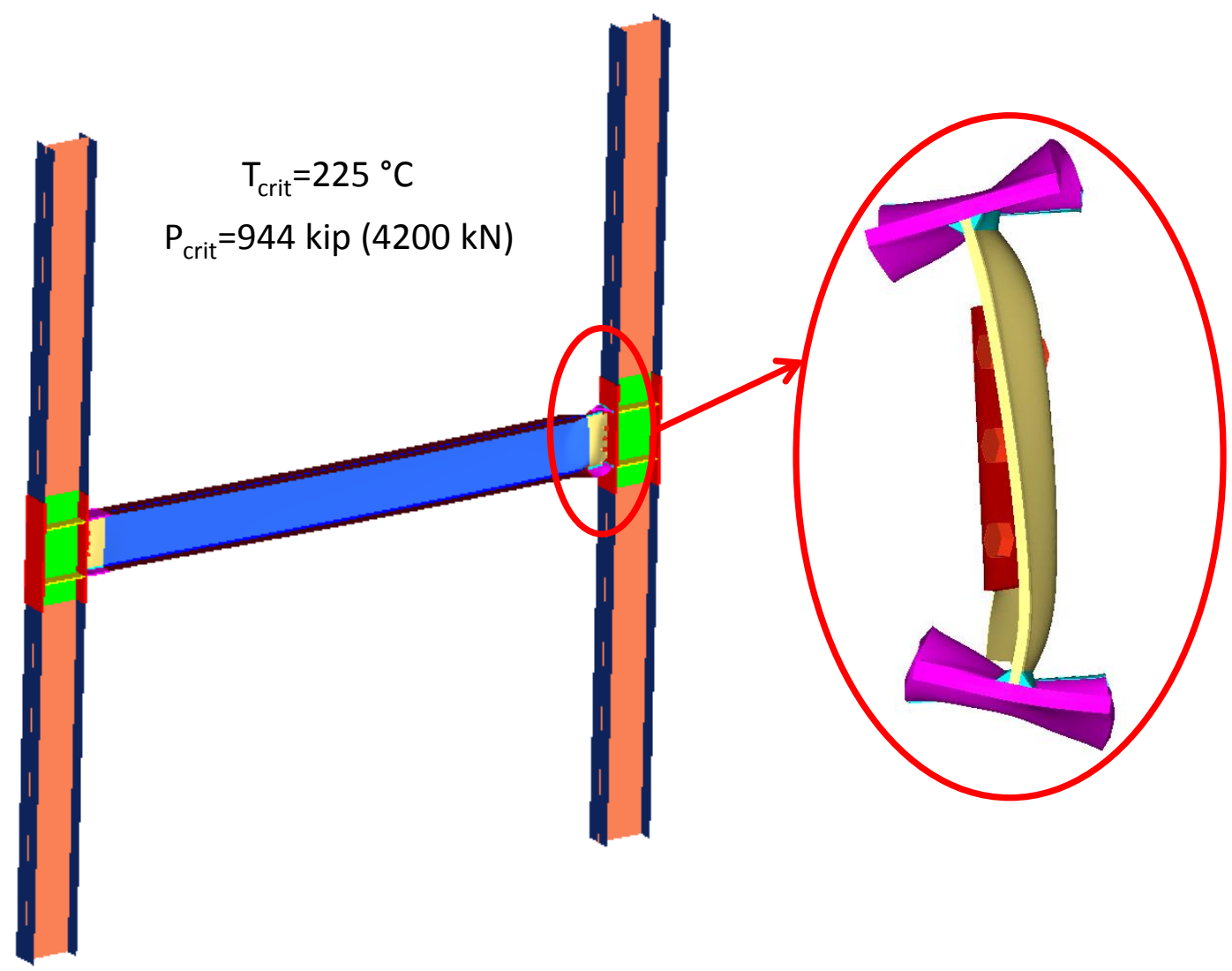

Figure 5-11 Local buckling mode of the connection at the end of the heating phase of the analysis of the fully constrained WUF-B assembly.

\subsubsection{Unconstrained assembly}

For the unconstrained assembly case, the beams were allowed to expand as they were only constrained by the stiffness of the columns (as a one-span assembly, with no beam continuity). Compared to the fully constrained assembly, this case led to much lower compressive forces in the beam and connections, at relatively higher temperatures in the heating phase. As seen in Fig. 5-10, the compressive axial force in the beam reached a peak value of $316 \mathrm{kip}(1406 \mathrm{kN})$ at $610{ }^{\circ} \mathrm{C}$, roughly one third of the force at nearly $400{ }^{\circ} \mathrm{C}$ higher temperature compared to the fully constrained case. At this point, the bolts in the connection failed due to shear fracture, in a manner similar to what was observed in Chapter 4, relieving the axial compression in the beam, and the 
beam's flanges deformed under gravity loads, as shown in Fig. 5-12. In the cooling phase, the axial compression in the beam reversed into tensile forces, partially reversing the flange deformations. The axial tension in the beam reached a peak of about $209 \mathrm{kip}(930 \mathrm{kN})$ as the beam cooled (about $20 \%$ of the peak tensile force reached in the fully constrained case). The strains due to the tensile forces did not exceed $\varepsilon_{e r}$, and as a result no fracture was observed in the analysis.

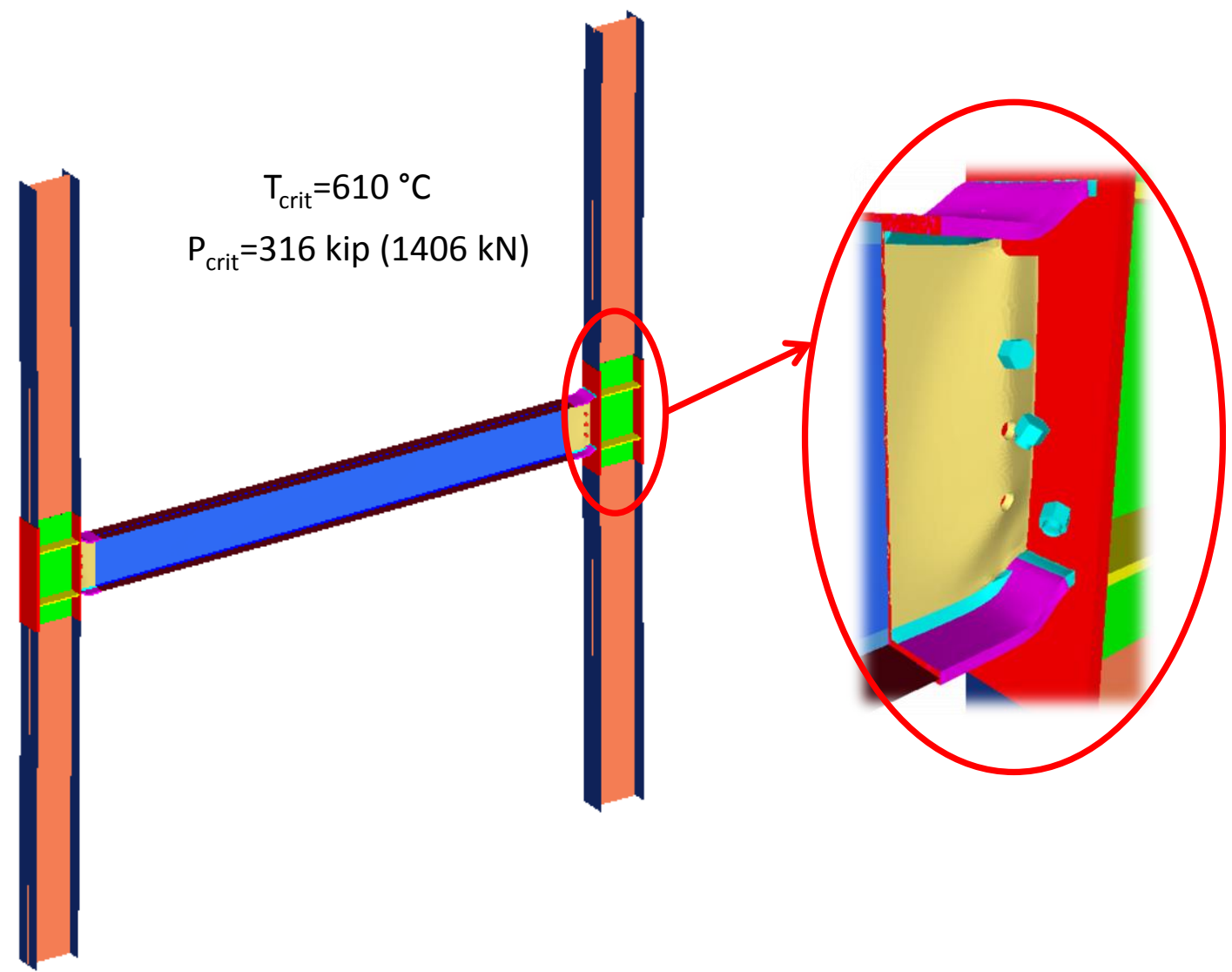

Figure 5-12 Failure mode of the connection at the end of the heating phase of the analysis of the unconstrained WUF-B assembly.

\subsubsection{Three-span assembly}

A three-span assembly, as illustrated in Fig. 5-9(c), was studied as an intermediate case between the fully constrained and the unconstrained assemblies. Gravity loads and prescribed temperature were only applied to the center span. The outer spans were included to more realistically capture the influence of adjoining framing in restraining thermal expansion. The three-span assembly exhibited the same failure mode as the unconstrained assembly, with the bolts fracturing in shear and the flanges deforming under gravity loads (see Fig. 5-12). However, as expected, higher compressive forces were generated in the beam and connections at slightly lower temperatures in the heating phase. In the cooling phase, the axial compression again reversed into tensile forces, 
reaching a peak of about $432 \mathrm{kip}(1922 \mathrm{kN})$ as the beam cooled (more than double the peak tensile force in the unconstrained case).

\subsubsection{SMF Assembly}

As listed in Table 5-1, four cases were considered for the SMF assembly with RBS connections: (a) an assembly with fully constrained beam ends (assuming rigid beams on adjacent spans, similar to the sketch in Fig. 9(a), (b) an assembly with unconstrained beam ends (assuming no continuity of beam, similar to the sketch in Fig. 9(b), and (c) an unconstrained assembly heated with a temperature gradient across the cross-section. Fig. 5-13 shows the axial force in the beam plotted against the prescribed temperature for all cases except case (c). Each case is discussed in detail in the following sections. It is noted that the gravity load was sustained in all cases without collapse.

Table 5-1 Analysis cases considered for the SMF assembly.

\begin{tabular}{c|l|l} 
Case & Beam end support & \multicolumn{1}{|c}{ Thermal loading } \\
\hline (a) & Fully constrained & Heated to $700{ }^{\circ} \mathrm{C}$ \\
\hline (b) & Unconstrained & Heated to $700{ }^{\circ} \mathrm{C}$ \\
\hline (c) & Unconstrained & Heated to $700{ }^{\circ} \mathrm{C}$ (with gradient)
\end{tabular}




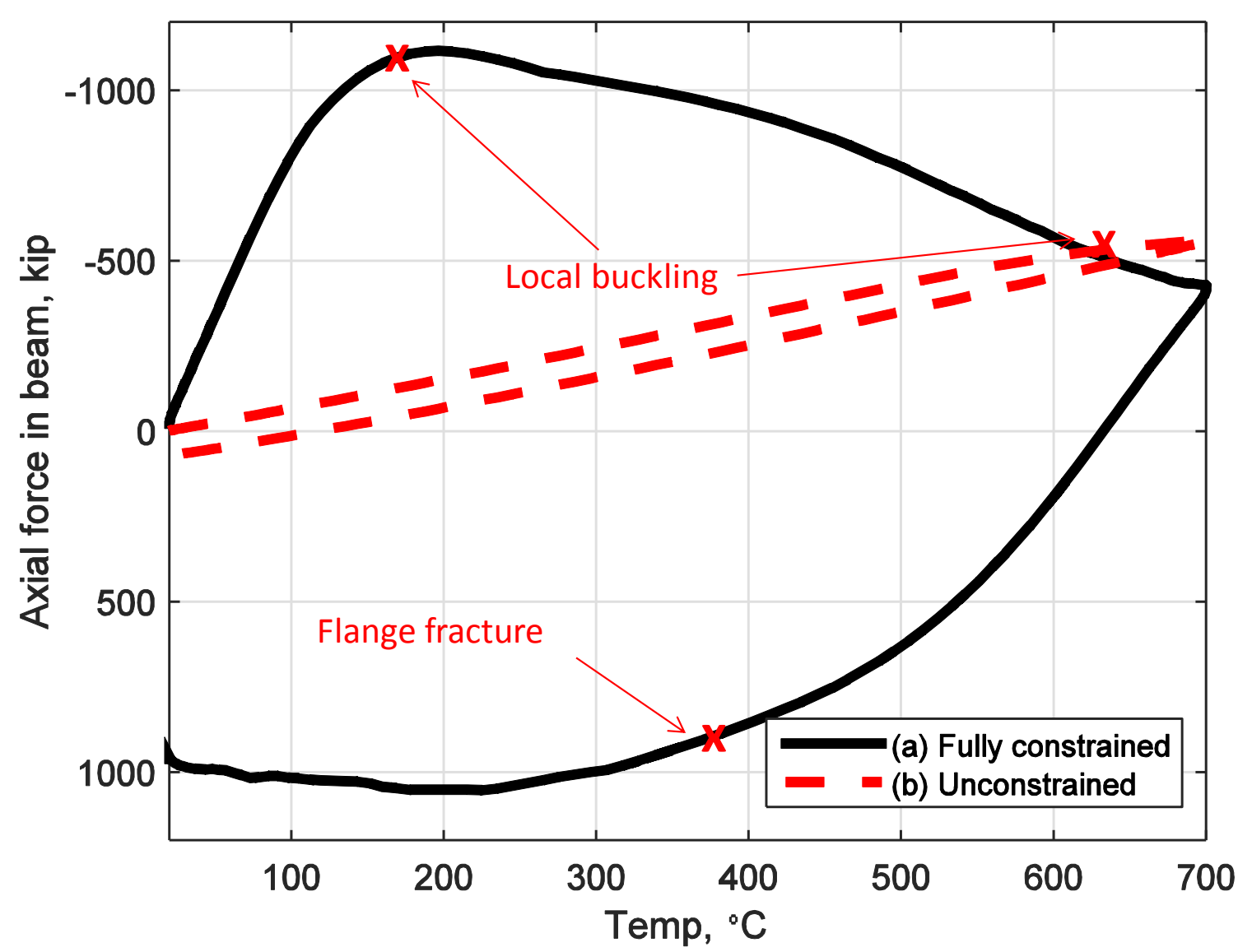

Figure 5-13 Axial force in the beam versus the temperature for the different RBS assembly cases.

$(1 \mathrm{kip}=4.448 \mathrm{kN})$

\subsubsection{Fully constrained assembly}

As noted previously for the IMF assembly, in the fully constrained case, the beam in the SMF assembly was not allowed to expand beyond its original length. This led to higher compressive forces in the beam and connections at lower temperatures in the heating phase. As shown in Fig. 5-13, the axial compression in the beam reached a peak value of $1226 \mathrm{kip}(5454 \mathrm{kN})$ at $175^{\circ} \mathrm{C}$. At this point, the RBS connection failed in a local buckling mode, relieving the axial compression in the beam. As the beam continued to heat, buckling deformations increased, and the axial force in the beam continued to decrease until it reached about $35 \%$ of its peak load at $700{ }^{\circ} \mathrm{C}$. Fig. 5-14(a) shows the buckling failure mode of the RBS connection towards the end of the heating phase in the analysis of the fully constrained assembly.

In the cooling phase, the axial compression reversed into high tensile forces, partially reversing the buckled connection deformations. The axial tension reached a peak value of $1050 \mathrm{kip}$ $(4670 \mathrm{kN})$ as the beam cooled to ambient temperature. As the beam cooled, at about $380{ }^{\circ} \mathrm{C}$, fracture initiated in the top flange. The beam was under a tensile force of about $920 \mathrm{kip}(4092 \mathrm{kN})$ 
when fracture initiated. As the beam cooled further, the fracture started to open and propagate, leading to a near-complete fracture through the top flange and ultimately to partial fracture in the web, as shown in Fig. 5-14(b). However, the intact portion of the web, and the intact lower flange, were able to sustain the applied gravity loads throughout without collapsing.
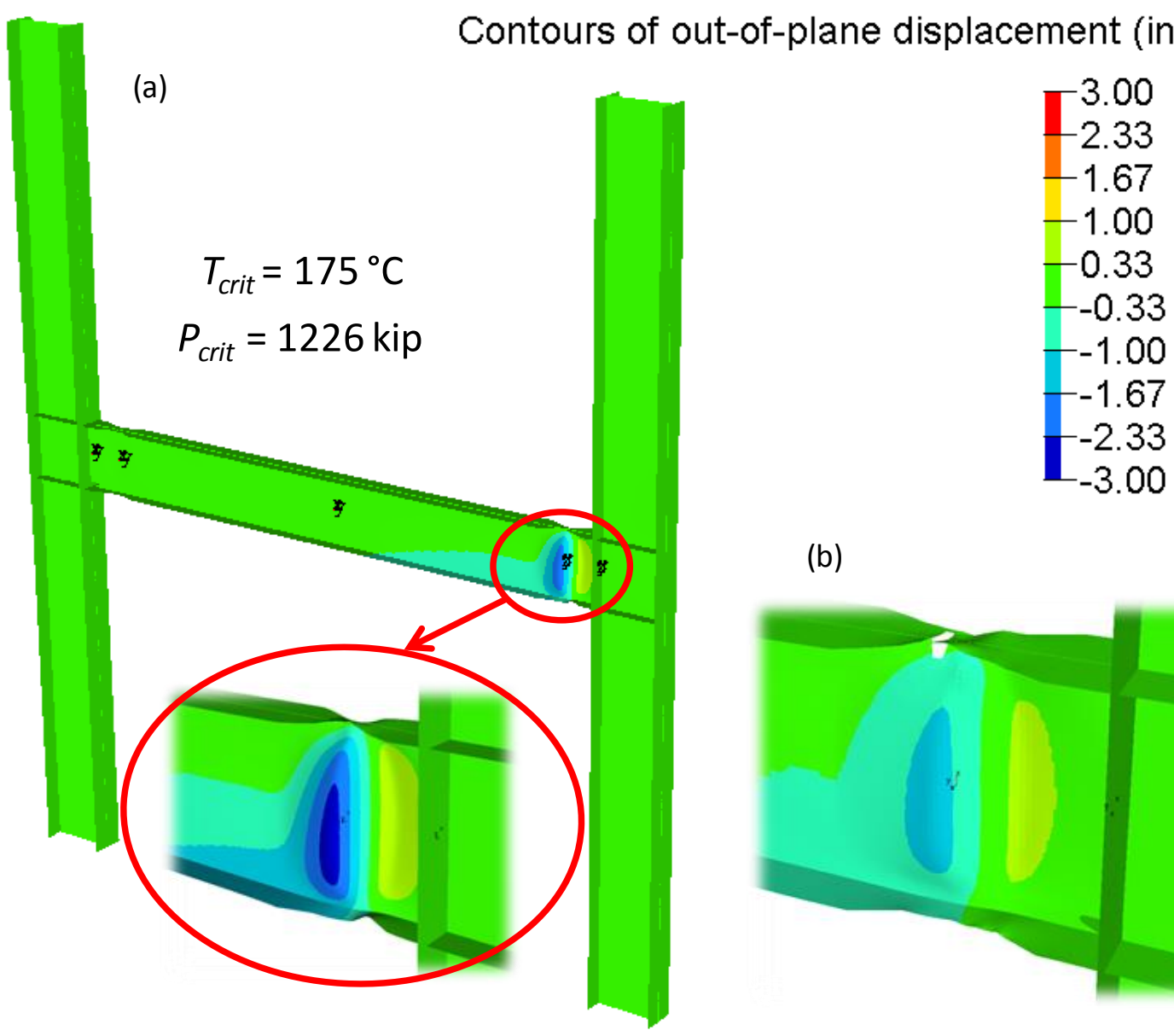

(b)

Figure 5-14 RBS connection failure modes for the fully constrained SMF assembly: (a) local buckling of connection during heating phase; (b) partial fracture during cooling phase. $(1 \mathrm{in}=25.4 \mathrm{~mm})$

\subsubsection{Unconstrained assembly}

The unconstrained SMF assembly exhibited a similar buckling failure mode to the fully constrained assembly during the heated phase, but with smaller buckling deformations. As shown on Fig. 5-13, much lower compressive forces were generated in the beam and connections in the heating phase, relative to the fully constrained assembly. Again, in the cooling phase, the axial compression reversed into relatively low tensile forces. The axial tension reached a peak value of about $75 \mathrm{kip}(334 \mathrm{kN})$ at the end of the cooling phase, roughly one third of the peak axial tension generated in the fully constrained case. The strains developed in the cooling phase did not exceed $\varepsilon_{e r}$, and therefore, no fracture was observed. 


\subsubsection{Unconstrained assembly, with gradient temperature}

The unconstrained SMF assembly was analyzed with a temperature gradient through the beam depth, which may be a more realistic temperature distribution when heat conduction can occur from the top flange into the cooler floor slab above. The same time history shown in Fig. 5-4 was used. However, the temperature reached $700{ }^{\circ} \mathrm{C}$ only at the bottom flange. An approximately linear profile through the depth was assumed, reaching a peak temperature of $200{ }^{\circ} \mathrm{C}$ at the top flange. Fig. 5-15 shows the axial force in the beam plotted against the bottom-flange temperature for this case. Similar to the unconstrained SMF assembly with uniform temperature distribution [Fig. 5-14(a)], the assembly with the gradient distribution failed through local buckling of the RBS connection. However, in the gradient-temperature case, the peak axial compression developed in the beam during the heating phase was $250 \mathrm{kip}(1112 \mathrm{kN})$ at $575^{\circ} \mathrm{C}$, less than half of the compressive force developed in the uniform-temperature case. The axial compressive forces were smaller because the cooler upper portion of the beam had less thermal expansion than in the uniform-temperature case. In the cooling phase, the axial compression again reversed into tensile forces. The peak axial tension in the cooling phase was about $114 \mathrm{kip}(507 \mathrm{kN})$.

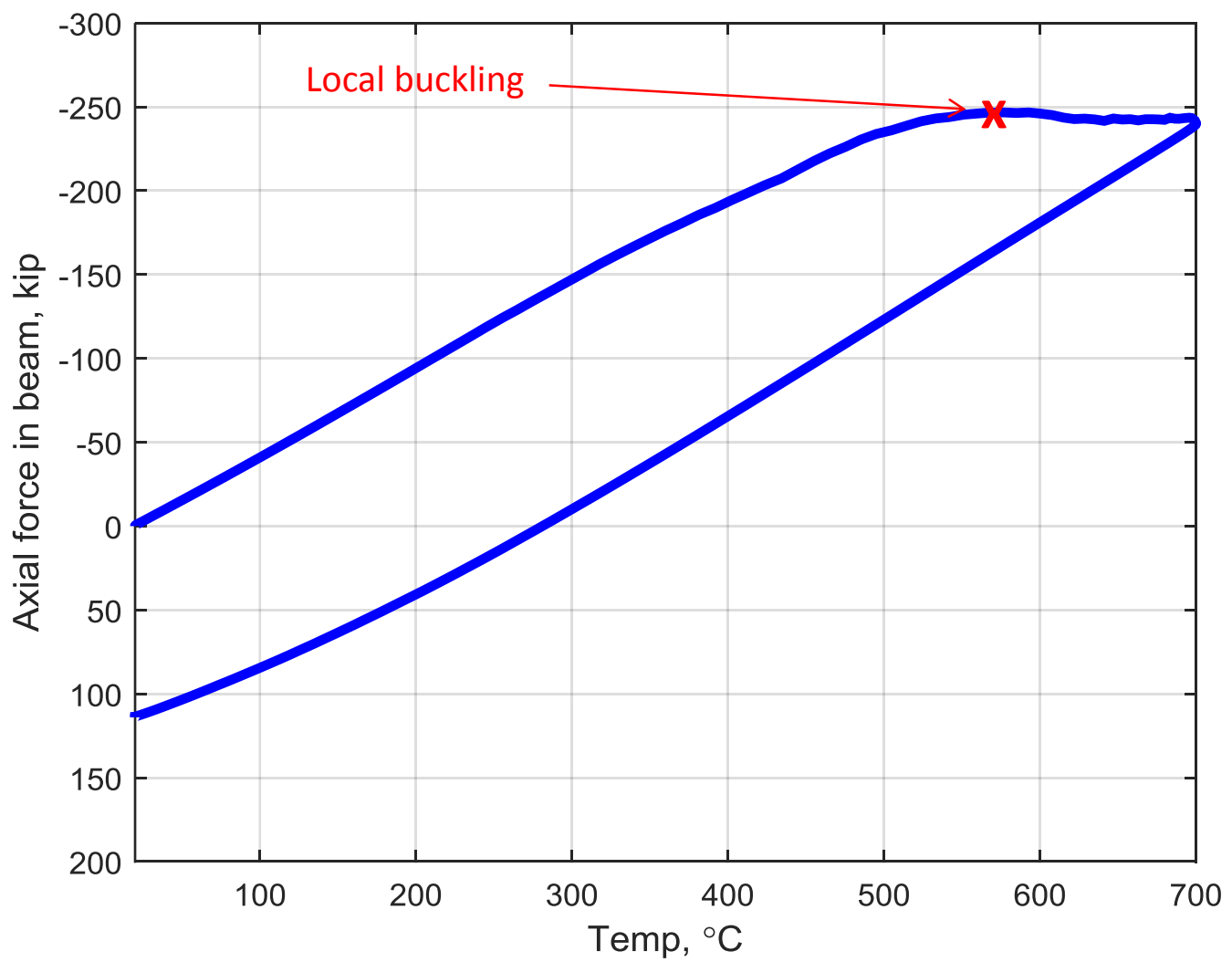

Figure 5-15 Cross-sectional longitudinal forces in the beam versus the temperature for the unconstrained RBS assembly, heated with a gradient temperature profile through the cross-section of the beam. 


\subsection{CONCLUDING REMARKS}

The material and failure models, developed in Chapter 2 and Chapter 4, respectively, were used in this chapter to analyze moment-resisting frames to demonstrate how these models can be used to gain insight into the behavior and failure modes of these frames. This chapter presented detailed finite-element modeling of seismically designed steel moment frames subjected to elevated temperatures. Models were developed for two moment-frame assemblies, which included an intermediate moment frame with welded unreinforced flange, bolted web (WUF-B) connections and a special moment frame with reduced beam section (RBS) connections. Both models incorporated temperature-dependent material models for structural steel and structural bolts (Chapter 2), with an erosion-based failure criterion to simulate fracture (Chapter 4).

Each moment-frame assembly model was subjected to a uniform gravity load along the beam in conjunction with a prescribed temperature time-history. The prescribed temperature-history included both a heating phase and a cooling phase, in which the temperature was increased from ambient temperature $\left(20^{\circ} \mathrm{C}\right)$ to a peak temperature $\left(700{ }^{\circ} \mathrm{C}\right.$ in most cases), was held constant at the peak temperature, and was then decreased back to ambient temperature.

These analyses have demonstrated the effectiveness of the developed material and failure models in estimating the responses of these frames, and provided useful insight into their behavior and failure modes. 


\section{Chapter 6 \\ SUMMARY, CONCLUSIONS, AND FUTURE WORK}

This report presents the formulation and applications of a newly developed temperature-dependent material model for structural steels.

\subsection{FORMULATION OF TEMPERATURE-DEPENDENT MATERIAL MODEL}

This report first presents a stress-strain model for structural steel at elevated temperatures, as an alternative to the stress-strain model used in the Eurocode 3 standard. It is based on a large dataset of the yield strength of structural steels, augmented by post-yield behavior derived from eight steels used in the construction of the World Trade Center towers. It accounts for the temperature dependence of the yield strength, the change in strain hardening with temperature, and the effect of strain rate on strength. The quality of the predictions of the model for stress-strain behavior for steels, such as ASTM A992, are similar to those of the Eurocode 3 stress strain model. The coefficient of variation of the modulus of elasticity, retained yield strength, and ultimate tensile strength, which are the largest components of the variability in the model, increase linearly with increasing temperature. Finally, the model is extensible to steels with improved high-temperature properties by either choosing a new representation of the temperature dependence of the hightemperature yield strength, or by fitting stress-strain data to generate new values of the parameters that describe the temperature dependence of the strain hardening. For structural steel materials, a temperature-dependent power-law model was used to represent the true stress-strain behavior up to the onset of necking at the temperature-dependent uniform strain. The uniform strain was determined based on a nonlinear least-squares fit to the uniform strain data for elevated temperatures available in the literature. The post-ultimate behavior was represented using a linear projection of the true stress-strain curve, based on the Considère criterion, to initiate necking at the uniform strain. Due to the more limited experimental data on structural bolts at elevated temperatures, a simpler tri-linear material model was proposed to represent the true stress-strain behavior of structural bolts.

\subsection{STABILITY OF STEEL COLUMNS}

The newly developed temperature-dependent material model for structural steels was then used to study the flexural buckling of steel columns to (i) evaluate the applicability of, and (ii) validate, the NIST model for predicting the behavior of steel gravity columns at elevated temperatures using the finite-element method. The study compares the high-temperature flexural buckling of steel columns predicted using two different stress-strain models: Eurocode 3 model and the NIST model. Phase I used the simplified FEM models to compute the critical buckling temperature of 47 column specimens. The models assume that the effects of temperature distribution and test 
protocols are negligible to calculate the critical temperatures of columns. The results indicate that the NIST stress-strain model predicts the critical temperature for column buckling failure more accurately than does the Eurocode 3 model. Thirty FEM models were developed to analyze the behavior of the columns tested at Purdue University. The variables in the FEM model include the temperature distributions (uniform versus non-uniform), material model (Eurocode 3 versus NIST), and two different numerical analysis approaches (modified Newton-Raphson iteration approach and modified Riks (arc-length) approach). The results show that (1) the NIST stressstrain model accurately predicts the response, buckling strength, and failure time of columns at elevated temperatures. The Eurocode 3 model tends to conservatively estimate the stiffness and buckling strength of tested specimens regardless of temperature distributions and simulation methods. (2) Both the NIST-proposed and Eurocode-3 thermal expansion models accurately predicted the thermal elongations of column specimens with thermal gradients. (3) The critical buckling loads predicted using both numerical analysis approaches (modified Newton-Raphson scheme and modified Riks method) compared favorably with each other when the assumed temperature distribution was similar to that in the tests. (4) The behavior of columns can be significantly influenced by the assumed temperature distribution while the effect of axial load history appears to be negligible on inelastic column buckling. In Phase III, the new column curve is calibrated using the NIST stress-strain model. The same FEM approach for the current AISC 2010 curve and showed that the nominal compressive strength for flexural buckling could be updated by substituting the behavior of the yield strength and elastic modulus from the NIST stress-strain model, two of the equation parameters. The findings from the study are limited to the range of parameters included in the experimental investigations and finite-element models. This paper is not intended to draw any conclusions about columns with failure modes other than inelastic flexural buckling or cases where the thermal creep behavior is critical. Further work is recommended for evaluating predictions using the NIST-proposed steel material model for other failure mechanisms (yielding or lateral-torsional buckling), various fire loading conditions (e.g., transient heating condition or localized fire), various boundary conditions (e.g., the effects of thermally induced axial and rotational restraints), and cases where the thermal creep behavior is critical.

\subsection{FE COMPONENT FAILURE MODELING}

The newly developed temperature-dependent material model was then used to develop a practical modeling approach to represent temperature-dependent nonlinear behavior and failure of structural steel and structural bolts at elevated temperatures, using element erosion to represent material failure. This modeling approach can be used in explicit finite element analyses to represent the successive failures of components in bolted connections under fire-induced heating and the consequent redistribution of loads. A plastic strain-based failure criterion was used to activate element erosion, noting that the currently available experimental data on fracture of structural steel and structural bolts at elevated temperatures are insufficient to enable calibration of micromechanics-based models for ductile fracture. Values of erosion strain at elevated 
temperatures were calibrated against experimental data on the engineering strain at fracture of tensile coupons, using FE models of tensile coupons to determine appropriate values of erosion strain at each temperature. For structural steel, average failure strain values from tensile coupons of ASTM A572 Grade 50 and ASTM A992 steel were used as target values in the calibration of erosion strain. For structural bolts, erosion strain values were calibrated separately for ASTM A325 and A490 bolts, using failure strain data from tensile coupons of each type of bolt. Because the modeling of post-ultimate softening and strain-localization behavior is known to depend on the mesh discretization, FE analyses of tensile coupons were performed with two levels of mesh refinement, to investigate the sensitivity of the results to mesh size. The results were found to be particularly sensitive to mesh size at high temperatures, because of the earlier onset of necking and the more extensive softening behavior prior to fracture. When the element size was reduced by one-half to 0.03 in $(0.75 \mathrm{~mm})$ in an $\mathrm{FE}$ analysis of a tensile coupon at $600{ }^{\circ} \mathrm{C}$, with the erosion strain unchanged, the computed engineering strain at fracture was reduced by $44 \%$. The computed results at lower temperatures were less sensitive to the mesh refinement, with their computed engineering strains at fracture reduced by approximately $20 \%$. However, these results confirmed the importance of calibrating erosion strain values using the same mesh size that will be used in analyzing the failure of structural components. Because the material model and erosion strain values for structural bolts were developed and calibrated to represent tensile behavior, FE analyses of double-shear test specimens were performed to verify that the model was also capable of representing the behavior of structural bolts under shear loading. The computed shear behavior for an A325 bolt compared well with experimental data at ambient temperature: the ultimate shear capacity was within $1 \%$ of the experimental value, although the experimental displacement at fracture was somewhat higher than that predicted by the FE analysis, likely due to deformation of the plates during the experiment. Comparing to the nominal shear capacities, the shear capacity computed from the FE analyses at ambient temperature was found to be within $5 \%$ for A325 bolts and within $2 \%$ for A490 bolts. This work concluded that (i) analysis of the available experimental data showed that the uniform strain (i.e., the engineering strain at the onset of necking) decreased with increasing temperature, (ii) imposing a reduced stiffness onto the true stress-true strain curve for strains greater than the uniform strain, based on the Considère criterion, was sufficient to initiate necking at the uniform strain at each temperature, and (iii) the fracture strain was dependent on the temperature. Due to the limitations both in the presented modeling approach and in the currently available experimental data for material behavior and fracture at elevated temperatures, NIST researchers are currently planning future work including carefully controlled experiments with different levels of triaxiality at different temperatures. These tests will be used to explore ductile fracture characteristics at elevated temperatures.

\subsection{BEHAVIOR OF MOMENT-FRAME ASSEMBLIES}

Finally, the newly developed temperature-dependent material model, along with the erosion based failure criteria was utilized to study the behavior of steel connections under fire loading. The study presented a detailed finite-element approach developed to analyze the behavior and failure modes 
of seismically designed steel moment frames subjected to elevated temperatures. Finite-element models were developed of two moment-frame assemblies, which included an intermediate moment frame with welded unreinforced flange, bolted web (WUF-B) connections and a special moment frame with reduced beam section (RBS) connections. Both models incorporated temperaturedependent material models for structural steel and structural bolts. The model of the WUF-B assembly also incorporated erosion-based failure criteria to simulate fracture. Each moment-frame assembly model was subjected to a uniform gravity load along the beam in conjunction with a prescribed temperature time history. The prescribed temperature history included both a heating phase and a cooling phase, in which the temperature was ramped up from ambient temperature $\left(20{ }^{\circ} \mathrm{C}\right)$ to a peak temperature $\left(700^{\circ} \mathrm{C}\right.$ in most cases), was held constant at the peak temperature, and was then dropped back to ambient temperature. The effects of elevated temperature on the behavior and failure modes of WUF-B and RBS moment-frame assemblies were presented in this report. The analyses demonstrated the effectiveness of the developed material and failure models in estimating the response of these frames, providing useful insight into their behavior and failure modes. 


\section{REFERENCES}

ABAQUS (2012). ABAQUS/Standard Version 6.12 User's Manuals: Volume I-III, Hibbitt, Karlsson, and Sorenson Inc., Pawtucket, RI.

Agarwal, A., and Varma, A. H. (2011). "Design of steel columns at elevated temperatures due to fire: Effects of rotational restraints.” Engineering Journal, Chicago, pp. 297-314.

Agarwal, A., and Varma, A. H. (2014). "Fire induced progressive collapse of steel building structures: The role of interior gravity columns." Engineering Structures, 58, 129-140.

AISC (2010). "Specification for structural steel buildings," Specification ANSI/AISC 360-10, American Institute of Steel Construction (AISC), One East Wacker Drive, Suite 700, Chicago, IL 60601-1802.

Ali, F. A., Shepherd, P., Randall, M., Simms, I. W., O’Connor, D. J., and Burgess, I. (1998). Effect of axial restraint on the fire resistance of steel columns. Journal of Constructional Steel Research, 46(1-3):305-306.

American Institute of Steel Construction (AISC). (1999). Load and resistance factor design specifications for structural steel buildings. Chicago, IL.

American Institute of Steel Construction (AISC). (2002). "Seismic provisions for structural steel buildings." ANSI/AISC 341-02, Chicago, IL.

American Society of Civil Engineers (ASCE). (2002). "Minimum design loads for buildings and other structures." SEI/ASCE 7-02, Reston, VA.

Anderberg, Y. (1983). Behaviour of steel at high temperatures. Technical report, RILEM Technical Committee 44-PHT.

Anderberg, Y. (1988). Modelling steel behaviour. Fire Safety Journal, 13(1):17-26. doi:10.1016/0379-7112(88)90029-X.

ANSYS, I. (2012). ANSYS User Manual Version 14.0.

ASME (2004). Boiler and pressure vessel code. Section II materials, Part D properties (customary), Subpart 2 physical properties tables. Code, ASME International, New York. Table TM-1.

ASTM International (2009a). Standard specification for high-yield-strength, quenched and tempered alloy steel plate, suitable for welding. Standard A514/A514M-05, ASTM International, W. Conshohocken, Pa. doi:10.1520/A0514\s\do5(A)0514M-05R09.

ASTM International (2009b). Standard terminology relating to methods of mechanical testing. Standard E6-09b, ASTM International, W. Conshohocken, Pa. doi:10.1520/E0006-09B.

ASTM International (2009c). Standard test methods for elevated temperature tension tests of metallic materials. Standard E21-09, ASTM International, W. Conshohocken, Pa. doi:10.1520/E0021-09. 
ASTM International (2011), “ASTM Standard E119-11a Standard Test Methods for Fire Tests of Building Construction and Materials", Standard E119-11a, ASTM International, West Conshohocken, PA, 2009, doi: 10.1520/E0119-11A.

ASTM International. (2010). "Standard Specification for Structural Bolts, Steel, Heat Treated, 120/105 ksi Minimum Tensile Strength." ASTM A325-10e1, ASTM International, West Conshohocken, PA. doi: 10.1520/A0325.

ASTM International (2011). "Standard specification for structural steel shapes". Standard A992/A992M-11, ASTM International, W. Conshohocken, Pa. doi:10.1520/ A0992_A0992M-11.

ASTM International. (2012a). "Standard Specification for Carbon Structural Steel." Standard A36/A36M-12, ASTM International, West Conshohocken, PA. doi: 10.1520/ A0036_A0036M-12

ASTM International. (2012b). "Standard Specification for Structural Bolts, Alloy Steel, Heat Treated, 150 ksi Minimum Tensile Strength." Standard A490-12, ASTM International, West Conshohocken, PA. doi: 10.1520/A0490-12.

ASTM International. (2012c). "Standard Specification for Structural Bolts, Alloy Steel, Heat Treated, 150 ksi Minimum Tensile Strength." Standard A992/A992M-11, ASTM International, West Conshohocken, PA. doi: 10.1520/A0992_A0992M-11.

ASTM International (2012d). "Standard specification for structural steel with improved yield strength at high temperature for use in buildings". Standard 1077/1077M-12, ASTM International, W. Conshohocken, Pa. doi:10.1520/A1077_A1077M-12.

ASTM International. (2013), "Standard Specification for High-Strength Low-Alloy ColumbiumVanadium Structural Steel." Standard A572/A572M-13a, ASTM International, West Conshohocken, PA. DOI: 10.1520/A0572_A0572M.

ASTM International (2014). "Standard Test Methods for Fire Tests of Building Construction and Materials", Standard E119-14, ASTM International, W. Conshohocken, Pa.

British Standards Institution (1990). "Specification for weldable structural steels". Technical Report BS 4360:1990, British Standards Institution. Status: superseded, Withdrawn June 1994. URL: http://shop.bsigroup.com/en/ProductDetail/?pid=000000000011122236.

Brockenbrough, R. L. and Johnston, B. G. (1968). Steel design manual. Technical Report ADUSS 27-3400-01, United States Steel Corporation. Some data appear in Holt (1964).

Bjorhovde, R. (1972). "Deterministic and probabilistic approaches to the strength of steel columns," Ph.D. Thesis, Lehigh University, Bethlehem, PA., May.

Chen, J., Young, B., and Uy, B. (2006). Behavior of high strength structural steel at elevated temperatures. Journal of Structural Engineering, 132(12):1948-1954. doi:10.1061/ (ASCE)0733-9445(2006)132:12(1948).

Chijiiwa, R., Tamehrio, H., Yoshida, Y., Funato, K., Uemori, T., and Horii, Y. (1993). Development and practical application of fire-resistant steel for buildings. Nippon Steel Technical Report 58, Nippon Steel Corporation. Special Issue on New Steel Plate Products of High Quality and High Performance UDC669.14.018.291: 699.81. URL: http://www.nsc.co.jp/en/tech/report/no58.html. 
Choe, L. (2011). "Structural mechanics and behavior of steel members under fire loading", Ph.D. Thesis. Purdue University, West Lafayette, IN., December.

Choe, L., Varma, A.H., Agarwal, A., and Surovek, A. (2011). "Fundamental Behavior of Steel Beam-Columns and Columns under Fire Loading: An Experimental Evaluation," Journal of Structural Engineering, ASCE, 137, 954.

Cooke, G. (1988). An introduction to the mechanical properties of structural steel at elevated temperatures. Fire Safety Journal, 13(1):45-54. doi:10.1016/0379-7112(88)90032-X.

Dieter, G.E. (1976). Mechanical Metallurgy, 2nd ed., McGraw-Hill, New York.

ECCS (1983). European recommendations for the fire safety of steel structures: Calculation of the fire resistance of load bearing elements and structural assemblies exposed to the standard fire. Technical report, European Convention for Constructional Steelwork, Brussels, Belgium. Technical Committee 3-Fire Safety of Steel Structures. URL: http://www.eccspublications.eu/index.php?section=library\&content=\&act=detail\&id=95.

ECS (2005). Eurocode 3. Design of steel structures. General rules. Structural fire design. Standard EN 1993-1-2, European Committee for Standardization. URL: http://eurocodes.jrc.ec.europa.eu/showpage.php?id=133.

Ellingwood, B., Galambos, T. V., MacGregor, J. G., and Cornell, C. A. (1980). Development of a probability based load criterion for American National Standard A58 building code requirements for minimum design loads in buildings and other structures. Special Publication 577, National Bureau of Standards.

European Committee for Standardization. (2001). "Eurocode 3: Design of steel structures. Part 1.2: General rules structural fire design.” ENV 1993-1-2:2001, Brussels, Belgium.

Federal Emergency Management Agency (FEMA). (2000). "Recommended seismic design criteria for new steel moment-frame buildings." FEMA 350, SAC Joint Venture and FEMA, Washington, D.C.

Franssen, J., Schleich, J. B., Cajot, L. G., and Azpiazu, W. (1996). A simple model for the fire resistance of axially loaded members - comparison with experimental results. Journal of Constructional Steel Research, 37(3):175-204.

Franssen, J. M., Talamona, D., Kruppa, J., and Cajot, L. G. (1998). Stability of steel columns in case of fire: Experimental evaluation. Journal of Structural Engineering, 124(2):158-163.

Garlock, M.E. and Selamet. S. (2010). "Modeling and behavior of steel plate connections subject to various fire scenarios." Journal of Structural Engineering, 136 (2010), pp. 897-906.

Garofalo, F. (1952). The influence of temperature on the elastic constants of some commercial steels. In Symposium on Determination of Elastic Constants, number STP 129. American Society for Testing and Materials. presented at the fifty-fifth annual meeting (fiftieth anniversary meeting) American Society for Testing Materials, New York, N.Y., June 25, 1952.

Gonzalez, F. and Lange, J. (2010). Behaviour of galvanized high strength grade 10.9 bolts under fire conditions. In Structures in Fire - Proceedings of the Sixth International Conference, SiF'10, pages $908-915$, East Lansing, MI, United states. URL: http://www.structuresinfire.com/corpo/conferences.html. 
Gowda, B. C. (1978). Tensile properties of SA516, grade 55 steel in the temperature range of $25^{\circ} \mathrm{C}-927^{\circ} \mathrm{C}$ and strain rate range of $10^{-4}$ to $10^{-1} \mathrm{sec}^{-1}$. In Smith, G. V., editor, Characterization of Materials for Service at Elevated Temperatures, pages 145-158, New York. The American Society of Mechanical Engineers. presented at the 1978 ASME/CSME Montreal Pressure Vessel \& Piping Conference, Montreal, Quebec, Canada, June 25-29 1978.

Harmathy, T. Z. and Stanzak, W. W. (1970). Elevated-temperature tensile and creep properties of some structural and prestressing steels. In Fire Test Performance, number STP 464, pages 186-208. American Society for Testing and Materials. doi:10.1520/STP44718S.

Holt, J. M. (1964). Short-time elevated-temperature tensile properties of USS Cor-Ten and USS Tri-Ten high-strength low-alloy steels, USS Man-Ten (A 440) high-strength steel, and ASTM A 36 steel. Progress Report 57.19-901(1), Applied Research Laboratory, United States Steel Corporation, Monroeville, Pa. Data in Figure 1.5 appears in Holt (1964) and Holt (unk).

Holt, J. M. (unk.). Short-time elevated-temperature tensile properties of USS “T-1" and USS “T1” type A constructional alloy steels. Progress Report 57.19-901(3)(a-AS-EA-2, Applied Research Laboratory, United States Steel Corporation, Monroeville, Pa.

Hopwood, T., Jendrzejewski, J., and Hartmann, J. (2009). Addressing SCC-susceptible ASTM A514 steel on the I-275 twin bridges over the Ohio River. Bridge Structures, 5(2-3):6373. doi:10.1080/15732480903142542.

Hu, G., Morovat, M. A., Lee, J., Schell, E., and Engelhardt, M. (2009). Elevated temperature properties of ASTM A992 steel. In Lawrence G. Griffis, Todd Helwig, M. W. and Holt, M., editors, Proceedings of the Structures Congress 2009 Don't Mess with Structural Engineers-Expanding our Role. American Society of Civil Engineers. doi:10.1061/ 41031(341)118.

International Organization for Standardization (1999). Metallic materials-tensile testing at elevated temperature. Standard 783:1999, International Organization for Standardization. superseded by ISO 6892-2:2011. URL: http://www.iso.org/iso/iso_catalogue/ catalogue_tc/catalogue_detail.htm?csnumber=26858.

International Organization for Standardization (2008). Document management - portable document format - part 1: Pdf 1.7. Standard 32000-1:2008, International Organization for Standardization. URL: http://www.iso.org/iso/iso_catalogue/catalogue_tc/ catalogue_detail.htm?csnumber=51502.

JIS (1998). Method of elevated temperature tensile test for steels and heat-resisting alloys. Standard JIS G 5067:1998, Japan Industrial Standards. URL: http://www.webstore.jsa.or.jp/webstore/JIS/FlowControl.jsp.

Johnson, G. R. and Cook, W. H. (1983). A constitutive model and data for metals subjected to large strains, high strain rates and high temperatures. In Proceedings, Seventh International Symposium on Ballistics, the Hague, the Netherlands, 19-21 April, 1983, pages 541-547. American Defense Preparedness Association and Koninklijk Instituut van Ingenieurs. 
Kanvinde, A.M. and Deierlein, G.G. (2006). "Void growth model and stress modified critical strain model to predict ductile fracture in structural steels." Journal of Structural Engineering, 132(12), 1907-1918.

Kirby, B. and Preston, R. (1983). The behavior of structural steels manufactured by BSC under stress controlled anisothermal creep conditions. Technical Report SH/RS/3664/4/83/B, British Steel Corporation, Swinden Laboratories.

Kirby, B. and Preston, R. (1988). High temperature properties of hot-rolled, structural steels for use in fire engineering design studies. Fire Safety Journal, 13(1):27-37. doi:10.1016/03797112(88)90030-6.

Kirby, B. R. (1995). The behaviour of high-strength grade 8.8 bolts in fire. Journal of Constructional Steel Research, 33(10â"2):3-38. Special Issue on Fire and Steel. doi:10.1016/0143-974X(94)00013-8.

Kirby, B. R. and Preston, R. R. (1991). The application of BS5950:Part 8 on fire limit state design to the performance of 'old' structural mild steels. Report SL/RS/R/S1199/17/91/C, British Steel, Swinden Laboratories, Moorgate, Rotherham,S60 3AR. URL: http://www.mace.manchester.ac.uk/project/research/structures/strucfire/DataBase/Refere nces/ApplicationBS5950.pdf.

Kodur, V., Gu, L., and Garlock, M. E. M. (2010). Review and assessment of fire hazard in bridges. Transportation Research Record: Journal of the Transportation Research Board, 2172:23-29. doi:10.3141/2172-03.

Kodur, V., Kand, S., and Khaliq, W. (2012). Effect of temperature on thermal and mechanical properties of steel bolts. Journal of Materials in Civil Engineering, 24(6):765-774. doi:10.1061/(ASCE)MT.1943-5533.0000445.

Kulak, G.L., Fisher, J.W., and Struik, J.H.A., (1986). "Guide to design criteria for bolts and riveted joints". $2^{\text {nd }}$ edition, John Weiley \& Sons, New York.

Lew, H.S., Main, J.A., Robert, S.D., Sadek, F., and Chiarito, V.P. (2013). "Performance of steel moment connections under a column removal scenario. I: Experiments." Journal of Structural Engineering, ASCE, 139(1), 98-107.

Li, G. Q., Jiang, S. C., Yin, Y. Z., Chen, K., and Li, M. F. (2003). Experimental studies on the properties of constructional steel at elevated temperatures. Journal of Structural Engineering, 129:1717-1721. doi:10.1061/(ASCE)0733-9445(2003)129:12(1717).

Lie, T. T., editor (1992). Structural Fire Protection: Manual of Practice. ASCE Manuals and Reports of Engineering Practice; no. 78. American Society of Civil Engineers.

Lie, T. T. and Macauley, B. A. (1989). Evaluation of the fire resistance of protected steel columns. Internal Report IRC-IR-583, Institute for Research in Construction, National Research Council Canada.

Lord, J., Rides, M., and Loveday, M. (2005). "TENSTAND" WP3 final report: Modulus measurement methods. Technical Report DEPC MPE 016, National Physical Laboratory, Queens Road, Teddington, TW11 OLW United Kingdom. URL: http://www.npl.co.uk/publications/tenstand-wp3-final-report-modulus-measurementmethods. 
Lou, S. and Northwood, D. O. (1995). Effect of temperature on the lower yield strength and static strain ageing in low-carbon steels. Journal of Materials Science, 30:1434-1438. doi:10.1007/BF00375244.

Livermore Software Technology Corporation (LSTC). (2012), LS-DYNA Keyword User's Manual, Version 971, Livermore, CA.

Luecke, W. E., Banovic, S. W., and McColskey, J. D. (2011). High-temperature tensile constitutive data and models for structural steels in fire. Technical Note 1714, National Institute of Standards and Technology. URL: http://www.nist.gov/manuscript-publicationsearch.cfm?pub_id=908536.

Luecke, W. E., J.D. McColskey, C.N. McCowan, S.W. Banovic, R.J. Fields, T.J. Foecke, T.A. Siewert, F.W. Gayle (2005). "Federal Building and Fire Safety Investigation of the World Trade Center Disaster, Mechanical Properties of Structural Steels." NIST NCSTAR 1-3D, National Institute of Standards and Technology, Gaithersburg, MD.

Luecke W., Gross J.L., McColskey J.D. (2013). "High-temperature, tensile, constitutive models for structural steel in fire", AISC Engineering Journal, (Submitted).

Luecke W., Gross J.L., McColskey J.D. (2014). "High-temperature, tensile, constitutive models for structural steel in fire", AISC Engineering Journal, (Submitted).

Luecke, W. E., McColskey, J. D., McCowan, C. N., Banovic, S. W., Fields, R. J., Foecke, T., Siewert, T. A., and Gayle, F. W. (2005). Federal building and fire safety investigation of the World Trade Center disaster: Mechanical properties of structural steel. Technical Report NCSTAR 1-3D, National Institute of Standards and Technology. Available on-line at http://wtc.nist.gov. URL: http://wtc.nist.gov/NCSTAR1/PDF/NCSTAR\%2013D\%20Mechanical\%20Properties.pdf.

Main, J.A, Sadek, F., (2012). "Robustness of steel gravity frame systems with single-plate shear connections." NIST Technical Note 1749, National Institute of Standards and Technology, Gaithersburg, MD.

Main, J.A. and Sadek, F. (2013). "Modeling and analysis of single-plate shear connections under column loss." Journal of Structural Engineering, in press. doi:10.1061/(ASCE)ST.1943541X.0000866.

Manjoine, M. J. (1944). Influence of rate of strain and temperature on yield stress of mild steel. Transactions of the American Society of Mechanical Engineers, 66:A-211-A-218.

Outinen, J., Kaitila, O., and Mäkeläinen, P. (2001). High-temperature testing of structural steel and modelling of structures at fire temperatures. Report TKK-TER-23, Helsinki University of Technology, Laboratory of Steel Structures. URL: http://www.tkk.fi/Units/Civil/Steel/Publications/TKK_TER_series/TKK-TER-23.pdf.

Pakala, P., Kodur, V., Dwaikat, M. (2012). "Critical factors influencing the fire performance of bolted double angle connections.” Engineering Structures, 42, 106-114.

Phan, L.T., McAllister, T.P., Gross, J.L., and Hurley, M.J. (eds.) (2010). "Best Practice Guidelines for Structural Fire Resistance Design of Concrete and Steel Buildings," NIST Technical Note 1681, National Institute of Standards and Technology, Gaithersburg, MD. doi:10.6028/NIST.TN.1681. 
Poh, K. W. (1998). Behaviour of Load-Bearing Members in Fire. PhD thesis, Dept. of Civil Engineering, Monash University, Clayton, Victoria, Australia.

Quiel, S.E. and M.E.M. Garlock (2010) "Parameters for modeling a high-rise steel building frame subject to fire", Journal of Structural Fire Engineering, Vol 1, No. 2, pp 115-134.

Research Council on Structural Connections (RCSC). (2004). Specifications for Structural Joints using ASTM A325 or A490 Bolts, AISC, Chicago.

Ritter, J. C. and McPherson, R. (1970). Anisothermal stress relaxation in a carbon-manganese steel. Journal of the Iron and Steel Institute, 208:935-941.

Sadek, F., Main, J.A., Lew, H.S., Robert, S.D., Chiarito, V.P., El-Tawil, S. (2010). "An Experimental and Computational Study of Steel Moment Connections under a Column Removal Scenario." NIST Technical Note 1669, National Institute of Standards and Technology, Gaithersburg, MD.

Sadek, F., Main, J. A., Lew, H.S., and El-Tawil, S. (2013). "Performance of steel moment connections under a column removal scenario. II: Analysis." Journal of Structural Engineering, 139(1), 108-119.

Sakumoto, Y. (1999). Research on new fire-protection materials and fire-safe design. Journal of Structural Engineering-ASCE, 125(12):1415-1422. doi:10.1061/(ASCE)0733-9445 (1999)125:12(1415).

Sakumoto, Y., Keira, K., Furumura, F., and Ave, T. (1993). Tests of fire-resistant bolts and joints. Journal of Structural Engineering, 119(11):3131-3150. doi:10.1061/(ASCE)07339445(1993)119:11(3131).

Sarraj, M., Burgess, I. W., Davison, J., and Plank, R. J. (2007). "Finite element modelling of steel fin plate connections in fire." Fire Safety Journal, 42, 408-415.

Schleich, J. B. (1987). Computer assisted analysis of the fire resistance of steel and composite concrete-steel structures (REFAO - CAFIR). Technical Report EUR 10828 EN, Commission of the European Communities, ECSC-EEC-EAAE, Brussels-Luxembourg. Contract No. 7210-SA/502. URL: http://bookshop.europa.eu/en/computer-assistedanalysis-of-the-fire-resistance-of-steel-and-composite-concrete-steel-structures-refaocafir--pbCDNA10828/.

Schleich, J. B., Cajot, L.-G., Kruppa, J., Talamona, D., Azpiazu, W., Unanue, J., Twilt, L., Fellinger, J., Foeken, R.-J. V., and Franssen, J.-M. (1998). Buckling curves of hot rolled H steel sections submitted to fire. Technical Report EUR18380 EN, European Commission, Directorate-General Science, Research and Development, Luxembourg. Contract No. 7210- SA/316/151/618/931.

Seif, M.S., Main, J.A., McAllister, T.P. (2013) "Performance of Steel Shear Tab Connections at Elevated Temperatures." Proceedings of the Annual Stability Conference, Structural Stability Research Council, St. Louis, Missouri, April 16-20, 2013.

Seif, M., McAllister, T., Main J., and Luecke, W. (2014). "Modeling of moment connections for structural fire analyses." Proceedings of Structural Stability Research Council Annual Stability Conference, SSRC 2014, p. 626-642. 
Seif, M., Main, J., Weigand, J., McAllister, T., and Luecke, W. (2016) "Finite element modeling of structural steel component failure at elevated temperatures." Structures. Elsevier, Volume 6, March 2016, pages 134-145. dx.doi.org/10.1016/j.istruc.2016.03.002

Skinner, D. H. (1973). Steel properties for prediction of structural performance during fires. In Swannell, P., editor, Fourth Australasian conference on the mechanics of structures and materials: Proceedings, pages 269-276. Papers presented at the 4th conference held on August 20th-22nd, 1973 at University of Queensland, Brisbane, Queensland.

Spaeder Jr., C. E. and Brown, R. M. (1977). Elevated temperature characteristics of Cor-Ten highstrength low-alloy steels. In Smith, G. V., editor, Effects of melting and processing variables on the mechanical properties of steel, number MPC-6, pages 273-307, New York. American Society of Mechanical Engineers. presented at the winter annual meeting of the American Society of Mechanical Engineers, Atlanta, Georgia, November 27December 2, 1977; sponsored by the Metal Properties Council, Inc. the Materials Division, ASME.

Stevens, A. G., Cornish, R. C., and Skinner, D. H. (1971). Tensile data on four structural steels. Technical Report MRL 6/5, Melbourne Research Laboratories, The Broken Hill Proprietary Company, Clayton, Vic. Australia. also cited in Skinner (1973).

Takagi, J. and Deierlein, G.G. (2007), "Strength Design Criteria for Steel members at Elevated Temperatures," Journal of Constructional Steel Research, vol. 63(8), pp. 1036-50.

Takeuchi, S. and Argon, A. S. (1976). Steady-state creep of single-phase crystalline matter at high temperature. Journal of Materials Science, 11:1542-1566. doi:10.1007/BF00540888.

Tan, K.-H., Toh, W.-S., Huang, Z.-F., and Phng, G.-H. (2007). Structural responses of restrained steel columns at elevated temperatures. Part 1: Experiments. Engineering Structures, 29(8):1641-1652.

Twilt, L. (1988). Strength and deformation properties of steel at elevated temperatures: Some practical implications. Fire Safety Journal, 13(1):9-15. doi:10.1016/0379-7112(88)900288.

Twilt, L. (1991). Stress-strain relationships of structural steel at elevated temperatures: Analysis of various options \& European proposal, Part F: mechanical properties. Report BI-91-015, Netherlands Organization for Applied Scientific Research, Van Mourik Broekmanweg 6, Delft, The Netherlands. The report is only available by request from http://www.tno.nl.

USS (1972). Steels for elevated temperature service. Technical report, United State Steel Corporation.

Wallaert, J. J., Fisher, J. W., (1965). "Shear strength of high-strength bolts." Journal of the Structural Division, ASCE, 91, ST3, 99-125.

Wang, Y. C. and Davies, J. M. (2003). Fire tests of non-sway loaded and rotationally restrained steel column assemblies. Journal of Constructional Steel Research, 59(3):359-383.

Williams-Leir, G. (1983). Creep of structural-steel in fire - analytical expressions. Fire and Materials, 7:73-78. doi:10.1002/fam.810070205.

Yang, K.C., Chen, S.J., Ho, M.C. (2009) "Behavior of beam-to-column moment connections under fire load" Journal of Constructional Steel Research, 65(7), 1520-1527. 
Yu, L. (2006). "Behavior of bolted connection during and after a fire." Ph.D. dissertation, Univ. of Texas at Austin, Austin, TX.

Yu, H., Burgess, I.W., Davison, J.B., Plank, R.J. (2009). "Experimental investigation of the behavior of fin plate connections in fire", Journal of Constructional Steel Research, Vol 65, pp 723-736.

Zerilli, F. J. and Armstrong, R. W. (1987). Dislocation-mechanics-based constitutive relations for material dynamics calculations. Journal of Applied Physics, 61:1816-1825. doi:10.1063/1.338024.

Zhang, C., Li, G.-Q., and Wang, Y.-C. (2012). Predictability of buckling temperature of axially loaded steel columns in fire. Journal of Constructional Steel Research, 75:32 - 37. 